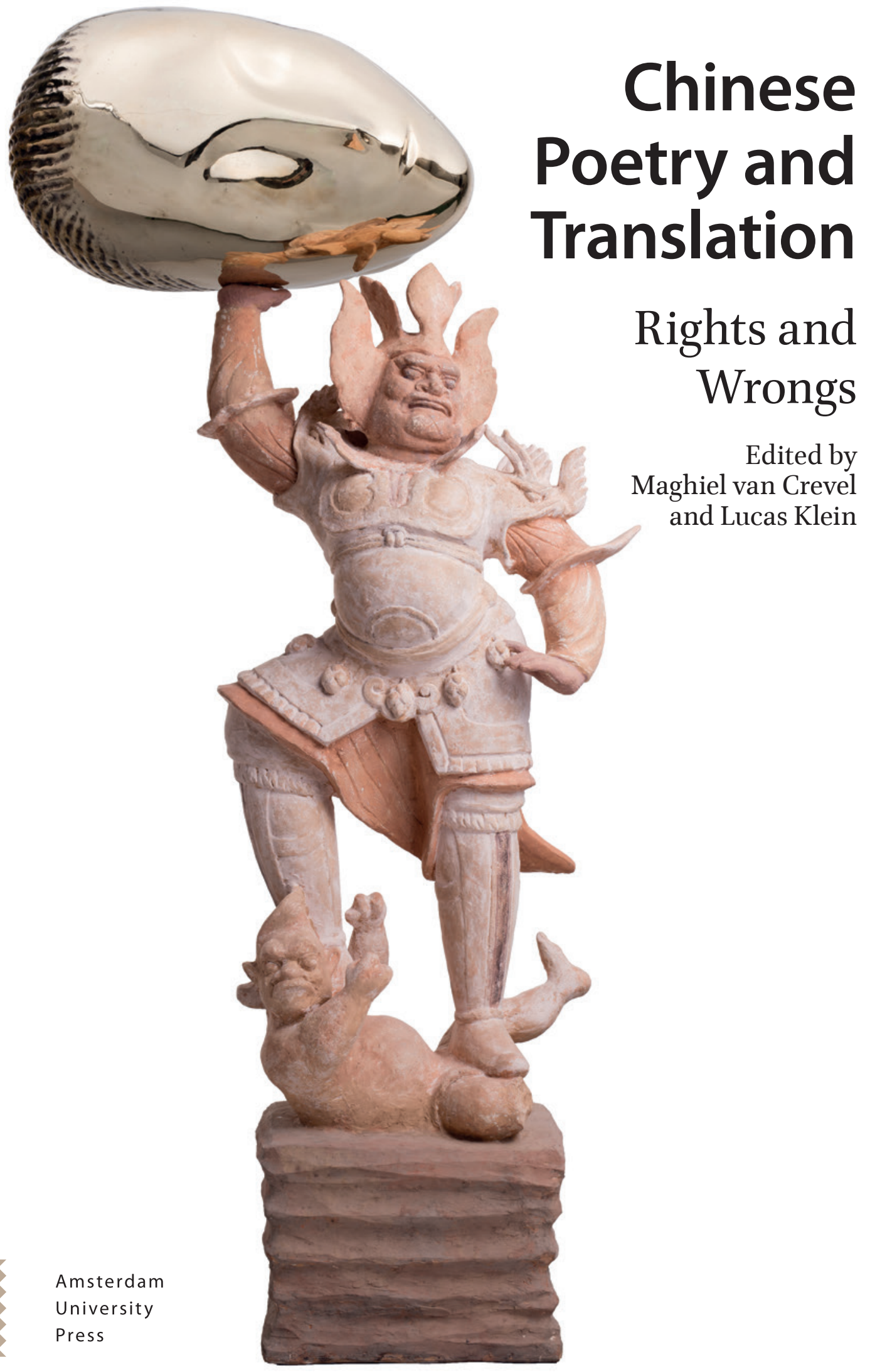


Chinese Poetry and Translation 



\title{
Chinese Poetry and Translation
}

Rights and Wrongs

\author{
Edited by \\ Maghiel van Crevel and Lucas Klein
}


Cover illustration: Eternity - Painted Terracotta Statue of Heavenly Guardian, Sleeping Muse (2016); bronze, mineral composites, mineral pigments, steel; $252 \times 125 \times 77 \mathrm{~cm}$ Source: Xu Zhen'; courtesy of the artist

Cover design: Coördesign, Leiden

Lay-out: Crius Group, Hulshout

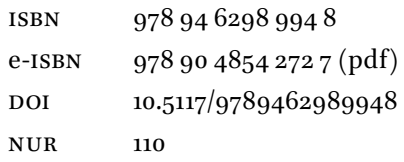

Creative Commons License CC BY NC ND (http://creativecommons.org/licenses/by-nc-nd/3.o)

@ All authors / Amsterdam University Press B.V., Amsterdam 2019

Some rights reserved. Without limiting the rights under copyright reserved above, any part of this book may be reproduced, stored in or introduced into a retrieval system, or transmitted, in any form or by any means (electronic, mechanical, photocopying, recording or otherwise). 


\section{Table of Contents}

$\begin{array}{ll}\text { Acknowledgments } & 7\end{array}$

Introduction: The Weird Third Thing $\quad 9$

Maghiel van Crevel and Lucas Klein

Conventions

\section{Part One: The Translator's Take}

1 Sitting with Discomfort $\quad 23$

A Queer-Feminist Approach to Translating Yu Xiuhua Jenn Marie Nunes

2 Working with Words

Poetry, Translation, and Labor Eleanor Goodman

3 Translating Great Distances

The Case of the Shijing

Joseph R. Allen

4 Purpose and Form

On the Translation of Classical Chinese Poetry Wilt L. Idema

\section{Part Two: Theoretics}

5 Embodiment in the Translation of Chinese Poetry Nick Admussen

6 Translating Theory

Bei Dao, Pasternak, and Russian Formalism Jacob Edmond 
7 Narrativity in Lyric Translation

English Translations of Chinese $\mathrm{Ci}$ Poetry

Zhou Min

8 Sublimating Sorrow

How to Embrace Contradiction in Translating the "Li Sao"

Nicholas Morrow Williams

9 Mediation Is Our Authenticity

201

Dagong Poetry and the Shijing in Translation

Lucas Klein

\section{Part Three: Impact}

10 Ecofeminism avant la Lettre

Chen Jingrong and Baudelaire

Liansu Meng

11 Ronald Mar and the Trope of Life

The Translation of Western Modernist Poetry in Hong Kong Chris Song

12 Ya Xian's Lyrical Montage

Modernist Poetry in Taiwan through the Lens of Translation Tara Coleman

13 Celan's "Deathfugue" in Chinese

A Polemic about Translation and Everything Else

Joanna Krenz

14 Trauma in Translation

Liao Yiwu's "Massacre" in English and German

Rui Kunze

15 A Noble Art, and a Tricky Business

Translation Anthologies of Chinese Poetry

Maghiel van Crevel

Index 


\section{Acknowledgments}

We express our gratitude to these institutions and individuals:

- The Leiden University Institute for Area Studies (LIAS), the Leiden University Foundation (LUF) / Mr. J. J. van Walsem Fonds, and the International Institute for Asian Studies (IIAS), for funding the workshop at which the papers in this book were first presented and discussed, held at Leiden University in June 2018.

- Marc Gilbert and his colleagues in the Special Collections department of the Leiden University Library, for providing a perfect venue for the workshop and hosting a pop-up exhibition of the unofficial journals that have played a key role in the development of contemporary mainlandChinese poetry.

- Corinne Tachtiris, for permission to use her Batman-inspired rejoinder to Robert Frost for publicity for the workshop.

- Wang Mi and Zheng Yanming, for expertly guiding the workshop participants through Leiden and handling logistics, without missing a single paper.

- Xu Zhen, for permission to use the image on the cover of this book.

- The editors of Orbis Litterarum, for permission to include Jacob Edmond's essay, which is a substantially reworked version of "The Elephant in the Room: Theory in World Literature," published in Orbis Litterarum 73 (4) (2018): 311-327.

- The Leiden Asia Centre (LAC), for funding the open access publication of this book.

- Saskia Gieling and her colleagues at Amsterdam University Press, for shepherding the volume to publication.

- Last but not least, our peer reviewers, for truly constructive criticism. 



\title{
Introduction
}

\author{
The Weird Third Thing \\ Maghiel van Crevel and Lucas Klein
}

This book first took shape during a two-day workshop on Chinese poetry and translation at Leiden University in June 2018. About halfway through, Nick Admussen said he found the community represented at the event to be inspirational to his work as a translator and a scholar of Chinese poetry. As an example he mentioned the recent Journal of Modern Literature in Chinese double ( $J M L C$, issues 14-2 and 15-1, edited by Maghiel van Crevel), with papers given at Lingnan University in 2017 by several of those who had now come to Leiden. What Nick said about community echoed Eleanor Goodman's earlier observation that her paper was inspired by an essay in which Nick digs into a mistake he made while translating a poem by Ya Shi 哑石 and into the ensuing correspondence with Ya Shi - who did not consider it a mistake. "Translators translate through their libraries," Joseph Allen said after Eleanor's paper, and he is right; but it is equally true that translators translate, and poets and scholars write, through personal relationships with one another. The topic of Chinese poetry and translation is a case in point. And the workshop reaffirmed that the community in question is, well, kind of happening right now. Nick later called it a ragged family (Admussen 2019, 122).

In this way, translation and writing about translation are even more intertextual and relational than is commonly assumed, because they offer so much room for encounters of individual positionality and creativity on the one hand, with fundamentals of human expression and experience, on the other. This book bears this out in one ongoing, expanding conversation, with topics ranging from a queer-feminist engagement with some of China's newest poetry to a philosophical and philological approach to some of its oldest, and from Tang- and Song-dynasty poetry in Western languages to Charles Baudelaire and Paul Celan in Chinese.

So how does this hang together? Of course, we could have chosen to tread safer ground than the vast, fissured spaces offered by the triptych

Van Crevel, Maghiel and Lucas Klein (eds.), Chinese Poetry and Translation:Rights and Wrongs. Amsterdam: Amsterdam University Press, 2019

DOI: $10.5117 / 9789462989948 \_$INTRO 
of poetry + translation + Chinese. For instance, by limiting ourselves to a subgenre, a historical period, translation from Chinese and not into Chinese, or the good old question of how to reconcile the phenomenon of poetic form with the arbitrariness of the sign across languages. But what we are after is precisely the $u n$-safeness offered by leaving things wide open between three words-and-things people have talked about forever and will continue to talk about forever - and then the dialogue that this yields.

First, the horizon of translation has widened over the past decades, and translation studies is a bubbly, interdisciplinary enterprise whose expansion and diversification worry some and thrill others. Witness, for example, discussions of the translational turn in scholarship. Second, to borrow from the $J M L C$ special issue, coupling translation with poetry will trigger claims the size of office blocks, all the way from Robert Frost (censored here) to Eliot Weinberger's "Poetry is that which is worth translating" $(2016,1)$. Third: add Chinese to the mix, and things get even better. The script and its myths and truths, the question of whether texts used at the imperial court in antiquity are at all relatable to what today's migrant workers post on social media beyond the fact that both are called "poetry," the stubborn, sheer specialness of the genre in various Chinese settings, and so on. And what is China? For this book, China should be understood less as a political entity than a linguistic and cultural presence in today's world whose (self-)identification reaches back a long way - we have chapters on poetry from the bronze age, the twenty-first century, and various moments in between.

So the last thing we aspire to is full coverage, which is a scary notion at any rate. Instead, we trust the triptych's ability to make us visible and legible to one another and to our readers, and this volume works toward establishing such connections. Needless to say, there are many things it doesn't do or, phrased more generously, many other things it could have done - but this does not make the nodes of the conversation we build around the individual chapters any less visible. These nodes are key concepts that have resurfaced throughout the process of making this book, from the call for abstracts to the finishing touches to the manuscript. They include norms and ethics of translation; its ontologies, uses, and effects, such as what translations can "do" in the target culture; valuations of translation, for instance as these are affected by power relations between source language and target language; but also gender issues in Chinese poetry and translation and in the study of these things; and a vision of translation as creative nonfiction. The latter offers plenty of space for the time-honored genre of reflection by the translator on their strategies, choices, and mood swings. 
We present our work in chapter groupings that these key concepts can run through. As such, this book is divided into three parts: "The Translator's Take," "Theoretics," and "Impact." Of course, different groupings could have resulted from the process that started with the call for abstracts, and we claim no necessity or self-evidence for these three. Nonetheless, our table of contents suggests a whole that is more than the sum of its parts, relating to translation studies as well as literary studies, China-focused and beyond. Below, with apologies for the enumerative mode we are about to enter, we introduce the chapters along these lines.

Part one, "The Translator's Take," opens with two essays that foreground activist aspects of poetry translation, by two poet-scholars who draw on the US context but build an argument that gestures toward translation and literature in general, with implicit and explicit reference to (geo)political, (geo)economic, and (geo)cultural power relations. Chapter 1 begins with Jenn Marie Nunes's radical renditions of poetry by Yu Xiuhua 余秀华, who catapulted to fame when her blog went viral in 2014. Jenn then lays out a queer-feminist approach to translating Yu, which is informed by fiercely intimate textual encounters as much as by the recognition of the poet's and translator's identities in their social and (geo)political contexts, and by translation as discomfort and failure as well as solidarity and collaboration. In chapter 2, Eleanor Goodman offers an activist perspective on the work of poetry and of translation. Noting that literary translation does many things, from enabling the practice of comparative literary studies to the representation outside China of Chinese migrant worker poetry in a global-capitalist world, she discusses how her translations of Zheng Xiaoqiong 郑小琼, Wang Xiaoni 王小妮, and Zang Di 步弫棣 confront English-language poetics at the same time as they interface with the work of several poets writing in English. In chapter 3, Joseph Allen takes the Take back - and forth - across great distances in space and time, illustrating a range of practical and theoretical issues that come to the fore in his new, in-progress translation of the Shijing (詩經, also known as the Classic of Poetry, The Book of Songs, or The Book of Odes). In incorporating the commentarial tradition of Chinese-intralingual interpretation into his English rendition of this foundational text, he brings together philosophy, philology, and literary aesthetics. Chapter 4 contains Wilt Idema's reflections on purpose and literary form in poetry translation, against the background of translation traditions that change over time. Circling out from a poem by Tang-dynasty poet Han Shan 寒山, he draws on examples from Dutch and English to address issues that bear relevance to classical Chinese poetry's translation into any language, and indeed to the art and the craft and the trade of poetry translation at large. 
Part two, “Theoretics," begins in chapter 5 with Nick Admussen's advocacy of the concept of embodiment in the translation of (Chinese) poetry to challenge what he calls the equivalence icosis, founded on dated yet dominant assumptions of objective method and the clean interoperability of different languages. Looking at Jennifer Feeley's translations of Xi Xi 西 西, Austin Woerner's of Ouyang Jianghe 欧阳江河, and Ming Di 明迪 and Jennifer Stern's of Liu Xia 刘霞, the argument conjoins embodiment with present-day manifestations of poetry's transmedial and political potential. In chapter 6, Jacob Edmond asserts the generally neglected importance of poetic theory in the study and practice of translation and of comparative and world literature, as a crucial complement to the overwhelming focus on the form/content binary. Theory not only travels but translates as well, as the essay argues through a case study of how Russian Formalism found its way into Bei Dao's 北岛 translations of Boris Pasternak. In chapter 7, Zhou Min investigates the phenomenon of narrativization in English translations of Tang- and Song-dynasty $c i$ 詞 poetry, in contradistinction to a widely assumed opposition of lyric and narrative poetic modes. Atop her deconstruction of the standard binary between these modes, she builds a new framework through which the translator can be appreciated as an "immersive reader" in texts of low experientiality. In chapter 8 , focusing on Qu Yuan 屈原, known as “China's first poet” (even though his life in the Kingdom of Chu predates the empire), Nicholas Morrow Williams argues that the translator should not assume that the $l i$ 離 of Qu's “Li sao” (離騷) always means either "to depart" or "to encounter," but look for translation strategies that embrace the contradiction. This exemplifies an approach to the translation of poetry that will allow for or indeed invite a "double exposure," a dialectical movement between different modes of interpretation. In chapter 9, Lucas Klein starts from the premise that a poem is a translational process: always, not just once it has been translated in the conventional sense. From there, he complicates and reorients the authenticity claims that have been built into the discourse around both the Shijing and today's migrant worker poetry. He argues that these two poetries' many moments of intralingual, interlingual, and cultural translation constitute and reiterate each other - and that the recognition of this should place proper attention on the work and the art involved in each.

Part three, "Impact," starts with chapter 1o, in which Liansu Meng reveals how Chen Jingrong 陈敬容 realizes the translator's agency in strikingly original ways in her influential mid-twentieth-century renditions of Baudelaire, and how Chen's translations are intertwined with her development of an ecofeminist poetics avant la lettre. Against the backdrop of modern 
China's tumultuous, politicized encounters with foreign literatures, the essay highlights Chen's personal trajectory as a female author in a pervasively male-dominated literary field. Another debt owed to translation comes to the fore in chapter 11, in Chris Song's discussion of the Chinese-language debut of Western surrealist poetry in Hong Kong and its effect on the local poetry scene through the work of Ronald Mar 馬朗, from the early years of the Cold War era onward. The essay traces the trope of poetry being "true to life" - as resistance to the surrealist influence - through evolving notions and experiences of Hong Kong identity over time, up to the present day in the post-handover era. In chapter 12, Tara Coleman shows that the postwar Taiwanese poetry scene is a particularly rich example of the fact that translation and its impact come in "vertical" (or indigenous) varieties as well as "horizontal" (or foreign) ones. In dialogue with film theory, she employs the notion of "lyrical montage" to consider how juxtaposition in Ya Xian's 瘂弦 poetry leads to interactions that are mutually transformative and destabilizing, questioning conventional assumptions about the original and the translation. In chapter 13, Joanna Krenz reads three embattled Chinese renditions of Celan - by Wang Jiaxin 王家新, Bei Dao, and Yi Sha 伊沙 - for what they reveal about discourse on poetry and poetics, and on translation, in mainland China today. Drawing on historical context as well as images of poethood and poetry, the essay asks why Celan is so important for contemporary Chinese poets, and contextualizes this question in debates and polemics that go back to the 198 os and continue today. In chapter 14, Rui Kunze traces various cultural translations of Liao Yiwu's 廖亦武 poetry into English and German. Her essay foregrounds a tight entanglement of literature and politics that starts with the suppression of the 1989 Protest Movement in China and extends to a dynamic engendered by publishers, prize-giving bodies, and prestigious cultural figures abroad. It reveals the complexities of communicating trauma between East and West and the gripping textual traces that are left in the process. In chapter 15, Maghiel van Crevel suggests that in the early twenty-first century, Chinese-toEnglish presents a fascinating case study for the genre of the multiple-author translation anthology - because of infighting on the Chinese poetry scene, foreign readers' unfamiliarity with this poetry, and profound changes in where the anthologists come from and what language they speak, with both questions taken in the broadest sense.

There is much to unite these essays and more to interlink them, within and across each of the book's parts. This includes a resounding affirmation at every level of what we know about binaries in the humanities: they usually don't work, which is not unrelated to our decision to arrange the chapters 
under the three headings outlined above. Also, any duality quickly creates what rhetoricians call a tertium comparationis. Likewise, in the Laozi 老子 the Two gives birth to Three 二生三 (after the Dao has given birth to One, and the One given birth to Two 道生一, 一生二); but it is the Three that gives birth to the Ten Thousand Things 三生萬物. Similarly, in our volume's title, the triptych of poetry + translation + Chinese produces a myriad.

The move to push past binaries, then, explains the title of this introduction, "The Weird Third Thing." During the workshop, Jenn Marie Nunes related an anecdote about the "Mamma Mia" episode of the American sit-com 3 o Rock, in which comedy writer Liz Lemon persuades her boss, Jack Donaghy, to tell his long-lost birth father the truth of his identity. "You're gonna be okay," she tells Jack: his father will either reject him or embrace him. "One of those two things is gonna happen. There's no weird third thing." Liz and Jack orchestrate a contest of three potential fathers in which Jack's true dad will be revealed. What happens, however, is neither all-obliterating rejection nor all-healing embrace. Instead, it turns out Jack's real dad... needs a kidney transplant. And guess who he is looking to.

Isn't there always a weird third thing, and certainly when dealing with translation? A collection of Chinese and Anglophone poets "in mutual translation" edited by W. N. Herbert and Yang Lian is called The Third Shore (2013), in homage to Walter Benjamin's concept of translation as the "third language" $(1977,102)$ and as creating a "third space" (Bassnett 2014, 12) - where the meaning of a word exists beyond the two languages that meet in translation. Homi Bhabha repositions this image from a postcolonial perspective, when he speaks of the "Third Space" of enunciation as an indeterminate, "inbetween" space that carries the meaning of culture, a precondition for the articulation of cultural difference, and "the cutting edge of translation," where we may "elude the politics of polarity and emerge as the others of our selves" (1994, 55, 311). In her turn, Doris Bachmann-Medick sees (multiple) "third spaces" as the sites for developing translational approaches and epistemologies within and across disciplines in the humanities and social science $(2013,187)$. And so on. As thirdness enters the equation, translation's proximity to transplantation troubles our reliance on simplistic affects of love or rejection of an other by a self. In literature, and certainly in poetry, this troubling and its resolution (or exacerbation) happen in how words are made to sound, but also in a translated text's need to find the right match between donor and recipient, or source and target contexts.

We are not sure which of the triptych's elements - poetry, or translation, or Chinese - is the weird third thing, or that any one of them should always be. They could take turns, right? But we know that per se, there being a 
third thing is trouble enough, and a wonderful kind of trouble. Thirdness destabilizes the symmetry of the binary, opening up multiple possibilities. There may be two sides to a coin, but there are more than two sides to a coinage, as there are usually more than two sides to an argument, especially an academic argument. The weird third thing articulates our approach: exploratory, in progress, embracing of uncertainty and possibility, and nimble, mobile.

Thirdness also means there is more than a simple "right" and "wrong." On this point, we could be taking our cue from the sculpture by contemporary Shanghai artist Xu Zhen 徐震 that graces the cover of this book. A Tang-era Heavenly Guardian 天王俑 holds aloft one of Constantin Brâncuși's early twentieth-century Sleeping Muse heads: the mash-up highlights not only the ways Chinese culture and the West do or do not fit together, and how the Chinese past looks in the light of the present - but also the ways both China and its others have been products of cultural translation from the beginning.

Similar questions and observations have always accompanied translation in formal and informal discourse, in the translator's practice as well as in academic theorization, and they explain Rights and Wrongs in the name of this book, after a suggestion by Jacob Edmond. When and why is the role of the scholar of translation to judge translations as right or wrong - technically, ethically, or otherwise - and when and why is it not? Can a translation wrong a person or party, and if so, can the translation still be right? If a translation is right, is its rightness forever and for always, or only for a certain purpose, time, or place? What rights does the translator have to respect in order for their translation to be right? What rights does the translator have, full stop - or rather, full question mark? What are the valences of aesthetics, ethics, and philology as they intersect in translation? How audible is the homophony of right and write - and of rite, in a vision of a text's translation as a rite of passage: think recognition, and entry into another community than that which now starts being called the source? Phrased and framed in multiple ways, questions such as these are well known in translation studies. The way we write them up here intends to give pride of place to the dyad of sound and sense that is so central to translation; and, in the process, not coincidentally, to blur any "hard" boundaries between translation and research.

Rights and Wrongs may sound like a binary at first, but it is "rights and wrongs," after all, not "right or wrong." Like the surface dualism under which translation's thirdness hides before exploding it, our subtitle signals polyvalence, a multifacetedness that insists the binary would be one of the wrongs. Or, there is no one correct or "right" translation, even if there may be no end to 
wrong translations. This is not to say that translations should not be critically assessed - but only with the awareness that we are doing it wrong ourselves if we fail to recognize that translation's uses and effects are as interesting, and as important, as its ontologies. Juxtaposing "rights" and "wrongs" in our title can reveal their duality to be structurally in flux, and productively unstable.

In this way, we hope our title will do what some of the best (Chinese) poetry and some of the best translations do. Ernest Fenollosa, whose notebooks played a crucial role in Ezra Pound's vision of Chinese poetry and of modernism, wrote that in the "process of compounding, two things added together do not produce a third thing but suggest some fundamental relation between them" $(2008,46)$. We see this to be that weird third thing.

Leiden / Hong Kong, August 2019

\section{Works cited}

Admussen, Nick. 2019. "The Work of the Field." Chinese Literature Today 8 (1): 117-123. Bachmann-Medick, Doris. 2013. "Translational Turn." In Handbook of Translation Studies: Volume 4, edited by Luc van Doorslaer and Yves Gambier, 186-193. Amsterdam: John Benjamins.

Bassnett, Susan. 2014. Translation. Abingdon: Routledge.

Benjamin, Walter. 1977. "The Concept of the Third Language" (excerpt), translated by André Lefevere. In Translating Literature: The German Tradition from Luther to Rosenzweig, edited and translated by Lefevere, 102. Assen: Van Gorcum.

Bhabha, Homi, 1994. The Location of Culture. Abingdon: Routledge.

Fenollosa, Ernest, and Ezra Pound. 2008. The Chinese Written Character as a Medium for Poetry: A Critical Edition, edited by Haun Saussy, Jonathan Stalling, and Lucas Klein. New York: Fordham University Press.

Herbert, W. N. and Yang Lian, eds. 2013. The Third Shore: Chinese and EnglishLanguage Poets in Mutual Translation. Bristol: Shearsman.

Weinberger, Eliot. 2016. 19 Ways of Looking at Wang Wei (with More Ways). New York: New Directions.

\section{About the authors}

Maghiel VAN CREVEL is professor of Chinese language and literature at Leiden University. A specialist of contemporary poetry, he has published a dozen books in English, Dutch, and Chinese, including scholarly monographs and 
edited volumes, literary translations, and language textbooks. His research draws on extensive fieldwork undertaken since the early 199os. See, for instance, the long essay "Walk on the Wild Side: Snapshots of the Chinese Poetry Scene” (2017), downloadable at the MCLC Resource Center.

Lucas KLEIN (PhD Yale) is a father, writer, and translator, as well as associate professor in the School of Chinese at the University of Hong Kong. His translation Notes on the Mosquito: Selected Poems of Xi Chuan (New Directions, 2012) won the 2013 Lucien Stryk Prize, and his scholarship and criticism have appeared in Comparative Literature Studies, LARB, Jacket, CLEAR, $P M L A$, and other venues. Other publications include October Dedications, his translations of the poetry of Mang Ke (Zephyr and Chinese University Press, 2018); and contributions to Li Shangyin (New York Review Books, 2018); and the monograph The Organization of Distance: Poetry, Translation, Chineseness (Brill, 2018). His translations of the poetry of Duo Duo, forthcoming from Yale University Press, won him a PEN/Heim Translation Fund grant. 



\section{Conventions}

These fifteen authors speak in different voices. While they are explicitly in conversation and speak together, the last thing this book wants to do is to harness these voices in the service of uniform approaches or conclusions. The cliché is true, and let's keep it so: within this book, amid the many resonances, there are tensions to explore as well, and we look forward to the new work it may trigger more than anything else. As regards conventions, too, while we use the Chicago style as our point of reference, we have wanted to steer clear of rigid oneness. Especially so for the inclusion of Chinese characters and romanization, and for an important point in citation practice. Neither issue is a mere technicality.

First, this book speaks not just to Chinese studies but also translation studies and literary studies. With an eye to its readability as an English text, each of us has considered how much their essay needs in the way of Chinese characters and romanization. In plain words, we have tried not to overdo it. Up to a point, one's subject matter can objectify this: grappling with the names of flora and fauna in the Shijing is different from grappling with editorial strategies in English-language anthologies of today's Chinese poetry. But in the end it is the author's call. Also, each of us has considered whether to stick with either full-form or simplified Chinese characters throughout their essay, or to alternate according to historical context and the material under scrutiny; and whether to use Hanyu pinyin romanization throughout or to also use other varieties, to respect convention or the preference of the person whose name is transcribed. Similarly, some essays give life years for their protagonists and others do not, depending on what the author feels the essay needs.

Second, as regards citation, it should not come as a surprise that this book identifies with a position of advocacy for the emancipation of the translator. In the face of a widespread, astonishingly stubborn blindness to, well, the translator's very... being, and sometimes the erasure of their presence from the public record, in academic and popularizing publications alike, we want to highlight not just translation but translators. As Eleanor Goodman put it, we shouldn't just pay lip service to the centrality of the translator but build it into the academic scaffolding itself. We have made it each individual author's choice to cite translations under the translator's name - which is common in the study of premodern texts but should be a normal option for all others - or under the name of the author of the source text. Either option can be defended, so if an author sticks with 
the source-text author, for instance because they think findability of the translation is best served by consistency across systems and settings, this doesn't mean they are not working for the emancipation of the translator. Of course they are. 


\title{
Part One
}

\author{
The Translator's Take
}





\title{
$1 \quad$ Sitting with Discomfort
}

\author{
A Queer-Feminist Approach to Translating Yu Xiuhua
}

\author{
Jenn Marie Nunes
}

\begin{abstract}
This essay begins with the author's radical renditions of poetry by $\mathrm{Yu}$ Xiuhua, who catapulted to fame when her blog went viral in 2014. She then lays out a queer-feminist approach to translating $\mathrm{Yu}$, which is informed by fiercely intimate textual encounters as much as by the recognition of the poet's and translator's identities in their social and (geo)political contexts, and by translation as discomfort and failure as well as solidarity and collaboration.
\end{abstract}

Keywords: Chinese poetry, translation, Yu Xiuhua, feminist translation, queer theory of failure, translator's visibility

\section{《我养的狗, 叫小巫》}

我跛出院子的时候, 它跟着

我们走过菜园, 走过田埂, 向北, 去外婆家

我跌倒在田沟里, 它摇着尾巴

我伸手过去, 它把我手上血舔干净

他喝醉了酒, 他说在北京有一个女人

比我好看。没有活路的时候, 他们就去跳舞

他喜欢跳舞的女人

喜欢看她们的屁股摇来摇去

他说, 她们会叫床, 声音好听。不像我一声不吭

还总是蒙着脸

Van Crevel, Maghiel and Lucas Klein (eds.), Chinese Poetry and Translation: Rights and Wrongs. Amsterdam: Amsterdam University Press, 2019

DOI: 10.5117/9789462989948_CHO1 
我一声不吭地吃饭

喊 “小巫, 小巫” 把一些肉块丢给它

它摇着尾巴, 快乐地叫着*

(Yu 2015, 4)

Dog I Keep, Called Little Wu

In "The Politics of Translation" Spivak claims that a feminist translation of work by women is one in which "the translator attends to the specificity of the language she translates" (180). One must be a good listener

I limp out of the courtyard time, it follows

We walk the garden, walk the ridge between fields, going north, to maternal grandmother's house

I stumble into a field ditch, it wags tail

I stretch hand across, of the blood on my hand it laps clean

He's drunk, he says in Beijing he has a woman

better looking than me. Doesn't have a means of survival time, they go dancing

He likes dancing women

Likes to watch their butts wag back wag forth

He says, they can call bed, voices sound good. Not like me a voice wordless

Still always hiding my face

I voice wordlessly eat

Call "Little Wu, Little Wu" of a few pieces of meat toss to it

It wags its tail, happily barking

I Keep a Dog, Called Xiao Wu

Is it then important that 小 means "little" and 巫/Wu is a common Chinese surname? As a name, it is a unit of sound, a script that marks dog and has no "meaning." How to truly translate a proper noun? How does the speaker hear her dog's name? For me, the meaning of the name, like the meaning in the dog, somewhat inscrutable. Instead I hear her voice “Xiao Wu." I am listening

When I limp out the courtyard, it follows

Yu Xiuhua refers to the dog as 它/it and to the man as 他/he. The sound the same, the pronoun clearly different. Reading in Chinese I think of the dog as "he," partly because of the aural overlap of 它/ta and 他/ta and partly because Americans would 
never refer to a pet dog as "it." Does the Chinese 它 have the same quality of thingness? Does it indicate a more practical, less intimate relationship between woman and animal? Does it allow the dog to overlap with the "he," implicating the dog in a lineage of patriarchal violence, or does "it" fully stand between the two, the indeterminacy of 它 also opening into a blankness of possibility, a liminality, a way out?

We walk the garden, walk the ridge between fields, going north, to my grandmother's house

Chinese, unlike English, has a complex vocabulary for articulating family relationships. The term 外 婆 means maternal grandmother, literally “outside grandmother," so this is the speaker's mother's mother, not her husband's grandmother or her father's mother, outside the patriarchal line of descent

I fall in a field ditch, he wags his tail

I stretch out my hand, of the blood on my hand he laps clean

伸手, stretching out one's hand, is a gesture and also an asking, it moves the body and it speaks, it asks for, it might even beg

He’s drunk, he says in 北京 he has a woman

$$
\text { As in "has" }
$$

better looking than me. When he doesn't have work, they go dancing He likes women who dance Inhabit their bodies in motion

Likes to watch their butts wag back and forth Now dog and women overlap in the verb "摇"

He says, they can call out in bed, and their voices sound good. Not like me without a word

叫床, one word that means to cry out in ecstasy (during lovemaking). I wonder if this word is used for the pleasure of both men and women

Always hiding my face

\section{I eat without a word}

\section{Call "Xiao Wu, Xiao Wu" toss him a piece of meat}

巫 also means "shaman" and Google translates the dog's name as Little Shaman. One of my professors asks me why I haven't translated it as such. She says that to her the poem is very spiritual. Again the dog's role is contested. It stands as a vessel between

The dog wags his tail, barking happily

"Happily" sounds insipid in English. I don't think this is a bad translation

Dog I Raise, Called 小巫

In the context of a feminist mode of translation, Lori Chamberlain suggests the process should be cooperative. Carol Maier says we should "get under the skin of both antagonistic and sympathetic works" and speak with the antagonistic work. Do we not also speak with sympathetic works? 
When I limp out the courtyard, it follows

I am not a dog person. I tend to think of all dogs as dumb dudes. Dogs don't understand us, they don't even understand themselves. Dogs are the shadow of our need to be needed

We walk the garden, walk the ridge between fields, north, to my grandmother's house

My maternal grandmother is my last living grandparent. A difficult woman who taught my mother who taught me to be insecure, inconsistent, and impatient with others who can't read your mind. Or who aren't your son. She used to have a little dog named Dusty. Now she has a cat she complains about who won't cuddle. She and my mother don't get along well, but my grandma lives closest to us. We've been three generations of women on our own for over thirty years. Now, she's beginning to forget things

\section{I fall in a ditch in the field, it wags its tail}

\section{I stretch out my hand, of the blood on my hand it laps clean}

I joke with my brother that the Nunes blood runs deep. He and I share a father. Our three uncles, our cousins, we all share a a look, we all brood. We do not ask for help. The violence in us, a slick seam, a wealth of silence

He's drunk, he says in 北京 he has a woman

My grandmother told my mother she didn't enjoy having sex with her husband, and my mother told me. We are not women who have taught each other how to take pleasure

better looking than me. When he's between jobs, they go dancing He likes women who dance

But we do all like to dance

\section{Likes to watch their butts wag back and forth}

My father met his current wife ballroom dancing. My mother says, "Your father always wanted a Barbie doll"

He says, they can call out in bed, and their voices sound good. Not like me without a word

\footnotetext{
My mother also told me it took her a long time to learn that finding your own pleasure is sexy for your partner. I don't know anything about my father's sex life, but his wife does wear leopard print and short shorts, and she does speak her mind. She runs her own business and buys things she likes no matter what my father thinks. She grew up in upstate New York and hasn't been to college. Sometimes I think she's jealous of my relationship with my father, a space where she is of no use. I don't know how I learned to perform my pleasure, how I learned this one way to make people feel like I need them
}

Always hiding my face

I eat without a word

Silence is complicity. Silence, for us, is also the glue that holds us together at the points we cannot meet without violence

Call “小巫, 小巫” toss it a piece of meat

It wags its tail, barking happily

But the violence is there 
Yu Xiuhua 余秀华 became a poetry sensation in China after her poem “Crossing Half of China to Sleep with You” (穿过大半个中国去睡你) went viral via the messaging platform WeChat in 2014. As a woman who lives in rural Hubei province and did not graduate from high school, her poetic talent has captured the Chinese imagination - or the Chinese imagination has captured her poetry. Excitement around her "natural talent" and prolific output intersects with her various identities, including the fact that she has cerebral palsy. Among a number of labels, she has been dubbed "the cerebral palsy poet" (脑瘫诗人) and even when the language is less direct it is clear that many link her disability and poetics: "she walks clumsily and talks haltingly. Yet she is keen on the physicality of language ... the words Yu uses are brutal, free, vivid, angry and violent. Writing poetry is a natural physical impulse for her" (Zhou 2015; Riep 2019 takes a disability studies perspective throughout). Yu herself enters the conversation saying, "label is necessary when you need to promote something ... But my disability really has nothing to do with my poetries. No matter a person is physically healthy or not, when they write poems, their mind and spirit are the same" (sic, Yao 2016). Yet, Yu does discuss her experiences with her disability on her blog and in interviews and suggests that poetry is a "spiritual crutch" allowing her to express herself in a way she otherwise cannot. In other words, in relation to her writing, she makes an effort to identify as a poet rather than a female poet or a rural poet or a poet with cerebral palsy, but her construction as a poet in the eyes of the public, and thus the way her poetry is consumed, cannot be disentangled from these labels.

As a key site of cultural exchange, literary translation has the potential to act in concert with transnational power structures, reaffirming global inequalities, but also to radically intervene in existing hierarchies, surfacing a more complex mapping of the transnational present. Yu's writing together with her status as a public figure place her at a slant relative to both established poetry circles in China and established translation practices outside China, highlighting the ethical issues that translators face. ${ }^{1}$ I encountered Yu's poetry through a Chinese friend who introduced her as a poetry sensation, the Emily Dickinson of China, and I have to admit that a significant part of my interest in translating her work stemmed from "the Yu Xiuhua phenomenon" and the way her writing and her status as a poet have become a compelling nexus in the complex web of cultural, political, and literary forces at play in contemporary Chinese poetry. As a writer myself, I am inclined to embrace my labels - feminist writer, queer writer, 
"experimental" writer - and I am well aware of the ways my ability and desire to make this choice reflect something about the state of contemporary poetry and our broader historical moment in the US. To put it more bluntly, my own position as a highly educated and able-bodied white woman located both at a university and within the small-press poetry world in the United States does not do much to alleviate the ethical issues surrounding the translation of Yu's poetry. The violence is there.

It is from this uncomfortable place that I would like to explore the possibilities of a queer-feminist approach to translation. The opening to this chapter is an excerpt from one of Yu's poems, followed by my translation. Like much of Yu's poetry, I find "Dog I Raised, Called Xiao Wu" (我养的 狗, 叫小巫) compelling because of its unsettling imagery, deceptively simple language, and confessional, intimate mode of first-person narration. These elements work together to create a world that feels grounded and familiar, and yet contains a great depth of complex affective possibility. The calm, direct telling of each moment, as if the speaker were simply listing the day's chores, poignantly illustrates the casualness, familiarity, and intimacy of domestic violence and the way it can become just one more thread woven into the tapestry of home life. At the same time, the way the poem tacks quickly but deliberately from walking through the fields toward grandmother's house to the speaker's fall and her bloody hand and then to her husband's drunken verbal abuse manifests the complexity of this web of violence, entangled with gender, ability, and class. Now vividly specific, the text speaks to the way the flow of violence in human relationships is shaped by larger social and cultural power structures, hailing me to recall the damaging ways gender identity has traveled across generations of women in my own family.

As one can see in my translations above, my approach interrogates the invisibility of the translator (Venuti 2018). In doing so, I resist imperialist tendencies - violences - in mainstream English translation that can limit the range of styles and voices that enter English literature via this route. ${ }^{2}$ As a disclaimer, I should add that while Lawrence Venuti and other scholars on whose work I draw focus on a transnational Anglosphere and my argument gestures toward translation and literature in general, my intervention is best situated in a US context, because of my familiarity with the state of translation and contemporary poetry in the US. At the same time that I attend to the visibility of the translator, I make room for varied and nuanced consideration of ethical reading practices by those 
positioned in relative positions of privilege (me) who translate work by those more easily exploited within transnational power structures, where issues of gender, class, ability, and so on are further inscribed with the "otherness" of the foreign.

Specifically, I find that with its attention to female sexuality, domestic abuse, depression, and desire in a disabled body, Yu's poetry makes both visible and felt certain internal and external landscapes often considered irrelevant to contemporary (Chinese) poetry and therefore not afforded much global movement. Combined with the way the internet frames Yu's success and simultaneously asks us to reconsider notions of authenticity, access, and authorship, I believe Yu's poetry allows, even invites, a mode of translation that retains, creates, and sits with discomfort. Therefore, I draw on a queer theory of radical failure and disruption, in conjunction with a "politics of relationality" and women of color feminism, ${ }^{3}$ to suggest an approach that refuses to produce the singular, fluent translation that is the English norm, in order to contribute to a feminist translation theory of accountability, relationality, and play. Instead of separating Yu's poetics from her interlocking identities, I attempt to visibly combine these various threads along with those of my own poetics and identities, aiming for a dynamic, collaborative, and subversive iteration of Yu's work.

But is it possible to subvert or disrupt elements of English translation more broadly while simultaneously attending to Yu Xiuhua's agency and the particularities of her poems? Would such a non-standard or unfamiliar mode do justice to $\mathrm{Yu}$ and her poetry if it were the first translation of her work

3 I have chosen to keep the term women of color feminism unhyphenated. This is because I attempt to listen to those who came before me, particularly women of color (for example, Sylvanna M. Falcón and Jennifer Nash, in their 2015 discussion of intersectionality and transnational feminism). I consider this listening important because women of color feminism grew out of a concerted effort by women of color to make their own voices heard in a field dominated by white women. For instance, the term is now used to describe Cherríe Moraga and Gloria Anzaldúa's This Bridge Called My Back: Writings by Radical Women of Color, first published in 1981, as a "foundational text of women of color feminism" on Moraga's website (on the occasion of the publication of the fourth, updated and expanded edition, in 2015: see bit.ly/2 $\mathrm{M}_{7} \mathrm{WU} 33$ ) as well as elsewhere on the web. The title of this book makes clear that women of color feminism, as a mode of theorizing, grew directly out of the work done by women of color; and women of color as used in American English is a noun phrase, signifying people. It takes up space - just as women of color feminism takes up space in feminist theory. To me, making it adjectival by inserting hyphens collapses its "noun-phrase-y-ness," removing the personhood the term intentionally speaks into existence. Throughout this chapter I am concerned with an ethics of translation via the use of language. Rendering women of color as a mere descriptor tagged to the fraught noun feminism does not feel to be in keeping with my push to work across and within difference, even if that might mean (grammatical) discomfort. 
made available? ${ }^{4}$ Is it ethical to disrupt the paradigm of English translation through the work of this poet? For instance, Yu has repeatedly asked to be seen as a person, a poet, rather than as a disabled person or a woman specifically. Her direct expression of her own sexuality, as a disabled person and as a woman, is a subversive, shocking move in a Chinese context that is at least in part a means of claiming a more normative, visible (hetero) sexuality. In that context, is the application of feminist and queer theories to the translation of her poetry appropriate? Then again, would it be ethical to allow Yu's subversiveness, this move toward visibility, to be dulled in translation? For how does one bring these elements of her poetry across when bold expression of female sexuality and complex female subjectivity is common in contemporary US poetry? And while disabled subjectivities are by no means allowed full range of expression, disability discourse is still more accommodating in the US than in China. My goal for this paper is not necessarily to answer these questions but to explore these points of tension and to consider how remaining in the uncomfortable and vulnerable place of incompletion, uncertainty, and reflexivity might offer new ways to address such tensions in the future.

\section{The whys: visibility and Yu Xiuhua}

\section{Discourses of fluency and the policing of difference}

Let me begin by clarifying Venuti's "invisibility of the translator" and how it might be enmeshed with an imperialist world view. This invisibility in mainstream, economically viable English literary translation is partly secured via "an illusionist effect of discourse" founded on the supremacy of fluency, essentially meaning that the style of the English should not intrude uncomfortably on the experience of reading $(2018,1)$. To put it another way, the translated text is meant to convey the impression that, using one of many flawed metaphors for translation, the reader is looking through a clear window into another world. The mark of the translator or the processes of translation should be undetectable - invisible - to target readers. The

4 At this writing (March 2019) there is yet to be a book-length translation of Yu's work in English. However, Chinese Literature Today recently published Elise Huerta and Hangping Xu's translations of twelve of Yu's poems (2018), including their version of “My Dog, Xiao Wu," as part of a Yu Xiuhua feature with other contributions by Michael Berry and Travis Fan (Fan Jian 范 俭), Tze-lan Sang and Shen Rui 沈睿, and Steven Riep. 
value of fluency has been regularly affirmed through the language chosen by reviewers if they elect to comment directly on the translation of a book at all: "gracefully if not flawlessly translated"; "pleasantly fluent"; "faithful ... if not quite idiomatic"; "fluently translated"; "readable" (2-3; Nabokov $1992,127)$. On the other side of the judgment coin, criticism is articulated as "wooden"; "doughy"; and "translationese"; "translatorese"; and "the dull thud of translatese" (Venuti 2018, 2-4). This critical language links fluency to quality and thus perceived accuracy, such that regardless of the nature of the source text, anything moving too far away from this standard - anything that stylistically proposes one is reading a work originally written in another language and cultural context - risks being considered inaccurate, or at least flawed and artless.

At the same time, in the US particularly translation as a genre has a lengthy history of being considered second-class literary output, exacerbating "the translator's invisibility." This stems from the hierarchical binary of creative-original versus reproductive-copy, where translation work is inferior: "to be a translator is to assume [the] role of a hoaxer, someone who might be undermining the quality and trustworthiness of literature (and taste)" (Göransson 2014). I am reminded of a poetry professor who refused to teach us work in translation because "you can't close-read a translation." The text has become too "untrustworthy" and can no longer be considered a creative work. This general attitude works in tandem with the discourse of fluency and current economies of translation to limit the number of texts being translated and the parameters of viable translation: is the excerpt of my own work at the beginning of this essay actually translation... or is it something else? And if it is something else, what value does it have?

It is this situation that encourages the policing of difference as it enters an Anglophone consciousness. Who and what gets translated is informed by economic, ideological, and cultural forces in the target culture that favor certain expressions of difference over others. In the case of the US and Chinese poetry, this tends to mean an emphasis on the imagistic and a certain political affinity. For instance, building on T. S. Eliot's claim that Ezra Pound "invented" Chinese poetry for the English-speaking world, poets and scholars have noted Pound's emphasis on "visuality" in classical Chinese poems, and his version of Chinese poetics has had a lasting influence on which Chinese poems are considered translatable and how those poems are translated (Eliot 1928, xvi; Weinberger 2016, 49; Yeh 2004, 251, 605). In terms of the political, not all that much has changed since 1996, when Yang Lian 杨炼 observed: "it still seems that Chinese literature has to be 'Red' (or, rather, 'anti-Red') in order to be noticed" (14). And because of the 
importance of English-speaking markets and their significance in terms of accruing cultural capital in a transnational literary sphere, these forces can even have an impact on what gets written in the first place (Bruno 2012, 268). In other words, because translation is widely undervalued and the fluency paradigm occupies a hegemonic position, the invisibility of the translator continues to be reaffirmed and the way difference enters the US literary sphere is limited.

\section{YuXiuhua: "phenomenon" and poet}

Of course, I do not intend to imply that transnational geographies of literature are organized solely by English-language standards and ignore "the many lives that literary texts lead beyond their place of origin and the diverse literary canons and values that, depending on the place and time," might rise to the forefront of "world literature" (Edmond 2012, 97). Nor am I implying that nothing is getting translated into English that does not fit neatly into certain preexistent categories of "Chineseness" or "poetry." This very book attests to the complexities of (Chinese) poetry and translation. Yet, I still find Venuti's argument relevant as it asks us to reconsider translation's evaluative tools and how those tools might inform the way difference moves across borders. Are the mainstream varieties of these tools suitable in all cases? 5

Let me pose a more specific question: why call on a queer-feminist theory to translate the poetry of Yu Xiuhua? While the scope of my argument for pushing the boundaries of English translation is bigger than one poet, one genre, or one avenue of exchange, I believe that Yu's trajectory as a poet combined with her poetics and the way her work has been received in China alongside my own positionality as translator all point to the need for a mode of translation that is not "standard." A mode that actively works not to smooth over the various tensions in her writing and around the propagation of her work. I propose an approach that embraces cultural translation (in the sense of culturally inflected interlingual translation [van Crevel 2017b, 247-248]), creating a space where Yu's poems are not sheared of context - including the context of the work of translation.

To begin with, the internet is a publishing platform that does not fit neatly into a print paradigm where texts are relatively stable, authorship is authenticated, and "the original" can generally be traced. Yu's presence on the internet thus complicates notions of natural talent, authorship, and originality, opening up a space for engaging "the original" of her work in new 
ways. For instance, even though she did not finish high school and was not previously a member of any poetry group, online or off, she has been actively posting and discussing poetry in online forums since 2008 (Zhou 2015). And while she may have started writing poetry before she started reading it, regardless of her geographic and socio-economic location, her poetry is certainly now informed by various textual exchanges and "dependent on other, preexisting materials" as facilitated by the internet (Zhao 2017; Venuti 2018, 265). Moreover, the internet, which supports constant recontextualization of text and images, asks us to reconsider what we mean by "authorship" and how we locate and ascribe value to an "original." For example, looking at the "Quake Poetry" that emerged after the 2008 Sichuan earthquake, it is clear that anonymity and a collective performance of cultural identity are part of online Chinese poetry discourse, demonstrating how poetry, like anything else posted online, can become the property of all (Inwood 2014,168 ). That is not to say Yu's work is not original or that she has no claim to it. Rather, my approach to reading her poetry takes into consideration how its online origins complicate the authority of the print versions of her poems and ask us to reconsider whether the texts she produces are fixed and permanently placed.

Furthermore, Yu's blog as a platform for publication creates a hybrid collection of textual production that includes her poetry as well as various contextual discussions, readings, responses, revisions, and so on. Yu's poetry is already part of a larger textual project, including her contributions to critical discourse, discussions of her own poems in response to their circulation and critique, personal entries about her life and experiences, and responses from readers. Her poems are visibly enmeshed in a dynamic, multi-textual landscape. In that sense, reading Yu's work through her blog is not wholly different from reading my translations. Just as the materiality of the internet as a means of presentation and circulation in combination with the varied content of Yu's blog inflect any reading of her poetry, so my translations also contextualize, recontextualize, situate, and unsettle her writing in English.

In addition to her position as an "internet poet," neither Yu's poetics nor how they intersect with her reception fit preexisting molds. For one thing, rather than coming up through one of the hip poetry "live scenes" that have flourished on the Chinese internet, Yu's rise to prominence was facilitated by the simple fact that her poetry has gone viral (Inwood 2014, 17). That is, her poetry demonstrably speaks to a broad audience - unlike the "avant-garde" (先锋) poetry that is predominantly written by educated, urban, male "members of a cultural elite" (van Crevel 2017a, par. 84). Although movements 
like the Lower Body (下半身) and the School of Rubbish (垃圾派) have loudly aligned themselves with a "Popular Standpoint" (民间立场), they have in fact been invested in conversations and poetics that lie at a far remove from "popular" sensibilities, and remain an elite product. Yu and her popularity explode this paradigm. Unsurprisingly, her poetry has not necessarily been endorsed by the avant-garde, where Shen Rui's 沈睿 characterization of Yu as China's Emily Dickinson did not land well, triggering debate about the quality of her work and her status as a "phenomenon" (Shen Rui 2015; Shen Haobo 2015). At the same time, Yu has been embraced by the "official arena" (官方诗坛) of more or less state-sanctioned writing, winning poetry awards and joining the Chinese Writers Association; but she continues with her frank attention to topics like female sexuality and the unpleasantness of rural life, rather than slipping into establishment rhetoric. ${ }^{6}$

In other words, $\mathrm{Yu}$ is difficult to place or pigeonhole. To quote Maghiel van Crevel (2017a), she has "crashed the party all by herself," and it is not just her persona but also very much her poetry that sets her apart (par. 112). Her deceptively simple use of language, unsettling imagery, and intimate first-person voice tear holes in the familiar narratives, both romantic and political, that construct rural landscapes as well as women's work, emotional labor, and desire, and create entry points that re-envision and challenge that very familiarity. As a farmer and an "uneducated" woman with cerebral palsy writing about female sexuality, domestic abuse, depression, and desire in a disabled body, Yu makes visible a subaltern consciousness in a way that is both tender and confrontational in its directness, not only "upending conventional images of avant-garde poethood" but upending the binary of art for art's sake versus art for society (par. 110). Her poetry might be "popular" but that does not mean it is "standard" or has no teeth.

Finally, it is because of my affinity for Yu's poetry and my sense of her as a person that I want the translations of her poetry and my process of engaging it to do more than sit still on a page. Like many others, I was struck by her poems when I first read them. At the same time, I feel that extracting those poems from their context - poetry in China today, how Yu has entered this dynamic sphere, the reception of her work, debates around its quality and necessity, and how I have been affected by reading her - is at best a

6 Poet Shi Zhi 食指 has criticized contemporary poets, and particularly Yu Xiuhua, for not having the proper political consciousness in their poems: "How can a poet not spend a moment considering the fate of humanity, or thinking about the future of her nation? How can a poet from the countryside not speak of the miseries of rural life or their dreams of prosperity? How can they just forget everything?" (Xu 2018). 
shame. At worst, it is another kind of violence, one that dehistoricizes her writing, making it an object of easy consumption, smoothed to match the target culture's template for Chineseness, poetry, Chinese poetry. Does an established mode of translation, then, do more justice to Yu and her writing than one that looks like mine? Or, again, a more specific question: how does my queer-feminist approach to translating Yu Xiuhua work?

\section{The hows: the "acid tools" of deconstruction and ethical "be longings"}

\section{The possibilities of queer failure}

My method of translation includes putting into play a host of strategies including multiplicity, foreignization, and heavy use of paratextual elements that explode textual cohesion. I am aware that within a paradigm of invisibility, where manipulation of the source text does not count as such if it is undetectable to target-language readers, this deconstructive move toward multivocality may appear to be at odds with an ethics that recognizes Yu's agency as an individual poet. I am aware that while I frame my intervention as the intentional disruption of a normative mode of translation, I could also be judged to have failed as a translator. I have failed at creating a familiarized and easily consumable object that appears "natural" in English in terms of style and form. And perhaps I have thus failed to "accurately" convey the author's intentions by unmistakably inserting my own. These translations do not look like the source texts. They proliferate. Appendages protrude. The lineage - from singular "original" to singular "copy" - appears harder to trace. Perhaps I have failed to do justice to Yu and her poetry. But rather than bemoaning or denying failure, it is within failure that I locate resistance and possibility.

In The Queer Art of Failure, Jack Halberstam explores masochism, pain, passivity, and failure as alternative forms of expression that refuse to work "within the same logic as the normative regimes against which they struggle" and are therefore powerfully subversive $(2011,129)$. Translation has long been implicated in gendered notions of passivity, whether in terms of the more "feminine," reproductive work of the translator as opposed to creative, "male" productivity or in terms of the text as a passive woman that must be "penetrated" and whose paternal lineage is all-important (Chamberlain $1988,461,462)$. Rather than simply flipping or upholding this passive/active binary by claiming (feminine) translation is equal to (or as masculine as) 
creation, maybe a queer-feminist perspective allows me to reclaim passivity and in doing so to disrupt how agency and value are defined in this context. If radical passivity can be a means of "opt[ing] out of certain systems built around a dialectic between colonizer and colonized" (Halberstam 2011, 131), then it might be a viable means of disruption that does not simply swap the terms of oppression but moves toward an ethics of translation by moving outside of the colonizer/colonized framework altogether. This passivity and failure - residual Chinese characters, multiple attempts, uncertainty, etc. - create translations that occupy a liminal space, refusing to commit to preexistent US cultural and literary expectations. Cultivating this inbetweenness and its resistance to definition allows translation to become an embodiment of cultural rupture, unafraid to be foreignness, alterity, difference walking among us, but an embodiment that is not so different as to be illegible and thus without power.

Recalling an earlier collaboration with Joyelle McSweeney (2012), Johannes Göransson calls translation "the deformation zone" where "the versioning and contagions of the foreign are part of the poem, not something that must be abjected in order to keep the poem whole" (2016). McSweeney and Göransson draw on notions of excess and kitsch to embrace translation as a knock-off, a hoax, the site of hybridity, contamination, and rupture. And yet we enjoy reading translations. Göransson argues that this enjoyment in reading a "knock off" threatens to destroy the supremacy and the very notion of "authentic" poetry to begin with. What is the specific value in an original if its knock-off is equally, if perhaps differently, enjoyable? What possibilities does this confusion reveal? Translation demonstrates how any text can generate versions, and these versions need not be put into place, one better than another, separated wholly from the original. Instead, the poem and its translation are constantly in motion, constantly hailing us to respond, constantly becoming. In my case, "the translator's take" is in part a leaning toward excess and an active becoming that enables my translations of Yu's poetry to flaunt numerous contaminating factors, including other texts, my own subjectivities, my own lyrical response, and Chinese script and syntax.

As such, embracing the failure in translation is a queer intervention that returns the translated poem as well as the "original" to its place "located in between ... permanently in transit, a continuous escaping from the boundaries of meaning" (Ruvalcaba 2016, 7). By creating a hybrid work that does not claim to smoothly transfer meaning from one context to another, and as such reveals how the "original" text is not a container for meaning but its own web of interpretive processes, queer translation challenges "the phallogocentrism of the West, with its worship of the monotheistic, 
phallic, authoritative, and singular work, the unique and perfect name," and "the assumption that we were born to "segregation, separation, isolation, competition" that is at the heart of a Western construction of subjectivity as individuality (Haraway 1991, 175; Rowe 2005, 16). A translation that embraces and is thus conscious of the ways it is "permanently unclosed" can then potentially attend to difference and the pleasure in confusion and construction of boundaries in a more responsible way (Haraway 157). Gaps between myself as translator and Yu Xiuhua as poet appear, and yet the line between our distinct voices and poetics becomes blurred - this blurring made apparent by the places where the line, the gaps, are clear. In a sense these are both failures, the failure of the translation to perform accuracy and authority and its failure to uphold the notion of originality and "the unique and perfect" text. The queer translation thus marks the current limits of translation, the limits of our ability to speak through difference, and also refuses to abide by those limits, embodying in its very strangeness the possibility of greater territories of understanding.

\section{"Womanhandling" a translation and an ethics of collaboration}

In order to expand on how an ethical practice might emerge from a disruptive mode and to address Yu's agency more directly, I now turn to several strands of feminist theory. First, I would like to point out that the history of feminist theory and translation is a history of feminist intervention and political engagement. Because women and translation have long shared a secondary status, women have found work in translation since the Renaissance, even when "to publish or appear in print was considered aggressive behavior for females," and many women used translation, including paratexts and manipulation of the text itself, as a means of entering literary and political conversations from which they were otherwise barred (Simon 1996, 46). The feminist translator continues to act with a deep "distrust of traditional hierarchies and gendered roles, deep suspicion of rules defining fidelity, and the questioning of universal standards of meaning and value," even if the author being translated is not necessarily writing from this place (8). However, that does not mean one should be "speaking for" women writers, ultimately perpetuating a cycle of cultural domestication (Sharoni et al. 2015, 654). One of the ways the feminist translator is able to avoid doing this is by intentionally making visible the manipulation in translation. As Barbara Godard proposes,

the feminist translator, affirming her critical difference, her delight in interminable re-reading and re-writing, flaunts the signs of her 
manipulation of the text. Womanhandling the text in translation would involve the replacement of the modest-self-effacing translator."

(Quoted in Simon 1996, 13)

This womanhandling looks much like my own "excessive interference" in Yu's poetry, including supplementation, "hijacking," and a foreignizing style that attends to the style of the author and source language (von Flotow 1991, 79; another contemporary example of this kind of translation practice, which I highly recommend, is Chantal Wright's translation of Yoko Tawada's Portrait of a Tongue [Porträt einer Zunge] [2013]). Nor is this interference based on creating excess alone.

Lori Chamberlain suggests a feminist theory of translation "governed by ... the double-edged razor of translation as collaboration, where author and translator are seen as working together, both in the cooperative and the subversive sense" $(1988,470)$. While I have not yet had the pleasure of directly collaborating with Yu Xiuhua, I believe it is still possible to approach translation within a framework that constitutes an ethics of collaboration. So I turn to women of color feminism, and in particular the work of Aimee Carrillo Rowe (2005) and Maria Lugones $(1987,1994)$, who articulate approaches to working across and within difference that are rooted in a critical mode of intentional awareness. I see their theorizing as the foundation for a framework where "collaborative" also means that any work - future theorizing, activism, translation - is done with constant recognition of and attention to one's position within a greater community, or as Rowe puts it, within "a 'politics of relation"” (16). If subjectivity is a discursive process wherein the "self" (and any experience of a written text) is configured differently in any given moment depending on where one is situated within shifting communities and how one is currently being hailed by existing power dynamics embedded in our relationships with each other, then it is possible for us to "be longing" or to engage "a process that places oneself at the edge of one's self ... leaning and tipping toward the 'others' to whom you belong, or with whom you long to be - those who are 'you'” (Rowe 17). This "longing" suggests a collaborative concept of being rooted in a certain ethics of active self-awareness and recalls Göransson's deformation zone, where contamination is not only unavoidable but desirable. It is, in fact, our true state of being and creating.

On the one hand, this could mean moving toward Yu Xiuhua such that my use of English takes on certain aspects of Chinese syntax - "I limp out of the courtyard time"; "their butts wag back wag forth" - or it might mean that I resist the pressure of a US poetics to "improve" on the word-choice 
"happily," or it may look like an attempt to speak to the way Yu's poem works on my own emotional landscape - "we are not women who have taught each other how to take pleasure." On the other hand, this means maintaining a certain vigilance regarding my ability to understand Yu's intentions - how might my concept of a pet inflect my translation of language around the dog in this poem? What might be the effect of my use of Chinese syntax in Yu's writing but not my own? It is by practicing the playfulness Lugones proposes as a way to begin to move toward another's "world" - an "openness to being a fool ... not being self-important, not taking norms as sacred and finding ambiguity" through creativity - that I resist the normative "rules" of translation and make evident many of the various belongings and "be longings" that hail Yu Xiuhua and myself $\left(1987,15^{-17}\right)$. By refusing to leave behind all markers of difference or foreignness in my translations, refusing to sever Yu's poems from their greater context in China, refusing to silence my own participation in the process of translation, by letting all these things remain at play, I enact Lugones's concept of "curdling" (1994). This lack of clean separation, my resistance to purity, homogeneity, and the fragmentation of a complex whole into discrete parts, removes the possibility of keeping myself at a distance, where I or my reader can perceive and engage the poem arrogantly, and lends my translations the potential to disrupt the kinds of creative domination that can be the result of the translator's invisibility (470).

I believe this extreme visibility aligns with the kind of critical awareness that Lugones and Rowe propose as necessary steps toward accountability and the disruption of sedimented lines of power, where we must keep in mind that our current ability to step outside of those lines of power is limited:

by rendering visible the conditions and effects - both oppressive and liberatory, and more often both - of belonging, the multiple sites and communities to which we belong or don't belong become apparent. This awareness pushes us to consider the political, social, and spiritual effects of our choices to belong.

(Rowe 2005, 36)

Because it is often quite clear within the translations themselves to which communities I belong and at what point my ability to know Yu's "worlds" is circumscribed, my own longing itself becomes apparent as an unrelieved tension. It is thus possible for someone reading my translations to have a sense of how I myself function within the work and how they the reader and I the translator must also work together to long towards Yu and her poetry. 
This longing is not about what is "lost" in translation but about creating space. The goal is not to make the translation about me, but to create a textscape where the work Yu and I do becomes visible in its various entanglements and invites the reader to become entangled as well. In so doing, I attempt to do justice to Yu as a being with agency, with the power to affect me, and who I can neither speak for nor refuse to listen to.

\section{Conclusion}

At its most basic level of intervention, my approach is meant to realize and further encourage an ecology of translation or a diversity of approaches that does not strive for the "authoritative" best. Starting from there, I attempt to expose my own processes of translation as well as many of the contexts and power dynamics that complicate that process, including how Yu Xiuhua writes, is read, and is received as a poet in China and how I write, read, and receive her as a poet in the US. My translations may look intrusive, but I posit that this approach is able to make palpable my yearning toward intimacy, and how as I "surrender to the text," it in turn works on me (Spivak 1993, 183). The failure in my work is an attempt to stay at play as Lugones defines it, and in doing so to move toward Yu Xiuhua's worlds without assuming an intimacy with her or an understanding that I have not fully earned and could never completely arrive at. It is a means of making myself open to what is different both in Yu's poetry and in myself.

I do not claim a mode of translation that is ethical in that it erases transnational power differentials, nor do I claim the best mode of translation. Instead, I have adopted a practice of vulnerability that attempts to work with the difference manifest in our various positionalities and the power dynamics embedded in that difference. As such, the tension between attending to $\mathrm{Yu}$ Xiuhua's style and poetics and making visible my own layered engagement with her poetry is not relieved but presented as an integral part of the translation. This queering of the understanding of the translator as authoritative expert, a nonbiased and technically inclined craftsperson and an eraser of difference, might appear to undermine my authority and claim to the role of "good" translator. But I believe that by making the tension visible, I hold myself and my readers more accountable for the kinds of violence we inflict in our readings of Yu Xiuhua while at the same time making space for voices that do not easily fit into the most wellworn channels of cultural and literary exchange. The result is translations that sit with discomfort. It is a means of posing an ethical reading practice 
where I make myself continuously vulnerable, and as such I hope it has the effect of encouraging vulnerability in the reader as well. By that I mean a desire not to judge, compare, or categorize either my translation work or $\mathrm{Yu}$ Xiuhua's poetry in any definitive way, but instead a desire to experience, to wonder, and to stay curious.

\section{Works cited}

Bruno, Cosima. 2012. "The Public Life of Contemporary Chinese Poetry in English Translation." Target 24 (2): 253-285.

Chamberlain, Lori. 1988. "Gender and the Metaphorics of Translation." Signs 13 (3): 454-472.

Edmond, Jacob. 2012. A Common Strangeness. New York: Fordham University Press. Eliot, T. S. 1928. "Introduction." In Selected Poems, by Ezra Pound, vii-xxv. London: Faber \& Gwyer.

Falcón, Sylvanna M. and Jennifer C. Nash. 2015. "Shifting Analytics and Linking Theories: A Conversation About the 'Meaning-Making' of Intersectionality and Transnational Feminism." Women Studies International Forum 50: 1-10. https:// bit.ly/2OFTJfE. Accessed August 4, 2019.

Godard, Barbara. 1986. Introduction to Nicole Brossard, Lovhers, translated by Godard. Montreal: Guernica Editions.

Goodman, Eleanor. 2017. "Translating Migrant Worker Poetry: Whose Voices Get Heard and How?" Journal of Modern Literature in Chinese 14 (2)-15 (1): 107-127.

Göransson, Johannes. 2014. “The Hoax of Translation.” The Boston Review, September. bit.ly/2PooOEh. Accessed July 31, 2018.

-. 2016. "'Transgressive Circulation': Translation and the Threat of Foreign Influence." Cordite Poetry Review, November. bit.ly/2fqoKCm. Accessed August 5 , 2018.

Halberstam, Jack. 2011. The Queer Art of Failure. Durham, NC: Duke University Press. Haraway, Donna J. 1991. "A Cyborg Manifesto: Science, Technology, and SocialistFeminism in the Late Twentieth Century." In Simians, Cyborgs, and Women: The Reinvention of Nature, 149-182. New York: Routledge.

Inwood, Heather. 2014. Verse Going Viral. Seattle: University of Washington Press. Li, Dian. 2018. "Yu Xiuhua: A Life Lived in Poetry." World Literature Today. bit. ly/2I6Mp8N. Accessed April 5, 2019.

Lugones, Maria. 1987. "Playfulness, 'World'-Traveling, and Loving Perception.” Hypatia 2 (2): 3-19.

—. 1994. "Purity, Impurity, and Separation." Signs 19 (2): 458-479. 
McSweeney, Joyelle and Johannes Göransson. 2012. Deformation Zone: On Translation. Brooklyn, NY: Ugly Duckling Presse: Dossier.

Moraga, Cherríe and Gloria Anzaldúa, eds. 1981. This Bridge Called My Back: Writings by Radical Women of Color. New York: Kitchen Table Press. Fourth, expanded edition, Albany: SUNY Press, 2015.

Nabokov, Vladimir. [1955] 1992. "Problems of Translation: Onegin in English.” In Theories of Translation: An Anthology of Essays from Dryden to Derrida, edited by Rainer Schulte and John Biguenet, 127-143. Chicago: The University of Chicago Press.

Riep, Steven L. 2019. "Body, Disability, and Creativity in the Poetry of Yu Xiuhua.” Chinese Literature Today 7 (2), 32-41.

Rowe, Aimee Carrillo. 2005. "Be Longing: Toward a Feminist Politics of Relation." NWSA Journal 17 (2): 15-46.

Ruvalcaba, Héctor Domínguez. 2016. Translating the Queer. London: Zed Books.

Sharoni, Simona, Rabab Abdulhadi, Nadje Al-Ali, Felicia Eaves, Ronit Lentin, and Dina Siddiqi. 2015. "Transnational Feminist Solidarity in Times of Crisis." International Feminist Journal of Politics 17 (4): 654-670.

Shen Haobo 沈浩波. 2015. “沈浩波: 谈谈余秀华的诗歌以及大众阅读口味” [Shen Haobo: On Yu Xiuhua's Poetry and Mass Taste in Reading]. 凤凰读书, January 20. bit.ly/2I87cIT. Accessed August 18, 2017.

Shen Rui 沈睿. 2015. 〈什么是诗歌? : 余秀华 - 这让我彻夜不眠的诗人〉 [What is poetry?: Yu Xiuhua - the poet who kept me up all night]. Weibo (blog), January 13. bit.ly/2Ianpxh. Accessed July 31, 2018.

Simon, Sherry. 1996. Gender in Translation: Cultural Identity and the Politics of Transmission. London and New York: Routledge.

Spivak, Gayatri Chakravorty. 1993. Outside in the Teaching Machine. New York: Routledge.

van Crevel, Maghiel. 2008. Chinese Poetry in Times of Mind, Mayhem and Money. Leiden and Boston: Brill.

- 2017a. "Walk on the Wild Side: Snapshots of the Chinese Poetry Scene." MCLC Resource Center. bit.ly/2GaWWhc. Accessed July 31, 2018.

- 2017b. "The Cultural Translation of Battler's Poetry (Dagong Shige)." Journal of Modern Chinese Literature. 14 (2)-15 (1): 245-286.

Venuti, Lawrence. 2018. The Translator's Invisibility: A History of Translation, third edition. New York: Routledge.

von Flotow, Luise. 1991. "Feminist Translation: Contexts, Practices, and Theories." TTR 4 (2): 69-84.

Weinberger, Eliot. 2016. 19 Ways of Looking at Wang Wei (with More Ways). New York: New Directions.

Wright, Chantal, trans. 2013. Yoko Tawada's Portrait of a Tongue. Ottawa, ON: University of Ottawa Press. 
Xu Xiao. 2018. “Two Poets' War of Words Shows China's Yawning Generation Gap.” Sixth Tone, February 8. bit.ly/2UNWpJK. Accessed July 31, 2018.

Yang Lian. 1996. “Living in Now and Forever.” Times Literary Supplement 4882: 14. Yao Yongmei. 2016. “The Moonlight Rests on My Left Hand' by Yu Xiuhua.” Studio Plus, March 16. bit.ly/2Ko7CwO. Accessed July 31, 2018.

Yeh, Michelle. 2004. "The Chinese Poem: The Visible and the Invisible in Chinese Poetry." In The Poem Behind the Poem: Translating Asian Poetry, edited by Frank Steward, 251-264. Port Townsend, WA: Copper Canyon Press.

Yu Xiuhua 余秀华. 2015. 《月光落在左手上》 [The moonlight rests on my left hand]. Guilin: Guangxi shifan daxue chubanshe.

—. 2018. "Twelve Poems," translated by Elise Huerta and Hangping Xu. Chinese Literature Today 7 (2): 6-17.

Zhao, Kiki. 2017. "A Chinese Poet's Unusual Path from Isolated Farm Life to Celebrity." The New York Times, August 18. https://nyti.ms/2XoO43p. Accessed March 22, 2019.

Zhou Yu. 2015. "The poetry of suffering." Global Times, February 6. bit.ly/2U9deui. Accessed July 31, 2018.

\section{About the author}

Jenn Marie Nunes is the author of two books of poetry, AND/OR (2015), winner of the Switchback Books Queer Voices Award, and the forthcoming those people, winner of the 2016 National Poetry Review Press Prize. She holds an MFA from Louisiana State University and is currently at Ohio State University where she is pursuing a $\mathrm{PhD}$ in Chinese literature with an emphasis on modern poetry and film, and a minor in Women, Gender, and Sexuality Studies. 



\title{
$2 \quad$ Working with Words
}

\author{
Poetry, Translation, and Labor \\ Eleanor Goodman
}

\begin{abstract}
This essay offers an activist perspective on the work of poetry and of translation. Noting that literary translation does many things, from enabling the practice of comparative literary studies to the representation outside China of Chinese migrant worker poetry in a global-capitalist world, the author discusses how her translations of Zheng Xiaoqiong, Wang Xiaoni, and Zang Di confront English-language poetics at the same time as they interface with the work of several poets writing in English.
\end{abstract}

Keywords: Chinese poetry, translation, workers poetry, translator, work, labor

I have thought about work often: whether I was doing enough of it; whether the work I did was good enough; whether writing, because it is largely enjoyable, is in fact work; whether anybody was ever going to pay me for doing this work I love doing. I have also thought about other kinds of work, physical work and emotional labor, work that goes disregarded or unrecognized. I think of Robert Hayden's "What did I know, what did I know / of love's austere and lonely offices," and the father who was never thanked. In my own poems I've addressed the pleasures and efforts of certain kinds of work, like in "Obey, Obey":

Your mother made the earth obey her will.

Not like your father did - no chemicals, no machinery, no engineered seed.

Her hands were her tools, wrinkled and twisted

from hauling boys around by their collars,

Van Crevel, Maghiel and Lucas Klein (eds.), Chinese Poetry and Translation: Rights and Wrongs. Amsterdam: Amsterdam University Press, 2019

DOI: 10.5117/9789462989948_CHO2 
cutting fat into biscuits with her fingers.

At the height of summer, she stood sweating

in the kitchen canning collards, Kentucky

wonders, summer pickles, jellies of gooseberries,

chokecherries, grapes from your Aunt Helen's vines.

(Goodman 2016c, 26)

"I haven't worked a day in my life," begins Donald Hall's literary and rural memoir Life Work (1993), a book I have long admired and frequently reread. The highly prolific former American poet laureate continues:

With the trivial exceptions of some teenaged summers, I've never worked with my hands or shoulders or legs. I've never stood on the line in Flint among the clangor and stench of embryonic Buicks for ten hours of small operations repeated on a large machine. Oh, I've watched this work, visiting a plant; I've watched Modern Times also. When I taught at the University of Michigan, many of my students worked summers installing gas tanks at River Rouge or building generators in Ypsilanti. Some of them came from families of line-workers; the university was a way out of Flint and Toledo. These children of line-parents moved to desks in offices, nine-to-five, which was my own father's work, and which I escaped. Doubtless my grandfather Hall, my father, and I made a stereotypical three generations: My father's father grew up without much school, doing muscle-work, and built a successful business; so he sent my father to college who worked out his life at a desk adding columns of figures among blonde-wood cubicles where properly dressed men and women worked with numbers five days a week and half a day on Saturday. Then there's me: I stay home and write poems - and essays, stories, textbooks, children's books, biography ... Work?

$(1993,3)$

In the United States, some work is easily recognized and valued as "real work": it involves effort, frequently physical effort, and a tangible product. Intellectual or creative effort is in some circles not considered work, but rather leisure. As Hall goes on to emphasize in his comparisons of different kinds of work (teaching, writing reviews, editing, etc.), if art is pleasurable, if it functions as an escape from work, as it certainly can, where does that leave someone who "works" as an artist? The poet makes something that is intangible and potentially passed to unlimited consumers. Now take the literary translator, who takes something intangible and monetarily worthless 
and spends a great deal of time and effort turning it into something else that is intangible and, for the most part, worthless.

But is a poem or a translation worthless, or is it invaluable? Its worth cannot be pinned down and quantified, unlike the hours of a day laborer. Then there is the sticky issue that poets and literary translators tend to enjoy their work. Work is something we frequently assume to be unpleasant, trying, tiring, difficult, and either dangerous or boring. My thesaurus helpfully offers these synonyms for work: "labor, toil, slog, drudgery, exertion, effort, industry, service; grind, sweat, elbow grease; travail." The antonyms? "Leisure, rest."

The contemporary Chinese migrant worker poet Xu Lizhi 许立志 described the working life in the factories of Shenzhen in just such terms:

seven years ago you came alone

to this part of Shenzhen

high-spirited, full of faith

and what met you was ice,

black nights, temporary residence permits, temporary shelter ....

after false starts you came here to the world's largest equipment factory standing, screwing in screws, doing overtime, working overnight painting, finishing, polishing, buffing, packaging and packing, moving finished products bending down and straightening up a thousand times each day

“My Friend Fa” (发哥)

(Goodman 2017b, 413)

The verbs here are simple and dynamic. They all imply movement, while the cascade of motion upon motion demonstrates the unstoppable pace of the work itself. Zheng Xiaoqiong's 郑小琼 take is even darker, in "Language" (语言):

Rust-speckled switches, stations, laws, the system. I speak a black-blooded fired language

of status, age, disease, finances ... a fearful, howling language. Tax collectors and petty officials.

Factory bosses. Temporary residence permits. Migrant workers ... their languages

language of a girl jumping off a building. The GDP's language. Language of official projects. Language of a kid's school fees.

(Goodman 2016b, 122) 
There is no enjoyment here, but pure alienation in a Marxian sense. To capture that sense of alienation is key to translating these works into English, and in both cases here, some of that depends upon the rhythm of the texts, which walk a tightrope between the energy in the rush of information that drives the lines forward, and the breaks necessary to maintain meaning, commas in the case of Xu Lizhi, and periods and commas in the case of Zheng Xiaoqiong. How is the translator to balance these factors effectively?

Perhaps one of the things that annoy dyed-in-the-wool capitalists about the claim that poetry is work is that a lot of the writing of poetry and the translation of poetry involves reading. And if writing poetry probably isn't work, reading poetry definitely isn't. Yet for both poet and translator, reading is one of the primary sources of nourishment, and for the translator, translating is inherently reading. In this sense, translation is fundamentally and complexly intertextual. As Hans J. Vermeer puts it, in Andrew Chesterman's translation:

To the extent that a translator judges the form and function of a source text to be basically adequate per se as regards the predetermined skopos [the purpose of the translation] in the target culture, we can speak of a degree of "intertextual coherence" between target and source text. This notion thus refers to a relation between translatum and source text, defined in terms of the skopos. For instance, one legitimate skopos might be an exact imitation of the source text syntax, perhaps to provide target culture readers with information about this syntax. Or an exact imitation of the source text structure, in a literary translation, might serve to create a literary text in the target culture. Why not? The point is that one must know what one is doing ...

(Chesterman 2004, 229)

That is indeed the point. But beyond the intertextuality between source text and translation, and between two different linguistic traditions, there is also an underlying intertextuality between the source text and the texts the translator has read and can use - consciously or unconsciously - as models, in the same way that an author in any language uses the models that she finds around her. In understanding a translator and her practice, we should ask not just what she was writing and translating at given time, but also what she was reading, and had at that time read. Below I will offer a few glimpses of the background to some of my translations as instances of how this kind of intertextuality might work. 


\section{The translator as intertextual worker}

As of mid-January 2018, if someone in America were to google "workers poetry," one of the first hits would be a review of my translation of Iron Moon, an anthology of contemporary Chinese poetry (2016b). Of the nine links listed on the first page, four have to do with workers in Asia, the other two being the website singaporeworkerpoetry.com and a review of a film about workers in Singapore. The only American poet named among these links is Langston Hughes.

I remember reading Hughes as a middle-school student and becoming immediately drawn to his voice, and in particular, to his rhythms.

I've known rivers:

I've known rivers ancient as the world and older than the flow of human blood in human veins.

My soul has grown deep like the rivers.

“The Negro Speaks of Rivers" (1994, 23)

The whole poem is incantatory, incandescent. The repetition draws the reader along like a current, while the grand scope (rivers, the world, human blood, leading to "my soul") opens the reach out into the metaphysical. Hughes of course also wrote many poems about the working life, having held various manual jobs after dropping out of college.

I am the poor white, fooled and pushed apart,

I am the Negro bearing slavery's scars.

I am the red man driven from the land,

I am the immigrant clutching the hope I seek -

And finding only the same old stupid plan

Of dog eat dog, of mighty crush the weak.

I am the young man, full of strength and hope,

Tangled in that ancient endless chain

Of profit, power, gain, of grab the land!

Of grab the gold! Of grab the ways of satisfying need!

Of work the men! Of take the pay!

Of owning everything for one's own greed!

“Let America Be America Again" (1994, 190) 
Zheng Xiaoqiong's “Language” begins:

I speak this sharp-edged, oiled language of cast iron - the language of silent workers

a language of tightened screws the crimping and memories of iron sheets a language like calluses fierce crying unlucky

hurting hungry language back pay of the machines' roar occupational diseases

language of severed fingers life's foundational language in the dark place of unemployment

between the damp steel bars these sad languages

....... I speak them softly

(Goodman 2016b, 122)

There are many differences here, of course, but Zheng's "I speak," like Hughes's "I am ... I am," is a pronouncement of identity and a declaration of agency, no matter how compromised. The sentences that begin Hughes's "Let America Be America Again" eventually break down, just as Zheng's beginning quickly shifts into declarations and lists, exclamations of anger, and taut descriptions of modes and methods of exploitation. The semantic disintegration reflects an increasingly forceful emotional call and response between writer and reader. As the writer's pain increases on the page, so the reader's empathetic response intensifies. That is the power of literature.

The chances that Zheng Xiaoqiong read Langston Hughes in translation before writing "Language" are slim. But the influence I am arguing for is not poet upon poet, but poet upon translator, and thereby upon poet-in-targetlanguage: I am influenced by Langston Hughes, therefore Zheng Xiaoqiong in my English carries some of his traces.

I see a similar pattern with respect to Philip Levine. Here is the beginning of "Fear and Fame," from his 1991 collection What Is Work, whose first section is built around issues that also concern many of the Chinese migrant worker poets I've translated:

Half an hour to dress, wide rubber hip boots, gauntlets to the elbow, a plastic helmet like a knight's but with a little glass window that kept steaming over, and a respirator to save my smoke-stained lungs. 
A gallon of hydrochloric

steaming from the wide glass mouth, a dash

of pale nitric to bubble up, sulphuric to calm,

metals for sweeteners, cleansers for salts,

until I knew the burning stew was done.

$(1991,3)$

Levine is both more lyrical and more narrative here than either $\mathrm{Xu}$ or Zheng, but something in the flow of his language is familiar. There is a push through the details that might otherwise bog the reader down, produced by the concatenated lines and delicate internal half-rhymes (window/over, nitric/sulphuric, sweeteners/cleansers). I have done something similar in both translations above, as in the movement of these lines, from Xu's "My Friend Fa": "high-spirited, full of faith / and what met you was ice, / black nights". My off-rhymes of "faith," "ice," and "night" are in part meant to propel the reader down through the lines into the litany of motions that follow. Am I copying Levine? Certainly not - or, not consciously. But it is there in the background as an influence, a text that informed not only how I translated this Chinese migrant worker poetry, but, just as importantly, part of the internal context in which I read that poetry in the first place.

\section{The translator as witness}

Why does Donald Hall bother to describe work he's never done at the beginning of a book about the work he does do? Is it to establish that he knows what "real work" is, to posit his bona fides before he goes on to argue that his creative writing is work? One of the reasons Hall's description of his background draws me in is that it so closely mirrors my own, one generation removed. My father is a retired university professor who, as it happens, went to the same fancy university as Hall, while my father's father was a low-status professor of German at a large public university. His father (my great-grandfather) worked in a steel mill in Middletown, Ohio: ARMCO, the American Rolling Mill Company, on the banks of the Miami River. When I visited Middletown long after the deaths of my great-grandfather and grandfather, the decaying decadence of the mansions of the steel barons gave the town the solemn air of a cemetery; it reminded me of the eerie stilled opulence of the Père Lachaise Cemetery in Paris, with moss and vines framing the houses along wide silent avenues. The mill continues to 
operate, now as AK Steel, and it seems that everyone who can continues to leave Middletown, just as my grandfather did.

As a child, my father told me stories that his father had told him, of working conditions in the mills, of abuses of power and dangerous conditions, injuries and the loss of digits and limbs, dangerous chemicals and unbreathable air, and the backbreaking labor that men (nearly all men then) returned to, day after miserable day. These stories are a part of my family lore, and one reason hard work is so prized. The work that is valued above all in my family tends to be intellectual work, or, in my case, creative work. The underlying my thos - and I believe this of many other families around the world - is that my grandfather escaped the fate of working in the steel mills through willpower, effort, and luck, sent my father to a fancy college on a scholarship for poor kids, and thus released our family from lives spent in manual labor. Donald Hall points to the same pattern.

Rather than the contempt for manual workers that some in our economically privileged strata seem to hold, I feel a deep ancestral interconnection with them. It informs my own poetry, as it informs my translation, both of the poetry of migrant workers and of those poets who serve as witness. The translator is also a witness to the experience of text as text, an experience that she then endeavors to pass on to other readers in her own language. I am also a witness to my own family, to the generational fear passed down by my grandfather to my father and on to me, a palpable dread of the furnace of the steel mill and a resistance to ever going back there.

While my great-grandfather was working in the steel mill all day, my great-grandmother was taking care of six children, a ramshackle house, a kitchen garden, and a sizable chicken coop for eggs and meat, along with all the cooking, cleaning, feeding, weeding, shopping, organization, and budget-making necessary for running a large household of limited means. Her labor, and the labor of many millions of women like her, has long been overlooked, and continues to be today. As Wang Xiaoni 王小妮, in her typically understated feminist way, puts it: "I let my significance / happen only at home" (“Starting Anew as a Poet” 重新做一个诗人) $(2014,25)$.

The first feminist poet I read consciously as a feminist was Adrienne Rich. As a woman in my twenties, her work was a shock to my system: I hadn't realized I (read: a woman) was allowed to be that angry. In addition to her writings in poetry and prose about feminism, lesbianism, Judaism, and politics, Rich also wrote powerfully about workers. A daughter of a well-to-do family, she did not herself work in farm fields or on an assembly 
line or in a steel mill. But her acute eye and capacity for empathy, as well as her anger, brought workers' lives and livelihoods into vivid relief.

A dark woman, head bent, listening for something

- a woman's voice, a man's voice or

voice of the freeway, night after night, metal streaming downcoast

past eucalyptus, cypress, agribusiness empires

THE SALAD BOWL OF THE WORLD, gurr of small planes

dusting the strawberries, each berry picked by a hand

in close communion, strawberry blood on the wrist,

Malathion in the throat, communion,

the hospital at the edge of the fields,

prematures slipping from unsafe wombs,

the labor and delivery nurse on her break watching

planes dusting rows of pickers.

$(1991,3)$

This is the beginning of the poem that opens Rich's seventeenth (talk about hardworking) collection, An Atlas of the Difficult World (1991). The lines palpitate with indignation, and we become the "dark woman," listening to the stories of these strawberry pickers, likely migrant workers from countries south of our border. There is one small detail that stands out to me now, and it's a humble indefinite article. Each berry is not picked by hand, but by $a$ hand, a human hand, a hand that is attached to a body, a history, a name, an individual. With this one move, Rich humanizes what has been systematically dehumanized, either deliberately or by unfeeling oversight.

Was Rich's poetry in my mind when I began reading Wang Xiaoni's work? Certainly I am reminded of it now when I read my own translations of Wang, particularly in the case of what I think of as Wang's "train poems." There are at least six train poems collected in Something Crosses My Mind (Goodman 2014), in which the perspective of the speaker is placed behind a train window, or at a distance, and from that angle serves as a witness to rural life. One of these poems is “November's Rice-Gleaners" (11月里的割稻人):

From Guangxi to Jiangxi

I glimpse rice-gleaners bent to the ground.

In province after province

the vegetation yellows 
in province after province

this country was once willing to pave the ground with gold.

Still there are always people at dusk

looking like bent black nails.

Who will come to admire the ancient sorcery

of rice-gleaners turning a bit of gold into a grain of rice.

Don't be like me hurrying along on the train

as though there's urgent business

crossing three provinces in a single day

occasionally noting the earth is still adorned with rice-gleaners.

I want to call for them to stand up

to see the faces worth the least gold

to see the color of sweat they produce.

(Goodman 2014, 43)

Wang's touch is softer than Rich's here: there are no poisonous pesticides like Malathion, no blood of strawberries. The tone is less urgent. But there is the same demand for attention to be paid to "the faces worth the least gold" who are working "in province after province" to feed the nation. The rice bowl rather than the salad bowl, and yet the risks and the lack of compensation are similar.

Likewise, the understated use of "by a hand" rather than "by hand" in Rich's poem is a similar move to one in Wang's "Plowman" (耕田的人), another poem narrated from a distance by a speaker who is not a worker but who empathizes and records:

He is turning over the whole mountaintop with a plow.

He follows behind an ox and the two reveal the earth's forehead by force.

A dark red wound appears the red seen after a fever passes.

The red that comes after punishment.

The red that comes after pain has been quietly survived.

Suddenly the small plowman disappears

the just-turned red mud has buried him in the mountainside. 
His partner raises his enormous head

like he's another plowman wearing an ox mask

like the pair at the front and back of the plow are brothers.

(Goodman 2014, 47)

The easy move here is to compare the agricultural worker to an animal. Instead, Wang inverts the expected metaphor, and the ox becomes a man in a mask. The man is not lowered to the status of an animal being exploited for its labor; rather, the animal is being raised to the level of the man, an equal partner, a "brother." This emphasizes the dignity of the man and animal both. We also see the cooperation, the reliance, and the personal relationship between these two working partners, an ancient relationship that has faded only with the industrialization of agriculture across the world, an industrialization whose sheer scale has led to the degradation of the individuals involved.

The role of witness is fraught, and it is easy - especially in the current climate - to be accused of cultural appropriation or exploiting another's pain. In 2018, when I presented on "the poetry of work" in Beijing, the audience reacted positively to the poems by Xu Lizhi, but were very suspicious of "Plowman." Wang Xiaoni's account rang false to them. What right does she have to write about farmers? Part of their response had to do with my framing: I gave very little context, and my audience did not know that Wang was among the educated youth sent down during the Cultural Revolution and is no stranger to physical labor. But here she serves as a witness to the labor, not a participant in it like $\mathrm{Xu}$ Lizhi. Rich gives an elegant defense of the poetry of witness in her powerful collection of essays Blood, Bread, and Poetry. Discussing Elizabeth Bishop's "Songs for a Colored Singer," she writes:

This is a white woman's attempt - respectful, I believe - to speak through a Black woman's voice. A risky undertaking, and it betrays the failures and clumsiness of such a position. The personae we adopt, the degree to which we use lives already ripped off and violated by our own culture, the problem of racist stereotyping in every white head, the issue of the writer's power, right, obligation to speak for others denied a voice, or for the writer's duty to shut up at times or at least to make room for those who can speak with more immediate authority - these are crucial questions for our time, and questions that are relevant to much of Bishop's work. What I value is her attempt to acknowledge other outsiders, lives marginal in ways that hers is not, long before the Civil 
Rights movement made such awareness temporarily fashionable for some white writers.

$(1986,131)$

Rich strikes exactly the right balance here, between the need for the writer to shut up sometimes, and to sometimes speak for others - respectfully, with a conscious acknowledgment of difference - as indeed the translator, by definition, always does.

The "white" is important here, and so is the "woman." Rich grew up in a time when women were expected to have children first and careers only if they must. Similarly, Wang Xiaoni has always had to navigate a situation that critic and poet Zhou Zan 周珗 describes as centering on “suspicions about the concept of 'women's poetry' [女性诗歌], distortions of feminist theory, the objectification of women inherent in a consumerist culture, the decadence of a male-dominated culture, the backsliding of the state of equality between the sexes ..." (in Goodman 2016a, 72). Elsewhere, again in the context of discussing so-called "women's poetry," Zhou adds: "In Chinese literary circles, using the term 'beautiful woman writer' [美女作 家] ... is on the one hand a result of commercial considerations, and on the other hand an expression of the traditional male gaze that regards women as a 'seen object' or an 'object of desire'” (2014, 209).

This of course extends far back into history. As Shu-mei Shih puts it, "to call someone a 'talented lady' [才女] is a traditional way of relegating her to a special category outside the male-dominated literary canon" (2001, 211). This is even truer when women writers are referred to in terms of their appearance, a point Amy Dooling makes in her chapter in David Wang's New Literary History of Modern China (2017). Yet this way of thinking carries over into Western literary and sinology circles. I am eager for the day to come when we no longer need chapters titled "Women Writers in Early Modern China" (Widmer 2017), also in Wang's History, and instead can devote as much time and space to women writers - without categorizing them reductively by their gender - as is devoted to men.

Maghiel van Crevel notes the outcome of this underrepresentation of women in the Chinese poetry scene itself: "it is shocking how many men and how few women visibly and audibly get to speak on the Chinese poetry scene, as in producing and shaping the discourse through editorships, event organization, group formation, access to public and private funding, jury memberships, academic and publishing leverage, and more generally running the show" (2017, par. 15). Having observed the same phenomenon myself over many years, I also find this deeply disturbing. It is imperative 
that a space be created in which women are able (and invited!) to speak for themselves if they so wish, in person as well as on the page.

\section{The translator in the conversation}

The translator necessarily speaks for another. But she also speaks for herself, as well as with and between others. Translation is a conversation between author and translator, as Sherry Simon emphasizes throughout Gender in Translation. As she puts it:

Because it is an activity which has long been theorized in terms of a hierarchy of gendered positions, the rethinking of translation will necessarily upset traditional vocabularies of domination. In particular, the rethinking of translation involves a widening of the definition of the translating subject. Who translates? Fidelity can only be understood if we take a new look at the identity of translating subjects and their enlarged area of responsibility as signatories of "doubly authored" documents. At the same time, a whole nexus of assumptions around issues of authority and agency come to be challenged. When meaning is no longer a hidden truth to be "discovered," but a set of discursive conditions to be "re-created," the work of the translator acquires added dimensions.

$(1996,12)$

Although Simon is focusing on the role of women translators, and to a large extent on women writers as well, this sense of a "doubly-authored document" has been especially present for me when translating the work of the male poet Zang Di 藏棣.

Zang Di is a tremendously allusive poet. He loves references of all kinds Chinese and Western, contemporary and ancient, literary and pop - and uses them liberally. This is one reason his work can be difficult to understand, and to translate, but it also presents many opportunities for conversation: not just between poet and text, and poet and reader, but also between poet and translator. Zang Di wrote "After the New Wisdom Association" (随着那新鲜的深度协会) in the fall of 2013 after hearing of the death of Seamus Heaney:

The love of Ireland. Far enough but not unfamiliar. With every dig, Ireland's orchids follow 
that new wisdom, and find in the language of loneliness

a supreme support. The deep green tips of leaves sway

the careful heart. How will the pistils trembling

in those worded intentions regard

this side of human life, now poetry's prisoners.

As for the hole left by the digging, only sweat

can fill it. Only this kind of hole

leads to a deeper trust in this wearisome world.

Call the reflections -

they've already persisted this long

in a landscape set in the landscape. Love is ice.

If you don't believe it, you can go see for yourself.

The last day of August came like an elephant.

Don't look at me that way - for now, I'm blind.

Blind men for dark times.

As Delmore Schwartz, Humboldt's model

in Humboldt's Gift, painfully said -

"For like a gun is touch." All grim,

but still you open the blacksmith's oily shop curtain,

teach me to be like a hammer, to trust in every touch.

(Goodman 2017a, 133)

The question of how to translate this poem hinges on the intertextuality that underpins it. No translator can be expected to pick up on every single reference a poet makes; nor can any reader. But here the echoes of Seamus Heaney's famous poetic manifesto “Digging” are on the surface (1966, 13-14). Zang Di's second line brings it to the fore: "with every dig," we move deeper into Zang's conversation with Heaney, and also with himself. The translator is presented with a choice: she can trust the references to reveal themselves subtly, or she can try to emphasize the intertextuality by examining and then explicitly calling attention to the other text(s) in question.

This might seem to be an obvious choice: of course the translator has a responsibility to try to tease out all of the elements that went into the poem, and to bring that to her target-language readers. But this is a naïve expectation. For one, it's unclear what the referent text here is: Heaney's original English poem, or a Chinese translation of the poem? And if a translation, whose translation? Zang's term (挖掘) may be his own translation of "digging," or it may be someone else's. Does it matter? And does it matter that I already have a strong relationship to Heaney's "Digging," that it has long informed my own sense of what I am doing with my time on this 
earth? To what extent does my personal sense of Heaney's poem then affect my translation of Zang Di's poem speaking to Heaney's poem? How much should it?

I first read "Digging" in college, and found the depiction of a person who had come to a decision to do something different from his predecessors deeply inspiring. The speaker states his intention plainly and with conviction:

The cold smell of potato mould, the squelch and slap

Of soggy peat, the curt cuts of an edge

Through living roots awaken in my head.

But I've no spade to follow men like them.

Between my finger and my thumb

The squat pen rests.

I'll dig with it.

(Heaney 1966, 14)

That sense of unapologetic, though nuanced, commitment to individual purpose affected the course of my life. It informed how I answered every well-meaning (and not so well-meaning) When are you going to get a real $j o b$ ? It girded my obduracy through years of barely making it financially while failing spectacularly to publish anything. It carried me past barriers both internal and external. I had chosen my vocation, and my tool, and I was going to learn how to use it. Heaney was speaking, I felt, directly to me.

He clearly also spoke to Zang Di. But was the message we received the same? In translating "After the New Wisdom Association," I wanted to be careful not to impose my own relationship to Heaney's poem onto Zang Di's experience of it. And yet I was necessarily in the room; I was part of the three-way conversation. What can a translator do but be careful and humble?

It helped that my translation failed from the very first line. Zang Di plays a lovely little game with the sinification of the word Ireland. The first and third lines of the poem read, transliterated: “Aierlan de ai" (爱尔兰的爱) and "Aierlan de lan" (爱尔兰的兰). It is possible in English to mimic the taking apart of the components of the words. In fact, the second instance works reasonably well: Ireland's land. The "orchid" of the literal meaning of lan is lost, and it sounds rather flat, but it's something to work with. But the first instance is a disaster - Ireland's ire - since not only is it awkward, but the meaning is wrong, turning love (ai) into anger. So the whole structure of the original wordplay has to be abandoned. 
Instead, I worked with the meaning. "The love of Ireland" captures some of the soundplay - the round vowels and alliterative l's - and also reflects the emotional warmth the poem goes on to explore. "The orchids of Ireland," however, isn't as good. The positioning stresses the hard $k$-sound in orchid and that second syllable risks getting swallowed to turn into "orcs." But "Ireland's orchids" aurally emphasizes the parallel assonance of "ire" and "or" and consonance of "ands" and "ids." And since in English, the orchid also hints at something rare and precious, it captures some of the sense of the Chinese word, with its allusion to unusual talent.

Indeed, Heaney shows a nuanced approach to talent in his poem. For the young Heaney - the poem appears in his first book, Death of a Naturalist, written when he was in his late twenties - an aptitude for agricultural labor is admirable. Like Donald Hall in many of his books, or Wang Xiaoni in her agrarian poems, the physical labor of working with the land is not only a skill, but a vocation. Heaney's father "could handle a spade / Just like his old man. // My grandfather cut more turf in a day / Than any other man on Toner's bog" and there is an undercurrent of discomfiture (or guilt?) that Heaney himself has not inherited those gifts. Yet the decision to dig with his pen is conscious; he vows to labor with his mind instead of his hands. In addition to the force of conviction, there is also the tension of a young man pushing himself forward, a wish as much as a vow.

That was what I felt at eighteen: I wanted to work with words, and I was determined to do so. That sense of youthful self-enjoinment is absent in Zang Di's poem. This is one mature poet speaking to another. The digging in Zang Di's poem is also one step further removed than the digging in Heaney's poem. For Zang, it is the metaphorical sweat of intellectual effort that fills the hole, rather than dirt or seeds. Still, in the final lines, like Heaney's youthful exhortation to himself, Zang reaffirms his commitment to his vocation, and to the genuine work and genuine pleasure it entails. "To trust in every touch": as a gifted farmer knows where to dig, the poet knows where to aim his line. Translating this poem, I felt myself suddenly negotiating between my youthful self and the future self I hope to move toward. I am in the middle, where the translator stands.

\section{The translator between worlds}

Not long ago, I gave a reading from Iron Moon at a venue not far from Boston, full of well-dressed, well-read people. In the Q\&A afterward, an elegantly 
appointed woman asked me why workers poetry doesn't exist in America. "Or at least not since Walt Whitman," another audience member helpfully clarified.

Since publishing Iron Moon, I am frequently asked to compare Chinese migrant worker poetry with American worker poetry. Just as often, I get asked how "workers" can even write poetry, since, after all, they're just workers. There are a lot of assumptions underpinning these questions that are worth confronting briefly, and doing so will I hope also clarify what makes this poetry particularly Chinese in addition to worker. What constitutes this Chineseness, if we accept that there is such a thing in the first place?

Perhaps I can approach this question by first discussing what is universal about these poems. At another reading, considerably less fancy, I read my translation of Zheng Xiaoqiong's “Language." Afterward, a man came up to me, told me he was from Panama, and exclaimed: "That poem could've been written by a Panamanian working here in the US."

The problems that workers face - like a lack of basic social protections, dangerous working conditions, exploitative bosses, limited access to legal recourse, and so on - are by no means limited to the Chinese case.

I do all I can to protect myself

From this existence

I have unknowingly allowed to be created for me

As a manual laborer

I wear leather gloves

To lessen the sore, aching calluses on my palms

To protect my fingers from

Wondering $[s i c]$ mind-stray hammer blows

Jagged sheet metal

Flesh tearing saw blades

So I can type these poems in the morning time

"Walking into My Mind" (Yurcic 2009, 50)

These lines easily could have appeared in Iron Moon: the need for protection, the calluses, the self-identification as a "manual laborer," poetry as a relief from drudgery, and drudgery as a means to afford the time to write poetry. But this is from Jason L. Yurcic, a poet who grew up poor in Albuquerque, New Mexico, about as far geographically from the factories of Shenzhen as one can get. 
Or take the acute awareness of class in the work of another American poet, Julie Sheehan:

There's a certain class of drinks - the "nicer" class, ordered by the "nicer" lady drinkers - that are made with the whites of eggs. Naturally, they are labor-intensive, but as we know, labor is the currency of respect.

"How to Make a Pink Lady" (2010, 53)

This tension between "high" and "low," as well as where the speaker stands with respect to those tenuous categories, recalls Bing Ma's 冰马 poem “Cleaning a Wedding Gown" (清洗婚纱):

Beating and scrubbing, I use

a hog-bristle brush to scrub in detergent like thin rice gruel

The filth! Grease, lipstick, mud, sweat-stains and body odor, on the bodice and skirt, the lower hem and the straps all over the white and pink sections it's totally trashed

How can a filthy wedding dress be made spotless? How can trash become holy and pure? These are the drycleaners' worries.

(Goodman 2016b, 40)

The drycleaner's task, like the bartender's task, is in part to protect the customer - the one who has power and status by way of money - from having to face the fact of her own flaws and weaknesses. One of the purposes of money is to conceal one's human dirtiness from oneself. In obliquely addressing dirtiness and cleanliness, Juan Felipe Herrera, former American poet laureate and son of migrant farm laborers, brings Marxism into the picture:

\section{Martínez:}

Soap soap soap soap

all we do is make soap here soap on the belt in \& out it comes in \& out forever it goes \& nobody knows who makes it you got that Schwartz? Nobody 
you know I know all the guys here know \& sergeant García knows right sarge?

\section{Schwartz:}

Don't mess with him this may not be his best day swinging that baton all dressed up for nothing but us guys on the line me and you and Lim hey Lim yeah get with it you getting that soap out? you better get it right - soap for the bourgeoisie right Martínez?

\section{Martínez:}

What does that bourgeoisie need it for they don't use soap Schwartz you know that

"The Soap Factory" $(\mathbf{2 0 1 5}, 64)$

This is a political note that Li Yongpu 李永普 articulates even more explicitly:

at worksites the hired foremen and overseers

give directions to make use of every bit of time and space

and force the sky's blue to turn toward limestone's iron-pale direction while the eight-hour workday came from the direction of the Paris Commune's blood struggles and became the direction of the system's social classes outside the system the additional four hours given to workers were fixed to allow for this trifling transplanted era of capitalism and its direction of so-called equal justice

Similarly, Janice Mirikitani, who spent much of her childhood on an impoverished chicken farm, also does not shy away from terminology, nor the difficult cultural issues they point to:

we dance with the knowledge of similar struggles:

we samba, boogie down, turgete, LEAP

from the maw of racism, sexism, homophobia, classism, from the fire of riots and demonstrations, from ashes of our self-immolation, the addictions, abuse, the batterings 
Such issues of politics, interpersonal and national, are the foundation of Mark Nowak's book of palimpsests and found poems, Shut Up Shut Down.

The remainder of the year

Reagan toured G.E. factories,

speaking to employees and local civic groups on,

as he put it in his autobiography,

"the attempted takeover of the [electrical] industry

by Communists" and "the swiftly rising tide

of collectivism that threatens to inundate

what remains of our free economy."

"Capitalization" (2004, 33)

I doubt that any of this is what my interlocutor meant when she asked me about American workers poetry. Are these worker poets? Is this workers poetry? Is it poetry at all?

I am bored with these questions. As Heather Inwood amply demonstrates in Verse Going Viral, twentieth-century poetry and poets of all styles and walks of life have made an easy target, for enemies and lovers of poetry alike. As the blogger Han Han 韩寒 put it, adding to a tradition of disparagement that reduces contemporary poetry to text with line breaks, "the only technique that modern poets need to master is how to hit the enter key" (Inwood 2014, 161).

Yet despite what I see as an underlying unity of themes, concerns, and challenges facing worker poets (or poets heavily invested in workers) around the world - and keeping in mind my limited approach in this essay of considering only American and Chinese poets - it seems also clear that there are some differences that speak to the question of Chineseness in particular. One is historical. Jack Linchuan Qiu reminds us that: "If the dominant industry for the British version of the 'world's workshop' was textiles, and the American version automobiles, then for China it is undoubtedly electronics ... Chinese workers and farmers, their families and communities, have borne the brunt of the upheaval brought by this Industrial Revolution of the twenty-first century" $(2016,15)$. Qiu goes on to mention Xu Lizhi's "posthumous fame" after committing suicide while employed at the Foxconn plant in Shenzhen, a notoriety that came about precisely because Xu could articulate in his poetry what workers there face on a daily basis (57). In a country that has both an extreme expression of capitalism (Qiu likens it explicitly to slavery) and a commitment to the ideals of communism, the poet - whether manual laborer or intellectual - is caught in between, as 
likely to be ignored or denigrated as to be vaunted or feared. As George Steiner put it in Language and Silence (a book that made a splash when it came out in Chinese translation by Li Shaojun 李少均 in 2013):

In a communist society the poet is regarded as a figure central to the health of the body politic. Such regard is cruelly manifest in the very urgency with which the heretical artist is silenced or hounded to destruction. This constant preoccupation with the life of the mind would alone serve to distinguish Marxist autocracy from other species of totalitarianism. To shoot a man because one disagrees with his interpretation of Darwin or Hegel is a sinister tribute to the supremacy of ideas in human affairs - but a tribute nevertheless.

$(1984,45)$

Perhaps that is what distinguishes these Chinese poets from American poets in this particular historical moment: the stakes.

The stakes are always high. There are three lines that come back to me again and again in my life as a poet and translator. It is the stanza that ends Richard Wilbur's poem "The Writer" $(1988,53-54)$, in which he describes hearing his daughter at her typewriter struggling to write, and sends her a silent blessing: "I wish her a lucky passage." I expect many poets of different stripes will relate to the poem's conclusion:

It is always a matter, my darling,

Of life or death, as I had forgotten. I wish

What I wished you before, but harder.

\section{Works cited}

Chesterman, Andrew, trans. 2004. Hans J. Vermeer, "Skopos and Commission in Translational Action." In The Translation Studies Reader, second edition, edited by Lawrence Venuti, 221-232. New York: Routledge.

Dooling, Amy. 2017. "Gender, Commercialism, and the Literary Market." In A New Literary History of Modern China, edited by David Der-Wei Wang, 348-354. Cambridge, MA: The Belknap Press of Harvard University Press.

Goodman, Eleanor, trans. 2014. Something Crosses My Mind:Poems by Wang Xiaoni. Brookline: Zephyr Press.

-. 2016a. "I Let My Significance Happen Only at Home: Women in the Contemporary Chinese Poetry Scene." Poetry Review (UK), vol 6, issue 4: 67-73. 
—, trans. 2016b. Iron Moon: An Anthology of Chinese Worker Poetry, edited by Qin Xiaoyu. Buffalo: White Pine Press.

-. 2016c. Nine Dragon Island. Shenzhen: Enclave Publishing and Zephyr Press.

—, trans. 2017a. The Roots of Wisdom: Poems of Zang Di. Brookline: Zephyr Press.

—, trans. 2017b. "Six Poems of Labor and Desperation: Xu Lizhi." In Technicians of the Sacred, edited by Jerome Rothenberg, third edition, 411-413. Oakland: University of California Press.

Hall, Donald. 1993. Life Work. Boston: Beacon Press.

Heaney, Seamus. 1966. Death of a Naturalist. London: Faber and Faber.

Herrera, Juan Felipe. 2015. Notes on the Assemblage. San Francisco: City Lights.

Hughes, Langston. 1994. The Collected Poems of Langston Hughes, edited by Arnold Rampersad and David Roessel. New York: Vintage Books.

Inwood, Heather. 2014. Verse Going Viral: China's New Media Scenes. Seattle: University of Washington Press.

Levine, Philip. 1991. What Work Is. New York: Alfred A. Knopf.

- 1991a. New Selected Poems. New York: Alfred A. Knopf.

Mirikitani, Janice. 2001. Love Works. San Francisco: City Lights.

Nowak, Mark. 2004. Shut Up Shut Down. Saint Paul: Coffeehouse Press.

Qin Xiaoyu 秦晓宇, ed. 2015. 《我的诗篇: 当代工人诗典》 [My poems: the canon of contemporary workers poetry]. Beijing: Zuojia chubanshe.

Qiu, Jack Linchuan. 2016. Goodbye iSlave: A Manifesto for Digital Abolition. Urbana: University of Illinois Press.

Rich, Adrienne. 1986. Blood, Bread, and Poetry: Selected Prose 1979-1985. New York: W. W. Norton \& Co.

-.1991. An Atlas of the Difficult World: Poems 1988-1991. New York: W. W. Norton \& Co.

Sheehan, Julie. 2010. Bar Book: Poems and Otherwise. New York: W. W. Norton \& Co.

Shih, Shu-mei. 2001. The Lure of the Modern: Writing Modernism in Semicolonial China, 1917-1937. Berkeley: University of California Press.

Simon, Sherry. 1996. Gender in Translation: Cultural Identity and the Politics of Transmission. New York: Routledge.

Steiner, George. 1984. George Steiner: A Reader. New York: Oxford University Press. van Crevel, Maghiel. 2017. "Walk on the Wild Side: Snapshots of the Chinese Poetry

Scene.” MCLC Resource Center. bit.ly/2GaWWhc. Accessed March 16, 2018.

Widmer, Ellen. 2017. "Women Writers in Early Modern China." In A New Literary History of Modern China, edited by David Der-Wei Wang, 103-108. Cambridge, MA: The Belknap Press of Harvard University Press.

Wilbur, Richard. 1988. New and Collected Poems. New York: Harvest/Harcourt Brace Jovanovich. 
Xu Lizhi 许立志. 2015. 《新的一天》 [A new day], edited by Qin Xiaoyu 秦晓宇. Beijing: Zuojia chubanshe.

Yuric, Jason L. 2009. Odes to Anger. Albuquerque: West End Press.

Zhou Zan 周珗. 2014. 《挣脱沉默之后》 [Once silence is cast off]. Beijing: Beijing daxue chubanshe.

\section{About the author}

Eleanor GoodMAN's first collection of poetry, Nine Dragon Island (Enclave/ Zephyr, 2016), was a finalist for the Drunken Boat First Book Prize. Her translation Something Crosses My Mind: Selected Poems of Wang Xiaoni (Zephyr, 2014) was the winner of the 2015 Lucien Stryk Prize and shortlisted for the International Griffin Prize. She is also the translator of the anthology Iron Moon: Chinese Worker Poetry (White Pine, 2017), The Roots of Wisdom: Poems by Zang Di (Zephyr, 2017), and Days When I Hide My Corpse in a Cardboard Box:Poems of Natalia Chan (Zephyr, 2018). She is a research associate at the Harvard University Fairbank Center. 



\title{
$3 \quad$ Translating Great Distances
}

\author{
The Case of the Shijing \\ Joseph R. Allen
}

\begin{abstract}
This essay reflects on translatorial practice across great distances in space and time, illustrating a range of practical and theoretical issues that come to the fore in the author's new, in-progress translation of the Shijing (also known as the Classic of Poetry, The Books of Songs, or The Book of Odes). In incorporating the commentarial tradition of Chinese-intralingual interpretation into his English rendition of this foundational text, he brings together philosophy, philology, and literary aesthetics.
\end{abstract}

Keywords: Chinese poetry, translation, Shijing, intralinguality, ambiguity, archaic language

What happens when we attempt to translate a text that is largely "unreadable" in the original? That is what we face in proposing a new translation of the Chinese poetry classic, the Shijing (詩經, Book of Songs). ${ }^{1}$ The theoretical and practical issues raised with such a translation may not be unique, but two things about this project are definitely special: the questions of distance and of intralinguality. The intervening millennia, diachronic linguistic drift, and inherent qualities of the Chinese literary language have created conditions of extreme distance for the reader of this classic. As I have argued in "The Babel Fallacy" (2019), interlingual translation was not an important cultural or intellectual matter for early, or even medieval, Chinese literature, but intralingual work was of paramount importance. That intralinguality begins at least by the Han dynasty (206 BCE-22o CE) and centers on the

1 For an introduction to this sixth-century BCE anthology, see my "Postface" in Waley-Allen 1996, 336-383; for a different configuration of that information see Kern 2018.

Van Crevel, Maghiel and Lucas Klein (eds.), Chinese Poetry and Translation: Rights and Wrongs. Amsterdam: Amsterdam University Press, 2019 DOI: 10.5117/9789462989948_CHO3 
Shijing and the Shuowen jiezi 說文解字 (Explaining Graphs and Analyzing Characters), the world's first monolingual dictionary (c. 100 CE). This essay explores the issues of distance and intralinguality that a new translation of the Shijing needs to address.

\section{A new translation}

There are at least eight different translations of the Shijing available in English, by James Legge (1871 and 1876), Clement Allen (1891), William Jennings (1891), Arthur Waley (1937), Bernhard Karlgren (1950), Ezra Pound (1954), and Arthur Waley and Joseph Allen (1996). These translations offer the reader a wide range of renderings and apparatus to engage the Shijing. So we must first ask, how could one find a useful, new intellectual or poetic position within this array? Let me review some ways this might be achieved. First, like Legge's and Karlgren's, this translation will be a Chinese-English bilingual edition, but it will offer the poems for the first time in line-for-line en-face format, on recto (right-hand) pages. Moreover, accompanying each poem will be selected passages from key traditional commentaries, especially from the Mao Prefaces (毛序), Zheng Xuan 鄭玄, Kong Yingda 孔穎達, and Zhu Xi 朱喜. These passages are to be translated into relatively close renderings, distinct from but complementary to the poems, forming their own intralingual gestalt in translation. In other words, the selections from commentaries will appear on recto pages with weight nearly equivalent to the poems themselves, allowing the reader to see obliquely the intralingual frames in which Chinese readers came to know these poems over the centuries. Steven Van Zoeren (1991) and Haun Saussy (1993) have detailed how those different levels of commentary created an interpretational protocol (what Van Zoeren calls the "hermeneutic context") for the traditional reader. As Saussy suggests, to ignore that protocol and context is to ignore the very meaning that the anthology held for millennia (23; see Klein's essay in this volume for an appreciation of Saussy's work). My presentation of these commentaries will diverge from that of Legge and Karlgren. Legge quotes and critiques the commentaries in his notes, but always to make an argument for a translation, not to provide broad contextual knowledge of the commentaries themselves. Karlgren's detailed treatment of the commentaries in Glosses on the Book of Odes are used to eke out certain contested readings, not to provide a range of possible readings available to the traditional reader (1964). In many ways, Legge and Karlgren are employing a reading strategy developed by Qing philologists whose 
work I discuss below. I am seeking to maintain a more neutral stance, one that allows for possible divergent readings.

On the facing, verso (left-hand) pages will be two types of secondary material for each poem. The "Annotations" are to be notes on central philological and textual issues of each poem, ranging from glossing of key words to discussions of the architecture of the poem. The sources for the annotations are various, from the earliest interlinear Mao commentary (毛 傳) to the latest scholarship, but are especially indebted to the Qing-dynasty scholars of the Shijing, Chen Huan 陳奐 (1975), Ma Ruichen 馬瑞辰 (1971), and Yao Jiheng 姚際恆 (1963). In constructing these "Annotations," I will follow closely the comments and notes of Cheng Junying 程俊英 and Jiang Jianyuan 蔣見元 (1991) - they often cite Qing commentaries at length, which is especially useful. The other component of the verso materials will be the "Comment," where I relate more of my own thoughts, or of others that I have read, to provide a reflection on the poem in a contemporary literary or cultural context. While the "Annotations" will follow a similar format and logic throughout, the "Comments" will be more eclectic, drawing inspiration from the circumstances of the poem in question. Taken together, these different components create an intralingual context for the translation, which can become a refraction of the intralinguality of the original.

\section{The language of the Shijing}

As for the issue of the language of the Shijing, I am here not so much interested in grammatical or phonological structures, although those are extremely important to my work. Rather I seek to place the poems within the frame of what we conventionally term "literary" or "classical Chinese" (wenyanwen 文言文). As Paul Rouzer (2007), Michael Fuller (1999), and many others have argued, although the literary language of China constantly evolved and diversified over its long history, there is a consensus that the base-standard for this language resides in the philosophical and historical texts of the late Zhou-Han period. Of those texts, we might argue that in terms of style, content, and consistency, the Mengzi (孟子, Mencius), from the fourth century BCE, set the early standard, while Sima Qian's 司馬遷 Shiji (史記, Records of the Historian), from c. 9o BCE, defined this language at its peak. Yet, even in these standard texts, the literary language is noted for its multivalent potential and vague referents. It is assumed, however, that for early readers these qualities did not render the text unreadable or even ambiguous. If we accept these propositions, then we have to recognize 
that the language of the Shijing is a type of proto-classical Chinese, and not a language that is compatible with the reading protocols of standard literary Chinese. In many of its formations, the language of the Shijing is more akin to the language found on Zhou bronze vessels than that of the Mengzi or Shiji. This "bronze-script nature" of the Shijing is masked, however, by the transcription of the text into standard script forms beginning in the Han period. At the graphemic level the Shijing may look like these other texts, but that impression dissolves when one turns to reading it.

As the earliest commentaries with their intensive glossing attest, even during the Han period, the Shijing was written in a "foreign" language that needed interpretations for the reader of the time. In addition to this inherent linguistic difference, the need for this glossing also rises from the pervasive secondary orality of the poems - they were most often transmitted in an oral context, even within an extensive written culture. In that transmission there were only spoken words; yet when the text was recorded (and there were many occasions when this happened), then one needed to transcribe it into written form, and the resulting sound-based graphs became the famous "loan words" that commentaries needed to clarify for the belated reader. Without the commentarial glossing of its vocabulary, no one could read very far in the Shijing without getting stuck. Thus, when we read 不顯不承 'not brilliant, not continuing' in poem no. 266 , we need the commentary, in this case Chen Huan quoting the Mengzi, which cites the Shujing (書經, Classic of Documents), which is glossed by Shici (釋詞, Lexicon), to inform us that $b u$ is not a negative, but rather a word of praise (讚美之詞; Cheng and Jiang 1991, 935): yielding something like "such brilliance, such continuity." That is what the Shijing commentaries do: they "translate" proto-Chinese into Chinese, first into the standard literary language, and more recently into standard modern Chinese, and currently often into a combination of the two.

Thus, very few people now actually read the Shijing, rather, they most often decipher it; and when they do "read" it, they often do so already knowing what it means from various other types of exposure. There are lines of the Shijing that work perfectly well in standard classical language, and some even in modern literary language - the latter often being transformed into aphorisms (成語). In most cases, however, we are reading the Shijing through a series of substitutions, led by the glosses and commentaries, whether we recognize that or not. This is what I call "surrogate reading." The "Annotations" described above will extend that reading into the English context, alerting the reader of the translation to the general nature and specific examples of this type of reading. The final hermeneutical move is then to read the poems in translation. 


\section{Issues of translation}

Within this linguistic and intralingual context, there are a set of intellectual and cultural issues raised in translating the Shijing that need special attention.

\section{Who's listening?}

When we enter into the contract of translation, we must imagine the original text in a communication context. We need to know not so much what the writer of the text meant to communicate, but rather how the text "sounds" to the listener/reader, either actual or imagined. We need to know not so much authorial intent, but rather textual resonance. When that context is clear, we can then strive to reconstruct it in the target language: not the intention but the reception of the text. The degree of transparency of those communication contexts and their textual resonance varies greatly. These can be as lucid as contemporary third-person reportage where we can ask/imagine almost any source-language reader/listener what they "hear." Or it can be a difficult and ambiguous text, such as the poetry of high modernism, which may require us to imagine a much more informed source-language listener. But how do we approach a text as distant and difficult as the Shijing? Is there a contemporary listener whom we should ask or imagine? Or are we to imagine a listener at some other point in the long trajectory of this text's reception - the Qing philologist, the Tang commentator, the Han annotator, the audience of the royal court, the wineflushed guests at a clan dinner, or the old lady in the lane humming a local tune and making up the words as she goes along? Haun Saussy describes the difficulty, if not impossibility, of finding the "first meaning" of the Shijing poems (1993, 60-61). Even if we assume that the first singers and listeners understood these songs very well, by the time of the earliest textual versions for which we have evidence (second century BCE), the extensive glossing of individual words and phrases in the poems can only mean that the early commentators believed their contemporaneous readers needed these aids. The text would be incomprehensible without them, and thus emerges the first layer of intralingual work. That glossing only became more labored over the centuries, wherein there are glosses of glosses of glosses: Kong Yingda glosses Zheng Xuan's glosses of the Mao glosses of the poems, to which critics from the Song to the Qing added their own evaluations.

So to whom does one listen if the task is to translate the Shijing? Both Legge and Waley relied very much on Zhu Xi's text, about which Legge is 
clear and Waley is less so. Karlgren more often went back to Mao and Zheng Xuan, but also struck off on his own, as only he could. And Pound? Pound often relied on Pound, although he did have the assistance of Veronica Sun to read the annotations for him (Carpenter 1988, 797-798). No matter the strategy, in every case the text is rendered more comprehensible in English than it is in Chinese, and that is because the English translation is largely a translation of intralingual glosses. If we actually translated the text as it stands, I would predict that fifty percent of it would be gibberish to almost any reader. To wit, no. 280 :

Set up business, set up ju

Lofty incisors tree feathers
設業設虚

崇牙樹羽

The HYDCD gives sixteen discrete definitions of the common term ye 業 of the first line (1993), Paul Kroll gives nine for classical Chinese (2007), and Xiang Xi's dictionary dedicated just to the language of the Shijing gives two, "danger" and "bell stand" (1997) - but there is already a bell stand in the line, $j u$ 虞. $J u$ is an extremely rare character for which the HYDCD cites this poem, so it would have also been a puzzle to most readers, historical and contemporary. I won't even go into the tangled web of the second line, other than to say that every graph is given extensive annotation and commentary, producing a meaning something akin to "On their wooden dentals, plumage stands" - this assumes the reader of English knows what architectural "dentals" are, and does not confuse them with false teeth. This is why we need intralingual glossing in both Chinese and English.

\section{The names of things}

The Shijing's deep engagement with the material world makes for fascinating reading. Yes, these are works of great emotional weight: poems of ritual and spirituality, poems of dynastic glory, poems of social woes, poems of family affairs, and poems of romance. Yet this emotional weight is often borne on the backs of things. Things from the most wrought to the most natural: from elaborate bell stands to ospreys on an island in the river. Bill Brown has argued that an object becomes a thing through its increased subjectivity: "The story of objects asserting themselves as things, then, is the story of a changed relation to the human subject and thus the story of how the thing really names less an object than a particular subject-object relation" (2001, 4). That is a relationship found throughout the Shijing, where objects find their subjects, both in the poems and in their reception. This creates an 
ecology of things, a complex of material relationships. It is difficult to know if we can enter into the ecology that generated the things, but we should be able to appreciate the ecology that emerges from the text's long reading history. But is that an ecology that can be translated?

The first issue is the thing named. As with the ju bell stand, there are certain objects named in the Shijing for which we have no equivalent term, even when we know exactly what that object is. Other things named are irretrievable, except as a vague term, such as "type of plant." Problems are compounded when the objects have special "thing-ness" in their naming.

Poem no. 292, "Silk Robes" (絲衣), which describes the sacrifice to a star

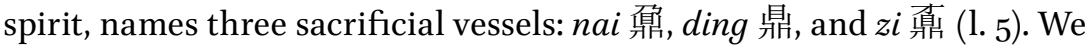
know what these are: beginning with the ding, the most common term, "a meat-stewing tripod" (Von Falkenhausen 2006, 524), or "ancient cooking cauldron with two handles and three or four legs" (MDBG). This usually gets rendered simply as "cauldron." The other two vessels are much more obscure, not appearing in extant listings of sacrificial objects; here the Mao glosses come to our rescue, saying that the nai is a large ding, and $z i$ is a small ding, which is repeated by the HYDCD (but note that in the Lu school commentary, the nai is said to be a small ding). So we know what we have, more or less - different vessels for preparing and holding the sacrificial meats - but we cannot really translate the terms without a prosaic paraphrase or transliterating the original names. We can imagine that for the singer and reader, this small catalogue of things would possess affective weight, as if we were to read, "Chalice, goblet, and wineglass." It is this weight, the subject-object relationship, that is difficult to recover.

This weight can extend to materials of the natural world as well. The Shijing is famous for its language of flora and fauna, generating extensive attention and scholarship (Lu Ji 1967, Lu Wenyu 1957). Referents to animals and plants are also often fraught with cultural meaning. On occasion that meaning is transferable in translation. The peach blossoms of poem no. 6 need no apologia (although see Saussy's detailed analysis [1993, 110-114]):

$\begin{array}{ll}\text { The peach is young and strong } & \text { 桃之夭天 } \\ \text { Blossoming into buds } & \text { 灼灼其華 } \\ \text { This girl goes to her new home } & \text { 之子于歸 } \\ \text { All is right with house and chamber } & \text { 宜其家室 }\end{array}$

But other cultural-connotative transfers are not in the making, such as with the auspicious omen of swarming locusts alluded to in poem no. 5. These we either have to explain or translate away. 
In addition to these singular names/images of flora or fauna, there are also the catalogues where material and cultural information piles up, creating a density of denotative and connotative meanings that challenge the translator, sometimes at the denotative level, but almost always at the connotative level. One such catalogue of fishes is found in poem no. 281, "Depths" (潛). This is a very short, perhaps fragmentary, poem of sacrifice, where the fish are presumed to be the viands of the offering. In characters and transcription:

$\begin{array}{ll}\text { 猗與漆沮 } & \text { Yi yu qi ju } \\ \text { 潛有多魚 } & \text { Qian you duo yu } \\ \text { 有鱣有鮁 } & \text { You shan you wei } \\ \text { 鲦鱨鮿鯉 } & \text { Tiao chang yan li } \\ \text { 以享以祀 } & \text { Yi xiang yi si } \\ \text { 以介景福 } & \text { Yi jie jing fu }\end{array}$

These fishes (1l. 3-4) are variously identified. The first and last have common, accepted English identifications: shan 'sturgeon' and $l i$ 'carp'. Yet Zheng Xuan glosses shan as "big carp” (大鯉), while the HYDCD identifies it with another character, 鮮, which is a type of eel - appropriate in the Chinese context, but not felicitous at all in English. Citing a description by Chen Huan, Cheng and Jiang identify shan as huso sturgeon (鰉魚, Huso dauricus). "Sturgeon" seems acceptable. The other names present more denotative problems. Wei is now a term for tuna, which would work except the names need to be freshwater fishes. Zheng Xuan glosses it as luo 鮥, another type of sturgeon (Acipenser sinensis, Chinese sturgeon), which Kroll glosses as "beaked sturgeon, paddlefish," though he gives it a different Latin name. The tiao is also called a bai tiao (白鲦 'white tiao'), identified as a "Korean sharpbelly" (Hemiculter leusiscultus), but also called a "chub." The chang is of the catfish (Bagridae) family; the HYDCD identifies it in another Shijing poem as 黃鱨魚, for which Kroll has "golden catfish" with a different Latin name (Pseudo-bagrus aurantiacus). The yan is unfortunately commonly identified as a "mudfish," although HYDCD has, citing the Mao commentary, 鯰魚 'catfish'. Kroll, without identifying a Latin name, gives "cutler, sheatfish" - sheatfish is a European catfish; cutler is an East Asian fish of the Cyprinidae (carp) family.

It is very unlikely that a contemporary Chinese reader, even a highly literate one, would know more than two or three of these fishes. Yet the catalogue would be easily seen as one of fishes, because of the "fish radical" for each graph - a reading protocol not reproducible in English. So what do we do with this catalogue of fishes? These have been some solutions: 
Sturgeons, large and snouted,

T'ëaous, yellow jaws, mudfish, and carp. (Legge)

Sturgeons and snoutfish,

Long-fish, yellow-jaws, mudfish and carp, (Waley)

There are shan sturgeons and wei sturgeons, tiao fish, and ch'ang fish, yen fish and carp (Karlgren)

Lo, how our love of god is shown in fish, here be all sorts in sacrificial dish. (Pound)

While Legge and Waley have walked a middle way, Karlgren and Pound have taken the extremes, both avoiding translation per se: one in extreme foreignization and the other in domestication of such a degree that it is difficult to identify the couplet. I think it is important to keep the catalogue in place, since it is a dominant rhetorical device in the Shijing (and in Chinese literature generally), but I favor manipulating the things named for some poetic effect. My first reaction, as a North American angler, was to turn to the fishes of the American Northwest and Midwest:

There are rainbow, there are steelhead

Bass, walleye, perch, and whitefish

I particularly like the first line: just as shan and wei are the same fish with different names (types of sturgeon), so are rainbow trout and steelhead - steelhead are rainbow that have gone to sea and returned to freshwater as monster versions of their former selves. But I also thought of keeping the native fishes with some affect. Sturgeon remains, but paddlefish (which is an endangered species in the Yangtze River) is used as more euphonious than the "snout" - I wish I could use "swordfish" but that is now too oceanic; even more so, I wish we had a one-syllable name for this slot. For the second line I have chosen names (often secondary in their dictionary entry) based on alliterative euphony (except for "chub," which has "visual" alliteration) - "cutler" is a bid toward foreignization.

No. 281, Depths

Lo, the rivers Qi and Ju

Hide many fishes in their depths

There are sturgeon, there are paddlefish 
Chub, catfish, cutler, and carp

To be enjoyed, to be sacrificed

In order to get great fortune

In this naming of things, there are occasionally happy accidents. The variety of plants named in the Shijing is astounding, having received monographlength classification and analysis (Lu Wenyu 1957). Sometimes identification is relatively easy, if not fortuitous. In poems no. 289 and no. 291, the plant liao 蓼 is used metaphorically to allude to something politically adverse. Liao is a member of the Polygonum genus, of which there are hundreds of species; in the Shijing, it is typically translated by its common name "smartweed" (Legge, Waley, Karlgren). However, since the implications of the plant are consistently negative, "smartweed" is not a felicitous choice. This is especially so when its more common name is "knotweed, knotgrass" - presumably the "knots" refer to the swollen jointed stems, just as does the Greek term Polygonum. The name "knotweed" would seem to carry connotations of "difficulty." In fact, Shakespeare is our proof. From A Midsummer Night's Dream, 3.2:

Get you gone, you dwarf,

You minimus of hindering knotgrass made,

You bead, you acorn!

(1993)

Thus, we in turn have:

Inept at dealing with family troubles

I again landed in the knotweed
未堪家多難

予又集于苶 $(289)$

and

To weed out the thistle and knotweed

以莀荼蓼

Thistle and knotweed rot away 茶蓼朽止 $(291)$

In this case the denotative sense is unchanged, but the connotation cleaves closer to the original sense.

Also by happy accident, sometimes the connotations of a translation are more effective than the original, producing a translational gain. The most famous plant in the entire corpus is the floating water plant (xingcai 荇菜) of the first poem, which is gathered (presumably by women) for either its medicinal or edible quality. Variously described and identified, Zhu Xi has a full, if somewhat late description: 
Xing approaches excess [per Mao]. The roots grow from water's bottom; its stems are thin threads like hairpins. They are green on top and white underneath. The leaves are purplish red, more than one inch (cun) around, and float on the water surface.

荇, 接余也。根生水底, 荎如釷股。上青下白。葉紫赤, 圓莖寸餘, 浮 在水面。

Legge translates xingcai as "duckweed," which is both inaccurate (accepting Zhu Xi's description) and awkward; Waley has "water mallow," which is euphonious and culturally appropriate (it is also a medicinal plant and may be edible), but is not botanically close - water mallow is a flowering bush of the hibiscus group. Originally, I translated xingcai loosely as "water cress" - it is gathered, eaten, and healthful; yet, I knew water cress was not a floating plant and that it grew in moving water. Then I discovered that xingcai has been identified as Nypmhoides peltata (Anderson, 33), a miniature water lily of East Asia, with the common name "floating heart." I am unaware of edible or medicinal qualities of this plant, but the plant is attractive, and given the romantic overtones of the poem, the name "floating heart" is coincidentally perfect:

Short and tall stands floating heart

Left and right she plucks it

Fine and fair is the good lady

Awake and asleep he wants her

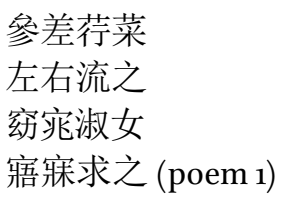

At times the right name has the wrong effect. The vine, $g e$ 葛, in poem no. 2 , with the variation gele $i$ 葛葸 in poem no. 4, is clearly identified as a type of kudzu (Pueraria lobata), which is eaten, used for medicinal purposes, and made into cloth. The connotations of the plant is thus entirely positive and domestic. Yet in American English the name "kudzu" brings with it connotations of invasion, strangulation, and destruction; it is called "the vine that ate the South." The Missouri Department of Conservation describes it, in relatively mild terms:

Kudzu rapidly forms dense mats over the ground, shrubs, mature trees, and buildings. It kills or injures other plants by smothering them under a solid blanket of leaves that allow little light to penetrate. It can girdle shrubs and trees, break branches, and uproot entire trees with its weight. 
Thus, we cannot name ge by its actual name, but must choose a more cultural neutral term, to wit:

The cloth vine so long

Spreads across the valley floor

and

In the south, a tree with bended branches

Has woodvine climbing up it
葛之覃兮

施于中谷 (2)
南有樛木

葛葸纍之 (4)

\section{Say again}

One of the most ubiquitous of the rhetorical devices in the Shijing is the use of “reduplicatives" (晎詞), which are either adjectival or adverbial expressions composed of the same, repeated graph, or of two closely rhyming graphs. The first stanza of the first poem offers both, in guanguan and yaotiao:

\author{
Guanguan jujiu \\ Zai he zhi zhou \\ Yaotiao shunü \\ Junzi haoqiu
}
關關雎鳩
在河之洲
窈宨淑女
君子好述 (1)

These types of repetition are readily available in Chinese, especially with its wide range of potential rhymes. Although English allows for some modifier repetition and some rhyming binomes, it is impossible to reproduce the original density of these devices in translation. Yet, it seems at odds with the goal of this translation, where I hope to preserve important rhetorical forms that can be seen as innovative poetic practices in English, to convert the reduplicatives into undistinguished modifiers - lonely ospreys, pretty ladies. The awkwardness of reduplicatives (lonely lonely) and most rhyming binomes when possible (loveydovey) is also counter to the goals here: to produce viable poetic expressions, albeit innovative ones. Although to my ear the Shijing forms of repetition are not available or effective in English, there is a type of repetition that does work, both poetically and in calling attention to its foreignness. This is the alliterative binome, often joined by the conjunction "and." We have a good number in English already - fast and furious, down and dirty, rough and ready. Moreover, for a language in which alliteration is more available than rhyme, innovative alliteration is eased: big and bountiful (harvest), mighty and martial (king's 
deeds), fine and fair (young woman), full and flourishing (plants). Once this basic form of repetition is established as a rhetorical device shared across the breadth of the anthology, then one can use variations that allude to the basic form: pick, picking (plants, no. 3), whistling whoosh (blades, no. 291), ornate and adorned (ritual hats, no. 292). These types of repetitions then become a new poetic form in English - a "Chinese" form, as it were.

\section{Beautiful, just beautiful}

Sometimes the information provided by the traditional commentaries does not present problems because of the specificity of the glosses or the rich cultural connotations of the terms, but rather just the opposite: there is too little information. The most common of these glosses are the 貌 'appearance' and 然 like' suffix-constructions: the suffixes turn phrases into vague adjectives or adverbs. Thus, in poem no. 4, the term ying 縈 is glossed (following a substitution) as 草施貌 'the appearance of vegetation coming out', and in the highly laconic poem no. 268, the adjective 熙 is glossed by Cheng and Jiang, following Zheng Xuan, as 光明貌 “the appearance of radiant and bright"; but we already have numerous uses of "radiant" and "bright," so we need yet another word:
See how clear and luminous
維清緝熙
Are the judgments of King Wen
文王之典 $(268)$

The most overused glosses, however, are mei 美 'beautiful' and $d a$ 大 'big'. If there is no clear definition of a word, other than it should be positive, it is then often described as mei. So in poem no. 290, mei 媚 is defined as mei; in 292, xiu 休 is defined as mei; in 293 shuo 鑠 is defined as mei; and in 296 huang 皇 is defined as mei. If the positive qualities of a word are also infused with a sense of grandeur, then it is often glossed as $d a$. In 274, that is the gloss for the reduplicative jianjian 簡簡, and in no. 293 for the common term chun 純 'pure'. In the best of translational worlds, we should find a unique and consistent translation for each of these terms, one that perhaps catches some echo of the other meanings associated with the term. Given the plethora of these terms, we will need a large thesaurus to name each, and a database to keep track of them.

\section{Oh, alas, what to do?}

Lo, there is, alas, yet another problem in translating the Shijing - indeed there is. Yea, 'tis true, and it has to do with the auditory expressions (語助 
詞 / 讚嘆詞 / 發語詞), of which many, oh so many, are found in the text. Oh my, what to do, oh what to do? Whoo hoo, yes, here's an idea!

There is a wide variety of auditory expressions used in the Shijing and if we tried to translate them all, the effect could be similar to the preceding paragraph - like an email message larded with emoji. These expressions are dense and diverse, presenting two problems for English translation. First, their density extends from the level of the text as a whole to within individual poems and indeed lines. The last line of poem no. 3 is three-quarters atmosphere:

Oh, how dreadful it is!

云何吁矣。

Yun 云, he 何, and $y i$ 矣 are all relatively absent of meaning, but full of affect. The only substantive word is $y u$ 吁, which looks like an exclamation (with its "mouth radical") but is said to be a loan for 䀒 - here read not as “to stare with eyes wide open” but as 憂 'sorrow', per Mao. Although I think the translation above is quite effective, it is hard to maintain that over many lines.

Second, the language of the Shijing is replete with words that are said to "have no meaning" (無意) but still have affect. Some are well established: 哉、 矣、於、止、言, and the delightfully contemporary but not quite appropriate wuhu 鳴呼 (often written 於乎). These alone present challenges, in part because English has fewer such expressive/empty terms: "ah," "so," "oh so," "yes," "yea," and Waley's favorite, "lo." Moreover, English has always used them less. Even in a corpus of overwrought emotion such as Shakespeare's sonnets there is only about fifty-five uses (mostly O/Oh) in 2,154 lines (1993). What is more, it seems that in the Shijing almost any graph, no matter its denotative meaning, even ones of very common usage, can be deployed (through phonetic loan) as an emotive expression. So in poem no. 280, we have what appears to be a straightforward use of 有 'there is': 有韾有韾 / 在周之庭 (there are blind ones, there are blind ones / in the court of Zhou), but Cheng and Jiang (1991, 961) inform us that here 有 is a "prefix [頭詞], without meaning" - this, despite the fact the formula you ... you appears elsewhere in this subset of poems in its substantive sense (no. 281 and no. 285 ). With this type of reading, the potential number of "meaningless" words greatly increases.

The disparity of the two poetics presents a difficult choice: to Oh, or not to Oh. In the sober, often laconic Zhou Hymns I have chosen to reduce the "Oh-factor," sometimes with substantive replacements such as: "indeed" for final $y i$ : 
Then in time, they were splendid indeed＼cjkstart時純熙矣

In translating the more open and syntactic Airs, there seems more room for the pop-song quality of the catchy rhythms of the Oh-factor:

Awake and asleep, he ponders

Oh, it's so, so long
嶈寐思服

悠哉悠哉

One way to "pad" a line without the Oh-factor is with prepositions and conjunctions, abundant in English but relatively scarce in literary Chinese. Their cautious use can help fill out a line and also bring more syntactic flow to the English line, as opposed to the strongly paratactic poetics of Chinese (see Zhou Min's essay in this volume). Again we can turn to see how Shakespeare has used these in his sonnets, especially the empty "and" (1993). He does that with extravagance in Sonnet 66, in ten lines out of fourteen; a more moderate and model use is in Sonnet 67:

$A h$, wherefore with infection should he live,

And with his presence grace impiety,

That sin by him advantage should achieve

And lace itself with his society?

Why should false painting imitate his cheek,

And steal dead seeing of his living hue?

Why should poor beauty indirectly seek

Roses of shadow, since his rose is true?

Why should he live, now nature bankrupt is,

Beggared of blood to blush through lively veins?

For she hath no exchequer now but his,

And, proud of many, lives upon his gains.

$O$ him she stores, to show what wealth she had

In days long since, before these last so bad.

This is a hard act to follow and less suitable for the oblique, liturgical poems, such as the Zhou Hymns, but for the more fluid, narrative pieces, it can enhance both content and form.

\section{One poem}

I will conclude with a representative sample of the format described above. 
Annotation: Bernhard Karlgren (Glosses) says that nearly every line of this poem is disputed, and he offers readings that often diverge from the mainstream. The first issue is the title zhuo (to pour/drink), a term that does not appear (as is the usual practice) in the poem. This has led to a series of substitutions; yet, none of those proffered graphs appear in the poem either, so it seems prudent to let it stand as is. L. 1 is perhaps the simplest to parse, one merely needs to decide if shi is a noun (troops) or a verb (to lead), either one is possible, as it is modified by shuo, beautiful mei美 per Mao. Questions with l. 2 surround the main verb yang (nourish), which Mao glosses as $q u$ 取 (seize); Karlgren thinks this gloss highly unusual, but the Chinese commentaries follow Mao up through at least Chen Huan, whom Cheng and Jiang cite (991). This reading then turns hui (dark) into its object, which is read as "un-enlightened one," that is, King Zhou of the Shang/Yin, the defeated (seized) enemy of King Wu. The alternative reading is to take hui adverbially as "in obscurity/darkness" and yang as "nourish/lead (troops)." Understanding, per Zhu Xi, that King Wu trained his troops secretly, and waited for the time of glory of l. 3 . The identical graphs shi in 1.2 and l. 3 are read differently: "this" and "timely," respectively.Jie (1. 4) is glossed, per the Erya, as shan 善 (good/goodness). The first-person pronoun (l.5) is said to refer to King Cheng, who is leading this ritual song/dance; but it is also glossed as wo Zhou; "we the Zhou people." Long (dragon) is a loan for chong in the sense of tianchong天寵, the favor of heaven. The reduplicative qiaoqiao (l. 6) is glossed by Mao as 武然 “martial-like.” The $s i$ in 1.7 has been used above to refer to King Cheng, as the "successor" of King $\mathrm{Wu}$; I am assuming that he is the referent here again. The configuration of the last line(s) is in dispute. First, Chen Huan has proposed that there are two lines not one: one of four syllables, and one of two syllables. Cheng and Jiang follow, as does the Maoshi yinde. However, Kong Yingda, Zhu Xi, Legge, and Karlgren do not; Karlgren saying that a two-syllable verse ending a poem is "quite out of the question." Second, the reading of key words is disputed: gong, Mao reads, and Zheng follows, as "affairs/ duty" shi 事, but others understand in the sense of “ancestral rulers" xiangong 先公 (that is, King Wu) - Cheng and Jiang, 991. The term shi, which in l.1 means "troops/ lead" is said here to mean "model" by Cheng and Jiang (991), citing Wang Xianqian. This reading (as model) is followed by Legge and Waley, but not by Karlgren. Zheng Xuan paraphrases, "the affairs/duty of the king was to raise the army and conquer, this is truly your duty, to sincerely obtain the Way of using the troops."

Comment: Waley says, "This is perhaps the most difficult poem in the whole book, and I am not confident that I have understood it correctly." Needless to say, I feel the same, just more so. My solution is to leave the inherent ambiguity in the text where I can. This is especially when I cannot reconcile the differences in any other way. Thus for yang shi hui (1. 2), where there are strong arguments to read it as "to nurture in darkness" or "to seize the darkness," I have created intentional ambiguity with "to take of this darkness" - it sounds like it means something but it's not clear what. For the final line, I have decided to accept "duty" for gong (not "duke") but try to split the difference between "troops" and "model" for shi - "your martial model." As for the question of the concluding one or two lines, I have opted for one line with a strong punctuation break. 


\section{No. 293, Libation 酌}

Mao Preface: "Libation" announces the completion of the "Great Martial." It speaks of how in offering a libation to the way of the ancestors, one is able to take the empire. 《酌》, 告成《大武》也。言能酌先祖之道, 以養天下也。

Yes, glorious are the king's troops

Bringing them to take of this darkness

Then in time, they were splendid indeed

From this method comes great good

5 And with favor we do receive it

Mighty and martial were the king's deeds

And now his method has a successor

Rightly this is your duty: a true warlike model
於鑠王師
遵養時晦
時純熙矣
是用大介
我龍受之
蹻蹻王之造
載用有嗣
實維爾公允師

Zheng Xuan: In the sixth year of the Duke of Zhou's regency, he prepared the rituals and created the music. Returning governance to King Cheng, he offered prayers in the temple and had it performed. He began and he completed it; announcing this, all is done. 周公居攝六年, 制禮作樂, 歸 政成王, 乃後祭於廟而奏之。其始成告之而已。

Kong Yingda: The poem "Libation" is a song announcing the completion of the "Great Martial" dance. It refers to the sixth year of the Duke of Zhou's regency. In imitating the deeds of King $\mathrm{Wu}$, they created the music of the "Great Martial," and having completed it, they announce it in the temple. The creators observing that the music was completed, and contemplating his martial merits, describe it and make this song from it. 正義曰: 《酌》 詩者, 告成《大武》之樂歌也。謂周公攝政六年, 象武王之事, 作《大武》 之樂既成, 而告於廟。作者睹其樂成, 而思其武功, 述之而作此歌焉。

Zhu Xi: This is a poem that praises King Wu. It speaks of how in the beginning although he had glorious troops, he did not use them; he held back and continued to train them, at the time all was in the dark. And when there was indeed splendid light, they put on their battle clothes, and as soon as they did, the empire was entirely settled. Later people were thereby favored and received the merits of the mighty and martial-like king. The one who thereby succeeded him will also take this work of King Wu as model, and all is thus. 此亦頌武王之詩。言其初有於鋢之師而不用, 退自循養, 與 時皆晦。媓純光矣, 然後一戎衣而天下大定。後人於是寵而受此蹻蹻 然王者之功。其所以嗣之者、亦維武王之事是師爾。 


\section{Epilogue}

This sample translation introduces most of the issues and protocols that I have discussed. Yet there is one practice that needs to be highlighted: the use of strategic ambiguity. This practice, which runs through my translation from start to finish and is illustrated here by "to take of this darkness" (1.2), helps maintain the complex intralinguality of both the Chinese commentaries and the English translations. The ambiguity is strategic in that it does not inhibit understanding, but rather allows for as many interpretational approaches as possible. It opens moments of the poem to intersecting, even contradictory readings. As such, it lies at the heart of my approach to negotiating the complexities generated by the Shijing's antiquity and layers of multivocal commentary.

\section{Works cited}

Allen, Clement Francis Romilly, trans. 1891. The Book of Chinese Poetry: Being a Collection of Ballads, Sagas, Hymns, and Other Pieces Known as the Shih Ching; or Classic of Poetry. London: K Paul, Trench, Truber.

Allen, Joseph R. 2019. "The Babel Fallacy: When Translation Does Not Matter." Cultural Critique 103: 117-150.

Anderson, E. N. 1988. The Food of China. New Haven: Yale University Press.

Brown, Bill. 2001. "Thing Theory." Critical Inquiry 48 (1): 1-22.

Carpenter, Humphrey. 1988. A Serious Character: The Life of Ezra Pound. New York: Dell Publishing.

Chen, Huan 陳奐. 1975. 詩毛氏傳疏 [Commentary to the Maoshi]. 2 Volumes. Taipei: Xuesheng shuju.

Cheng Junying 程俊英 and Jiang Jianyuan 蔣見元. 1991. 詩經注析 [New analysis of the Shijing], two volumes. Beijing: Zhonghua shuju.

A Concordance to the Shih Ching. 1962. Harvard-Yenching Institute Sinological Index Series. Supplement No. 9. Cambridge, MA: Harvard-Yenching Institute.

Fuller, Michael. 1999. An Introduction to Literary Chinese. Cambridge, MA: Harvard University Asia Center.

HYDCD, 漢語大詞典 [The great dictionary of Chinese]. 1993. Shanghai: Cishu chubanshe.

Jennings, William. 1891. The Shi King: The Old "Poetry Classic" of the Chinese. London: Routledge.

Karlgren, Bernhard, trans. 1950. The Book of Odes. Stockholm: Museum of Far Eastern Antiquities. 
Karlgren, Bernhard. 1964. Glosses on the Book of Odes. Stockholm: Museum of Far Eastern Antiquities.

Kern, Martin. 2018. "The Formulation of the Classic of Poetry." In The Homeric Epic and the Chinese Book of Songs: Foundational Texts Compared, edited by Fritz-Heiner Mutschler. Newcastle upon Tyne: Cambridge Scholar Publishing: 39-71.

Kong, Yingda 孔穎達. 1964. 毛詩正義 [Correct meaning of Maoshi]. Hong Kong: Zhonghua shuju.

Kroll, Paul. 2007. A Student Dictionary of Classical and Medieval Chinese. Leiden: Brill.

Legge, James. 1871. The She King or The Book of Poetry. The Chinese Classics, Volume 4. Reprint Oxford: Oxford University Press, 1935.

- 1876. The She King. London: Trübner.

Lu Ji 陸璣. 1967. 毛詩草木鳥獸蟲魚疏 [Explication of plants, birds, animals, bugs, and fish in the Maoshi]. Taipei: Yiwen.

Lu Wenyu 陸文郁. 1957. 詩草木今釋 [Contemporary meaning of plants in the Shi]. Tianjin, Renmin chubanshe.

Ma Ruichen 馬瑞辰. 1971. 毛詩傳箋通釋 [Complete explanation of Maoshi zhuanjian]. Taipei: Guangwen shuju.

MDBG Chinese Dictionary. bit.ly/2j7tmvT. Accessed July 23, 2018.

Missouri Department of Conservation. "Kudzu." bit.ly/2P1zXry. Accessed July 23, 2018.

Pound, Ezra, trans. 1954. Shih-ching: The Classic Anthology Defined by Confucius. Cambridge, MA: Harvard University Press.

Rouzer, Paul. 2007. A New Practical Primer of Literary Chinese. Cambridge, MA: Harvard University Asia Center.

Saussy, Haun. 1993. The Problem of a Chinese Aesthetic. Stanford: Stanford University Press.

Shakespeare, William. 1993. The Complete Works of William Shakespeare, MIT online edition. bit.ly/2Jsu6v4. Accessed July 23, 2018.

Van Zoeren, Steven. 1991. Poetry and Personality: Reading, Exegesis, and Hermeneutics in Traditional China. Stanford: Stanford University Press.

Von Falkenhausen, Lothar. 2006. Chinese Society in the Age of Confucius (100o-250 BC): The Archaeological Evidence. Los Angeles: Cotsen Institute of Archaeology.

Waley, Arthur, trans. 1937. The Book of Songs: The Ancient Chinese Classic of Poetry. New York: Grove Press, reprint 1960.

Waley, Arthur, trans., Joseph R. Allen, ed. and trans. 1996. The Book of Songs: The Ancient Chinese Classic of Poetry. New York: Grove Press, 1996.

Xiang Xi 向喜, ed. 1997. 詩經詞典 [Dictionary of the Shijing]. Chengdu: Sichuan renmin chubanshe. 
Xu Shen 許慎, comp. 1977. 說文解字 [Explicating wen analyzing $z i]$, annotated by

Duan Yucai段玉裁. Taipei: Lantai shuju.

Yao Jiheng 姚際恆. 1963. 詩經通論 [Complete discussion of the Shijing]. Hong Kong: Zhonghua shuju.

Zheng Xuan 鄭玄. 1936. 毛詩鄭箋 [Zheng's annotations of the Maoshi]. Sibu beiyao. Zhu Xi 朱喜. 1977. 詩集傳 [Collected commentary on the Shi]. Taipei: Zhonghua shuju.

\section{About the author}

Joseph R. ALLEN is professor emeritus of Chinese literature and cultural studies and was the founding chair of the Department of Asian Languages and Literatures, University of Minnesota. Trained in classical Chinese poetry, his work includes editing Arthur Waley's Book of Songs, with additional translations (Grove Press, 1996). He has also translated and written about modern and contemporary Chinese poetry, including Sea of Dreams: The Selected Writings of Gu Cheng (New Directions, 2005). His Taipei: City of Displacements (University of Washington Press, 2012) won the 2014Joseph Levenson Prize of the Association of Asian Studies. 


\title{
4 Purpose and Form
}

\author{
On the Translation of Classical Chinese Poetry
}

Wilt L. Idema

\begin{abstract}
This essay contains reflections on issues of purpose and literary form in poetry translation, against the background of translation traditions that change over time. Circling out from a poem by Tang-dynasty poet Han Shan, the author draws on examples from Dutch and English to address issues that bear relevance to classical Chinese poetry's translation into any language, and indeed to the art and the craft and the trade of poetry translation at large.
\end{abstract}

Keywords: Chinese poetry, translation, audience, rhyme, meter, parallelism

There was very little in my background when I grew up in the Dutch countryside to predispose me to the study of Chinese Languages and Cultures, which I chose as my major when I entered Leiden University in the fall of $1963 .{ }^{1}$ Also during my years of study at Leiden, and later in Sapporo, Kyoto, and Hong Kong, there were few indications that suggested that I would end up spending a large part of my adult life reading and translating classical Chinese poetry, first into Dutch, but later also into English. During these early years of my career my interest wavered between contemporary rural sociology and late imperial vernacular literature. My first job at Leiden University was as a researcher at the Documentation Center for Contemporary China, a newly founded section of the well-known Sinological Institute, where I was to follow social developments in the inaccessible People's Republic of China of the Cultural Revolution years,

1 This article is an extended version of a paper presented at the Symposium on Chinese Studies 2018 in Beijing (July 23-24).

Van Crevel, Maghiel and Lucas Klein (eds.), Chinese Poetry and Translation: Rights and Wrongs. Amsterdam: Amsterdam University Press, 2019 DOI: $10.5117 / 9789462989948 \_C H O 4$ 
and my earliest publications are devoted to the educational reforms of the 1960 s and early 1970s. I left the contemporary China field abruptly when Dirk Jonker, the Department's teacher of classical Chinese (文言文) and Chinese literature, suddenly died in the weekend before the start of the 1973 spring term: when I got to work that Monday morning, I was asked to take over his classes from that very day, and that was the end of my career as a China watcher.

Throughout my years in contemporary China studies I had always continued to read traditional Chinese vernacular fiction in large quantities. I liked these sprawling narratives of backstage political intrigues and private bedchamber adventures, so different from the official image of Chinese society projected by the authorities to their own subjects or the outside world, in the past or the present. Some of my first attempts at translation concerned the vernacular short stories (話本) that had been collected and printed by Feng Menglong 馮夢龍 in the 1620s. While these stories are mostly written in prose, they also include occasional couplets, poems, and lyrics. When rendering these texts into Dutch, I wanted to stress the alternation between prose and poetry in its various forms, and so I used meter and rhyme in the poetry passages. With due modesty, I dare say I have a certain talent for rhyming in my native Dutch. I also tried to prepare myself even better for my self-appointed task by reading large quantities of Dutch rhymed verse from the nineteenth century, when Dutch poets all used rhyme as a matter of course. I even became something of an expert in the field, publishing two anthologies of nineteenth-century Dutch poetry in cooperation with Anton Korteweg, a good friend who is a practicing poet and served as the director of the Dutch Museum of Literature. But neither my native talent in versifying nor my assiduous reading of rhymed poetry proved much use. Like many translators of Chinese verse before me, I discovered that in the overwhelming majority of cases it was impossible to come up with an acceptable rhyming translation without sacrificing much of the content and almost all of the other formal elements of these poems. Too often it was the padding words that provided the rhymes, and too often the rhymes were lame. True enough, there were occasions where one might hit on a lucky rhyme, but they were very rare indeed.

The first collection of classical poetry of the Tang dynasty (618-906) that I published was Han Shan's 寒山 Poems of Cold Mountain (Gedichten van de koude berg, 1977). Han Shan's Buddhist verse may not enjoy high status in China, but his works have always remained popular in Japan, and in the 1950s and 196os, when Zen Buddhism attracted followers outside Japan 
in ever-increasing numbers, selections of his poems were translated into English (starting with Gary Snyder's renditions), French, and German. My interest in Han Shan had been aroused not so much by his poetry as by his reputation as a vernacular author, because I wanted to deepen my knowledge of the development of the vernacular language (白話). But once I started reading the poems with the aid of the excellent Japanese commentaries that were available, I could not help trying to render some of them into Dutch. And after I had succeeded in doing so once to at least my own satisfaction, I could not stop myself from doing more, until I had translated two hundred poems. I had the good fortune to be able to place this collection with a publisher, because the Cultural Revolution had raised considerable interest in China abroad - as well as heated debate - and De Arbeiderspers, which originated as the publisher of the socialist movement in the Netherlands, had set up a series of publications devoted to China past and present.

While working on Poems of Cold Mountain I became aware of a phenomenon that, I thought at the time, might well be peculiar to Dutch. ${ }^{2}$ When translating a five-syllable line and following the Chinese word order, many Dutch lines proved to be regular iambic lines of five feet. Now if the first line is a regular iambic line and the second is not, there is no problem. But if the second line also happens to be a regular iambic line, one has set up a pattern that creates the expectation in an experienced reader of Dutch poetry that he or she is reading blank verse, and that therefore the third line also will be an iambic line - if it is not, the reader will be unpleasantly surprised. From this I drew the conclusion that I had to make a choice: I either had to avoid regular iambics, or else to stick to iambic lines throughout. I chose the latter option. First of all, this saved me from the unwelcome tendency to extend the lines by inserting all kinds of explanatory materials. More importantly, it allowed me to suggest, if only faintly, something of the strict formal constraints under which China's traditional poets worked. Unlike many of their modern and contemporary counterparts, Chinese poets in premodern times did not write in free verse but adhered to strict formal rules, and a translation should preferably contain some reflection of that fact, even if it is impossible to replicate the rules in question in other languages. While an iambic line cannot reflect the tonal aspects of the

2 It is my impression that because of grammatical differences between English and Dutch, Dutch words often contain more unstressed syllables than English words, which makes for the easier generation of iambic lines. Conjugations and declensions in Dutch are often expressed by unstressed prefixes (such as ge-) and suffixes (such as - $e$ and -en). 
Chinese language at all, its consistent use throughout a poem, whether a quatrain (絕句) or a regulated poem (律詩), at least presents the reader with formal constraints, albeit not the exact same ones as in the original. For rhymeless but metrical translations I had a model in Dutch translations of classical Greek and Latin poetry (which did not rhyme in the original) and in the strictly metrical original Dutch verse which enjoyed a short vogue near the end of the eighteenth century.

Let me illustrate my approach with an example. One of Han Shan's poems is rendered by Robert C. Henricks as follows:

The thing to be pitied is this disease of living things; 憐底眾生病

They taste and they eat - but they generally never get full. 餐嚐略不厭

They steam the piglet - soaking it in garlic sauce;

Roast up the duck - add a dash of pepper and salt.

They take out the bones, making "raw slices of fish";

Leave the skin on, cook up the face meat.

They don't know the "bitterness" of other's [sic] lives;

Only hold on to the "sweetness" of their own homes. ${ }^{3}$
蒸豚搵赫醬
采鴨點椒鹽

去骨鮮魚膾 兼皮熟肉臉

不知他命苦 只取自家甜 $(1990,289)$

One may well wonder whether such a vegetarian tract is fit for poetry, and Henricks's version reads rather prosaic. Still, Han Shan left us his message in the shape of a perfect regulated poem, including the prescribed parallel couplets. In a poem like this it is neither the message nor the images that are original, but the witty versification. I turned Han Shan's poem into the following eight lines of metrical verse, also keeping as much as possible to the parallelism:

De kwaal der mensen waarmee 'k ben begaan?

Ze schransen, smullen onverzadigbaar!

Ze stoven big in knoflook en in soja,

Ze braden eend met peper en met zout.

3 In the second line, “They taste and they eat” translates 餐嚐, which more precisely should be rendered as "they dine and they taste." Han Shan's poem is not criticizing eating to still one's hunger, but the tendency to seek more and more exceptional flavors to please one's palate and kill living beings for that purpose. 
Ontdaan van graat - de rauwe visfilets;

Met huid en haar - de gare varkenswangen.

Ze laten rustig and're wezens lijden

Om zich de eigen tong te kunnen strelen.

(Idema 1977, 55, amended)

If poets "love to dance in fetters" (Perry 1920, 202, quoted in Wen 1996, 319), Han Shan may not exactly be doing grands jetés, but he is at least still wearing some shackles in this translation. I have never claimed that rhymeless metrical verse is the only way to render classical Chinese poetry. All I can say is that it worked for me, and I have stuck to it also in my later Dutch translations. ${ }^{4}$

Making this choice initially was made easier not only by the relatively low status of Han Shan, but also by the virtual absence of a tradition of Chinese poetry translation in the Netherlands. When I entered Leiden University, it had a tradition of teaching Chinese that stretched back for over a hundred years, but that tradition was rooted in the need of the administration of the Dutch East Indies for specialists in Chinese (later East Asian) affairs, and the teaching program was geared toward the future job situation of the students. ${ }^{5}$ For the first century of Dutch sinology, literature hardly featured in the teaching program. Translations of Chinese poetry directly from the Chinese had always been few and far between. "Chinese poetry" had enjoyed quite some popularity in the Netherlands in the 1920s and 1930s, but these "Chinese poems" (all metrical and rhymed) were free adaptations from the German Nachdichtungen (creative rewritings) by the German poets Hans Bethge (1876-1946) and Klabund (Alfred Henschke, 1890-1928), who had based their free adaptations on earlier French adaptations, for instance by Judith Gautier (1845-1917). ${ }^{6}$ The less authentic these poems were, the more popular they were with Dutch poets. The poem that was most often adapted by Dutch poets was Klabund's “The Tired Soldier” (Der müde Soldat), for

4 After moving to the United States in 1999, I also started to translate classical Chinese poetry, especially women's works, into English. Not being a native speaker of English, I initially did not try to produce metrical translations but followed the local preference for free verse. It is only in my recent Two Centuries of Manchu Women Poets (2017) that I did include a sizable number of metric renditions.

5 For a survey of Dutch studies in the Netherlands, see Idema 2014; for a detailed survey of China in Dutch literature, see Pos 2008.

6 Discussions of translations of poetry in English and Dutch are hampered by the absence of the German distinction between Nachdichtung and Übersetzung (translation that follows the source text, as distinct from creative rewriting). 
which no Chinese source can be identified. Here is the first stanza of the German poem, followed by my English translation:

Ein kahles Mädchen. Heckenblassentlaubt.

Sie steht am Weg. Ich gehe weit vorbei.

So stehen alle: Reih in Reih

Und Haupt an Haupt.

(Pos, Cheng, and Scheltens-Boerma 1993, 21)

A bald girl. A hedgerow wan without any leaves.

She stands by the side of the road. I pass her by.

So all of them stand there: row upon row,

And head upon head.

The best-known author of "Chinese poems" of this kind was the famous Dutch poet J. Slauerhoff (1898-1936), whose version turned the image completely around. This is Slauerhoff's rendition, followed by my translation into English:

Achter de hagen langs de straat

Staan zij in feestgewaad;

Geen schone kan mij nog wat schelen,

Zij mogen mijn soldij verdeelen!

(Pos, Cheng, and Scheltens-Boerma 1993, 21-23)

Behind the hedgerow by the side of the street

They stand in festive dress:

I don't give a damn about any beauty,

Let them divvy up my pay!

Most of Slauerhoff's adaptations were based on the English translations of Arthur Waley (1889-1966) (see Idema 2003). But Waley's renditions too were freely adapted by Slauerhoff, who turned the ambitious bureaucrat Bai Juyi 白居易 (772-846) into an alter ego of the alcoholic wanderer Li Bai 李白 (701-762), in whom Slauerhoff recognized much of himself. One example of this kind of rewriting is offered by Slauerhoff's adaptation of this translation by Waley of a poem by Bai Juyi:

“The poem on the wall” (駱口驛舊題詩)

Yüan Chên wrote that on his way to exile he had discovered a poem inscribed by Po Chü-i on the wall of the Lo-k'ou Inn 
My clumsy poem on the inn-wall none cared to see;

With bird-droppings and moss's growth the letters were blotched away. There came a guest with a heart so full, that though a page to the Throne, He did not grudge with his broidered coat to wipe off the dust, and read.

(Waley 1919, 46)

Slauerhoff's Dutch version reads as follows:

Ik heb een ruw gedicht op den herbergmuur gegrift.

Door vogelvuil en woek'rend mos half uitgewist.

Totdat een gast kwam: een die staat bij den Troon,

Hij veegde met zijn zijden mouw de steenen schoon

En las en weende, hij wist:

Po Tsju I is balling weer, verdreven door zijn drift.

(Pos, Cheng, and Scheltens-Boerma 1993, 86)

Slauerhoff's first four lines follow Waley's version quite closely, except that Slauerhoff's version rhymes. But the last two lines, which translate as "He read and wept: he knew / That Bai Juyi had been banished again, chased away by his own fury," are entirely of Slauerhoff's making.

Some Dutch poets of the Interbellum went so far as to produce volumes of "Chinese poems" of their own creation. When, several decades later, I started to produce my bare and unadorned direct translations of classical Chinese poetry, these would on occasion be criticized for their lack of Chinese flavor by Dutch critics. What they meant was, of course, that these translations disappointed them because of their lack of chinoiserie and of decadent romanticism in the manner of Slauerhoff.

By choosing to render Chinese poetry into metrical verse in my Dutch translations, I was going against the international trend at the time. Since the 1910s, when Arthur Waley started to publish his translations, English translators of Chinese verse had increasingly abandoned the use of rhyme and meter in their renditions. In my student days A. C. Graham (1919-1991) created quite a stir with the introduction of his Poems of the Late T'ang (1965), in which he stressed the primacy of the image in the translation of Chinese poetry. A few years later, in his article "A New Translation of a Chinese Poet: Li Ho" (1971), he repeated this argument, stressed the importance of maintaining the original word order, and blamed all the shortcomings he perceived in J. D. Frodsham's 1970 translation of the poems of Li He 李 賀 (790-816) on Frodsham's tendency to produce metrical versions. This emphasis on the image, laudable as it may be, has resulted in the relative 
neglect of almost all formal elements of classical Chinese poetry, and since then free verse - or lame prose, depending on the quality of the translator - has been by far the most popular vehicle for the translation of classical Chinese poetry in the Anglophone world.

\section{Purpose and difficulty}

Translators of Chinese poetry as a rule engage in their work because of their love of poetry, both in the source language and in the target language. Though haunted by Robert Frost's (in)famous dictum that "poetry is what gets lost in translation,"7 and only too aware of the impossibility of a perfect translation, they engage in the treasonous act of translation (as in the Italian "traduttore, traditore") because of the inherent pleasures it brings: finding the right word, phrasing a fitting sentence, and producing a version that at least to some extent approximates the original and reads well in the target language are a source of joy and gratification. Translators may of course stress the importance of their work in a global world (and rightly so), but I wonder how often that is their primary motivation. So far I have never encountered a translator of poetry whose primary motivation was financial. "Writing poetry brings me little profit" (Van dichten comt mi cleine bate), complained the unknown author of Beatrijs, a fourteenth-century Dutch legend in verse, and translating poetry is even less profitable. Poetry translators don't make good money at the expense of the poets they translate, whether dead or alive - as a rule, translators need other sources of income to make a living.

Still the purposes and audiences of their translations can vary a great deal, and this impacts the way one translates. In the words of Stephen Owen, "Translation is a craft that is contingent on its purpose, and the purpose is usually determined by the readers for whom it is intended" (2016, lxxxi). This is clearly demonstrated by the various English translations of the Book of Odes (Shijing 詩經; see Joseph Allen's essay in this volume). When the Hong Kong-based missionary James Legge (1815-1897) produced his translation of the Chinese Classics for the benefit of his fellow missionaries in China, he provided prose versions alongside the Chinese texts together with detailed annotations making ample use of Chinese characters. When the Swedish

7 Or, alternatively, "Poetry is that which is lost in translation." Both are misquotations of what Frost actually said: "I like to say, guardedly, that I could define poetry this way: it is that which is lost out of both prose and verse in translation" $(1959,7)$. 
sinologist and linguist Bernhard Karlgren (1889-1978) set out to reconstruct the original meaning of the Odes on the basis of the earliest preserved glosses, he too only provided rebarbative prose versions of these poems, for the enjoyment of his fellow philologists. When Legge produced a translation of the Book of Odes for a general audience back in Great Britain, being a good Victorian he produced a metrical, rhymed version, because contemporary readers expected poetry, whether in the original or translated, to be metrical and rhymed (as Legge often followed the metrical patterns of church hymns, his renditions of the poems in the Book of Odes are eminently singable, and as such a true Book of Songs). But when Arthur Waley published his English rendition of the Book of Odes, his translations were rhymeless, because by that time British and American poets were increasingly abandoning the use of rhyme. And while Waley tried to stay as close as possible to the source text, Ezra Pound (1885-1972) produced a highly idiosyncratic version that probably is best appreciated as an original creation. Much discussion of Pound's qualities as a translator could be considerably simplified if English, like German, could distinguish between Übersetzung 'translation' and Nachdichtung 'poetry composed after a source text'.

Since the 1950s, the United States have witnessed a third kind of audience for translations of classical Chinese poetry: the "captive audience" of undergraduate students who have signed up for classes in Chinese literature in translation. Such classes are rarely taught in European universities, where the lasting influence of their sinological tradition leads to an emphasis on reading texts in the original language, but they have been quite popular in the United States with its system of liberal education, allowing Departments of Chinese Language and Literature to reach out to a larger student body beyond those learning the language (initially only a very small number, in contrast to more recent decades). As these days the final destination of many translations for the general audience is that of prescribed reading for undergraduates (to the delight of our publishers), this is perhaps something many translators should take into account more consciously. After all, a typical freshman or sophomore can rarely be considered an experienced member of the general audience of poetry readers.

Some people like to stress the difficulty of classical Chinese poetry. But if one sees it as the translator's mission to translate the explicit message of the text in its own words and not necessarily its meaning, Chinese classical poetry is not all that difficult. Of course there are difficult poets and difficult poems, but they tend to be exceptions. But even in the case of notoriously difficult poems, such as "Brocade zither" (錦瑟) by Li Shangyin 李商隱 (813858 ), it is not the grammar or the allusions that trouble the translators, but 
the interpretation. Readers who are raised on classical Western poetry with its often highly rhetorical language and panoply of ancient gods and mythical characters are often positively struck by the simplicity and directness of Chinese classical poetry. Chinese classical poems tend to be short, and, as enjambment is rare if not non-existent in shi (詩) poems, lines are mostly end-stopped. Such lines of four, five, or seven syllables do not allow for the rhetorical contortions commonly found in classical Latin and Greek poetry, or Classicist poetry in the European vernaculars. It is not the fault of the ancient Chinese poets that speakers of Indo-European languages have to deal with conjugations and declensions, gender and number. The Chinese poets stick to the rules of their own grammar, and these are clear enough. When analyzing individual poems, Chinese critics then and now rarely feel a need to discuss individual lines in detail as regards grammar. Of course foreign readers may occasionally be baffled by the grammatical construction of individual lines (as they may by longer passages), but the more they read, the less that happens. Extensively annotated editions and numerous reference works are available to help them find their way through the minefields of rare expressions and obscure allusions. As younger Chinese know less and less of traditional Chinese culture, these annotations become more and more detailed. Translators may find themselves compelled to make choices to ensure grammatical usage in the target language, but that is a generic issue of translation, and not because Chinese poetry is "difficult" per se.

If Chinese poetry presents difficulties of understanding it is because it is the product of a different culture, but if the past is a foreign country, the Tang dynasty must be as alien to contemporary Chinese readers as to foreigners. The poetry of the past was written by different people, for different purposes, and for a different audience than Romantic and postRomantic poetry East and West, and as such it was written on different topics, used a different language, and employed other allusions than modern and contemporary poetry. I am afraid that this is what causes the greatest problems in translation. Many of us may agree that $\mathrm{Du} \mathrm{Fu}$ 杜甫 (712-770) is China's greatest poet, at least of the Tang dynasty. When introducing a selection of his poems to Western audiences, David Hawkes (1923-2009) commented as follows on his regulated poems $(1967,47)$ : "[Their] perfection of form lends [them] a classical grace which unfortunately cannot be communicated in translation. That is the reason why $\mathrm{Du} \mathrm{Fu}$, one of the great masters of the form, makes so comparatively poor a showing in foreign languages." When Stephen Owen (2016, lxxxi) modestly describes his fine translations of the complete works of $\mathrm{Du} F u$, the result of a lifetime of study and experience in translation and published in a bilingual edition, as only 
"a crib" for "those who have some level of Chinese, but whose Chinese is not up to reading Du Fu" (in the original, without assistance), that statement may well be informed by the same thought. But even more of an issue may be the fact that $\mathrm{Du} F u$ is also very much a Confucian poet, deeply frustrated by his inability to contribute to the ordering of the realm as an official in the imperial bureaucracy. And while it may be relatively easy to find the right words for the translations of his feelings of homesickness during his years of wandering, I found it very hard when working on a small Dutch anthology of Du Fu to find fitting expressions in my native language for the rendition of his repeatedly expressed fervent desire to serve the emperor and the realm (Idema 1989). That difficulty was further compounded by the fact that I wanted to avoid words with overly obvious Christian connotations in translating Du Fu's Confucian values and sentiments. ${ }^{8}$

Of course it is often difficult to ascertain the meaning of an individual poem, but then the search for single correct interpretations is doomed anyway. I also believe that the translator has a task in enabling the reader to explore the various possible meanings of the poems presented in translation. By the choices the translator unavoidably makes, he or she is already very much present in the translation, but to the extent possible he or she should not impose his or her own interpretation. Granted, because the translator often is the first to present the poet of his or her choice to a foreign audience, he or she also has to be a critic. But for that aspect of our activities, I believe, we have prefaces and introductions, postfaces and annotations.

8 “On the River" (江上; Owen 2016, vol. 4, 195-196), a regulated poem from Du Fu's years near the end of his life in Kuizhou, may serve as an example. After the first four lines have evoked the desolate autumn scenery of Kuizhou with its endless rain and barren trees, the poet continues with four lines that in a very literal rendition might read: "Merits and legacy? I often look in the mirror; / Service or retirement - Alone I lean on the tower['s balustrade/window.] / The times are perilous, I long to repay the lord: / Weakened and wilted I cannot let go (勳業頻看鏡 / 行 藏獨倚樓 / 時危思報主 / 衰謝不能休). The language is so simple that a modern, annotated edition of Du Fu does not provide any annotations for this poem (Wang Shijing 1999, 633). Now repay may be a fine translation of 報, but to me it smacks too much of a circumscribed financial transaction, and there is no way in which a person can ever fully repay the boundless grace of the Son of Heaven. Therefore, in my Dutch translation I opted for dienen 'to serve'. I would have liked to write "mijn Heer te dienen" (to serve my Lord) to bring out the nature of official service as the highest calling for a Confucian gentleman, but I toned my translation down to "mijn vorst te dienen" (to serve my king), which still shows Du Fu as a good patriot but makes the sentiment of the last couplet somewhat trite. The final Dutch translation reads: "Mijn daden? Dikwijls kijk ik in de spiegel. / De keuze - eenzaam leun ik uit het venster. / De lust om in de nood mijn vorst te dienen / Kan ik, ook oud en zwak, nog niet bedwingen" (Idema 1989, 118). When I reused this translation in a later publication $(1991,327)$, I changed "vorst" to "Vorst," with the uppercase $V$ suggesting that to $\mathrm{Du} \mathrm{Fu}$ the Chinese ruler may not be God, but is still the Son of Heaven. 
How much annotation one should provide will remain a topic of contention. By way of an example, in my opinion, the regulated poem by Han Shan which I introduced earlier can stand very well on its own and doesn't need much explanation. Chinese cuisine is nowadays sufficiently well known outside China that most readers will know that pork is its meat of choice, and Peking roast duck and its regional variants have established a worldwide reputation. The "minced fish" or "slices of fish" may be an allusion to the story of Xue Wei 薛偉, who as a lover of fish was turned into a fish in a dream, caught, and about to be served to his friends; and when he cried out to his friends for help when the chef prepared to slice him, they could see his mouth move but did not hear his pleas (see the story by Li Fuyan 李復 言 in Kao 1985, 266-270). But again, with the spreading popularity of sushi and sashimi, many non-Japanese have seen a Japanese chef wield his blade. In the following line, the expression "meaty cheeks" (肉臉) has perplexed interpreters, but I think the two characters mean exactly what they say. ${ }^{9}$ The use of "cheeks" is striking here because in poetry cheeks usually are the rosy cheeks of pretty girls, and not the pig cheeks prepared as a delicacy. But once one realizes the suggestion of the human in the word "cheeks," one may of course wonder whether the poet was already alluding to the kind of stories we know from later imperial times in which a convinced butcher abandons his trade on the spot when he realizes that the pig he is about to slaughter is his reincarnated parent (see Grant and Idema 2011, 124-135). And perhaps in the Dutch translation, "varkenswangen" will remind some readers of the frequent use of pigs in vivisection.

I must confess that I am not a fan of footnotes, even though I have not been able to avoid them completely. In my A Mirror of Classical Chinese Poetry from the Book of Odes to the Qing Dynasty (Spiegel van de klassieke Chinese poëzie van het Boek der Oden tot de Qing dynastie, 1991) I privilege poems that need little or no annotation, also because a translation that relies on annotation reads like a joke that has to be explained. One strategy I have applied from time to time is clarification through more translations. If I wanted to include a poem that made allusions to another poem, I would include that too, hoping the reader would catch the allusions by themselves. But this is tricky and increases the bulk, and the poem alluded to may not be a good poem at all. I also privilege longer poems which create their own atmosphere, suggesting an understanding of the images they contain. But whatever the translator will do, it will never be enough to recreate the original context of the poem, in which the poem functioned and was understood "by itself." 


\section{Rhyme and parallelism}

As long as the translator's aim is to provide cribs for reading the poem in its original language, he or she does not need to be overly concerned about the formal features of the works he or she translates. But if one aims for a general audience that is unable to read the originals, one has to take up the challenge of presenting the translations as poetry. Despite Graham's arguments of more than forty years ago, few classical Chinese poems can survive translation on the strength of their images alone. The fact of the matter is that only a few Chinese poets were as original as Li Shangyin and Li He in their use of imagery, and in their works too, these images further gain from the formal constraints of the poem. Li He and Li Shangyin belonged to generations that deliberately aimed for novelty or even strangeness (奇) in their diction, but in general the emphasis would appear rather to have been on the expression of the appropriate emotion. Much of classical Chinese poetry was social poetry, ruled by strict rules of decorum. Many fine poems achieve their quality not by the originality of their images, pace Graham, but by their skillful variation in the use of common imagery. As one commentator has remarked (I forget who and where), Chinese poets may be compared to jazz musicians as their poems all too often are variations on given themes.

Every translator has to choose which formal elements of the original poem to retain. In a way, the Victorian translators took the easy way out. For the sake of meter and rhyme in their own language they sacrificed almost all aspects of the original Chinese poem, except for an often vague correspondence in content. ${ }^{10}$ Arthur Waley, as mentioned before, broke with that practice: abandoning rhyme and adopting "sprung rhythm" he could often reproduce the word order of the original. Waley's sprung rhythm works out better for five-syllable lines than for seven-syllable lines; in my opinion, the latter are often indistinguishable from prose in his renditions. ${ }^{11} \mathrm{James} \mathrm{J}$. Y. Liu, who in his pioneering The Art of Chinese Poetry (1962) had included rhymed translations that faithfully followed the original rhyme patterns, later abandoned rhyme in his translations as he had come to realize "the virtual impossibility of keeping the rhymes without damage to the meaning" (quoted in Frankel 1984, 308). ${ }^{12}$ Following Graham's criticism of Frodsham's

\footnotetext{
10 Edward H. Schafer, otherwise known as a quite barbarizing translator of Chinese poetry, once provided multiple translations of a single Chinese poem in different period styles of English poetry (1963).

11 For a recent discussion of Arthur Waley as a translator, see Raft 2012.

12 The most successful examples of rhymed translations of Chinese poems from the second half of the twentieth century may well be David Hawkes's renditions of the poems in his translation
} 
translation of Li He, many translators have since abandoned any attempt to maintain a metrical equivalence between the lines in the Chinese poem and in their translation. ${ }^{13}$

Chinese readers of English translations of Chinese classical poetry are often disappointed by the lack of rhyme in these translations, and in recent decades several Chinese translators of classical Chinese poetry have produced rhyming translations. Unavoidably, they run into the same issues as foreign translators of classical Chinese poetry, having to sacrifice almost every other formal element for the sake of rhyme, and often to adapt the content to the available rhymes. The diction in such translations is often trite. Nor do they always seem to be aware that in English, rhyme works in conjunction with meter and rhyme without meter easily results in doggerel. I find their insistence on the use of rhyme puzzling. True enough, all genres of classical Chinese poetry rhyme in one way or another, but so do some genres that are classified as "prose" in China, for instance the "rhapsody" (賦). So rhyme cannot be counted as a distinctive characteristic of poetry in China. Moreover, if the sound of the rhyme were so important to Chinese readers, one would expect them to read poetry in the pronunciation of the time of its composition, but that is not the case. Since the Tang dynasty, the “entering tone" (入聲) has disappeared from the standard language, and many words have changed their tone and sound. Even during the Tang, rhyme categories were to a certain degree artificial constructs. Some dialects claim relative proximity to Tang-era pronunciation, and some maintain at least most of the tonal distinctions of that period, but no one proposes to make these dialects the standard for reading and reciting Tang poetry. Last but not least, traditional Chinese critics rarely if ever discuss the use of rhyme of the poems they analyze - apparently, its formal perfection is taken for granted.

These critics can assume formal perfection because rhyming is relatively easy in Chinese. The number of rhyme sounds is limited, and many rhyme categories are "broad," containing hundreds of words. Even the so-called "narrow" rhyming categories contain dozens of words. Because rhyming is easy, there rarely is a special emphasis on the rhyming word. The most important word in a line of verse rarely is the rhyming word; the "eye" (眼) of a verse is usually found elsewhere in the line. Chinese poets can maintain, if

of the first eighty chapters of the eighteenth-century Story of the Stone (石頭記 or 紅樓夢) by Cao Xueqin 曹雪芹. See Hawkes and Minford 1973-1986.

13 Attempts to translate classical Chinese poetry in lines of the same number of syllables as in the original have been few and far from successful. 
they wish, the same rhyme for dozens and scores of lines, and occasionally one comes across poems in which the poet uses as many as possible of the words from a given rhyme category without a single repetition. In Germanic languages, however, many rhyme sounds have a limited number of rhyming words, so using a specific word in rhyming position usually creates strong expectations about the possible rhymes in the subsequent lines. Multiply repeated rhyme is often experienced as contrived and boring, precisely because rhyming is much more "present" in poetry in Germanic languages than in Chinese poetry. Most translators who use rhyme in their English renditions of classical Chinese poetry silently acknowledge the limitations of rhyme in that language: even when rhyming they rarely make an effort to reproduce the rhyming patterns of the source language.

Whereas traditional Chinese critics devote little attention to rhyme, they are fascinated by the well-crafted couplet. Of course they also discuss individual lines, but it would seem that the parallel couplet is even more important in their eyes. This fascination with the parallel couplet is of course not limited to poetry: parallelism is encountered in all genres of Chinese writing, and has even engendered its own genre as free-standing couplets (對聯). Couplets are encountered as inscriptions on buildings and are displayed at all manner of events, and in traditional education students were trained from early on in the composition of increasingly complex parallel lines. Whereas in the West one finds stories about words for which no one has ever come up with a fitting rhyme word (until someone finally does), there are many anecdotes in China about difficult lines for which no one had ever been able to come up with a matching line (until a child prodigy does). The characteristics of classical Chinese greatly facilitate the composition of parallel couplets, which has doubtless enhanced their popularity, but I believe that the composition of parallel lines is more than an erudite skill and playful competition. In traditional Chinese cosmology the world is made up of contrasting and competing but also synergetic forces and elements, and just as abstract concepts are often created by naming two representative but different members of a group, the author of a couplet tries to grasp the totality of a scene or an emotion by contrasting its most conspicuous elements. In parallel couplets it is not the single image that counts, but the paired image. One of the most important genres of classical Chinese poetry since the Tang has been the eight-line "regulated poem," of which the two inner couplets have to be parallel. Yet the majority of translators of classical Chinese poetry East and West have treated parallel couplets in a cavalier fashion - and indeed often deliberately broken up the parallelism. Hans Frankel, otherwise a 
sensitive reader of classical Chinese poetry, commented as follows in his survey of the ways in which translators had dealt with the formal features of classical Chinese poetry:

Parallelism and antithesis are significant features in classical Chinese poetry, and they are occasionally employed in English poetry. But a long series of end-stopped lines and too much precise parallelism tends to sound bad in English. Therefore some of the best translators deliberately break up the parallelism of Chinese couplets.

$(1984,318)$

Even the translators who are said by Frankel to "skillfully preserve syntactic and semantic parallelism" rarely achieve the precision of their source texts. In Graham's discussion of the problems in translating Tang-dynasty verse one may observe the same reserve towards the parallel couplet: "It is clear that in English strict parallelism without repeating a word is nearly impossible, while parallelism involving repetition will quickly seem rigid and monotonous" $(1965,27)$.

Let's have one more look at the poem by Han Shan we discussed earlier. Let me first refresh your memory by quoting two more English translations by experienced translators. Red Pine offers the following rendition:

The unfortunate human disorder

a palate that never wearies

of steamed baby pig in garlic

of roast duck with pepper and salt

of deboned raw fish mince

of unskinned fried pork cheek

unaware of the bitterness of others' lives

as long as their own are sweet.

$(2000,173)$

And Paul Rouzer translates:

A pity, this sickness in human beings:

In eating, nearly insatiable.

Steamed piglets, soaked in garlic sauce,

Roast duck with salted peppers,

Fresh minced fish, their bones removed,

Broth of meat simmered with its skin. 
They don't know the sufferings of other living things,

Only choose the sweetness for themselves.

$(2016,220-221)$

As a regulated poem, its second and third couplet consist of parallel lines. But the rules for regulated poems don't stop there. Whereas the tonal contrasts inside the third couplet should replicate the tonal contrasts of the second, ${ }^{14}$ the grammar of 11.5 -6 should not replicate that of $11.3-4$. As a quite conventional poet in formal matters, Han Shan's ll. 3-4 each consist of two verbal phrases, whereas 11.5 -6 consist, in my reading, of nominal phrases with strongly emphasized caesuras following the second syllable. None of the three English translations quoted above attempts to reproduce the parallelism within the couplets, and none highlights the different grammatical structure of the second couplet and the third. Henricks comes close, but in the second couplet "garlic sauce" is matched by "pepper and salt." If a given position in the second line of a couplet has two things, the corresponding position of the first line should presumably also have two, and I suppose the poet intended "garlic and soy sauce" as the relevant cooking ingredients. ${ }^{15}$ Rouzer's "garlic sauce" is at least paralleled by "salted peppers" (which may be questionable as a translation), but whereas he has his piglets "soaked" in garlic sauce, no verb precedes his "salted peppers." Red Pine simply omits the sauce. Perhaps even more remarkable is that both Red Pine and Rouzer turn 1l. 3-6 into nominal phrases, deemphasizing the difference in grammatical structure between the second and third couplets.

That the internal couplets of a regulated poem have a paratactic structure does not mean there is no logical progression. In Han Shan's poem we move from a pig prepared with homegrown condiments to a duck prepared with spices and expensive salt. The removal of bones may suggest the extreme care with which the fish is prepared but the same line may hint at the fear of being eaten oneself. If the skin is left on, ${ }^{16}$ the diners are no better than wild

14 The rules for tonal contrast in new-style poetry (近體詩) were developed and perfected over the course of the fifth and sixth centuries, once the Chinese had become aware of the tonal nature of their own language through contrast with the prosody and chanting practices of Sanskrit and Prakrit, where prosody is based on the patterning of long and short vowels. See Mair and Mei 1991. 15 The dishes are not prepared in the simplest manner with only one spice but with several, in order to appeal to the demanding taste of gluttons.

16 In the spirit of the nitpicking I am engaging in here, I should also criticize my own rendition of 兼皮 as “met huid en haar" 'with hide and hair', which adds bristles to the skin and is not perfectly parallel to "ontdaan van graat" 'with bones removed'. I simply could not resist the temptation of this set phrase in Dutch. To achieve better parallelism, "nog met het vel" 'still with the skin' would have been preferable. 
animals devouring their prey - they may well be cannibals devouring their parents. The final couplet presents the conclusion; while it may have the form of a parallel couplet, the two lines often have a hypotactic structure. It is somewhat surprising that the three English translators stick to parataxis, presumably in an effort to bring out the contrast between the final words of the lines, "bitter/bitterness/suffering" (苦) and “sweet/sweetness/pleasant" (甜). But once one renders 苦 here idiomatically as "sufferings," as Rouzer does, one may of course also choose a more idiomatic rendering of the last line. Henricks's "sweetness of their own homes" goes off in the wrong direction because of a misunderstanding of the vernacular expression "self, oneself" (自家). Red Pine and Rouzer's translations seem to hint at a generally pleasant existence, losing the link to food. The final couplet of my Dutch version would translate into English as "They happily have other beings suffer / in order to please only their own palate."

The reluctance to do full justice to the frequent use of parallelism in Chinese classical poetry on the part of many translators is usually defended with an appeal to the characteristics of Germanic languages like English and the limited occurrence of precise parallelism in Western literature. More often, I fear, the sloppy treatment of parallelism in translation stems from a prejudice on the part of modern readers against parallelism as outmoded wordplay. But if the parallel couplet is such an essential aspect of Chinese poetry, translators have to try harder. Bai Juyi may be known for the deliberate simplicity of his style, but he also wrote a number of long regulated poems (排律) in which he displayed his magisterial virtuosity in crafting parallel couplets, and when working on my Dutch anthology of his works (2001), I felt a duty to include some of these poems in order to display the variety of his poetry. I can only say that I personally derived great pleasure from turning these poems into Dutch as precisely as possible, and I hope that some of my readers will have enjoyed seeing the author vary his syntactical patterns from couplet to couplet. Form matters, and if some aspects are impossible to reproduce in translation and others only at great cost, that is all the more reason to care especially about those aspects that it is actually possible to retain or represent.

\section{Skills and talent}

Literary translation as a craft requires numerous skills. The first of these is a sound knowledge of the source language and of the culture in which the author of the original flourished. This also implies extensive knowledge 
of the various editions of the poet's works and other relevant reference works. Secondly, literary translation requires true mastery of the target language, which results in the rule of thumb that translations are most likely to succeed when done by a native speaker. Thirdly, and most importantly, it requires the willingness to use these skills in the service of the poetry to be translated. Few translators fully combine these three qualities in their person. I certainly don't. And as if these three requirements were not enough, on top of all this literary translation also requires talent. Nor do skills plus talent guarantee that a translation will be successful and find a ready audience. For the committed translator of poetry, however, that disappointment pales alongside the frustration at the inability to find the perfect word.

\section{Works cited}

Frankel, Hans H. 1984. "English Translations of Classical Chinese Poetry Since the 1950s: Problems and Achievements." Tamkang Review 15: 307-328.

Frodsham, J. D., trans. 1970. The Poems of Li Ho (791-817). The Oxford Library of East Asian Literatures. Oxford: Clarendon Press.

Frost, Robert. 1959. Conversations on the Craft of Poetry, edited by Cleanth Brooks and Robert Penn Warren. New York: Holt, Rinehart and Winston.

Graham, A. C. 1965. Poems of the Late T'ang. London: Penguin.

- 1971. “A New Translation of a Chinese Poet: Li Ho 李賀.” Bulletin of the School of Oriental and African Studies, University of London 34 (3): 560-570.

Grant, Beata, and Wilt L. Idema, trans. 2011. Escape from Blood Pond Hell: The Tales of Mulian and Woman Huang. Seattle: University of Washington Press.

Hawkes, David. 1967. A Little Primer of Tu Fu. Oxford: Clarendon Press.

Hawkes, David, and John Minford, trans. 1973-1986. The Story of the Stone. London: Penguin.

Henricks, Robert G., ed. and trans. 1990. Han Shan 寒山. The Poetry of Han-Shan: A Complete, Annotated Translation of Cold Mountain. Albany: SUNY Press.

Idema, Wilt L., ed. and trans. 1977. Han Shan 寒山. Gedichten van de Koude Berg [Poems of Cold Mountain]. Amsterdam: De Arbeiderspers.

一, ed. and trans. 1989. Du Fu 杜甫. Deverweesde boot: klassieke Chinese gedichten [The orphaned boat: classical Chinese poetry]. Amsterdam: Meulenhoff.

—, ed. 1991. Spiegel van de klassieke Chinese poëzie van het Boek der Oden tot de Qing dynastie [Mirror of classical Chinese poetry from the Book of Odes to the Qing dynasty]. Amsterdam: Meulenhoff.

一, ed. and trans. 2001. Bai Juyi 白居易. Gedichten en proza [Poems and Prose]. Amsterdam: Atlas. 
-. 2003. "Dutch Translations of Classical Chinese Literature: Against a Tradition of Retranslation." In One into Many: Translation and the Dissemination of Classical Chinese Literature, edited by Tak-hung Leo Chan, 213-242. Approaches to Translation Studies 18. Amsterdam: Rodopi.

—, ed. 2014. Chinese Studies in the Netherlands: Past, Present and Future. Leiden: Brill.

—, ed. and trans. 2017. Two Centuries of Manchu Women Poets: An Anthology. Seattle: University of Washington Press.

Kao, Karl S. Y. 1985. Classical Chinese Tales of the Supernatural and the Fantastic: Selections from the Third to the Tenth Century. Chinese Literature in Translation. Bloomington: Indiana University Press.

Liu, James J. Y. 1962. The Art of Chinese Poetry. Chicago: The University of Chicago Press.

Mair, Victor and Tsu-Lin Mei. 1991. "The Sanskrit Origins of Recent Style Prosody.” Harvard Journal of Asiatic Studies $5^{1}$ (2): 375-470.

Owen, Stephen, trans. 2016. The Poetry of Du Fu. Berlin: De Gruyter.

Perry, Bliss. 1920. A Study of Poetry. Boston: Houghton Mifflin.

Pos, Arie. 2008. "Het Paviljoen van Porselein: Nederlandse Literaire Chinoiserie en het Westerse Beeld van China (1250-2007)" [The Porcelain Pavilion: Dutch literary chinoiserie and the Western image of China (1250-2007)]. PhD dissertation, Leiden University.

Pos, Arie, Shaogang Cheng, and Nanneke Scheltens-Boerma, eds. 1993. Dronken in de Lente: De Chinese gedichten van J. Slauerhoff [Drunk in spring: the Chinese poetry of J. Slauerhoff]. Leiden: Barabinsk.

Raft, Zeb. 2012. "The Limits of Translation: Method in Arthur Waley's Translations of Chinese Poetry." Asia Major 25 (2): 79-128.

Red Pine (Bill Porter), trans. 20oo. Han Shan 寒山. The Collected Songs of Cold Mountain. Port Townsend: Copper Canyon Press.

Rouzer, Paul F., trans. 2016. Han Shan 寒山. The Poetry ofHanshan (Cold Mountain), Shide, and Fenggan. Berlin: De Gruyter.

Schafer, Edward H. 1963. "Mineral Imagery in the Paradise Poems of Kuan-Hsiu." Asia Major 10: 73-102.

Waley, Arthur, trans. 1919. More Translations from the Chinese. New York: Knopf. Wang Shijing 王士菁. 1999. 《杜诗今注》 [Du Fu's poetry annotated for the present day]. Chengdu: Ba Shu shushe.

Wen Yiduo 聞一多. 1996. "Form in Poetry." In Modern Chinese Literary Thought: Writings on Literature, 1893-1945, edited by Kirk Denton, translated by Randy Trumbull, 318-327. Stanford: Stanford University Press. 


\section{About the author}

Wilt L. IDEMA studied sinology in Leiden, Sapporo, Kyoto, and Hong Kong, and taught at Leiden University from 1970 to 1999 and at Harvard University from 2000 to 2013 . He has published widely on vernacular traditions in Chinese literature of the period 900-19oo and late-imperial Chinese women's poetry. For his Dutch translations of classical Chinese poetry, especially his 1991 Mirror of Classical Chinese Poetry from the Book of Odes to the Qing Dynasty (Spiegel van de Klassieke Chinese poëzie van het Boek der Oden tot de Qing-dynastie [Meulenhoff]), he received the 1992 Martinus Nijhoff Award. His recent publications include Two Centuries of Manchu Women Poets: An Anthology (University of Washington Press, 2017), Mouse vs. Cat in Chinese Literature: Tales and Commentary (University of Washington Press, 2019), and Insects in Chinese Literature: A Study and Anthology (Cambria Press, 2019). 



\section{Part Two}

Theoretics 



\title{
5 Embodiment in the Translation of Chinese Poetry
}

\author{
Nick Admussen
}

\begin{abstract}
This essay advocates for the concept of embodiment in the translation of (Chinese) poetry to challenge what the author calls the equivalence icosis, founded on dated yet dominant assumptions of objective method and the clean interoperability of different languages. Looking at Jennifer Feeley's translations of Xi Xi, Austin Woerner's of Ouyang Jianghe, and Ming Di and Jennifer Stern's of Liu Xia, the argument conjoins embodiment with present-day manifestations of poetry's transmedial and political potential.
\end{abstract}

Keywords: Chinese poetry, translation, embodiment, icosis, equivalence, digital turn, media studies

\section{Equivalence}

Much of translation theory, both with regard to Chinese poetry and in the larger field, has long moved away from the structuring narrative that translations are transpositions between interchangeable languages, that translators can or should be transparent, and that there is a particular method of translation that is objectively preferable to all others. Already in 1995, Lydia Liu could confidently say that "the idea that languages are commensurate and equivalents exist naturally between them is, of course, a common illusion that philosophers, linguists, and theorists of translation have tried in vain to dispel" (3). That illusion seems to persist today under the influence of the habits of translators, the expectations of readers, and the power of institutional structures that remain invested in a small number of overlapping ideas concerning cultural unity and linguistic interoperability. This essay will attempt to reconceptualize these three influences as

Van Crevel, Maghiel and Lucas Klein (eds.), Chinese Poetry and Translation: Rights and Wrongs. Amsterdam: Amsterdam University Press, 2019

DOI: 10.5117/9789462989948_CHO5 
outcomes of a long effort to construct a globalized and translingual poetics, and set them against new and continuing efforts to engage in embodied translation, a set of practices that emphasize performances over texts, bodies over essences, and ethics over epistemes.

Lucas Klein follows Lydia Liu by arguing that modern Chinese, in contradistinction to classical or literary Chinese, participates in an "international economy of the super-sign," a relatively stable relationship with other languages arising from a shared economic and social order $(2017,12,14)$. Between modern languages like Chinese and English, Klein argues, poetry can be translated more directly and with greater transparency, involving what he calls "weak interpretation" (10-20). In part, he says, this is because of the construction of "conventions and norms becoming taken for granted" (37). The passive voice in "taken for granted," however, deemphasizes the immense, concerted effort it takes to construct and propagate the conventions and norms of modern language, and allows the power politics of the undertaking to remain implicit. Norms that feel "congealed" and "naturalized" (37) were made so by the labor of translators with a particular set of ideological practices and goals in a process that we now often euphemize as "globalization" (Robinson 2014, 51). Rather than seeing the conventions of the super-sign as inert, already-produced tools, Liu's original formulation of the concept was a critique of what she calls a "linguistic monstrosity" (2004, 13), a hidden colonization of terms by distant powers that represents an imperial struggle over the power of signification.

The underlying ideologies that have motivated the production of naturalized norms in translation have changed over time. What makes the norms powerful is not the strength of their ideology but the way in which various ideologies can share the benefits of a consensus about linguistic equivalence. Klein does not endorse the globalization he observes: he simply believes it has shrunk the distance between modern languages in a way that should make translations more measurably equivalent to source texts. He quotes Eliot Weinberger: "A translation is based on the dissolution of the self. A bad translation is the insistent voice of the translator" (2017, 17-18). Almost a hundred years ago today, from a different ideological underpinning, Walter Benjamin made the argument that "the tremendous and only capacity of translation" is to "regain pure language fully formed in the linguistic flux" $(1988,80)$, and use the differences between languages to pierce through to an underlying, transcendent stratum. During this process, the specificity, instrumentality, and necessity of extant languages fades; the resulting translation is not an interpretation of an original text by a translator, but a pair of texts that are twinned by their common relationship to an underlying 
system, and are best printed in parallel, so that readers can most directly read the equivalence between source and translation. Even though Benjamin's "quietly mystical" (Yao 2002, 2) belief in pure language is not common in contemporary translation studies, the parallel printing of texts that it advocates is surely valorized by the norms of contemporary translators, including Klein.

Belief in equivalence, as well as subscription to the value of equivalence in translation, is on constant display in the texts and paratexts of the translation of contemporary Chinese poetry. Praising Steven Bradbury's translation of Hsia Yü, Rajiv Mohabir writes: "Preserving or transposing the sonorous quality of Taiwanese Chinese into English, Bradbury realizes [Hsia] Yü's extraordinary wordplay" (2015). Mohabir is not a speaker of what he calls "Taiwanese Chinese" - one sees in the unsure moment of "preserving or transposing" the belief that whether the music is directly recognizable from the original or has been reproduced with difference, there must be some structure of equivalence at play. The sentence also reaches towards the substrate in a palpably Benjaminian way: even if the Chinese sounds have not been reproduced in English, the "sonorous quality" has. From a different ideological standpoint, Matt Turner criticizes Austin Woerner's translation of Ouyang Jianghe's 欧阳江河 “Notes toward a Fiction of the Market Economy" for privileging audiences over the "artifact" of the poem, writing that "even when all we have to read is 'the poem itself,' whether or not one can read the original text, the reading subject is interpellated by the same ideological actors which informed the artifact" (2016). Turner's position extends Klein's observation that globalization has created a shared experience from which translational equivalence can be drawn by arguing that in this case, it should be drawn.

As a translator myself, I also participate in tropes of equivalence. My essay "Errata" insists that a line of my translation is in error even though the poet and a professor of translation both argue otherwise (2017b). I felt that the line was in error because, in the words of the poet Ya Shi 哑石, my translated line "appears to conflict with the surface of the original text": it is not traceable or defensible via a one-to-one relationship with the source poem. For this reason, even though my version has its own representational and affective rewards, and Ya Shi prefers it to other options, the translation still presents itself to me as a

1 To this listener, Hsia Yü has the ability to emphasize, suppress, or alter the regional accent of her Mandarin Chinese, and her lexical choices are similarly flexible. Any commentary should also take into account the French and English in the collection, as in "She sleeps as deeply as a pair of sabot" (Hsia 2014, no. 40). 
mistake. I feel that my readers generally see interlingual equivalence as a good thing, and irreducible interlingual difference as unfinished work. I may have my own feelings about the attitudes of this audience - "Errata" is largely about the origins and value of what is not equivalent in a poetry translation - but my assessment of the audience's expectation remains quite stable and simple. Mohabir likes a translation and speaks his appreciation in terms of equivalence; Turner dislikes a translation and asks for more equivalence; when I translated a poem in an unequivalent way, I had the impulse to make a public apology.

Following Douglas Robinson, I interpret the habitual discourse around interlingual equivalence as a particular kind of icosis, which he defines as a "regulatory circulation" of "evaluative affects," a constantly refreshing method of judgment that rewards certain normative behaviors and normative beliefs $(2013,298 ; 2014,51)$. Robinson coined the word "icosis" from the Greek term eikos (zixós) 'plausible', and means it to represent the system of intellectual and institutional habits by which we determine whether or not a translation is plausible $(2014,42)$. An icosis is not conceptually stable, and it needs no particular philosophy. I suspect that some editors of translation presses or journals, when reading Jenn Marie Nunes's translations of Yu Xiuhua 余秀华 in this volume, would be unable or unwilling to say that they were bad work, or that the translator didn't understand the source texts, or that the translations weren't enjoyable to read; they would instead say something like "this isn't the kind of thing we do," that the work violates a sense of category, a sense of belonging that determines what counts as translation in the first place. Maghiel van Crevel points out the strength with which some theorists and translators resist the use of translation as a metaphor for certain kinds of cultural activity, and glosses that resistance as an insistence on the "real deal" of "interlingual (literary) textual operation" (2017a, 248-249). I submit that the source of this position is not a theory of "real" translation but a sense of it that arises from group habitus. Moving forward, I will call this the "equivalence icosis," the group feeling that translations are, can only be, or should exclusively be built from linguistic equivalence, and the more direct, the better. ${ }^{2}$

Whether or not it is politically or aesthetically desirable, identifying the equivalence icosis does not make it disappear or even diminish its current popularity. Seeing it as a consensus shaped by economic, political, and cultural contexts instead helps scholars and translators react flexibly when

2 Van Crevel's assessment that resistance to alternate definitions of translation comes from a sense of "ownership" (249) is a good reminder that mastering an icosis has institutional, social, and economic rewards. To many scholars and translators, they are well worth "owning." 
those contexts change. The regulatory habits of the equivalence icosis have created a functional system: dictionary work, the retention of word order, the preference for grammatical similarity between source and target, and the authority of demonstrable commensurability as part of a shared habit based on a feeling of plausibility all work together to educate audiences, marshal resources, and incentivize intercultural study and reading, among other positive effects. Concretely, a translation that can be traced to a dictionary and matches noun for noun, verb for verb, sentence for sentence can be safely marketed to monolingual audiences as an authentic translation. Such a translation can be funded and taught by institutions and defended by invoking the discourse of equivalence as this is visible in the translation's trail of documentation and justification.

However, when we understand the discourse of equivalence not as a superior translation ideology but as one possible way - that is currently widely accepted - to organize and interrelate writers, translators, critics, institutions, and readers, this creates the space for imagining alternative icoses, new habits by which to engage with translations that frustrate expectations of equivalence. These translations already exist; by surveying them, what this essay means to do is think through some regulatory and categorical perspectives by which non-equivalent work can be identified, assessed, and ultimately, valorized. Implicit in this project is the fear that the equivalence icosis in some cases reinforces globalizing processes that ignore or suppress the specificities of non-imperial languages, the writing of alterity and the alterity of writing, and the importance of contexts to texts. 3 After all, to use the international order of the super-sign is to strengthen the international order of the super-sign. What other orders are possible?

\section{Embodiment}

If the equivalence icosis can make the translator transparent, encourage "weak interpretation," and look past or behind extant languages in search

3 I realized at the workshop in Leiden that I have been working on these questions for several years. In 2014 I wrote a review of Eric Hayot's On Literary Worlds that suggested that every literary world is comprised in part of the reader's sense of its authorship, i.e. its context; in 2016 I outlined how Bing Xin's 冰心 translations of Tagore used concepts of "faithfulness" to suppress his biblical language, turning a meaningfully anti-modern poetics into modern prose poetry. My contribution to the 2017 Journal of Modern Literature in Chinese special issue on Chinese poetry and translation described the way in which international poetry festivals foreground the performance of translators, and advocated that festivals add translations into local vernaculars and dialects. 
of a "pure" language, then a reasonable alternative should insist on the presence of the translator, put reperformance in the place of interpretation, and focus on the bodily sensuality of both spoken and written language. The Bible translator Henri Meschonnic begins his work of translation theory not with epistemology - how we can know a work in one language through another - but with ethics. Without an ethics of translation, he says, "a typical blur appears ... this generalized essentialization of language, of poetry, of germanity that put the whole of translating into understanding" $(2011,35)$. In the place of this generalized blur, Meschonnic advocates for a kind of translation that is constantly responsible to the movement of human bodies, one that begins in rhythm and sound and ends in the politics of intersubjectivity. Language, he says, does not reside in the sign or the system of signs: rather, "the sense of language implies the sense of rhythm, the sense of body-in-language continuum" $(2011,66)$. Accordingly, the poem is not simply a document to be decoded and explained, it is "the transformation of a form of language by a form of life and the transformation of a form of life by a form of language" $(2011,68)$. The poet moves their mouth, their hands, and something happens in language; the listener perceives that language with their body and it affects them thus. Translation of poetry should therefore create "discourse equivalences in the target language: prosody for prosody, metaphor for metaphor, pun for pun, rhythm for rhythm" (2011, 71). The interpretation of signs falls by the wayside as "it is what a text does that must be translated; more than its meaning, its power, its affect" (2011, 69).

This embodied approach to poetry translation is, it must be said, just as utopian and transcendental as Benjamin's search for a pure language. Robinson points out Meschonnic's evasion of the question of the subjectivity of the translator $(2014,43)$, and his resort to mystical ideas of poetry that draw together the translation and its source text. Ultimately, the idea that a word can be spoken that will reliably or predictably transform a body is a tenet of faith, not a truth to be embraced to the exclusion of other possibilities. The value of Meschonnic's ideas arises instead from the variety of extant translation practices that are situated, justified, and encouraged by his desire to see translation as an equivalence not of words or languages, but of movements performed by and inside bodies. These practices have the power not just to produce new and diverse versions of poems, but to allow for the translation of poems that the equivalence icosis rejects as untranslatable, and to engage in political and social behavior that the equivalence icosis forbids. Translational equivalence as it is conventionally understood is an interaction between static texts: Meschonnic's embodied poetics instead 
specify and individuate translations as performed texts that are inseparable from physical and social contexts.

A clear, highly self-conscious example of a Chinese-English poetry translator pursuing Meschonnic's type of translation poetics is Jennifer Feeley, whose translation of Xi Xi's poetry, Not Written Words, won the 2017 Lucien Stryk Prize. Feeley's translations make consistent use of assonance and consonance, rhyme and near-rhyme, and visual and sonic patterns. She writes that "it is imperative to bring as much of the poem into the target language as possible - including wordplay" $(2017,45)$ and that "I wish to encourage readers and translators to unshackle themselves from rules, assumptions, and conventions, and to use the potential of poetry and of language at large to the full" (46). The rules and assumptions she sets herself against are indistinguishable from the specific preferences of the current equivalence icosis, which prefers syntactical and semantic identity over other types of correspondences (45). In the introduction to Not Written Words, Feeley describes her process in this way: "Where she creates semantic dissonance, I respond with similarly jarring phrasings ... where she revels in rhyme, repetition, and aural wordplay, I strive to incorporate such sound devices, though at times this decision results in slight shifts in word choice" (Xi Xi 2016, xxi). Where the reader of the source text is jarred, the reader of the translation is jarred: if the sensation of the source text has a pattern, there should be a pattern in the translation. This is a version of Meschonnic's "prosody for prosody, metaphor for metaphor, pun for pun, rhythm for rhythm."

The embodied translation of Xi Xi's poetry is not, however, simply a shape in language performance, and the ideal that drives it is not exclusively a new idea of fidelity. The source texts themselves seem to call for embodied translations, as in the poem that gives the collection its title, "What I'm Thinking of Is Not Written Words" (我想到的不是文字). ${ }^{4}$ What the speaker of that poem is thinking of is "actually a certain woman's temperament" (Xi $\mathrm{Xi}$ 2016, 32-33). The claim of this woman's particularity appearing alongside just one specifying and embodying detail - the bare fact of her gender - calls to mind the title of Xi Xi's story “A Woman Like Me" (像我这样的一个女 子). The title introduces a layer of distance: the story is not about me but

4 I believe that intentionally foregrounding Xi Xi's call for language outside words helped editors and readers inside the equivalence icosis to accept and reward Feeley's ludic, inventive translations: through the title and introduction, she makes precise equivalence seem impossible, and her innovations seem like necessary technical adjustments in the face of overwhelming challenge. 
the kind of person who is similar to me. Both the story title and the poem insist that what is under discussion is not women (a concept) but a specific woman (the inhabitant of a body). Xi Xi's poem contains the lines “我相信 生命/永远比文字超脱/比文字活泼” (I believe that life / Will always be more transcendent than words / Livelier than words) (Xi Xi 2016, 33), and this surplus, this quickening of a gendered body, is what $\mathrm{Xi} \mathrm{Xi}$ is thinking of. It therefore seems reasonable and meaningful that Feeley's translation of the poem is in excess of the text of the poem, that it reaches towards a particular woman's "temperament" through wordplay and soundplay that are Feeley's own.

The need to perform an often-unspeakable difference from the dominant adheres to the body of Xi Xi's poetic speakers: they are women in an alltoo male language. Feeley's translation, an English utterance of Chinese language, has a similar kind of alterity. Barbara Godard writes, "The feminist translator, affirming her critical difference, her delight in interminable re-reading and re-writing, flaunts the signs of her manipulation of the text. Womanhandling the text in translation would involve the replacement of the modest, self-effacing translator" $(1989,50)$. Because the thing Xi Xi is thinking of happens inside an individual woman and outside language, Feeley's English version can, in Godard's sense, be double: "the echo of the self and the other, a movement into alterity" $(1989,44)$. In this sense, the willingness of the translator to be other than the author signals and reperforms an alterity necessary to the author's text. This difference represents not a unity between translator and artist, or an equivalence between source and translation, but a united front, a shared project.

Participants in the equivalence icosis might point out that an embodied ideology of translation validated through a shared politics of alterity requires no minimum connection between the source text and the translation, that one could claim any text is a translation of another. This criticism would stem, however, more from the still-nascent state in which the icosis of embodied poetics finds itself than from a lack of connections between embodied translations and their sources (consider translations created in the early history of the equivalence icosis: without a good dictionary and a set of bilingual speakers who had come to a consensus about how languages were related, how would you know that a translation was equivalent?). What is missing is a set of habits by which to confidently judge a translation that operates on a different authority than that of equivalence, and this lack is temporary. Many important contemporary translations connect to their sources through bodies rather than texts and through reperformance rather than parallel equivalence, and they have provoked the translation 
community to ask questions of judgment and plausibility. These are icotic questions, and their answers will build an alternative to the present regime of translations.

Feeley's most concrete act of embodied connection is her habit of checking with Xi Xi to validate an interpretation or context (Feeley 2015, 73). This act of personal authentication is common across contemporary translation, as an epistemological tool: Andrea Lingenfelter says her first-hand experience of poets' lives gives her an "educated intuition" $(2017,73)$ that helps her understand texts. But Feeley gets more than validation of equivalence from her interactions with Xi Xi: she also receives "approval" (2017, 52), Xi Xi's permission to experiment, reconceptualize, and invent in particular ways. Whether or not the translation is a faithful or precise transposition of its source's language, $\mathrm{Xi} \mathrm{Xi}$ consents to having her work represented in this way. In Meschonnic's term, this is an embodied translational process that starts with ethics. It asks not whether the translation is correct, but whether it is right or wrong to produce.

This habit of validating and verifying translations is more radical, and more deeply contrary to the equivalence icosis, than it seems. Austin Woerner's introduction to Doubled Shadows, his translation of Ouyang Jianghe, begins with what we might call Meschonnic's (or Xi Xi's) temptation:

It is tempting to imagine that, as a translator working directly with a living author, one might be able to circumvent the written words entirely and delve straight into the author's imagination, digesting the work back into its basic inspirational impulses and reassembling it, alive and breathing, in one's own language.

(Ouyang 2012, xiii)

Note the biotic metaphors: digestion, assembly, liveliness, breath, reembodiment. Although Woerner and Ouyang are not as consistently interested in sonic play as Feeley and $\mathrm{Xi} \mathrm{Xi}$, what Woerner is dreaming of is "not written words" as well, and he sees a potential path towards translation in direct collaborative work. Accordingly, he spent weeks in discussion and debate with the poet, at one point translating and retranslating the dynamic drafts of a single poem as Ouyang wrote and revised it (Ouyang 2012, xix). These experiences do not comfortably reside in any archive from which equivalences can be drawn. Verbal, ephemeral, and social, they reveal not a pure language but an impossible-to-grasp plurality of lived connections between writers and translators, writings and translations. This is why, perhaps, Turner criticizes Woerner for ignoring the artifact 
that is the poem: the study of textual equivalence cannot see or judge the validity of a translation informed and shaped by an atextual or extratextual relationship.

Part of the complexity of the Woerner-Ouyang relationship is the way in which it opens the possibility to transform power relationships between poet, translator, and reader. Woerner's work on Doubled Shadows seems to have begun as early as 2009, when he was twenty-two. Rather than a situation in which an author's text is raw material with which a translator constructs or invents equivalences - rather than an icosis in which most people produce translations according to an order outside the control of the poet - Ouyang's ideas about translation and his instructions about how to translate were, in some ways, a dominant force that shaped Doubled Shadows. In his introduction, Woerner describes Ouyang explaining that the poem “Our Hunger, Our Sleep" (我们的睡眠, 我们的饥饿) is “a string quartet, with four main characters - bat, rat, man, leopard - in the roles of violins, viola, and cello. In each stanza one or more of these characters appears in solo or duet; from stanza to stanza they enter and exit, relationships constantly shifting" (Ouyang 2012, xvii). This drastically changes the way we read the translation, for example in the first part of section four:

We in our sleep have invented birds, invented song, invented pure white feathers. But birds are just the party line on flight: the bat has no residence in light...
人在睡眠中发明了一些飞鸟, 一些好听的叫声, 洁白的 松弛的羽毛。但它们只是 关于飞行的官方说法。 而蝙蝠没有白天的住处.......

(Ouyang 2012, 69)

We can assess the translation through equivalence, and see difference there: “song” for 好听的叫声, literally "good-sounding animal call," the elimination of 松弛 'limp' as a descriptor for feathers, and the difference between "residence in light" and the more literal "daytime residence." All these can be easily explained by the information in Ouyang's description: 叫声 'call' in the original clearly refers to birdsong, and the extra concepts might be sacrificed to keep l. 2 trim. Inserting "limp" between "pure" and "white" would change the rhythm of 11.2 and 3 , as the original had just two adjectives ("pure white" in Chinese being a single binome). Exchanging "light" for the more equivalent "daytime" in l. 4 adds a rhyme to the poem that makes it more songlike. These are all ways of handling what was described as a "string quartet"; the result should feel musical. But what about the Chinese text's first character, 人 or (in Ouyang's description) "man"? Does "we" 
appropriately represent "man"? Is the quartet structure Ouyang describes intended to be audible - should the word itself appear, as it usually does with the leopard, bat, and rat, or is it a conceptual structure? The first section of the poem has none of the four words 蝙蝠 'bat', 老鼠 'rat', 人 'man', or 豹子 'leopard', although human beings appear in it as 侍者 'servants'. If "servants" is to be interpreted as the entry of the viola, the "man," then "we" could easily stand in for 人. The interaction with the poet dominates the interpretation of the translation. Those of us trying to judge the translation find ourselves reading Ouyang's paratextual commentary as closely as we do the text itself, ruing both the fact that most of his instructions to Woerner went unrecorded - what if he gave a specific instruction not to translate 人 as "man" or "people" in this case? - as well as his habit of speaking in metaphors, parables, and riddles. ${ }^{5}$

The power structure of this kind of relationship, taken to its extreme, could very well end in a translator who becomes transparent in an entirely different way from the translator of equivalence. Living with the artist, participating deeply in the artist's conceptual and physical world, and subject to the artist's decision and revision, a translator could become a kind of second-language tool wielded by the poet. Alternatively, according to the specific dynamics of their relationship, Woerner could have affected Ouyang's attitude towards, or even his writing of, the Chinese-language poem - the translator's activity destabilizing our assumption that the source text is the origin of the translation. The sense of the two parallel undertakings, namely Chinese composition and English recomposition, that result in a trustworthy set of interlingual equivalences would shatter into a series of contingent, interpersonal relationships that could create diverse forms of coherence between source and translation. Rather than a source text being used as raw material to help construct a globe-spanning system of equivalences, and the translator acting as an agent of a transnational order, a translation could be validated and judged according to the strength of the consensus between artist and translator. These lived connections have the potential to change the power relationships that affect the author-translator dynamic, including the structural inequities that exist between European languages and less globalized and capitalized languages. This would please

5 See, for example, the interview between Ouyang, Woerner, and Sierra Nelson where Ouyang describes the translation process as an English-language reader chasing a woman up a staircase, only to find out that the woman's face is a full head of braided hair, and that she looks the same from the front as from the back. Then he bursts into laughter, having irreversibly destabilized reliable tropes of equivalence (Nelson 2009). 
the scholar who first introduced Ouyang and Woerner: Lydia Liu, critic of the imperial "monstrosity" of the super-sign (Nelson 2009).

Because they are so dynamic and unpredictable, historically and socially contingent social relationships are shifting ground upon which to base a translation. They also give translations new social and political roles. Empty Chairs, a translation of the poetry of Liu Xia 刘霞 by Ming Di 明 迪 and Jennifer Stern (the pen name of poet Jennifer Kronovet), summons the body of the poet in its very title. Liu Xia's husband Liu Xiaobo 刘晓波 was in prison when he won the Nobel Peace Prize in 2010, and the prize was awarded to him as the virtual occupant of an empty chair. During his incarceration and after his death, Liu Xia was placed under house arrest and until summer 2018 she was prevented from traveling freely or speaking to the media (in July 2018, she was flown to Berlin and she must now live in exile, with little hope of return). The plural "chairs" in the English title of the collection groups Liu Xia's chair, and Liu Xia's house imprisonment, with the injustices experienced by Liu Xiaobo. ${ }^{6}$ The translators' afterword makes the volume's undertaking quite clear:

We are fueled by Liu Xia's absence to make her work as alive and potent as it is in the original Chinese so that her absence becomes a presence. We want her readers to feel the weight of her silence through her powerful voice. We want her readers to long to sit with her as we do ...

(Liu 2015, 115).

Here, poetic presence and the way in which the shape of words moves bodies stand in for physical presence; as the poem stands in for Liu Xia, so the translation stands in for the poem. Implicit in these imaginative collocations there is a collaboration between the work of translation and the long struggle for the release of Liu Xia. A 2015 reading of Empty Chairs was held by PEN America, and in August 2017 Liu Xia's imprisonment became their featured advocacy case. 7 Their advocacy campaign was a mixture of links to direct political action - a petition, a request to call ambassadors and senators ${ }^{8}$ - and translated poetry. As the translators of Empty Chairs propose, the poetry was included to turn Liu's absence into a presence,

6 The translated collection's title comes from a 1998 poem by Liu Xia, written long before the image of Liu Xiaobo's empty chair would come to represent his incarceration by the state.

7 The reading was on December 1 at Bookcourt in Brooklyn, NY. PEN's advocacy case file for Liu Xia is available at bit.ly/2VG2FRa.

8 The core petition resides at bit.ly/2ItMORX. 
and motivate readers to work on her behalf, to "long to sit with her" as one would with an imprisoned friend. As Meschonnic says, the poem is a method by which the actions of the reader come into a relationship to the actions of the poet.

The politics of bodies in the translation of Empty Chairs are intertwined both conceptually and practically with the politics of undertakings like the PEN advocacy campaign: PEN America and PEN China published poems from the collection before it appeared in print (Liu 2015, front matter). This concern with the body of the artist provokes translation ethics and aesthetics that are substantially different from those of the equivalence icosis. Unlike Xi Xi or Ouyang Jianghe, Liu Xia has a stripped-down, straight-talking aesthetic: her poetry is clipped, direct, and intense, using a great deal of white space and the slowness of the short poetic line. The translators of Empty Chairs, however, insert large quantities of punctuation, create interlinear effects in English that rethink aural lines as visual ones, and suppress some idiomatic effects that are Chinese-only. These choices appear intentional and are stably repeated over the course of the entire collection, for example in the first stanza of "One Bird Then Another":

Back then,
we were always talking
about the bird. Not knowing
where it came from - the bird,
the bird - it brought us
warmth and laughter.

Back then,

we were always talking

about the bird. Not knowing

the bird - it brought us

warmth and laughter.

\section{我们 \\ 在很早以前 \\ 就常常说起那只鸟 \\ 不知道来自哪里的鸟 \\ 我们兴致勃勃 \\ 它给我们带来了笑声}

(Liu 1995, 2-3)

This runs counter to Klein's preference to "respect the physical order of the source text" $(2017,9)$. The changes are not, however, mistakes, and are not arbitrary: the translation differs from the rhythm of the source text in a particular, directed way. Where the Chinese uses the end of the line to create heavy and carefully timed pauses, making each line a single phrase spoken in a single breath, the English breaks up some lines with caesuras, and strengthens the sense of enjambment by, for example, cutting lines between verb and object ("talking / about the bird," "not knowing / where," "it brought us / warmth"). Where the source signals its ritual slowness in the brevity and conceptual emptiness of the first two lines, the translation compresses that empty space and applies it later in the stanza to break up clauses that make up complete lines in the original. The number of lines remains the same, but the English distributes them more evenly. The 
rhythms of the Chinese are, in some cases, available in English, although they are uncommon. Compare my translation below:

\author{
We \\ long ago used to \\ talk about that bird constantly \\ that bird whose origins we didn't know \\ we flourished in fascination \\ it brought us the sound of laughter
}

This translation is not holistically better or worse, but it does retain the single-breath line, requiring the bodies of those who recite the translation to perform a rhy thm closer to the source text. Although Ming Di and Stern's translation is deeply embodied, Meschonnic's focus on rhythm does not dominate the particular nature of its embodiment.

What is at play in the translation of "One Bird Then Another" is instead an attempt to transpose the emotional and political affect of the poem into the lives of English audiences. Liu Xia's poetics are highly recognizable in Chinese, based on a premodern tradition of one-breath lines broken by strong, unpunctuated lineation as well as a modernist interest in negative space. Those poetics are not presently standard in English - a respected contemporary poet in the Anglophone world would rarely, for example, leave "We" on a line by itself. Ming Di and Stern's version instead cuts its lines to create a visual emphasis on a line's final word ("talking," "knowing"), as well as a brief expectant hush into which the next line rushes. This rhythm is much more current in Anglophone poetry, for example C. D. Wright's opening couplet from her poem "Personals": "Some nights I sleep with my dress on. My teeth / are small and even. I don't get headaches" $(2002,78)$. The hardness and strangeness of "teeth" opens multiple possibilities for the next line, and because the first line ends with an incomplete clause, it pitches the reader forward.

That anticipation and resolution is a powerful affective structure in English poetry, deployed quite intentionally in Ming Di and Stern's translation between lines four and five, where the expectation that each ensuing line will travel or change is lightly upended by the way the poem drapes a repetition across the line break: "the bird, / the bird." These line breaks enliven points at which a more equivalent translation of the original would sound flat and prosaic. In my more equivalent translation, the excerpt's last line is less successful than Ming and Stern's translation, which moves more by hanging a space between "brought us" and "warmth and laughter." 
The focus in Empty Chairs on extant affective structures in English rather than the introduction of new ones - follows from the physical and political goal of the translation. Poems that make readers feel something are more likely to motivate their engagement in direct political action; poems that provoke affective response are more likely to create bonds of affinity between poet and reader. PEN America used Ming Di and Stern's translations to strengthen their campaign, something that might not be true for a set of poems that tried to educate readers into inhabiting unfamiliar rhythms or structures whose emotional color was not immediately clear. As the translators say in their note, they are "attempting to bring the poems into an English that creates a sense of absence" (Liu 2015, 118). The translations do not attempt to create new English, but access a preexisting tradition of English free-verse rhythm whose lineation practices have an embodied, sensory effect. The paradoxical way in which this project succeeds is clear from a 2015 review in $Z Y Z Z Y V A$ magazine:

We sense [Liu Xia] in the Chinese text that lies adjacent to the English translation - the monolingual reader can follow line breaks and stanza length and engage in the visual form of each poem. And Liu Xia suggests that she, too, sees herself as embodied in her writing. "I'm a philosopher who thinks / with my body ...," she writes in "Rant," "the body / of spirit whose language is / poetry. I am prosody."

(Luan 2015)

I submit that the monolingual reader's senses are engaged in this case not by Liu Xia, but by the selection of "an English" from the Anglophone tradition by translators who react to and care about the position of Liu's body. This is an embodiment that does not require, or even allow, the reader to "follow line breaks" in the original, but produces its physical effects through local, traditional means. The prosodic body of Liu Xia's written Chinese is not as present as it could be in Empty Chairs: rather than bend their resources to meticulously reproducing the effects of her craft, the translators worked towards maximizing the translations' circulation and visibility, to raise her chances of going into exile in order to escape relentless oppression at home. The choice to Anglicize and localize Liu's poetics was a humane and practical response to her political situation; the need to Anglicize was yet another cost of Liu's long arrest. By provoking this Anglicization, the power of the state again succeeded in a small way in making Liu's poetic bodies - the seat of her philosophy, her prosodic identity - more invisible and less autonomous, more recognizable and less radical. When we assess 
Empty Chairs, the question of equivalence fails to engage in this life-or-death struggle for the space in which to speak. Anglicization or localization, word order retained or sacrificed, none of these elements seem meaningful outside their ethical relationship to the corporeality of poets and readers.

\section{Transmediation}

My interpretation of Liu Xia's prosody, specifically the way she performs single lines without pause, has a source outside the Chinese text of Empty Chairs. Like many interested parties, I've seen her read her poetry on YouTube. ${ }^{9}$ The digital turn promises to shape and intensify both the equivalence icosis and the embodiment icosis now under construction: rather than a set of concordances and identities carried around by highly trained specialists, it produces the system of the super-sign as a massive, ever-expanding database open for use by translators, readers, and critics at all levels of erudition and initiation. Machine translation, at least in its current iteration, reflects the equivalence icosis in a particularly straightforward form: services like Google Translate have no power to identify words that are identical between languages, but instead predict which words will be accepted as so by readers. It still falls to trained translators to create the system of the super-sign, but as the interpretations of digital tools become more firmly rooted in transnational consensus, it seems more and more likely that interlinguistic equivalence will feel increasingly real, and the translator will feel increasingly distant and predictable. The impact of digital transmission on the embodiment icosis will be similarly substantial, and will center around the power of transmediation to represent, extend, and shape the sensory effects of poetry.

Poetry has always worked in multiple media, and moved across media, from spoken word to song to text and back again. In its most ancient form it is, as James Joyce later said of the printed newspaper, "verbivocovisual" (Ford 2013, 450). Its shifting nature and its sensory multiplicity have taken shape after shape: the phonograph record of the famous poet speaking, the face-to-face reading, poems printed on the sides of buses, bridges, and buildings. Digital technologies allow the verbal (the printed word), the vocal (the sound of the word), and the visual (images associated with the word) to be circulated simultaneously and in new combinations. All the embodied translations listed above feature illustration: Not Written Words has Xi Xi's own drawings of cats on the cover, the introduction to Doubled 
Shadows has a cartoon exchange between artist and translator that uses spatial metaphors to describe unwritten words, and Empty Chairs has several of Liu Xia's famous photographs of tormented dolls. Digital technology makes the image equal to the word in ease of printing and circulation; online, where poems are increasingly circulated as .gif or .jpg images, texts already feel like, and are used like, photographs. This makes it easy to mix embodied translations with original art. Lines and shapes affect the eye of the reader in translation just as Meschonnic's ideal of rhythm hopes to affect the ear, and eventually the body. Any future embodiment icosis will privilege mixtures of original texts, translations, and untranslated media: rather than giving us a sense of the text's meaning, embodied translations will be meaningful by engaging our senses in multiple ways.

Poetry in translation is becoming increasingly multimedial; it is also becoming transmedial. In many cases today the poem becomes an image or a performance in video, and this makes techniques and tactics of embodiment unavoidable. Speaking about "battlers poetry" 打工诗歌 written by Chinese migrant workers, van Crevel writes that "just about every representation of battlers poetry I have seen begins with extensive reference to the world behind this poetry rather than the words in it" (2017a, 280), and talks about battler poetry's particular focus on people, migration, and context as the foundation of an enterprise of cultural translation. Battler poems and battler bodies are always multiply translated from countryside to city, from dialect to standard Chinese, from the working class and into the literary establishment (251-253). This must be one reason that the genre has found a meaningful home in transmediation: in Qin Xiaoyu 秦晓宇 and Wu Feiyue's 吴飞跃 documentary Iron Moon (2015), audiences can hear the voices of poets, see their contexts, briefly experience the stultifying rhythms of their labor, and examine their abused bodies. Poetic texts as they are recited over the backdrop of these sounds and images are vastly more embodied than print texts alone, and this is likely why battler poets and editors engage so intentionally with film as a medium. It is also why these transmedial texts provoke critical and readerly anxiety. In his review of the film, van Crevel records the sense of some people in Chinese poetry circles that Qin "is building personal fame and wealth on the backs of the migrant workers whose interests he claims to have at heart," and a resistance to the film's claims of "authenticity" (2017b).

Anxiety over the transmediation of poetry is deeply related to the underdevelopment of the embodiment icosis in translation studies. Nobody believes that poets should not perform while sound and images play in the background, or that a translator should refuse to post an image of a page of their translation 
decorated by their author's doodles or designs. We simply have not agreed upon a means for judging which of these undertakings do and do not represent worthwhile cultural and cross-cultural reproduction. In the previous section, I outlined three important qualities of recent embodied translations: that source texts and translations share an alterity that is in surplus of their printed text, that translators are in personal contact with the artist, and that a translation reacts to or engages with the social or political project of the artist or source text. These map quite neatly onto a prospective ethics - which Meschonnic argues should be the heart of the poetics of the body - that could serve as an icosis for embodied translations as well as transmediations.

First, is there something in the text that requires extratextual viewing or hearing? Is the poem in its context substantially different from the poem in its text? Poems are embodied to different degrees, and it seems appropriately attentive to accept that works by poets like Xi Xi, Yu Xiuhua, and Liao Yiwu 廖亦武 care about and are engaged in the interaction between poetry and the body. ${ }^{10}$ It is this quality, and a translator's sense of it, that might signal whether a text is plausibly open to embodied translation or transmediation.

Second, has the translation been produced with the consent of the poet, and how does the translation react to the poet's preferences? Our current institutions of copyrights are baldly insufficient to allow real consent of the translated. Highly transnational artists like Ouyang Jianghe have networks of supporters and friends who can backtranslate, recommend, and assess on behalf of the poet. The precarious situation of battler poets, by contrast, exposes them to manipulation, whether by filmmakers, publishers, translators, or others. If embodied translation is missing an institution, it is one that can provide every poet or rights-holder an understanding of their translator, translation, and potential audience. The attitudes and opinions of artists and rights-holders, as well as their interactions with translators and publishers, should then be made available to scholars and later translators. Just as the equivalence icosis allows translators to transparently and intentionally violate equivalence in any number of ways - the current trend against translating rhyme is one example - the embodiment icosis could also permit the principled evasion or opposition of writerly consent. To do so, however, those who assess the plausibility of translations must be able to see and understand the nature of that consent. An archive of

10 Liao Yiwu is an especially good example: see Rui Kunze's chapter in this volume. In his essay "Recitation," he writes, "Am I named Liao Yiwu? No, I am not named Liao Yiwu, I am a flesh-and-bone body with the written symbol 'Liao Yiwu' pasted to it" $(1997,47)$. In the same essay, he also reflects at length on the ethical challenges of poetic performance. 
the interactions between poet, translator, and editor could serve the same function as a parallel printing of source text and translation: rather than forcing translators to make interventions or undertake conflicts in secret, an archive would make ethical decisions visible to readers and strengthen trust between reader, critic, poet, and translator. ${ }^{11}$

Finally, perhaps most importantly, when creating an embodied translation or transmediation, we should have to ask: do the politics of the translation collaborate with the politics of the text? Does the translation move bodies through culture in a way that cooperates with the text's effect and affect? The equivalence icosis has produced a broad, multinational set of relationships between words in many languages, and a method of assessment by which those relationships can feel real. Embodied translation has the potential to produce relationships of political solidarity, and an icosis of embodied translation could make shared translinguistic and transregional identities feel as solid and meaningful as a lexical equivalent in a dictionary. ${ }^{12}$ As was true for the equivalence icosis, work to produce translinguistic solidarity through embodied translation will be subjective, collective, and intercultural, and it will take place over generations - with each culture in a translation pair coming to understand the possibilities and challenges, the ideologies and practicalities, of the other.

Translators and theorists have long shared a consensus that translation has always been an overtly or covertly political act, and not simply an operation of linguistic signs. As the digital turn reconnects the translation of poetry to the body and its performance, there is no better time to make a translation's effect on bodies an overt topic for assessment, and to formally ask whether a translated text is right, rather than correct.

\section{Works cited}

Admussen, Nick. 2014. Review of On Literary Worlds, by Eric Hayot. MCLC Resource Center. bit.ly/2WSDCKJ. Accessed June 22, 2018.

11 Happily, a Chinese Literature Translation Archive is currently being built at the University of Oklahoma, collecting correspondence between author and translator among other translationrelated documents.

12 Literary historians often accept this proposition more easily than translation theorists. After reading Liansu Meng's essay in this volume, one finds it hard to put time into measuring how equivalent Chen Jingrong's translations are to Baudelaire's source texts. Their accuracy is simply not the most important question she asks about them. Instead, the essay asks: were the translations influential? Did they move the translator? In what ways did they affect audiences? 
- 2016. "Genre Occludes the Creation of Genre: Bing Xin, Tagore, and Prose Poetry," in the Oxford Handbook of Modern Chinese Literatures, edited by Andrea Bachner and Carlos Rojas, 578-596. Oxford: Oxford University Press.

- 2017a. "Forms of World Literature and the Taipei Poetry Festival." Journal of Modern Literature in Chinese 14 (2)-15 (1): 213-244.

-. 2017b. "Errata." New England Review Online. bit.ly/2FTb78M. Accessed June 22, 2018.

Benjamin, Walter. 1988. Illuminations, translated by Harry Zohn. New York: Schocken Books.

Feeley, Jennifer. 2015. "More than Just Embracing Han Shan: Cultural Transfer in Translating Xi Xi's “Written on the Flyleaf of a Gary Snyder Poetry Collection.” Translation Review 93 (1): 68-80.

- 2017. "Can We Say an Ear of Cabbage: On Translating Wordplay in Xi Xi's Poetry." Journal of Modern Literature in Chinese 14 (2)-15 (1): 45-73.

Ford, Thomas. 2013. "Poetry's Media." New Literary History 44 (3): 449-469.

Godard, Barbara. 1989. "Theorizing Feminist Discourse / Translation.” Tessera 6: 42-53.

Hsia Yü 夏宇. 2014. Salsa, translated by Steven Bradbury. Brookline: Zephyr Press. Klein, Lucas. 2017. "Strong and Weak Interpretations in Translating Chinese Poetry." Journal of Modern Literature in Chinese 14 (2)-15 (1): 7-43.

Lingenfelter, Andrea. 2017. "Where You End and I Begin: Notes on Subjectivity and Ethics in the Translation of Poetry." Journal of Modern Literature in Chinese 14 (2)-15 (1): 73-106.

Liao Yiwu 廖亦武. 1997. <朗诵> [Recitation]. 《山花》 6: 47-53.

Liu, Lydia. 1995. Translingual Practice: Literature, National Culture, and Translated Modernity. Stanford: Stanford University Press.

- 2004. The Clash of Empires: The Invention of China in Modern World-Making. Cambridge, MA: Harvard University Press

Liu Xia 刘霞. 2015. Empty Chairs, translated by Ming Di and Jennifer Stern. Minneapolis: Greywolf.

Luan, Emily. 2015. “The Poison of a Long Imprisonment: Liu Xia's Empty Chairs.” ZYZZYVA. bit.ly/2OZ6gHj. Accessed June 22, 2018.

Meschonnic, Henri, 2011. Ethics and Politics of Translating, translated by Pier-Pascale Boulanger. Amsterdam: John Benjamins.

Mohabir, Rajiv. 2015. “Imaginative Reading.” Jacket2. bit.ly/2UIYkPY. Accessed June 22, 2018.

Nelson, Sierra. 2009. “Ouyang Jianghe and Austin Woerner." The KR Conversations. bit.ly/2uZmbw1. Accessed June 22, 2018.

Ouyang Jianghe 欧阳江河. 2012. Doubled Shadows, translated by Austin Woerner. Brookline: Zephyr. 
Qin Xiaoyu and Wu Feiyue, dirs. 2015. Iron Moon (international edition). MeDoc / Shanghai Eternity.

Robinson, Douglas. 2013. Schleiermacher's Icoses: Social Ecologies of the Different Modes of Translating. Bucharest: Zeta Books.

-. 2014. "Embodied translation: Henri Meschonnic on Translating for/through the Ear and the Mouth." Parallèles no. 26, 38-52.

Stern, Jennifer. 2017 "Poems by Liu Xia, With an Introduction from Her Translator." Scoundrel Time. bit.ly/2Ikgile. Accessed June 22, 2018.

Turner, Matt. 2016. “Translating Difficulty.” Jacket2. bit.ly/2Ut7vob. Accessed June 22, 2018.

van Crevel, Maghiel. 2017a. "The Cultural Translation of Battlers Poetry (Dagong shige)." Journal of Modern Literature in Chinese 14 (2)-15 (1): 245-286.

- .2017b. "Review of Iron Moon." MCLC Resource Center. bit.ly/2TejwbC. Accessed June 22, 2018.

Wright, C. D. 2013. Steal Away: Selected and New Poems. Port Townsend: Copper Canyon Press.

Xi Xi 西西. 2016. Not Written Words 不是文字, translated by Jennifer Feeley. Hong Kong: Zephyr Press / mccm creations.

Yao, Stephen. 2002. Translation and the Languages of Modernity: Gender, Politics, Language. New York: Palgrave Macmillan.

\section{About the author}

Nick ADMUSSEN is associate professor of Chinese literature at Cornell University. His research centers on modern and contemporary poetry, and ranges between hermeneutics, translation, and the sociology of literature. He is the author of Recite and Refuse: Contemporary Chinese Prose Poetry (University of Hawai'i Press, 2016). His translations of the Sichuan poet Ya Shi, titled Floral Mutter, are forthcoming from Zephyr Press, and his fifth chapbook of poems was recently published by the New Michigan Press. 



\title{
6 Translating Theory
}

Bei Dao, Pasternak, and Russian Formalism

\author{
Jacob Edmond
}

\begin{abstract}
This essay asserts the generally neglected importance of poetic theory in the study and practice of translation and of comparative and world literature, as a crucial complement to the overwhelming focus on the form/content binary. Theory not only travels but translates as well, as the essay argues through a case study of how Russian Formalism found its way into Bei Dao's translations of Boris Pasternak.
\end{abstract}

Keywords: Chinese poetry, translation, Bei Dao, Pasternak, Russian Formalism, literary theory

We often think about the challenge of translating poetry in terms of form and content. ${ }^{1}$ Should one attempt to preserve the semantic content of, say, a Chinese poem in English translation, or should one attempt to replicate formal devices such as rhyme, rhythm, and wordplay? This form/content binary also inflects discussions of literature on a global scale. Franco Moretti (2000) has influentially argued that the story of modern literature is largely one of foreign, primarily European forms - such as the novel - inflected by local content, be it Chinese or West African. Jahan Ramazani likewise draws on the form/content binary in his taxonomy of the permutations of the foreign and the local in contemporary poetry: foreign form and local content, foreign form and foreign content, local form and foreign content, and local form and local content $(2016,122)$. Ramazani's taxonomy is finer-grained

1 This essay is a substantially reworked version of my article "The Elephant in the Room: Theory in World Literature" (2018). I am grateful to the editors of Orbis Litterarum for their permission to reuse material from that article here.

Van Crevel, Maghiel and Lucas Klein (eds.), Chinese Poetry and Translation: Rights and Wrongs. Amsterdam: Amsterdam University Press, 2019

DOI: 10.5117/9789462989948_CHo6 
than Moretti's, but he admits that even this variegated account of "localglobal enmeshments" has its limitations, since "most poems will fit into several of these slots at once, and no amount of long-distance squinting can accurately reduce them to one or the other" (123).

Such accounts of global modernism and world poetry have done much to capture the complex negotiations between form and content in crosscultural literary exchange and globalization. However, they neglect a third category that profoundly shapes how poets and their translators conceive of and negotiate between form and content: theory. I want to suggest that we would do well to consider translations between literary theory and practice alongside translations of literary texts from one language to another, and that doing so will enrich and alter our theories of both translation and comparative and world literature. We need, in other words, to attend not only to the transnational travels of form and content in literary texts and in their translation, but also to the equally important and contested movements of ideas about - for instance - what constitutes form and content in the first place.

Like form and content, theory travels. Literary-theoretical concepts and terms are arguably the key conduit through which foreign poetic forms and content have been assimilated and adapted over the modernist and contemporary period, from Symbolism to Conceptualism. Contemporary writers frequently engage literary and aesthetic theory in developing their own modes of negotiating form and content. They borrow forms (the haiku, the sonnet, the novel) and content (words, translated phrases, stories) from other places and times, but they also borrow and adapt ideas about the nature of form, its relation to content, and the relation of literature to the world.

The failure to address such uses, translations, and adaptations of theory constitutes a blind spot at the center of current attempts to understand the global travels of poetry. The oversight seems almost inexplicable when we consider how fundamentally theory-driven modern poetry has been. The text by T. S. Eliot that has had the most influence on poetry globally is arguably not The Waste Land or Four Quartets, but "Tradition and the Individual Talent."2 Ezra Pound's poetics theories (from Imagism to Vorticism and beyond) and Charles Olson's "Projective Verse" - especially that

2 On the translation and influence of Eliot's essay in China, see Liu Yan 2006. On Caribbean poets' response to Eliot's conception of tradition, see Pollard 2004; and Matthew Hart's chapter "Tradition and the Postcolonial Talent" (2010, 106-141). On the influence of Eliot's account of tradition on modern Arab poetry, see Al-Musawi 2002 and Ranjan Ghosh, who notes how "modern Arab poets ... were deeply influenced by [Eliot's] notion of tradition, intertextuality and mythic method of poetry-writing" (2017, 171n31). 
essay's famous slogan, borrowed from Robert Creeley, "FORM IS NEVER MORE THAN AN EXTENSION OF CONTENT" - have shaped and reshaped how poets relate form to content. ${ }^{3}$ Not only was Language writing at least as influential as a theory as it was as a practice; Language writers such as Lyn Hejinian, Ron Silliman, and Barrett Watten drew extensively on other literary theories, especially Russian Formalist theory (Edmond 2012, 72-94). In many of their poems, Language writers describe local US content in forms of their own invention. These poems might look like combinations of local form and local content, but the poets' conception of how form and content relate depends fundamentally on foreign theory (cf. Weinberger 1996).

As this last example suggests, the movement of theory, like poetic forms, has not been unidirectional from the West to the Rest but involves a complex global history of cross-cultural exchange among many theoretical traditions. ${ }^{4}$ It has been argued, for instance, that the poetic theory of Imagism was not a Western export but the product of a dialogue between Noguchi Yonejirō and Ezra Pound, and that their "agreement on imagism constituted an interpenetrating relationship of Japanese poetics and Western intentions in early modernism" (Hakutani 1992, 68).

Scholars of literature are, of course, aware of the important role played by "traveling theory" (Said 1983). But despite this awareness, theory still constitutes something of an elephant in the room in the study of literary translation and comparative and world literature. We all know of its importance, but we tend at times to strategically ignore it because its role upsets the clear distinction between our theorizing and the literary or translation practices that our theories are meant to describe. Asserting this clear distinction - and, coincidentally, picking the same animal I have just mobilized, but for a different argument - Roman Jakobson objected to the appointment of Vladimir Nabokov at Harvard, claiming you wouldn't put an elephant in charge of a zoo (Boyd 1991, 303). But Jakobson's analogy is false: in literature, there exists no such clear line between what is being studied and who is doing the studying. Jakobson's Russian Formalist colleague Victor Shklovsky also wrote prose fiction that exemplifies many of the literary devices his theory describes. In Third Factory (Третья фабрика),

3 Olson 1997, 240. See, for example, the claim that the theories of Pound, Eliot, and T. E. Hulme are "largely responsible for shaping the modernism we have inherited" (Beasley 2007). For examples of the key role played by Olson's manifesto in New Zealand poetry as both an influence and a touchstone for polemical debate, see, inter alia, Curnow 1982; Manhire 1987; Rapatahana 2015; Horrocks 2016, 46-49; Sturm 2017, 556-559.

4 On the need for more scholarly recognition of non-Western literary theory, see Krishnaswamy 2010. 
for instance, Shklovsky deploys the device of "making strange" - ostranenie остранение, a neologism that would travel from Russian into other languages - which he saw as a defining characteristic of art, in describing his son's first impression of a horse: "he thought it was doing four legs and a long nose just for fun" $(1926,13)$. Literary theory here does not simply describe practice; it shapes it.

The concept of world literature is likewise not just a theoretical framework for understanding the global interactions that constitute modern and contemporary literatures; it is also a concept that has played a key role in shaping literary practice. World literature is both a theoretical framework for thinking beyond a single language, nation, or region and, at times, an evaluative term: an aspirational ideal, a strategic label, or even a compositional method used by writers seeking recognition and cultural capital within an unequal literary, economic, and geopolitical world system (L. Liu 1995, 188; Lovell 2006; Edmond 2012, 95-124). Mindful of how such inequality has shaped their discipline, today's scholars of world and comparative literature have generally become less concerned with comparing and evaluating the literatures of the world (Melas 2007). They have instead turned to examine, for example, the uses to which a literary work is put as it travels beyond the borders of one language or nation (Damrosch 2003), or how these crossborder literary exchanges reflect and contest the unequal distribution of power in our modern world system (Moretti 2000; Casanova 2004).

Similarly, translation theory, since the time of Itamar Even-Zohar's "Polysystem Theory" (1979), has turned from evaluation to description: from examining the rights and wrongs of a translation - in the traditional sense of accuracy - to attempting to understand how, why, and for what purposes texts are translated (Bassnett 2014, 8-9). However, in moving from prescription to description, scholars of both translation theory and comparative or world literature risk losing sight of the role of theory itself in the translation and adaptation of literary texts, techniques, and ideas across languages and cultural and historical contexts.

Modern Chinese literary history might offer a corrective to this blind spot because it presents a striking example of the "function of theory" as a "mediating factor" in translingual literary exchanges that are reducible neither to "foreign impact nor to ... indigenous tradition" (L. Liu 1995, 184, 186, xix). The Chinese adaptation of Western theory in the Republican period, for example, has been widely recognized as playing a key role in the development and interpretation of modern Chinese literature (e.g. McDougall 1971; Gálik 1980; L. Liu 1995). Lu Xun's 魯迅 foundational text of modern Chinese literature (and invocation of Gogol) "Diary of a Madman" (狂人 
日記) appeared in the same issue of New Youth (新青年) in which Hu Shi 胡適 published an essay on the short story as the fiction genre best suited to the age. And from his early engagements with Kant's aesthetic theory onwards, Lu Xun's adaptation of foreign theory developed alongside and shaped his literary practice. The theoretical idea of world literature itself has exerted a powerful influence on the development of modern Chinese literature from the 1920 s and 1930s through to its more recent history (Lovell 2006; L. Liu 1995; Edmond 2012, 95-124).

Scholars of modern Chinese literature have often focused on the strategic use or creative adaptation of Western literary theory to respond to Western cultural hegemony - to insist, for instance, on the importance of Chinese literature by asserting that China has Romanticism, modernism, postmodernism, or world literature too - and to score points in local literary and political disputes (Wang 1986/1987; Chen 2002; L. Liu 1995; Saussy 2001; Zhang 1992). But such uses of theory are evident not just in literary and political polemics but also in the practice of literature and of literary translation. Xu Zhimo 徐志摩, for example, deployed a theory of translation derived from the Zhuangzi (莊子) in his translation and interpretation of Baudelaire (Saussy 2006). And the practice of translating poetry in China today continues to be inseparable from polemics about the theory and practice of writing and translating poetry, as Joanna Krenz illustrates elsewhere in this volume. Such moments where theory shapes translation and literary practice are commonplace but insufficiently explored in translation theory or in theories of world and comparative literature.

In this essay, I will illustrate the role of theory in the writing and translation of contemporary poetry by exploring the cross-cultural adaptation of aesthetic theories in the work of one influential poet-translator: the use of Russian Formalist theory in the work of Bei Dao 北島. Bei Dao's use of Russian Formalist theory is evident in his translations of Russian poets such as Boris Pasternak, in his discussion of his own and other Chinese translations, and in the poetry he wrote in response to Pasternak's and in emulation of its techniques. Bei Dao's adaptation of the form and content of Pasternak's poetry comes filtered through Jakobson's and Shklovsky's theories of how form and content relate. In developing his own implicit theory for writing and translating poetry, he adapts Shklovsky's concept of "making strange" and Jakobson's account of "poetic function," of language's axes of selection and combination, and of the related tropes of metaphor and metonymy. Bei Dao doesn't just adopt these theories but conflates and transforms them into an account of the poles of commonness and strangeness in poetic language. 
Bei Dao not only uses Russian Formalism to conceptualize form, content, and their relation; he also develops Russian Formalist ideas into an implicit theory of translation and cross-cultural comparison. His work connects translation and comparison to the metaphoric and metonymic poles of similarity and contiguity, and to the interplay of commonness and strangeness. This implicit poetics of comparison offers a way to reconcile the tension in current theories of comparative and world literature between what one might term metonymic comparison, based on non-hierarchical "circulation" or on "relational" or "spatial" connection (e.g. Friedman 2012; Shih 2013; Melas 2007), and metaphoric comparison: the enumeration of similarities, as found in the taxonomies of scholars such as Moretti and Ramazani. The poetic figures of metaphor and metonymy lie unrecognized at the heart of much theorizing about world literature, just as theory is the unrecognized third term that shapes the relationships between the local and the foreign and between content and form in the globalized exchanges that produce the poetries of today's world.

Recognizing the role of theory in literature's global travels implies new ways of understanding not only translation and comparative and world literature, but also the relationship between theory and practice. Bei Dao adapts and develops poetic theories that undermine the form/content and local/foreign dichotomies that still plague discussions of translation and comparative and world literature. His example also suggests that poetic texts and translations provide not just objects for analysis, data that our theories must explain; they also offer theoretical insights into translation and world literature. In developing our theories of literature and translation, therefore, we should seek not only to describe but also to learn from the role theory plays in the writing, translation, and global circulation of poetry.

\section{Strange and common}

In 1985, Bei Dao received a submission for the journal of poetry in translation that he was co-editing, International Poetry World (國際詩壇). The submission included a handful of poems by Pasternak in Chinese translation (Bei Dao 2005, 265-266). Bei Dao would later write about the powerful impression these poems made on him, echoing his account of reading modern poetry in Chinese translation during the Cultural Revolution, when, in his words, translation remained "practically the only medium for the transformation of literature and literary style” $(1993,60)$. 
The importance of these translations of modernist literature to Bei Dao and other poets of his generation has already been shown (Edmond 2012, 19-20). As Bei Dao's response to Pasternak's translations also illustrates, however, the cross-cultural adaptation of literary theory had an equally significant impact. In an essay on Pasternak, Bei Dao filters his encounter with the Russian poet through Russian Formalist literary theory, especially the work of Jakobson and Shklovsky. Early in the essay, Bei Dao cites Pasternak's poem "February" (Февраль) as an example of what Jakobson terms "poetic function" (in quoting from Bei Dao here and below, I offer English approximations of his Chinese translations of Pasternak, rather than translating directly from the Russian text):

The correspondences in the first stanza between "ink" and "mud," "bitter crying" and "rumbling noise" are precisely the result of the vertical alignment of Jakobson's aforementioned axis of combination, which reveals the difficult process of writing. The second and subsequent stanzas drive further steps forward; leaving the city, they return to nature. From the "white-beaked crows" that resemble "burnt pears" to the "dry sorrow," from the "puddles" to "the fundus of the eye," the emotions and scenery mix, and the sadness comes from this mixing. The beginning of the final stanza mentions the thaw, whose "blackness" distantly echoes the "ink" and "mud" of the poem's opening lines; the "wind ploughed by shrieks" is the "eye of the poem," hinting at a penetrating pain.

\section{第一段“墨水”與“泥濘”、“痛哭”與“轟響”的對應, 正是我們提到過的雅 各布森關於組合軸的那種縱向性的對位效果, 展現了寫作艱難的過 程。第二三段進一步推進, 遠離城市回歸自然, 從“焦梨”般的“白嘴鴉” 到“枯愁”, 從“水窪”到“眼底”, 情景交融, 悲從中來。最後一段開端提到 解凍, “黑色”和開篇的“墨水”與“泥濘”遙相呼應, “風被尖叫聲犁過”是 “詩眼”, 暗示銳利的痛苦。}

(Bei Dao 2005, 267)

Bei Dao here recalls his reference to Jakobson's definition of poetic function earlier in his collection of essays $(2005,75)$ : "The poetic function projects the principle of equivalence from the axis of selection into the axis of combination. Equivalence is promoted to the constitutive device of the sequence" (Jakobson 1987, 71). In other words, for Jakobson, poetic function is the combining of words linked by similarity, be it similarity in sound (e.g. rhyme) or meaning (as in metaphor). In "February," for example, Pasternak takes 
various things that share a common liquid quality - "ink," tears ("cry"), "slush," and "puddles" - and places them in a "sequence."

In his essay, Bei Dao implicitly connects the role of poetic function in Pasternak's "February" to the process of translation. The essay presents four Chinese versions of Pasternak's poem in translations by Fei Ye 菲 野, Gu Yunpu 顧蓝璞, Mao Xinren 毛新仁, and Bei Dao himself. Thus he emphasizes the "principle of equivalence": the "selection" that a translator must make in finding a word in one language for a word in another. That is, he transforms Jakobson's poetic principle from a mode of poetic composition into an implicit justification of his presentation of multiple translations of the same poem in their entirety. Jakobson says language becomes poetic when the similarity principle becomes the driver of the word combinations in a given text and the conveyance of meaning is relegated to a secondary status. Redoubling Pasternak's poetic language, Bei Dao promotes similarity "to the constitutive device of the sequence" by presenting four translations of the same text. He extends Pasternak's chain of words and things linked by liquid to encompass the multiple possible Chinese renderings of these terms and of the poem as a whole.

The word sliakot' слякоть 'slush', for instance, becomes three different kinds of muddy slush, nining 泥濘 'mud', xini 稀泥 'watery mud', and nijiang 泥漿 'slurry', enhancing the watery mixing of concepts and words that the poem describes and enacts. This semantic rhyme partially makes up for the loss of Pasternak's sonic rhyme of sliakot' with plakat' плакать 'wеep', a rhyme preserved only in Gu Yunpu's translation, where the sound of xini slant-rhymes with kuqi 哭泣 'weep'. Bei Dao associates Jakobson's poetic function with the way poetry and translation can cause terms to mix and interrelate: "the emotions and scenery mix, and the sadness comes from this mixing." In the process, Bei Dao makes translation and poetry synonymous: the mixing of terms and the parallelism of rhyme and rhythm in poetry match similar acts of interlingual - and, in the case of the four translations, intralingual - repetition and parallelism in translation.

In his discussion of Pasternak's poem "Marburg," Bei Dao associates such mixing with Shklovsky's device of "making strange" - in Chinese, 陌生化:

The third stanza of the poem is the most brilliant: "The flagstones grew hot, and the street's brow was dark. / From under eyelids cobblestones coldly / Glowered at the sky, and the wind like a boatman / rowed the lindens. All these were symbols." Still and moving, angry and harmonious, hard and soft - all mixed together. Poetry needs both the "strange" and the "common." The so-called "strange" is what Russian Formalism termed 
"making strange," and the "common," in my understanding, refers to poetic reason. For example, "cobblestones coldly / Glowered at the sky, and the wind like a boatman / rowed the lindens": these two images are both "strange" and "common"; they are truly a stroke of genius.

其中第三段最精彩: “鋪路石發璗, 街的額頭黧黑。/眼瞼下我鳥卵石 冷漠地 / 怒視天空, 風像船夫 / 劃過椴樹林。一切都是象徵。” 靜與 動、憤怒與和諧、堅硬與柔軟都融合在一起。詩歌中既要講“奇”, 又 要講“通”。所謂“奇”, 就是俄國形式主義所說的“陌生化”; 而“通”, 按我 的理解, 則是一種詩意的合理性。比如“找卵石冷漠地/怒視天空, 風 像船夫 / 劃過椴樹林”這兩組意象既“奇”又“通”, 真可謂神來之筆。

(Bei Dao 2005, 281)

Bei Dao here cites the following stanza from "Marburg":

Плитняк раскалялся, и улицы лоб

Был смугл, и на небо глядел исподлобья

Булыжник, и ветер, как лодочник, греб

По липам. И все это были подобья.

(Pasternak 1985, 1:70)

The flagstones grew hot, and the street's brow

Was swarthy, from under the brow cobblestones peered

At the sky, and the wind, like a boatman, rowed

The lindens. And all these were resemblances.

(Pasternak 2003; amended) $^{5}$

In his commentary on the stanza, Bei Dao celebrates Pasternak's ability to mix things together based on "resemblances" (подобья), or what Jakobson termed "equivalence." It is these resemblances that enable congruence with reality (cobblestones really do face the sky; wind really does make the trees move as it itself moves, just as oars move and are moved by the water) at the same time as enabling surrealism (the faces of the cobblestones have eyes that "peer"). Of course, not all these strange parallels survive translation: the rhyme of ispodlob'iа исподлобья 'from under the brow' with родоb'iа подобья 'resemblances' finds sonic resemblances between the words, and between a human face and a street. This wordplay is difficult to convey in translation. It is conveyed neither 
in the English translation above nor in the Chinese translation that Bei Dao offers: 一切都是象徵 'all these were symbols'. Here, the Chinese reflects neither the wordplay of the source text nor the possibility that similarity is founded not only on symbolic or visual representation (metaphoric likeness) but also on the resemblance or closeness of the sounds of different words.

Instead of translating the form or content of Pasternak's resemblances, Bei Dao translates and connects Jakobson's and Shklovsky's theories to explain and redeploy the mixing of words and images that characterizes Pasternak's poetic practice. He describes Pasternak's mixing of the common and the strange in a way that recalls not just Shklovsky's concept of making strange but also Jakobson's demonstration of how Pasternak produces an "expression far from common" out of the very metonymical connections that the poet insisted gave his work a more realistic quality (Jakobson 1987, 307). This sense of realism or commonness - that poetry takes place "in collaboration with real life" (Pasternak 1985, 2: 208) - produces writing in which "all images are in some way potentially contiguous" (Jakobson 1987, 312). The strangeness comes through the displacement of the subject onto contiguous objects: in "Marburg," Jakobson writes, "the principal characters in the action are flagstone, paving-stone, wind ... storm, sky, etc." $(1987,313)$. Outside reality becomes a mirror of the self (307), a metonymic device that affirms an external real world - the everyday reality of the flagstones in Marburg - while at the same time distorting expected literary representations of that world. Bei Dao extends this process to translation, finding in the external world of another's words a reflection of his own.

Bei Dao goes on to explain the effect of Pasternak's metonymies in "Marburg" by paraphrasing Shklovsky's account of how "making strange" avoids cliché and prolongs and deepens the reader's experience:

Let's now look at the seventh stanza: "As if playing the part of Romeo embracing the tragedy / I staggered through the town rehearsing you / carrying you all day, from head to feet / memorizing you till you rolled off the tongue." Imagine oneself as a rehearsing actor, take the lover to be the script one is remembering by heart - and in a very concrete way: from head to feet. This really is the quality of "making strange," avoiding cliché, of prolonging and deepening the reader's experience.

再來看看第七段: “像扮演擁抱悲劇的羅米歐, / 我蹣跚地穿過城 市排練你 / 整天帶著你, 從頭到腳 / 把你背得滾瓜爛熟。” 把自己想 
像成排練的演員, 把情人當成台詞牢記在心, 且非常具體化 - 從頭 到腳。正是這種“陌生化”的效果, 避免了陳詞濫調, 延長並加深了讀 者的閱讀體驗。

(Bei Dao 2005, 281-282)

In the stanza from "Marburg" that Bei Dao translates here, Pasternak uses an extended simile that is nevertheless metonymically connected to the subject who is also in the "provincial" town of Marburg:

В тот день всю тебя, от гребенок до ног,

Как трагик в провинции драму Шекспирову,

Носил я с собою и знал назубок,

Шатался по городу и репетировал.

(Pasternak 1985, 1:71)

On that day I carried you with me

And knew you by heart, from your combs to your feet,

Like a provincial actor knows a Shakespearean drama;

I wandered the city, rehearsing.

(Pasternak 2003; amended)

In replacing the object of desire with words (the beloved "you" becomes a script), Pasternak links his metaphor metonymically to the writing of the poem, an effect that is weakened in Bei Dao's Chinese translation by the reference to the character Romeo, rather than the author Shakespeare. The link between script and poem in turn connects to Bei Dao's recounting in the essay of his own visit to Marburg, during which his "aimless strolling through the streets" merges with that of Pasternak's lyric subject who "wandered the city, rehearsing" (2005, 273). In this way, Bei Dao implies a link between Pasternak's poem and his own embodying of Pasternak's words in translation. This sense of embodiment is made more visceral by the poem's conflation of speaking another's words with literally carrying another person's body. Bei Dao extends this conflation of script and body further in using the word 背, which I have translated here as "memorizing," but which can also mean "back" or "carry on one's back," as in the back on which the lyric subject carries his beloved.

The strangeness of the metonymic link between script and actor matches the strange experience of repeating another's words - whether in rehearsal or, in Bei Dao's essay, drafting a translation. Such repetition affirms an experience common to two people and emphasizes the strangeness of 
taking another's words as one's own. Here, Bei Dao's analysis of Pasternak through multiple translations serves a similar purpose. Where learning words by heart might make them lose their estranging novelty, Bei Dao's essay effectively counters this potential banality with the freshness produced through multiple translations of the same lines.

Shklovsky's "making strange" also provides Bei Dao with a means of cross-cultural comparison based on commonness and strangeness. He emphasizes the common commitment of Pasternak, Shklovsky, and himself to the poetics of strangeness in the face of communist regimes that attacked the autonomy of art. The reader's perceptual experience guarantees for Shklovsky in "Art as Device" (Искусство как прием) the autonomy of art. Later in his essay, Bei Dao quotes directly from Shklovsky's famous account of how "making strange" increases "the difficulty and length of perception, since the perceptual process in art is autonomous and must be prolonged" (Shklovsky 1929, 13; Bei Dao 2005, 293). He also notes Shklovsky's defense of art's autonomy after the Bolshevik revolution, when art came under increasing pressure to serve politics: "Shklovsky has a famous saying: 'Art has always been free of life. Its flag has never reflected the color of the flag that flies over the city fortress"' (Bei Dao 2005, 292; Shklovsky 1919). Bei Dao then explains the political attacks on Formalism and quotes from an essay written by Shklovsky in the 196os:

But after Stalin came to power, literature's so-called independence no longer existed; all the flags had to be red. Shklovsky received severe criticism; he was forced in 1930 to write an essay eulogizing socialism and realism. Times changed, and Formalism was eventually rehabilitated. In a 1961 article, Shklovsky lamented his path: "Time slipped away, the sun rose more than ten thousand times, the spring and autumn passed forty times, and now in the West there are people who want to use my words to dispute the meaning of my flag flying above my city fortress."

但隨著斯大林大權在握後, 文學所謂的自主性不復存在, 所有的旗幟 都必須是紅的。施克羅夫斯基受到嚴厲批判, 不得不於 1930 年寫讚美 社會主義現實主義的文章。時過境遷, 形式主義終於得到平反。1961 年, 施克羅夫斯基在一篇文章感歎道: “光陰荏䔁, 太陽升起過一萬 多次, 四十個春秋過去了, 現在西方有人想藉我的話來爭辯飄揚在 我的城堡上我的那面旗幟的意義."

$(2005,293)$ 
Bei Dao not only identifies Pasternak with Shklovsky's device of "making strange"; here he also implicitly connects his encounter with Pasternak's poetry to his encounter with Shklovsky's theory in the mid-1980s and the corresponding effort at the time to free Chinese literature from narrow subservience to Communist Party politics. Bei Dao takes the date and Chinese translation of Shklovsky's quotations about his flag and the flag of art from Zhang Longxi's 張隆溪 Critical Introduction to Twentieth-Century Western Literary Theory (二十世紀西方文論述評), published in Beijing in 1986, the year after Bei Dao first read Pasternak's poetry. ${ }^{6}$ The quotations from Shklovsky would likely have caught his eye, especially as they chimed with Karl Marx's emphasis on the many colors of art cited in the editorial to the first issue of the unofficial literary journal Today (今天), which Bei Dao founded together with his fellow poet Mang Ke 芒克 and the painter Huang Rui 黄锐 in 1978. The editorial quotes Marx's statement from “Comments on the Latest Prussian Censorship Instruction" (Bemerkungen über die neueste preußische Zensurinstruktion) that "there are no black flowers" and that likewise human culture should not be devoid of color and variety (Jintian bianjibu 1978, 1-2). Bei Dao uses this quotation knowingly and ironically to recall Mao Zedong's phrase "let a hundred flowers bloom," a call for artistic and intellectual diversity that was viciously curtailed by the Anti-Rightist campaign (Edmond 2012, 116). In citing Shklovsky's statements and alluding to these quotations from Marx and Mao, Bei Dao implies that he and Shklovsky share a desire for a multihued and autonomous art, and that their countries share the historical experience of art being forced to toe the political line. For Bei Dao, Shklovsky's theory of "making strange" becomes not just a way of reading literature but a means of identifying similar historical tensions between art and politics in China and Russia.

\section{Two windows, one moon}

In discussing the concluding stanzas of "Marburg," Bei Dao extends his use of Shklovsky's and Jakobson's accounts of poetic language to address the common experiences and perspectival differences that characterize translation and cross-cultural comparison:

6 The quotation actually comes from a brief essay dated 1958-1965 that introduces Tales about Prose (Повести о прозе; Shklovsky 1966, 1: 3-4). 
The high tide of the poem is in its second part: this is the end of roaming and the beginning of waking up to reality. Without this part, "Marburg" is almost untenable. The first stanza of this part is transitional, that is, it is the point of linkage between inside and outside: "The mist from all directions opens its bundles / two windows hang one moon. / And melancholy will pass these books / lingering in a book on the sofa." We only have to compare it to the first version to see what has happened: "the great mist takes our luggage and scatters it everywhere / in each of the two windows there exists a moon. / Worry like a traveler sweeps past each book / and together with the books is placed on the sofa" (Fei Ye's translation). Whether it is a discrepancy in the translation or the result of an author's revision, we cannot tell. We can only compare the "current situation." In my view, "The mist from all directions opens its bundles / two windows hang one moon" is both "stranger" and "commoner" than the other; it is a more imaginary and broader thing. Firstly, the imagined mist must have a lot of bundles of clothing, but the two windows constitute the limits of concreteness, "unveiling" - in Heidegger's words - the concealed: "two windows hang one moon."

這首詩的高潮在第二部分, 那是漫遊的終結與醒悟的開始, 若無這部 分, 〈馬堡〉幾乎是不能成立的。其中的第一段是過渡, 即內與外的連 接點: “霧從四面八方打開它的包䘞，/兩個窗口懸掛一個月亮。 / 而 憂秕將略過那些書 / 在沙發上的一本書中停留”。只要和初稿相比, 我 們就知道到底發生了什麼: “大霧把我們的行李袋散放各處, / 在兩個 窗口各存一個月。/憂愁像遊客在每本書上劃過/並和書本一起被 放入沙發”。(菲野譯) 至於是翻譯上的差異還是作者修改的結果, 都 無從判斷, 我們只能比較“現狀”。依我看, “霧從四面八方打開它的包 䘞，/兩個窗口懸掛一個月亮”比另一版本更“奇”更“通”, 有一種更虛幺 更博大的東西。首先想想霧的包袱得有多大呀, 而兩個窗口又構成具 體的限制, “打開”, 按海德格爾的話來說, 即除去遮蔽——“兩個窗 口懸掛一個月亮”。

$(2005,282)$

Here, Bei Dao discusses the following quatrain:

Повсюду портпледы разложит туман,

И в обе оконницы вставят по месяцу.

Тоска пассажиркой скользнет по томам

И с книжкою на оттоманке поместится.

(Pasternak 1985, 1:71) 
Everywhere the mist will unpack hold-alls,

And they hang in both windows a moon a piece.

Longing will slip like a passenger along the volumes

And settle with a book on the ottoman.

(Pasternak 2003; amended)

In the Russian, Pasternak describes "a moon a piece" hung in "both windows." Whereas the two windows resolve into one moon in Bei Dao's translation and interpretation, there are two moons in Pasternak's Russian text and in Fei Ye's translation. Bei Dao sees the one moon in two windows as "stranger" and "commoner" in that it suggests the same thing exists in two places simultaneously but at the same time resolves this strangeness into the one common moon. This one moon can be seen from each window - just as we look up at the same moon from China, Russia, or anywhere else in the world.

Bei Dao's translation of Pasternak's line so that it describes one and the same moon seen through two windows implies a theoretical commitment to translatability - to the idea that we can encounter one and the same image through two languages - which his insistence on the success of his own translation only underscores. As Krenz notes in her chapter in this book, Bei Dao has become well known for his advocacy of the translatability of poetry, attacking, for instance, Wang Jiaxin's 王家新 more cautious and estranging approach to translation. Bei Dao's assertion that his translation of Pasternak's image is both "commoner" and "stranger," meanwhile, reflects his attempt, also noted by Krenz, to reconcile estranging and familiarizing approaches to translation and poetry.

When we look at the moon from two locations, do we notice the likeness of each of these two visions of the moon - or do we see them as one moon and so emphasize the metonymic connection that looking at the moon and hence being on the same world entail? Do we see two moons, two similar worlds, or one moon: one spatially (metonymically) connected world? Bei Dao's appeal to Heidegger's unveiling of the concealed offers both possibilities. Heidegger's concept refers both to the revelation of truth, the world, and being and also, arguably, to the realization that "there are various possible worlds or possible understandings of being" (Withy 2017, 1497), an idea here represented by the multiple perspectives, or "windows," on the moon. While Bei Dao's translation seems to violate the meaning of Pasternak's Russian text, it preserves Pasternak's commitment to metonymy, a commitment that is actually embodied by the combination of both Fei Ye's and Bei Dao's translations. On the one hand, to see two moons, rather than one, is to refuse the associations of likeness and metaphor in favor of 
an extreme subjectivism: what I see and what you see are never the same because our perspectives differ; nor is the moon the same when I view it through two different windows. On the other hand, in choosing to see one moon rather than two, we recognize that this one and the same moon is metonymically connected via the windows: there is no association by likeness but only association by spatial contiguity and coincidence - by metonymy and, since we only ever see one side of the moon, synecdoche.

The image of the moon or moons in two windows suggests the value of treating poems and translations not simply as objects for theoretical analysis but also as potential sources of new theoretical insights. The image might serve, for instance, as a figure for Bei Dao's adaptation of Russian literary theory to cross-cultural literary comparison, translation, and to his own approach to poetic language. For Bei Dao, Shklovsky's theory of "making strange" provides an imperative for poetic making and for his political struggle for the autonomy of art against a similarly oppressive communist regime. It connects two seemingly different poetic and political struggles - like the two moons - on the basis of their likeness.

At the same time, Bei Dao's cross-cultural comparison is metonymic, based on contiguity rather than resemblance (metaphoric). Bei Dao connects poetic strangeness and the autonomy of art through their coincidence in the theories of Shklovsky. He also implies a metonymic connection between Pasternak and himself by discussing the Russian writer's poem "Marburg" alongside his own visit to the German university town. Echoing a possible historical connection between "comparative astronomy" and comparative literature (Saussy 2016, 669-672), Bei Dao uses moon-gazing to emphasize that we each see - and so are metonymically connected to - the same things, but that we each see these things from different cultural, linguistic, geographic, and singularly individual locations.

Bei Dao makes these metonymic comparisons while drawing on a poet whose art, as Jakobson pointed out, is fundamentally metonymic, in whose work the person is dissolved into the things of the surrounding world: the actions of Pasternak's lyric subject are displaced onto the outside world of "flagstones," "cobblestones," and "mist." Hence, as Bei Dao notes, the house stands metonymically for the person within it and figures the interplay between the outer world and the inner world of the lyric subject, not unlike in Robert Frost's “Tree at My Window” (1951, 277-278). The house, in other words, is both a metonym for the person and a figure for Pasternak's use of metonymy to negotiate between inner feelings and the surrounding world.

Bei Dao conflates Shklovsky's and Jakobson's theories of artistic device and poetic function and transforms them into theories of the relationship 
between inner and outer worlds, of cross-cultural comparison, and of translation, including his translation of Russian poetry and literary theory into Chinese. Pasternak offers the two windows as a figure for seeing through another's pair of eyes. The lyric subject's actions are displaced onto the mist and his eyes onto the apertures of the "windows," or okonnitsy оконницы, a word in Russian that has the same root as the old Slavonic word for "eye," okо око, which is archaic or poetic in modern Russian. Bei Dao extends this figure to cross-cultural interpretation and translation: the translator allows us to see a text through new eyes by interpreting or remaking that text in another language.

Bei Dao displaces his own poetics onto the words of another via a Russian theory of the relationship between poetic language and inner and outer worlds. He displaces, for instance, his own experience of the battle for the autonomy of art and the role of strangeness onto Shklovsky, Jakobson, and Pasternak, drawing a comparison that is both a likeness and a metonymy: a connection not just of shared experience but of the same words on the page and of a walk through the same city. Jakobson reveals that metonymy in Pasternak is a formal device for highlighting the contents of the diegetic world and displacing feeling and agency onto those contents; Bei Dao extends Jakobson's insight to translation. The poet-translator finds in Russian Formalist theory the poetic license to metonymically displace one's own feelings and writing onto the contents of another's words, and, simultaneously, to assert the strange metaphoric likeness of translation and cross-cultural comparison.

Bei Dao also deploys that poetic license in his own poetry. His poem "February" (二月), here cited in Clayton Eshleman and Lucas Klein's translation, clearly alludes to Pasternak's poem of the same name:

The night is rushing to perfection

I drift inside language

the musical instruments of death

are filled with ice

who sings on the crevice

of days, water turns bitter

flames hemorrhage

pouncing like pumas to the stars

there must be form

for there to be dreams

夜正趨於完美
我在語言中漂流
死亡的樂器
充滿了冰

誰在日子的裂縫上

歌唱, 水變苦

火焰失血

山貓般奔向星星

必有一種形式

才能做夢 


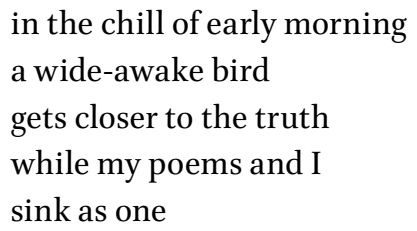

February in books: certain movements certain shadows

\author{
在早晨的寒冷中 \\ 一隻覺醒的鳥 \\ 更接近真理 \\ 而我和我的詩 \\ 一起下沉
}

書中的二月:

某些動作與陰影

Both "February" poems contain four stanzas; Pasternak's poem has sixteen lines, Bei Dao's seventeen. Bei Dao's poem not only echoes the form of Pasternak's poem, but comments on the importance of "form" and its relationship to content: "there must be form / for there to be dreams." That is, the imaginative associations of the poem can only take place in and through a form: form and content are inextricable.

Drawing on Jakobson, Bei Dao makes the form/content dichotomy dissolve in metonymy. His "February" echoes various features of the content of Pasternak's poem, including birds (compare Pasternak's тысячи грачей 'thousands of rooks'), watery imagery (“drift," “ice," “water”), the association of that watery imagery with uncontrollable emotion and pain ("hemorrhage," "bitter") and with noise ("musical instruments" and the implied sound of the bird), an emphasis on books and writing ("poems"), and the mixture of water with fire ("flames hemorrhage"; compare Pasternak's грохочущая слякоть / ... горит 'the rumbling slush / ... burns'). Other obvious echoes include the line "gets closer to the truth," which echoes Pasternak's чем случайней, тем вернее 'the more by chance, the truer' about verses that Слагаются ... навзрыд 'sobbingly compose themselves'. In Bei Dao's poem, the noisiness of truth is suggested not by violent sobbing but by the bird, which implicitly wakes the lyric subject from dreams in the early morning, and which metonymically represents that subject's wakefulness. The bird also echoes the summertime nightingales that stand for the lyric subject's sleepless night in Pasternak's "Marburg," which ends, like Bei Dao's poem, with the early morning.

Bei Dao not only borrows some of his content from Pasternak; he also adapts Jakobson's account of Pasternak's metonymic, phenomenological technique, where the surrounding world embodies the subject's feelings. The subject approaches the truth by attributing this approach metonymically to the surrounding world: to the bird who "gets closer to the truth." The water 
that turns bitter expresses the subject's bitterness. At the same time, Bei Dao's poem seems to adopt some extravagant similes and metaphors: "pouncing like pumas to the stars" and "the musical instruments of death." These appeals to likeness also remind us of the poetic emulation, or composition by analogy, that Bei Dao is undertaking.

The "shadows" in the last line, however, blend likeness (the silhouette or echo of the other poem) with metonymic adjacency, since shadows are "resemblances which must be in contiguity with that which they resemble" (Lock 1997, 336). Similarly, Bei Dao blends resemblance with metonymy in his reference to the poem that is his model. "February in books" might be better translated as "February in a book,"7 as it clearly refers, at least in part, to Pasternak's poem. Bei Dao not only emulates Pasternak's poem but brings it into the diegetic world of his own poem. The two poems, like the two moons, hang suspended each in their own linguistic and cultural frames, while simultaneously resolving into one.

In suggesting Pasternak's image of the moon or moons in two windows as a figure of translation and cross-cultural adaptation, I may seem to violate the distinction between my own critical or theoretical perspective and my object of analysis (Pasternak's poem and Bei Dao's essay and translation). I may seem, in other words, to blur the lines between theory and practice. But as I have been arguing, it is precisely the false dichotomy between theory and practice that inhibits a proper understanding of the interplay between the two in poetry and translation. Poetry and translation are not only shaped by literary and translation theory; they also often imply their own poetics or theories of translation.

As Bei Dao's use of Formalist theory illustrates, accounts of world literature and translation that operate within the form/content framework are likely to seek in vain for a better, more comprehensive understanding of how and why literature interacts across linguistic, cultural, and historical borders because they lack a crucial piece of the puzzle: the mediating role of theory. We need to think about the role of theory in translations between languages and cultural and historical contexts, but also and equally about the continuous translations that occur between the theory and practice of both literature and translation. It is not simply a question of putting the same content - the same moon - in a new formal frame or a new language, nor is it simply about recognizing how each new formal frame or language changes that content and produces another moon. Instead, we must recognize that poems and translations offer their own theoretical insights into the nature 
of form and content, the local and the foreign, and the relationships between them: they offer their own windows on the world.

\section{Works cited}

Al-Musawi, Muhsin Jassim. 2002. "Engaging Tradition in Modern Arab Poetics." Journal of Arabic Literature 33 (2): 172-210.

Bassnett, Susan. 2014. Translation Studies, fourth edition. New York: Routledge.

Beasley, Rebecca. 2007. Theorists of Modernist Poetry: T. S. Eliot, T. E. Hulme, Ezra Pound. London: Routledge.

Bei Dao 北島. 1993. “Translation Style: A Quiet Revolution.” Translated by Wei Deng. In Inside Out:Modernism and Postmodernism in Chinese Literary Culture, edited by Wendy Larson and Anne Wedell-Wedellsborg, 6o-64. Aarhus: Aarhus University Press.

—. 1996. Landscape over Zero, translated by David Hinton with Yanbing Chen. New York: New Directions.

-. 2005. 《時間的玫瑰》 [The rose of time]. Hong Kong: Oxford University Press.

-. 2011. Endure: Poems by Bei Dao, translated by Clayton Eshleman and Lucas Klein. Boston: Black Widow Press.

Boyd, Brian. 1991. Vladimir Nabokov: The American Years. Princeton: Princeton University Press.

Casanova, Pascale. 2004. The World Republic of Letters, translated by M. B. DeBevoise. Cambridge, MA: Harvard University Press.

Chen, Xiaomei. 2002. Occidentalism: A Theory of Counter-Discourse in Post-Mao China, second edition. Lanham: Rowman \& Littlefield.

Curnow, Allen. 1982. "Olson as Oracle: 'Projective Verse' Thirty Years On." In New Zealand through the Arts: Past and Present, The Turnbull Winter Lectures 1981, 31-44. Wellington: Turnbull Library.

Damrosch, David. 2003. What Is World Literature? Princeton: Princeton University Press.

Edmond, Jacob. 2012. A Common Strangeness: Contemporary Poetry, Cross-Cultural Encounter, Comparative Literature. New York: Fordham University Press.

- . 2018. "The Elephant in the Room: Theory in World Literature." Orbis Litterarum $73(4): 311-327$.

Even-Zohar, Itamar. 1979. "Polysystem Theory." Poetics Today 1 (1/2): 287-310.

Friedman, Susan Stanford. 2012. "World Modernisms, World Literature, and Comparativity." In The Oxford Handbook of GlobalModernisms, edited by Mark Wollaeger and Matt Eatough, 499-525. New York: Oxford University Press.

Frost, Robert. 1951. Collected Poems of Robert Frost. London: Jonathan Cape. 
Gálik, Marián. 1980. The Genesis of Modern Chinese Literary Criticism (1917-1930), translated by Peter Tkáč. London: Curzon.

Ghosh, Ranjan. 2017. Transcultural Poetics and the Concept of the Poet: From Philip Sidney to T. S. Eliot. New York: Routledge.

Hakutani, Yoshinobu. 1992. “Ezra Pound, Yone Noguchi, and Imagism.” Modern Philology 90 (1): 46-69.

Hart, Matthew. 2010. Nations of Nothing but Poetry:Modernism, Transnationalism, and Synthetic Vernacular Writing. New York: Oxford University Press.

Horrocks, Roger. 2016. "When the Mode of the Music Changes." Journal of New Zealand Literature 34 (2): 33-60.

Jakobson, Roman. 1987. Language in Literature. Edited by Krystyna Pomorska and Stephen Rudy. Cambridge, MA: The Belknap Press of Harvard University Press. Jintian bianjibu 《今天》編輯部 [Today editorial board]. 1978. 〈致讀者〉 [To the reader]. 《今天》 1: 1-2.

Krishnaswamy, Revathi. 2010. "Toward World Literary Knowledges: Theory in the Age of Globalization." Comparative Literature 62 (4): 399-419.

Liu, Lydia. 1995. Translingual Practice: Literature, National Culture, and Translated Modernity - China, 1900-1937. Stanford: Stanford University Press.

Liu Yan 劉燕. 2006. 《《傳統與個人才能》在 20 世紀中國的“旅行” [The “travels” of “Tradition and the Individual Talent” in twentieth-century China]. 《外國 文學評論》 3: 21-30.

Lock, Charles. 1997. “Debts and Displacements: On Metaphor and Metonymy." Acta Linguistica Hafniensia 29 (1): 321-337.

Lovell, Julia. 2006. The Politics of Cultural Capital: China's Quest for a Nobel Prize in Literature. Honolulu: University of Hawai'i Press.

McDougall, Bonnie. 1971. The Introduction of Western Literary Theories into Modern China, 1919-1925. Tokyo: Centre for East Asian Cultural Studies.

Manhire, Bill. 1987. "Breaking the Line: A View of American and New Zealand Poetry." Islands 38: 142-154.

Melas, Natalie. 2007. All the Difference in the World: Postcoloniality and the Ends of Comparison. Stanford: Stanford University Press.

Moretti, Franco. 2000. "Conjectures on World Literature." New Left Review 1: 54-68.

Olson, Charles. 1997. "Projective Verse.” In Collected Prose, edited by Donald Allen and Benjamin Friedlander, 239-249. Berkeley: University of California Press.

Pasternak, Boris. 1985. Избранное в двух томах [Selected works in two volumes], two volumes. Moscow: Khudozhestvennaia literatura.

- 2003. "Marburg." In From the Ends to the Beginning: A Bilingual Anthology of Russian Verse, translated by Tatiana Tulchinsky, Andrew Wachtel, and Gwenan Wilbur. bit.ly/2Uphjj6. Accessed September 4, 2018. 
Pollard, Charles W. 2004. New World Modernisms: T. S. Eliot, Derek Walcott, and Kamau Brathwaite. Charlottesville: University of Virginia Press.

Ramazani, Jahan. 2016. “Form.” In A New Vocabulary for Global Modernism, edited by Eric Hayot and Rebecca L. Walkowitz, 114-129. New York: Columbia University Press.

Rapatahana, Vaughan. 2015. “'Experimental' Poetry - Part Two.” Jacket2, October 22. bit.ly/2YTZR4Z. Accessed September 12, 2018.

Said, Edward W. 1983. The World, the Text, and the Critic. Cambridge, MA: Harvard University Press.

Saussy, Haun. 2001. Great Walls of Discourse and Other Adventures in Cultural China. Cambridge, MA: Harvard University Press.

-. 2006. "Death and Translation." Representations 94:112-130.

-. 2016. "Compared to What?" In "Trying to Make It Real: An Exchange between Haun Saussy and David Damrosch." Comparative Literature Studies 53 (4): 661-675.

Shih, Shu-mei. 2013. "Comparison as Relation." In Comparison:Theories, Approaches, Uses, edited by Rita Felski and Susan Stanford Friedman, 79-98. Baltimore: Johns Hopkins University Press.

Shklovsky, Viktor. 1919. «Об искусстве и революции» [Regarding art and revolution]. Искусство коммуны, March 30, по. 17.

- 1926. Третья фабрика [Third factory]. Moscow: Krug.

-.1929. O теории прозы [Theory of prose]. Moscow: Federatsiia.

—. 1966. Повести о прозе [Tales about prose], two volumes. Moscow: Khuozhestvennaia literatura.

Sturm, Terry. 2017. Simply by Sailing in a New Direction: Allen Curnow, a Biography. Auckland: Auckland University Press.

Wang, David Der-wei. 1986/1987. "Mao Tun and Naturalism: A Case of 'Misreading' in Modern Chinese Literary Criticism." Monumenta Serica 37: 169-195.

Weinberger, Eliot. 1996. “The 'Language' Letters.” In Written Reaction: Poetics Politics Polemics, 83-96. New York: Marsilio Publishers.

Withy, Katherine. 2017. "Concealing and Concealment in Heidegger." European Journal of Philosophy 25 (4): 1496-1513.

Zhang Longxi 張隆溪. 1986. 《二十世紀西方文輪述評》 [A critical introduction to twentieth-century Western literary theory]. Beijing: Sanlian shudian / Joint Publishing.

—. 1992. "Western Theory and Chinese Reality." Critical Inquiry 19 (1): 105-130. 


\section{About the author}

Jacob EDMOND is associate professor of English at the University of Otago. He is the author of A Common Strangeness: Contemporary Poetry, Cross-Cultural Encounter, Comparative Literature (Fordham University Press, 2012) and Make It the Same: Poetry in the Age of Global Media (Columbia University Press, 2019). His essays have appeared in such journals as Comparative Literature, Contemporary Literature, Poetics Today, Slavic Review, and The China Quarterly. 



\title{
$7 \quad$ Narrativity in Lyric Translation
}

\author{
English Translations of Chinese $\mathrm{Ci}$ Poetry
}

\author{
Zhou Min
}

\begin{abstract}
This essay investigates the phenomenon of narrativization in English translations of Tang- and Song-dynasty ci poetry, in contradistinction to a widely assumed opposition of lyric and narrative poetic modes. Atop the deconstruction of the standard binary between these modes, the author builds a new framework through which the translator can be appreciated as an "immersive reader" in texts of low experientiality.
\end{abstract}

Keywords: Chinese poetry, translation, experientiality, narrativization, formalist-cognitive approach, narratological analysis of lyric poetry

What does translation do to narrativity in lyric poetry? My interest in this matter begins with small observations on English translations of Chinese $c i$ (詞) poems, or classical Chinese song lyrics.

For instance, in Kenneth Rexroth and Ling Chung's 鍾玲 translation of Li Qingzhao’s 李清照 “To the Tune “The Perfumed Garden” (轉調滿庭芳) (1979, 47; emphasis added in this and the next three examples):
芳草
池塘
fragrant grass
pond $^{1}$

1 The word-for-word translation for each line of poetry in this essay balances on the two principles that it should be as literal as possible, and that where possible, it should use the words rendered in the "proper" translation under discussion. It is designed to assist readers to quickly identify the textual nuances pertaining to my argument in the translation in question. I would like to stress that I make no claim for these as being the "correct" translations, or the "closest equivalents" to the Chinese source texts.

Van Crevel, Maghiel and Lucas Klein (eds.), Chinese Poetry and Translation: Rights and Wrongs. Amsterdam: Amsterdam University Press, 2019

DOI: 10.5117/9789462989948_CHO7 
$\begin{array}{ll}\text { 綠陰 } & \text { 庭院 } \\ \text { green shade } & \text { garden }\end{array}$

There are fragrant plants around the pond

In the deep green shade of the garden...

Or, in Glen W. Baxter's translation of Wen Tingyun's 溫庭筠 “To the 'Waterclock' Tune [Keng-lou tzu]" (更漏子) $(1965,337)$ :

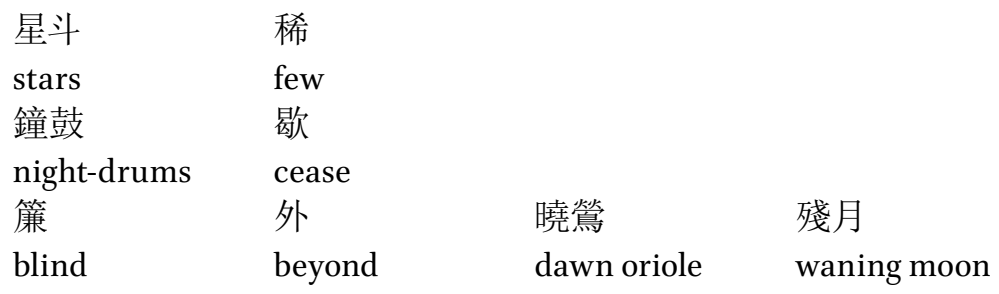

The stars grow few

The night-drums cease

Orioles call beyond the blind as the moon sinks into dawn ...

Or, in Jerome P. Seaton's translation of Ouyang Xiu’s 歐陽修 “Tune: 'Song of Picking Mulberry' (Ts'ai-sang tzu)" (採桑子) $(1975,331)$ :

$\begin{array}{llll}\text { 群芳 } & \text { 過後 } & \text { 西湖 } & \text { 好 } \\ \text { flocks of blossoms } & \text { gone } & \text { West Lake } & \text { good }\end{array}$

flocks of blossoms gone, yet West Lake's good.

Or, in Lois Fusek's translation of Wen Tingyun's 溫庭筠 “Deva-like Barbarian (P'u-sa man)" (菩薩蠻) $(1982,37)$ :

\begin{tabular}{|c|c|c|c|}
\hline $\begin{array}{l}\text { 水晶 } \\
\text { crystal }\end{array}$ & $\begin{array}{l}\text { 䇥 } \\
\text { curtain(s) }\end{array}$ & $\begin{array}{l}\text { 裏 } \\
\text { within }\end{array}$ & $\begin{array}{l}\text { 玻璃 } \\
\text { glass }\end{array}$ \\
\hline & 秋色 & 淺 & \\
\hline us-root (color) silk & autumn color ${ }^{2}$ & light & \\
\hline
\end{tabular}

2 "Autumn color" refers anaphorically to the pale white of lotus roots. In ancient China, white was regarded as the color of autumn. Moreover, in classical Chinese poetry, lotus roots usually have a strong association with autumn, when they ripen. 
Within crystal curtains, she rests on a crystal pillow.

...

She wears an ivory gown, pale as lotus root.

Most of the words highlighted above are function words normally believed to be added for grammatical purposes. Yet, trivial as they might appear to be, they inevitably help evoke a specific personal, spatial, and/or temporal relation that is absent from the original. Do these words merely fulfill the grammatical rules of the English language? Is it simply by insignificant coincidence that different translators all slip in such words? More importantly, do these words mean anything to the translated ci poems as lyric poems? What can they tell us about the translator's role in poetry translation?

This essay, modeled on Monika Fludernik's cognitive narratological framework, demonstrates a variety of textual manifestations and implementations of an increase of narrativity in the English translations of Chinese $c i$ poems. Based on Fludernik's idea of "experientiality qua narrativity" and "narrativization," it argues that this increase of narrativity, associated first and foremost with the presence of (at least) one anthropomorphic being and the representation of his or her experiences within a textual world, has emerged from the translator-as-reader's cognitive response to the original poems. Taking cues from the theory of aesthetic illusion, this essay then foregrounds the translator-as-reader's imaginary experience of the represented worlds in the originals "as if from the inside" (Wolf 2013a, 11), hoping to shed new light on the translator's role in lyric translation. There is an enduring dilemma of either overstating a poetry translation's deficiency as a poem because of its failure to reproduce all the glory of the source poem, and thereby forgetting that, as a translation, it is doomed to be similar to yet different from the latter - or else overemphasizing its production as a translation, thereby ignoring those features that matter to it as a poem. Premised on the belief that a translated poem should be treated as both a poem and a translation simultaneously, this essay also aims at developing a formalist-cognitive approach to poetry translation.

\section{Narrativity and the lyric}

What is narrativity in lyric poetry? Or, to push back even further, can lyric poetry, conventionally regarded as the antithesis of narrative, possess narrativity in the first place? 
The conventional view of lyric as the antithesis of narrative, as "all that narrative is not" (Müller-Zettelmann 2011, 232), has been forcefully questioned by recent scholarship, partly due to the conscious effort to make full use of the versatility of narratology, and partly, as Monique R. Morgan has pointed out, due to "a larger resurgence of formalist approaches to literature" $(2007,930)$ that calls for a return to favor of the formal and linguistic dimension of texts. Scholars have begun advocating a treatment of lyric and narrative not as opposites but as hybrids (e.g. Dubrow 2006; Morgan 2007), and the application of narratological concepts and approaches to lyric poetry (e.g. Hühn and Kiefer 2005). But despite the valuable insights of endeavors to cut across generic boundaries, in most of these studies narrativity has still been defined, explicitly or implicitly, in a traditional way, i.e. as the existence of a (physical or psychological) story or as the concatenation of story and discourse. The former is a response to the conventional claim that a lyric has a teller but no story (Scholes, Kellogg and Phelan 2006, 4; cf. Morgan 2009, 5), while the latter emphasizes how a story can be told in ways particular to lyric poetry. Either way, narrativity has been presented as "a categorical quality operating on a 'yes-or-no' basis" (Wolf 2003, 183), something that either does or does not exist.

However, though a lyric poem can be read as a narrative, it cannot be expected to be as narrative as a narrative; otherwise it would not have been a lyric poem in the first place! As Gerald Prince has repeatedly stressed, "different texts exhibit different kinds or different degrees of narrativity (with some being more narrative than others...)" (1996, 96; see also 1982, 1999). For a study such as mine that treats translated $c i$ poems simultaneously as lyric poems and as translations (that is, texts in relation to other texts), definitions that consider narrativity as a categorial quality would not be able to account for the subtle variations in narrativity between a lyric and its translations. What is needed is "a gradient that admits a 'more or less' and creates 'weaker' or 'stronger' narratives" (Wolf 2003, 183). Such is Fludernik's definition of narrativity, which centers on "experientiality of an anthropomorphic nature" $(1996,26)$, i.e. "on the parameters of specificity (temporally and spatially) as well as the embodiment of protagonists" $(2005,100)$.

When first proposed in Towards a 'Natural' Narratology, narrativity, or what Fludernik calls experientiality, is defined as "the quasi-mimetic evocation of 'real-life experience'" $(1996,12)$. It is constituted with a series of natural cognitive parameters. The first parameter is specificity, which is defined as "a record of the vicissitudes of human existence under the given circumstances of a particular place at a particular time" (29, emphasis added). Fludernik also emphasizes another parameter, namely embodiment 
(or embodiedness), which is "most basic to experientiality" and to which specificity can be subsumed:

Embodiedness evokes all the parameters of a real-life schema of existence which always has to be situated in a specific time and space frame, and the motivational and experiential aspects of human actionality likewise relate to the knowledge about one's physical presence in the world.

(3o, emphasis added)

Embodiment correlates, on the one hand, with the protagonist's spatial and temporal orientation, and on the other with the protagonist and/or narrator's "emotional involvement with the experience and its evaluation" (13), in the sense that evaluation makes "narrative experience relevant to oneself and to others." In other words, experientiality "reflects a cognitive schema of embodiedness that relates to human existence and human concerns" (29, emphasis added). Fludernik continues on the equivalence between experientiality and narrativity:

Experientiality in narrative as reflected in narrativity can therefore be said to combine a number of cognitively relevant factors, most importantly those of the presence of a human protagonist and her experience of events as they impinge on her situation or activities. The most crucial factor is that of the protagonist's emotional and physical reaction to this constellation ... since humans are conscious thinking beings, (narrative) experientiality always implies - and sometimes emphatically foregrounds - the protagonist's consciousness.

(1996, 30, emphasis added)

As for the narrator, who can be story-internal or not, she later elaborates:

For the narrator the experientiality of the story resides not merely in the events themselves but in their emotional significance and exemplary nature. The events become tellable precisely because they have started to mean something to the narrator on an emotional level. It is this conjunction of experience reviewed, reorganized, and evaluated ... that constitutes narrativity. (2003, 245, emphasis added)

Therefore, it is not so much that the central aim and function of narratives is to tell a story, a temporal sequence of happenings and events, as that "sequences are an integral part of human experience" that would feature 
most prominently in stories $(2006,59)$. Narrative can portray dynamic event sequences experientially, but more essential is "the experiential depiction of human consciousness tout court" $(1996,30)$. In a nutshell, experientiality qua narrativity "consists in its implication or activation of a number of cognitive parameters, i.e. basic structures of human engagement with the world," "particularly the embodiment of cognitive faculties, the understanding of intentional action, the perception of temporality [and spatiality], and the emotional evaluation of experience" (Caracciolo 2014). Therefore, the central aim of narrative is to communicate an "anthropocentric experience" by "drawing on fixed patterns of behavior as well as conveying thoughts and feelings, and depicting perceptions and reflections" (Fludernik 2006, 59).

But can lyric poetry possess experientiality? Is it not lyric poetry's ability to entice us to "step ... out of experience into something else" (Frye 1985, 35) that has always been celebrated as one of its most prominent features? Though Fludernik admits in Towards a 'Natural'Narratology that "poetry can turn to narrative ... to the extent that a situation is depicted which then allows for the constitution of experientiality" (311), she too adopts a rather conventional view on lyric poetry and speaks of "poetry's typical lack of experientiality (and hence narrativity)" due to the lack of "fictional situations" that "need to be situated at a particular (even if indefinite) moment in time, and the story-world" that "needs to be locatable as a non-hypothetical realm" (355). In her later works, Fludernik expands the purview of experientiality to lyric poetry and acknowledges that "many lyric texts - though they do not tell a story - purvey hints of experientiality in the intermittent evocation of a specific human consciousness embodied in a specific time and place" (2003, 259n11). Her "Allegory, Metaphor, Scene and Expression" (2005), her first (and so far, only) direct engagement with experientiality in lyric poetry, is particularly important to my work. It is here that Fludernik demonstrates the presence of experientiality (or the lack thereof) as a textually identifiable phenomenon through detailed textual analysis. ${ }^{3}$

As my study focuses on the translations of $c i$ poems, a question follows: if experientiality is textually identifiable, does it manifest itself in the same

3 For example, she comments that in Shakespeare's sonnet 30 , though it is marked by an initial when-clause ("when to the sessions of sweet silent thought"), which proposes a situation that the poem then goes on to describe, elaborate on, and resolve, "what makes a narrative reading possible in the first place, the temporal conjunction 'when,' at the same time prevents this type of poem from being truly narrative - 'when' in fact is to be read as 'whenever' and refer to a recurring scenario, not to a specific one" (121-122). She also argues that Sidney's sonnet 16, though it seems to "tell a story" by opposing a "then" with a "now," is in fact argumentative and a metaphoric description of the lover's emotional plight because the virtual scenarios in the poem are metaphorical and "rarely move ... towards an evocation of a specific setting or residual narrativity" (114-115). 
way and to the same level in the translations as in the originals? If not, what can we learn about the translated ci poems as poems and as translations from the perspective of experientiality?

\section{Experientiality qua narrativity in the English translations of $c i$ poetry}

To answer these questions, in this section, following Fludernik in moving from theorization to detailed textual analysis, I will offer my own reading of some English translations of $c i$ poetry vis-à-vis their Chinese originals. My comparative analysis demonstrates that compared to the source texts, the translations possess a higher degree of experientiality/narrativity, which manifests itself in textual features that amount to a stronger evocation of real-life experience, especially of at least one anthropomorphic being, or a specific human consciousness, of its temporal and spatial perception, and of its emotional and evaluational reaction as if it lives through or witnesses the events and observes existents, or objects, in a possible world as a human(-like) experiencer. ${ }^{4}$

Let me return, then, to the four translations mentioned at the beginning. Kenneth Rexroth and Ling Chung's translation of Li Qingzhao:

There are fragrant plants around the pond

In the deep green shade of the garden.

\section{芳草池塘 \\ 綠陰庭院}

The original lines consist of four poetic images (grass, pond, shade, garden), which, though textually juxtaposed, are given no specific spatial relation. The translation, however, with three prepositions ("around," "in," "of"), connects all of them together to form "an emergent constellation of spatially related entities" (Herman 2001, 534). This mirrors our real-life experience of perceiving existents within the same space as being spatially interrelated, and also

4 Modeled on a cognitive narratological framework, my study treats these translations as, in part, textual products of the translator-as-reader's mental responses to the Chinese texts. My analysis in this section therefore aims to demonstrate the textual representations of experientiality that the Chinese poems do not provide, in preparation for my argument in the next section of a mental phenomenon that results in them. It is not a comparison of the capabilities of Chinese and English as languages. 
implicitly enhances the impression of a perceiving consciousness imposing spatial contiguity onto the existents. In addition, three of the four existents are textualized as definite noun phrases, constituting a linguistic gesture towards the reader to feel "drawn into a 'world' already existing" (Wales 1989, 111) because definite references tap into the reader's familiarity with the referents. That is, they help prompt the reader to construe a world as if it really exists.

Baxter's translation of Wen Tingyun recasts the juxtaposition of images in the Chinese text not only as spatially related existents, but as dynamic events in a temporal relation:

The stars grow few

The night-drums cease

Orioles call beyond the blind as the moon sinks into dawn ...

\section{星斗稀 \\ 鐘鼓歇 \\ 簾外曉鶯殘月}

The original line 簾外 / 曉鶯 / 殘月 'outside blinds / morning oriole(s) / waning moon' offers three static existents, the last two of which form a spatial relation with the first: outside the blinds there are orioles and a moon. The translation expands two static existents, the morning oriole(s) and waning moon, into dynamic events that are temporalized as happening simultaneously ("as"). Moreover, in the Chinese text, the two existents are presented inanimately, as if suspended in an instant of time, creating a sense of everlastingness in timelessness (Poulet 1954, 6), a typical technique of lyric poetry (see Culler 2015, 211-243). The translation, however, by giving orioles and the moon the ability to act ("call," "sinks into"), locates them within the flow of time (and implicitly the change of space), and submits them to movement and changes, which, according to Werner Wolf, "have a particular affinity to experience" $(2009,156)$. On the other hand, like the last example, moving existents and their spatiotemporal relation also foreground a human-like consciousness on the scene to perceive the simultaneous movement of the existents.

The presence of a consciousness of anthropomorphic nature can also be enhanced by its mental or psychological reaction to the physical world it experiences, as in Seaton's translation of Ouyang Xiu:

flocks of blossoms gone, yet West Lake's good. 
The translation follows the original line lexically and syntactically. However, the additional conjunction "yet," signifying concession, immediately brings forth a consciousness through whose perspective praising West Lake in the absence of blossoms would contradict what is usually taken to be natural according to real-life experience - with all the blossoms gone, West Lake should not be good any more, yet it still is. ${ }^{5}$ Therefore, "yet" also implies this consciousness's affective response, a feeling of surprise, to the immediate environment.

In other cases, instead of calling forth a human-like consciousness to establish an implicit center of experientiality, adding personal pronouns on the textual surface will conjure up an anthropomorphic being or embodied human protagonist. This is Lois Fusek's translation of Wen Tingyun:

Within crystal curtains, she rests on a crystal pillow.

…

She wears an ivory gown, pale as lotus root.

\section{水晶䈴裏玻璃枕}

\section{藕絲秋色淺}

The original poem is set in a highly feminine atmosphere, but the "people" concerned, either personae or protagonists, remain completely shadowy (Chang 1980, 36-37). The most obvious hint of a (female) being does not appear until the last two lines of the poem, yet even there, she - if there is a she - can only be inferred synecdochically from "temples" and "head." But Fusek's translation increases experientiality via the presence of an embodied and gendered protagonist ("she") on the scene, and the making of this protagonist into a human in action ("rests," "wears"). Increased narrativity also manifests in the addition of a "real" existent ("gown") - or what we would really see if we were in her world - and in the evaluation imposed on the existent that draws an analogy ("as"). Both signal the immediate

5 This is one of ten poems from a ci sequence, all of which begin with a first line of identical syntax, for example, 輕舟短棹西湖好 or 畫船載酒西湖好. However, these two lines are rendered by Seaton as "a little boat with stubby oars, and West Lake's good" and "painted skiff with a load of wind, and West Lake's good." A comparison with these other translations makes it even clearer that the evaluating consciousness is aware of the contradiction with natural experience and the need for concession.

6 The two lines are 隻鬢 / 隔 / 香紅 'two temples / separated (by) / fragrant red (flowers)', and 玉釷 / 頭上 / 風 'jade hairpin(s) / atop head / wind'. 
participation of an experiencing consciousness with a world-internal position.

In what follows, I will analyze one complete poem alongside its translation. The analysis will show, on the scale of an entire poem, how experientiality is represented in ways and degrees that are different from those in the original. This is Wang Jiaosheng's 王椒升translation of “Tune: 'Sand Washed by Waves' In Memoriam” (浪淘沙), by Li Qingzhao (1989, 113, emphasis added):

Outside the curtains the howling fifth-watch wind

Blows away the last vestige of my melancholy dream.

Who will be my company

When I go up the painted tower again?

5 I remember how he loved to chaff me

Poking the fire sideways with my jade hairpin -

A memory now vanished like the auspicious omen

In the seal-character incense.

Recollections flood my mind

10 Ofhappy days gone by

When the two of us climbed Purple Gold Peak hand in hand

Gazing at the hazy view below:

A river of spring waves wrapped in rain and mist, Gliding away as if half-sober and half-tipsy.

15 I keep on my garment

Tears shed the day before -

To shoot to the wild geese

As they wing past.

\begin{tabular}{|c|c|c|c|c|}
\hline 簾 & 外 & 五更 & 風 & \\
\hline $\begin{array}{l}\text { curtain(s) } \\
\text { 吹 }\end{array}$ & $\begin{array}{l}\text { outside } \\
\text { 夢 }\end{array}$ & $\begin{array}{l}\text { fifth watch } \\
\text { 無踤 }\end{array}$ & wind & \\
\hline blow (away) & dream & no trace & & \\
\hline 畫樓 & 重 & 上 & 與誰 & 同 \\
\hline painted tower & again & go up & with whom & together \\
\hline 記得 & 玉釷 & 斜 & 撥火 & \\
\hline remember & jade hairpin & slantingly & poke fire & \\
\hline precious seal & & turn to & nothing(ness) & \\
\hline
\end{tabular}




$\begin{array}{llll}\text { 回首 } & \text { 紫金峰 } & & \\ \text { look back } & \text { Purple Gold } & & \\ & \text { Peak } & & \\ \text { 雨 } & \text { 潤 } & \text { 煙 } & \text { 濃 } \\ \text { rain } & \text { hazy } & \text { mist } & \text { thick } \\ \text { 一江 } & \text { 春浪 } & \text { 醉醒中 } & \\ \text { a river (of) } & \text { spring waves } & \text { tipsy-sober } & \\ \text { 留得 } & \text { 羅襟 } & \text { 前日 } & \text { 淚 } \\ \text { keep } & \text { garment } & \text { the day } & \text { tears } \\ & & \text { before } & \\ \text { 彈與 } & \text { 征鴻 } & & \\ \text { shoot to } & \text { wild geese } & & \end{array}$

In the Chinese text there is no mention of a second participant in the textual world - even if the presence, implicit or explicit, of a lyric persona is the default setting of a lyric poem. The only phrase that might hint at an interpersonal relationship is 與誰同 'with whom' at the end of 1.3 . This second participant, however conspicuous his (?) absence is in the Chinese, has not only been embodied as a male participant ("he"), but is also given the ability to act like a "real" human ("loved," "to chaff," "climbed," "gazing at") and to engage in interpersonal activity ("the two of us," "hand in hand"). This male participant also evokes a strong interpersonal relationship through which the lyric persona that has the potential of being "a universal ' $I$ ' belonging to no one and to everyone" (Howe 1996, 6) is further embodied, becoming a (supposedly) female personal subject.

The translation then creates, out of the single noun phrase 紫金峰 'purple gold peak', an event in the past involving two human participants in action. ${ }^{7}$ The sudden change to past tense temporalizes the event of "climb[ing] Purple Gold Peak" and at the same time pinpoints a specific experiential position, a "now" for the lyric persona, from which the event of climbing Purple Gold Peak can be regarded as past. Also heightened is the lyric persona's perceiving consciousness, which has been evaluating, commenting on, and reflecting on existents and events within the textual world. At the beginning of the translation, through the evaluative adjectives "howling" (l. 1) and "melancholy" (1. 2), the lyric persona as a protagonist has a psychological reaction to the situation like a real person; on the other hand,

7 Not to mention that the Chinese verb-object 回首 'to turn one's head' can refer to either physically turning around to look back at Purple Gold Peak, or psychologically looking back at an event that happened in the past. 
as a speaker, the lyric persona has also justified the mentions of "wind" and "dream," because they have an emotional significance for the protagonist. Secondly, the expression 璸管 / 成空 'precious seal-character / turns into nothing(ness)' functions figuratively, in that "precious seal-character" refers to the shape of the incense as well as to the incense itself, while "turning into nothing(ness)" could mean the incense burning up, but also brings forth a strong tendency towards reading past events figuratively as vanishing into nothing. Metaphorical images tend to impair experientiality, in the sense that we do not normally see flowers that can weep or a man who is also a lion; at first glance, then, the translation merely unfolds and combines all the meanings (incense shape, incense; turning into ash, turning into nothingness) into the vehicle of a simile. By clarifying what the real existent is ("a memory"), however, and by explicitly indicating that the connection between the metaphorical and the literal (between the "non-existing" and the "existing" within the represented world) is validated by the reflecting consciousness ("vanished like"), the metaphorical images have been "contextualized" to "make 'commonsense' ... [because] they are taken as metaphors and contextualized as such" (Stewart 1989, 35). The same can be said about 一江 / 春浪 / 醉醒中 'a river (of) / spring waves / tipsy-sober.' Since the translator understands 醉醒 'tipsy-sober' as the figurative modifier of 春浪 'spring waves' (rather than of the protagonist), giving the latter properties that it could not have in real life, the translation has recourse to a perceiving consciousness drawing an analogy ("as if"). That is, the "spring waves" are not really "half-sober and half-tipsy"; they are thus only as perceived by a consciousness within that world.

What my textual analysis shows is that the translations contain textual details that strongly enhance the emergence of the lyric persona and/ or protagonist(s), and the specification of their (temporal and spatial) experience(s) within the textual world, as well as their emotional and evaluational involvement with such experience(s). The translations therefore exhibit a higher degree of experientiality than the source texts.

\section{Narrativization, aesthetic illusion, and the translator as an immersive reader}

The analysis in the preceding section concentrates on the significance of the textual features under discussion to the translated $c i$ poems as lyric poems - in short, they increase narrativity. But why would translations demonstrate a higher degree of narrativity? In this section, I will introduce 
two other theoretical concepts, narrativization and aesthetic illusion, to show the implications of these textual features for the translated ci poems as translations and for our understanding of translational behaviors. That is, these textual features testify to the translator's mental involvement with the textual worlds as an immersive reader.

Silhouetted against the backdrop of cognitive narratology, which investigates "mental processes and representations corresponding to the textual features and structures of narrative" (Bortolussi and Dixon 2003, 24), Fludernik complements experientiality, which foregrounds the text's capability of mimetically eliciting real-life experience, with narrativization, the "receptional and creative aspect of narrativity" (1996, 373). In Fludernik's theoretical framework, the reading process is "fundamental to the constitution of narrativity" $(2003,244)$, in that the process of narrativization is "the sheer act of imposing narrativity" (1996, 34) on a text. Fludernik argues that

Narrativity is not something that is simply present in or absent from texts but rather something that is recognized by readers or sometimes projected onto the text by them. The narrativization of reluctant story material in the reading process thus reinforces or even creates narrativity for certain texts.

$(2006,109)$

That is, narrativization is the reading process "that naturalizes texts by recourse to narrative schemata" $(1996,34)$, i.e. by connecting them to cognitive frames based on "real-life" human experience. If a text itself is highly experiential, the process of narrativization comes automatically and probably unnoticeably. However, "[w]hen readers are confronted with potentially unreadable narratives, texts that are radically inconsistent, they cast about for ways and means of recuperating these texts as narratives" (ibid.). By doing so, narrativization imposes experientiality on a text, and thus "reinforces or even creates narrativity." I therefore argue that the reason the translations hold a higher degree of narrativity/experientiality is because translators are also readers in the first place, who in the mental process of comprehending the source texts narrativize them according to cognitive schemata based on their "real-life" human experiences, thus imposing experientiality on the original poems. Subsequently, in the production of the translations, the imposed narrativity can be projected onto the textual surface in the translations, thereby rendering the translations relatively more experiential/narrative. 
So how does the reader activate natural and cognitive parameters to narrativize a text? Fludernik explains that narrativization

produces narrativity by means of a mediation through consciousness. That mediating consciousness can be situated on the level of the fictional world, in a protagonist; on the level of narration ... or even in the reader (or her proxy).

$(1996,372)$

That is, narrativization takes place through identification with the consciousness (1) of a protagonist, "on the plane of the represented world, in its re-cognition by means of basic frames" (372), (2) of a narrator, "in the constitution of story experience as narration" (ibid.), or (3) of the reader, when a "story-internal consciousness" has been evoked and "the reader takes an internal position with regard to the represented events, as if she were a witness rather than a mere camera eye" (201). The result of the mediational process is "the establishment of the mimetic illusion, of narrativity" (372, emphasis added).

Fludernik does not go further down this path into the relation between experientiality-and-narrativization on the one hand, and the evocation of "mimetic illusion," on the other. But another theoretical concept turns out to be particularly relevant: aesthetic illusion. Aesthetic illusion refers to a "particular imaginative response" triggered by representational artifacts in their recipients (Wolf 2013a, 6), which can elicit a "quasi-experience of, and immersion in, represented worlds" (11). It "consists primarily of a feeling, with variable intensity, of being imaginatively and emotionally immersed in a represented world and of experiencing this world as a presence (even if it is a narrative of the past) in an as-if mode, that is, in a way similar (but not identical) to real life" (Wolf 2017, 32). In this immersion, the reader/ recipient would be allowed to "experience ... [the represented] worlds as well as what exists and happens within them as iffrom the inside" (Wolf 2013a, 11, emphasis added), and become "recentered," i.e. imaginarily occupying a position within the represented worlds (12), whether that position overlaps with a character's or not. Thus, aesthetic illusion foregrounds a state of immersion in which the reader imaginarily steps out of their own hereand-now situation and temporarily steps into an alternative textual world, experiencing this world from within as if it is real, while still maintaining a distance, i.e. a "rational and observational awareness 'from without" (22). Immersion and distance always coexist, and foregrounding the former does not nullify the latter. 
As I have explained in detail elsewhere (2018), Fludernik's experientialityand-narrativization framework echoes the theory of aesthetic illusion in many ways. Most importantly, aesthetic illusion, like Fludernik's experientiality, is a matter of degree, and relies on both the text's (or other artifact's) own potential and the recipient's contribution. That is, texts (or other artifacts) that hold a higher degree of experientiality also possess a stronger potential to induce aesthetic illusion, and vice versa. Yet when reading a less experiential text, the reader's "share" or "cognitive contribution" (Wolf 2013a, 8-9), i.e. the reader's active immersion, can supplement these experiential details. "Narrativization" is Fludernik's name for the reader's cognitive contribution as activated through the mental state of immersion.

Many if not most classical $c i$ poems are texts of low (but not zero) experientiality, ${ }^{9}$ and as with many lyric poems, they display a generic resistance to aesthetic illusion. They are usually quite short, which means the constitution of worlds inside them often takes place fragmentally and intermittently. They are written according to strictly prescribed rhyme schemes and tonal patterns set by the song tunes, which means they tend to foreground formal self-referentiality and linguistic defamiliarization. More often than not, they are highly ambiguous, and after centuries of metaphorical and allegorical reading imposed on them, they have almost been mystified into a genre that strives for the ultimate depth of inspiration and suggestiveness through extreme subtlety of expression. ${ }^{10}$ It is not a genre that has been used to keep detailed "lifelike" records of human experience.

8 I want to emphasize that the limits of a given text's cognitive contribution to inducing aesthetic illusion have nothing to do with any "lack" of ability in the language itself, but rather with its particular textual representations. Classical Chinese is fully capable of representing spatiotemporal relations through the use of prepositions and conjunctions or fully gendered, embodied, and socially specified personae/protagonists (e.g. 鳳歸雲 (兒家本是)). In addition, a text's (or other artifact's) ability or inability to induce aesthetic illusion is not only an inherent quality, but also a potential, the fulfillment of which relies on the recipient's response. In my study, it is the fact that the translations contain textual details that are absent from the source texts and that elicit a "quasi-mimetic evocation of 'real-life experience'" (Fludernik 1996, 12) that leads to my argument of the translator-as-reader's narrativization through mental immersion. I make no claims that classical Chinese texts intrinsically rate low in experientiality or ability to induce aesthetic illusion. 9 As Wolf points out, lyric poetry still fulfills at least two minimal conditions of aesthetic illusion, namely, "at least one anthropomorphic being ... present in a textual world, and (an) experience(s) related to this being” (2013b, 220). I do not claim that all ci poems are of equally low degree of experientiality, however. Some are more narrative than others.

10 In the tradition of criticism on $c i$ poetry, $c i$ poetry is often portrayed as so mysterious and intangible a genre that it can only be talked about in an equally mysterious tone. In the words of Miao Yüeh, one of the great critics of ci poetry: "The world of the lyric is like a mountain viewed through the mist, or a flower seen in the moonlight. Its beauty resides in its elusive ambiguity, 
Brief, defamiliarized, and ambiguous as they may be, however, just as in other texts of low experientiality, the limited share of aesthetic illusion on the texts' part will only encourage the reader to contribute by recourse to natural cognitive parameters, to actively and imaginatively (re)experience a world and its elements in analogous ways to real-life experience. In my opinion, the recognition of the reader's re-cognition of a textual world in the form of immersion is significant to our understanding of translational behaviors. It is my contention that this points to an important role of the translator that has been sidelined or neglected by translation studies, namely, that of the translator as an immersive reader.

Conventionally, a great many of the textual features discussed in the previous section have been readily explained as the translator's endeavor to fill the gaps between Chinese and English as languages. In other words, those textual features in the translations are obligatory shifts (Toury 1980), added to fulfill the grammatical requirements of the English language. However, I would like to stress that while English grammar might require, for example, that nouns be connected with conjunctions or prepositions, the choice of one particular conjunction or preposition demands an imagination of what the world is like to the translator in the first place, e.g. that fragrant plants are "around" the pond, not "over" it. Too many translational decisions long taken for granted as determined by the grammatical reproduction of the words, phrases, sentences of a text necessarily involve imagination of a world in a text with people, objects, events, actions, etc. To overlook the immersive participation in the world inside the text, a mental state intrinsic to the translator's primary role as reader, would run the risk of arbitrarily forcing the translator to "stay outside." The theoretical linkage between experientiality, narrativization, and aesthetic illusion explains many textual performances that otherwise seem uncorrelated, insignificant, or inexplicable under the presumption of the translator's distanced status, according to which the translator interacts either with the text (e.g. in pursuit of equivalence) or with the world outside the text (e.g. in response to social-historical context or ideologies of their own reality). More importantly, this theoretical linkage urges us to allow the translator to be what Kendall Walton would call an immersive "appreciator," who is "caught up in the spirit of the work and plays along with it," rather than merely a distanced "critic" who "considers the work and the games to be played with from without, from an onlooker's point of view" $(1990,393)$.

and if we insist on bringing it out into the light we are acting contrary to the very nature of the form, and will only end up with something shallow and crude" $(1980,37)$. 


\section{Conclusion: narrativity, poeticity, and translationality}

That a poetry translation should be, but too often fails to be, a poem has haunted translation studies ever since Robert Frost's curse, as it were, that poetry "is that which is lost ... in translation" $(1959,7) \cdot{ }^{11}$ Emphasis on the poeticity of translated poems takes many forms, but is most conspicuous in the accusation of their failure to achieve an idealist equivalence, be it that of the original's semantic, phonetic, syntactic, rhetorical, and stylistic excellence, or, in a broader sense, that of its "poetic value," and in the attempt to prove that translations "inevitably fall short of reproducing all the glory of the original" (Baker 1993, 234). On the other hand, the belief that translation is a complicated process that involves more than the processing of a source text advocates a closer engagement with social, cultural, economic, and political circumstances in which translating occurs and by which it is conditioned. Those features that matter to a (translated) poem as a poem are too often sacrificed in analysis, and "detailed textual signifiers, no matter how much respect they garnered in principle" might well be made "comparatively invisible, and therefore functionally insignificant" (Tucker 1999, 533). ${ }^{12}$ This essay is thus designed in response to what I see as a dilemma in the study of poetry translation, and attempts to answer what certain textual details in these translations mean to the translated $c i$ poems both as poems and as translations at the same time.

Inspired by new formalism ${ }^{13}$ and recent developments in cognitive narratology, this essay has adopted a formalist-cognitive approach through

11 The full sentence, usually misquoted, reads: "I like to say, guardedly, that I could define poetry this way: It is that which is lost out of both prose and verse in translation."

12 The ramifications, in the opinion of many scholars, could be serious for literary studies, and particularly for poetry studies. Marjorie Perloff expresses a strong concern that the boundaries between the literary and the nonliterary have been blurred, and "the literary, if it matters at all, is always secondary; it has at best an instrumental value" $(2007,655)$. She charges the claim of "interdisciplinarity" with being "other-disciplinarity" for "there is one discipline that is conspicuously absent, and that discipline is what the Greeks called poētikē, the discipline of poetics" (ibid.). For Mutlu Blasing, this is the culprit of lyric poetry's being gradually ignored by literary studies, for "poetry does not respond very well to current constructions of the 'discipline' of literary study, which emphasize the social, economic, or political determinants of literary production" $(2007,4)$. 13 The inception of new formalism has generally been dated to the year 2000, when a special issue entitled "Reading for Form" was published in Modern Language Quarterly, edited by Susan J. Wolfson and Marshall Brown. New formalism begins with the shared unease about the tendencies of literary studies towards macrostructural contexts. Formalist scholars worry that "the formal and linguistic dimensions of texts have been glossed over in favor of content, reference, themes, ideas, and political or other 'positions'" (Bogel 2013, 2), and that "we have come to treat artworks as "bundles of historical and cultural content"' (Levinson 2007, 561). They call for the return to favor of form, to "the minute details of language" (Bogel 2013, 68). 
which it simultaneously attends to the two properties of poeticity and translationality, as filtered through narrativity. By closely examining a textual phenomenon, I have retraced a mental phenomenon that functions below the textual surface, namely narrativization. I have then drawn a link between experientiality-and-narrativization and the theory of aesthetic illusion, foregrounding the translator's role as an immersive reader. This essay has thus developed a research model that can systematically account for a large amount of seemingly discrete, unconnected, and trivial textual details in the English translations of ci poetry, and explain the significance of these textual performances to the translated ci poems both as poems and as translations, i.e. textual products of a reading-translating process that inevitably involves natural, cognitive, mental activity.

\section{Works cited}

Baker, Mona. 1993. "Corpus Linguistics and Translation Studies: Implications and Applications." In Text and Technology: In Honour of John Sinclair, edited by Mona Baker, Gill Francis, and Elena Tognini-Bonelli, 233-250. Amsterdam: John Benjamins Publishing Company.

Baxter, Glen W., trans. 1965. "To the "Water-clock" Tune [Keng-lou tzu]." In Anthology of Chinese Literature: From Early Time to the Fourteenth Century, edited by Cyril Birch, 337-338. New York: Grove Press.

Blasing, Mutlu Konuk. 2007. Lyric Poetry: The Pain and the Pleasure of Words. Princeton: Princeton University Press.

Bogel, Fredric V. 2013. New Formalist Criticism: Theory and Practice. New York: Palgrave Macmillan.

Bortolussi, Marisa and Peter Dixon. 2003. Psychonarratology: Foundations for the Empirical Study of Literary Response. Cambridge: Cambridge University Press.

Caracciolo, Marco. 2014. "Experientiality." In The Living Handbook of Narratology, edited by Peter Hühn et al. Last modified July 1, 2014. bit.ly/2Zıfw2y. Accessed July 29, 2018.

Chang, Kang-i Sun. 1980. The Evolution of Chinese Tz'u Poetry: From Late T'ang to Northern Sung. Princeton: Princeton University Press.

Culler, Jonathan. 2015. Theory of the Lyric. Cambridge, MA: Harvard University Press.

Dubrow, Heather. 2006. "The Interplay of Narrative and Lyric: Competition, Cooperation, and the Case of the Anticipatory Amalgam." Narrative 14 (3): 254-271.

Fludernik, Monika. 1996. Towards a 'Natural' Narratology. London: Routledge.

-. 2003. "Natural Narratology and Cognitive Parameters." In Narrative Theory and Cognitive Science, edited by David Herman, 243-267. Stanford: CSLI Publications. 
-. 2005. "Allegory, Metaphor, Scene and Expression: The Example of English Medieval and Early Modern Lyric Poetry." In Theory into Poetry: New Approaches to the Lyric, edited by Eva Müller-Zettelmann and Margarete Rubik, 99-124. Amsterdam: Rodopi.

—. 2006. An Introduction to Narratology, translated by Patricia Häusler-Greenfield and Monika Fludernik. London: Routledge.

Frost, Robert. 1959. Conversations on the Craft of Poetry, edited by Cleanth Brooks and Robert Penn Warren. New York: Holt, Rinehart and Winston.

Frye, Northrop. 1985. "Approaching the Lyric." In Lyric Poetry: Beyond New Criticism, edited by Chaviva Hošek and Patricia Parker, 31-37. Ithaca: Cornell University Press. Fusek, Lois. 1982. Among the Flowers: The Hua-chien chi. New York: Columbia University Press.

Herman, David. 2001. "Spatial Reference in Narrative Domains." Text 21 (4):515-541. Howe, Elizabeth. A. 1996. The Dramatic Monologue. New York: Twayne Publishers. Hühn, Peter and Jens Kiefer. 2005. The Narratological Analysis of Lyric Poetry: Studies in English Poetry from the 16th to the 2oth Century, translated by Alastair Matthews. Berlin: Walter de Gruyter.

Levinson, Marjorie. 2007. "What is New Formalism?" PMLA 122 (2): 558-569.

Miao Yüeh 繆鋮. 1980. “The Chinese Lyric," translated by John Minford. In Song without Music: Chinese Tz'u Poetry, edited by Stephen C. Soong, 25-44. Hong Kong: The Chinese University Press.

Morgan, Monique R. 2007. "Lyric Narrative Hybrids in Victorian Poetry." Literature Compass 4 (3): 917-934.

-. 2009. Narrative Means, Lyric Ends: Temporality in the Nineteenth-century British Long Poem. Columbus: The Ohio State University Press.

Müller-Zettelmann, Eva. 2011 "Poetry, Narratology, Meta-Cognition.” In Current Trends in Narratology, edited by Greta Olson, 232-253. Berlin: Walter De Gruyter. Perloff, Marjorie. 2007. "Presidential Address 2006: It Must Change." PMLA 122 (3): 652-662.

Poulet, Georges. 1954. “Timelessness and Romanticism." Journal of the History of Ideas 15 (1): 3-22.

Prince, Gerald. 1982. Narratology: The Form and Functioning of Narrative. Berlin: Mouton Publishers.

—. 1996. "Remarks on Narrativity." In Perspectives on Narratology, edited by Claes Wahlin, 95-106. Frankfurt am Main: P. Lang.

—. 1999. "Revisiting Narrativity." In Grenzüberschreitungen: Narratologie im Kontext/Transcending Boundaries: Narratology in Context, edited by Walter Grünzweig and Andreas Solbach, 43-51. Tübingen: Gunter Narr verlag. Rexroth, Kenneth and Ling Chung, trans. 1979. Li Ch'ing-Chao: Complete Poems. New York: New Directions. 
Scholes, Robert, Robert Kellogg and James Phelan. 2006. The Nature of Narrative. New York: Oxford University Press.

Seaton, Jerome P., trans. 1975. “Tune: 'Song of Picking Mulberry' (Ts'ai-sang tzu).” In Sunflower Splendor: Three Thousand Years of Chinese Poetry, edited by Liu Wu-chi and Irving Y. Lo, 330-332. Bloomington: Indiana University Press.

Stewart, Susan. 1989. Nonsense: Aspects of Intertextuality in Folklore and Literature. Baltimore: Johns Hopkins University Press.

Toury, Gideon. 1980. In Search of a Theory of Translation. Tel Aviv: Porter Institute for Poetics and Semiotics.

Tucker, Herbert. 1999. "The Fix of Form: An Open Letter." Victorian Literature and Culture 27 (2): 531-535.

Wales, Katie. 1989. A Dictionary of Stylistics. London: Longman.

Walton, Kendall L. 1990. Mimesis as Make-Believe: On the Foundations of the Representational Arts. Cambridge, MA: Harvard University Press.

Wang Jiaosheng, trans. 1989. The Complete Ci-poems of Li Qingzhao: A New English Translation. Sino-Platonic Papers 13.

Wolf, Werner. 2003. "Narrative and Narrativity: A Narrotological Reconceptualization and Its Applicability to the Visual Arts." Word \& Image: AJournal of Verbal/ Visual Enquiry 19 (3): 180-197.

—. 2009. "Illusion (Aesthetic)." In Handbook of Narratology, edited by Peter Hühn et al., 144-160. Berlin: Walter de Gruyter.

—. 2013a. "Introduction: Aesthetic Illusion." In Wolf, Bernhart, and Mahler 2013, 1-63.

-.2013b. "Aesthetic Illusion as an Effect of Lyric Poetry?" In Wolf, Bernhart, and Mahler 2013, 183-233.

- 2017. "Aesthetic Illusion(s)? Toward a Media-Conscious Theory of MediaElicited Immersion as a Transmedial Phenomenon." In The Aesthetic Illusion in Literature and the Arts, edited by Tomáš Koblížek, 29-70. London: Bloomsbury Academic.

Wolf, Werner, Walter Bernhart, and Andreas Mahler, eds. 2013. Immersion and Distance: Aesthetic Illusion in Literature and Other Media. Amsterdam: Rodopi.

Wolfson, Susan J. and Marshall Brown, eds. 2000. Reading for Form: A Special Issue of Modern Language Quarterly. Durham, NC: Duke University Press.

Zhou Min. 2018. "Towards a Poetics of Immersion in Lyric Translation: Aesthetic Illusion and the Translator as Immersive Reader in English Translations of Classical Chinese Ci Poetry." Target 30 (3): 383-407. 


\begin{abstract}
About the author
ZHOU Min holds a PhD in translation studies from the Chinese University of Hong Kong. Her dissertation focused on the impact of translation on the interplay between lyricism and narrativity in classical Chinese poetry; previously, for her MPhil, she studied Chinese renditions of Shakespeare's sonnets. Her research interests center on literary theory (aesthetic illusion, cognitive narratology, and new formalism) and its application in translation studies, on literariness (particularly lyricism and narrativity) in translation, on poetry translation, and on intermediality studies. She is particularly interested in new approaches and concepts for the reimagination and revitalization of classical literature in translation studies.
\end{abstract}





\title{
8 Sublimating Sorrow
}

\author{
How to Embrace Contradiction in Translating the "Li Sao"
}

Nicholas Morrow Williams

\begin{abstract}
Focusing on Qu Yuan, known as "China's first poet" (even though his life in the Kingdom of Chu predates the empire), this essay argues that the translator should not assume that the li of Qu's "Li sao" always means either "to depart" or "to encounter," but look for translation strategies that embrace the contradiction. This exemplifies an approach to the translation of poetry that will allow for or indeed invite a "double exposure," a dialectical movement between different modes of interpretation.
\end{abstract}

Keywords: Chinese poetry, translation, Qu Yuan, auto-antonym, Hegel

in the bright wrinkle of a stretch of water the double exposure of his and your footsteps a shaft of light tests the age of the ancestral hall

like the fire pit sentenced to a single lifelong last gasp

twilight is a tenseless opus too

burying his mitre scimitar orchids gorgeous poems

tinkling of jade pendants buried in the muddy shore that pillowed you does childhood imply millennia? ...

一道水的明亮㱀褶裡疊印他和你的

腳步 一道光檢測者祖屋的老

像被判決終身奄奄一息的火塘

暮色也是件沒有時態的作品

把他的高冠 長劍 蘭蕙 華章

Van Crevel, Maghiel and Lucas Klein (eds.), Chinese Poetry and Translation: Rights and Wrongs. Amsterdam: Amsterdam University Press, 2019

DOI: 10.5117/9789462989948_CHO8 


\section{玉珮之叮噹 埋進你枕著的泥岸}

小時候意味著幾千年? ‥

\section{- Yang Lian 楊煉}

from Narrative Poem (2017, 132-133), translated by Brian Holton

Yang Lian's recently translated Narrative Poem (敘事詩) is a book-length poem cycle organized largely around different moments of Yang's own life. In one section entitled “History Elegy” (歷史哀歌), though, Yang instead selects seven pivotal moments in the lives of historical figures from China and abroad, ranging from general and historian Thucydides to cellist Pablo Casals. The first of the seven figures is the ancient Chinese poet Qu Yuan 屈原, and the poem dealing with him is entitled "Qu Yuan, $283 \mathrm{BC}$, the $15^{\text {th }}$ year of King Qingxiang of Chu” (屈原, 楚頃襄王十五年). The date 283 BCE corresponds to the date when, according to one of the key twentieth-century Qu Yuan scholars, Jiang Liangfu 姜亮夫, Qu drowned himself in the Miluo River. The quotation above is merely the opening of a complex forty-six-line composition that reflects on Qu's death as a "double exposure" with another, present-day figure, perhaps the poet himself. Here the "scimitar," "orchids," "gorgeous poems," and "jade pendants" are all items closely associated with the romantic poet Qu Yuan, while the rhetorical question that follows them - "does childhood imply millennia?" - is Yang Lian himself pondering the difference between ages within a single person's life, and different lifetimes in different epochs.

Or so it would seem. One tension in the bilingual edition, between the poem itself and the translator's footnote to the poem, complicates this picture. Holton, citing the classic translation of Qu Yuan's poems by David Hawkes, provides a one-sentence biographical summary with the parenthetical dates: "fl. 4th-3rd century BC." So did Qu drown himself in 283 BCE or not? No early source provides any specific date, so modern Chinese scholars have offered a range of hypotheses, while Western and Japanese scholars prefer to see Qu as a semi-mythical figure, not necessarily the author of all or any of the poems attributed to him. We could understand this disparity in scholarly paradigms via the modern cult of Qu in the twentieth century, which is closely tied to the rise of Chinese nationalism; or via the opposing biases of non-Chinese scholars that lead them towards a skeptical stance regarding the historicity of key Chinese culture heroes like the Duke of Zhou, Confucius, and Qu Yuan. ${ }^{1}$ This debate continues in the discrepancy

1 I specify the modern cult of Qu Yuan because the emphasis on authorial dating is only in part an organic extension from Chinese tradition; it also derives its motivation from Western 
between Yang's specific dating in his poem and Holton's agnostic footnote to his translation of the same poem.

Regardless of one's answer to this kind of historical question, the stance we choose is important and affects our approach to translation. As a sinologist trained in America, my sympathies lie primarily with Hawkes, Holton, and their kin in Japan and the West, but as a lover of poetry I'm reluctant to quibble with Yang Lian. Should we read Chinese poems as historical documents of their author's time and place? Or should we remain skeptical of their authenticity, as evidence of some broader kind of mythical Weltanschauung that can be attributed to a range of centuries? How many thousands of years, though, are implied by a poem? Perhaps, as Yang Lian suggests, the answer is not going to be any particular approach but rather a "double exposure," a dialectical movement between different modes of interpretation. In the case of Qu Yuan and his poems, this would mean allowing at some level for the coexistence of both man and myth, seeing the uncertainty of Qu's biography and reception not as a crux to be resolved, but as a pivot by which to convey the multiplicity of historical experience.

For the uncertainty about Qu Yuan's biography is only in part an artifact of historical change and the disparity of modern scholarly assumptions. There is a real ambiguity embedded in the text of his most famous poem, the “Li sao" (離騷), from the Chuci (楚辭, Elegies of Chu): the poem can be - indeed, often has been - read as a suicide note, or as a declaration of his determination to become a Daoist recluse, or as lacking any definite motive altogether. Moreover, the ambiguity begins with the very title of the poem, as the character $l i$ 離 has at least two diametrically opposite significations: "to depart" or "to encounter." It continues through the body of the poem itself, where li recurs some twelve times. The gap between these two senses is a kind of microcosm of different approaches to the poem as a whole, as well as to Qu Yuan's biography, and even to Chinese tradition in general. None of the tensions or contradictions is resolved in the "Li sao" or in its reception history, so in translating the poem the best option is to engage and to represent the contradictions themselves, with some help from G. W. F. Hegel.

historicism and the cult of individuality, instantiated in such artifacts of contemporary culture as the Sonny Bono Copyright Extension Act or the author-date citation system. For alternative conceptions of the authorial role see Barthes 1977, Lessig 2005, or, for the medieval Chinese case, Williams 2015 . 


\section{The meaning of $l i$ in the title "Li sao"}

The first extant interpretation of the title is in Sima Qian's 司馬遷 $\left(145^{-86}\right.$ BCE) biography of Qu Yuan in the Shiji (史記, Historical Records), in an unusual passage that appears to be quoting another source. It follows the very brief account of how the talented young Qu was at first a successful advisor to King Huai 懷 of Chu, but later was “estranged" (疏) after suffering the slander of his jealous colleagues (Sima 1959, 84.2482). ${ }^{2}$ It glosses "Li sao" as liyou 離憂, recapitulating the ambiguity with the same word plus a synonym. On the other hand, the text goes on in a philosophical vein:

Qu Ping [i.e. Qu Yuan] followed the righteous path without deviation, and fulfilled the utmost of loyalty and intelligence in service to his lord. When slanderers created a divide between them, he must surely have been desperate. To be loyal but face suspicion, faithful yet endure slander, how can one be without resentment? Qu Ping composed the "Li sao" out of resentment over his own life ... What the text refers to may be minor, but its significance is extremely great; though it introduces categories that are nearby, they reveal meanings that are far-reaching. Qu Yuan's aspirations are immaculate, so the objects referred to are fragrant; his actions incorrupt, so he would die rather than make concessions. Estranging himself, so that rather than bathing in the muck or bemiring himself in the mud, he molted like a cicada departing from filth and pollution, so as to soar free beyond dust and dirt; thus he did not suffer the contamination or befouling of the world, but rose immaculate from the mire without a stain. When considering such a character as this, we must admit his brilliance was such as to contend with that of the sun and the moon.

屈平正道直行, 竭忠盡智以事其君, 堍人閒之, 可謂窮矣。信而見疑, 忠而被謗, 能無怨乎? 屈平之作離騷, 蓋自怨生也 ...... 其文約, 其辭 微, 其志絜, 其行廉, 其稱文小而其指極大, 舉類邇而見義遠。其志 絜, 故其稱物芳。其行廉, 故死而不容。自疏, 濯淖汗泥之中, 蟬蛻 於濁穢, 以浮游塵埃之外, 不獲世之滋垢, 皭然泥而不滓者也。推此 志也, 雖與日月爭光可也。

This passage is by far our earliest dateable and in any sense reliable guide to the “Li sao." The last few lines are probably from Liu An 劉安 (179-122 BCE),

2 See also the helpful annotated versions Jiang 2002 and $\mathrm{Wu} 2007,815-847$. Note that these events apparently took place before Qu Yuan's exile. 
Prince of Huainan, who wrote a commentary to the poem that is no longer extant (see Fan 1991, 5.45; Jiang 2002, 18). Altogether, Sima Qian and Liu An seem to understand "Li sao" as meaning "departing from one's troubles," achieving a higher and more pure state of being. It seems to correspond loosely with the syncretistic thought of the Huainanzi (淮南子), compiled under Liu An's auspices - extolling Confucian virtues, but also aspiring to a Daoist kind of personal purity, even if it requires removing oneself from society altogether. In other words, this earliest explanation of the meaning of "Li sao" turns out not to be a straightforward scholarly gloss, but very much part of the highly ideological interpretation of the poem that follows.

Thus, this gloss preserved in the Shiji suggests a more mystical, otherworldly understanding of the "Li sao" than later scholarship, particularly the definitive edition of the "Li sao" dating from the Eastern Han, after the consolidation of Han Confucianism. The preface to the poem in the earliest extant commentary, the Chucizhangju (楚辭章句, Chapter and Verse Commentary to the Elegies of Chu) compiled by Wang Yi 王逸 (c. 89-c. 158), glosses $l i$ as "parting" 別 and sao as "sorrow" 愁, suggesting that the title reads "The Sorrow of Parting" (Hong 2002, 1.2). ${ }^{3}$ This is hardly authoritative, though, considering that this preface makes the outrageous claim that jing 經 in the full title, "Li sao jing" (離騷經), ought to be glossed as its near-homonym "path" 徑 rather than "classic." Slightly earlier, historian Ban Gu 班固 (32-92) glossed $l i$ instead as "encounter” 遭, while following Sima Qian's gloss of sao as you 憂 'trouble' or 'worry' (quoted in Hong 2002, 1.51). We do not have the full context of Ban Gu's gloss, since it belongs to a “Preface to the Encomium to the Li sao" (離騷贊序), quoted in Wang Yi's Chuci. Nevertheless, it is Ban Gu's interpretation that justifies the most common rendering into English of "Encountering Trouble" (as in Hawkes 1985, 67; followed by Wu 2008, 41). ${ }^{4}$

The differences just among these three interpretations are considerable, and may in part be motivated by the political contexts of the interpreters rather than the text. For instance, the primary meaning of sao seems to be something like "turbulence," metaphorically "trouble" or "anxiety." Its use in the title here can be understood in a psychologized sense of "sorrow," as with Wang Yi, but also in the more urgent sense of "anxiety" about looming

3 The commentary is a composite work, so it is risky to assume that any particular sentence in it was written by Wang Yi himself. See note 1.

4 Similarly, Mathieu 2004 gives "À la rencontre du chagrin" (440). Redoubtable translators Marquis d'Hervey de Saint-Denys (1822-1892) and Stephen Owen both romanize without offering a translation per se (Hervey 1870; Owen 1996, 162). 
disaster that both Ban Gu and Liu An (or Sima Qian) identify in the poem. ${ }^{5}$ The latter emphasis makes it easier to understand "Li sao" within the threemillennium tradition of Chinese poetry about political anxieties, but also removes some of the strange, otherworldly quality which Liu An praised in it.

In interpreting the title as a whole, the character li plays the pivotal role. Ban Gu's first-century CE gloss relies on the homophony of $l i$ 離 and 罹 'to suffer'. This dual meaning of $l i$ has a long history before the "Li sao" itself (see Wang 200o, s.v. li, 1611-1612). Li 離 is glossed in the Eastern-Han dictionary Shuowen jiezi (說文解字), which does not attempt to provide all the denotations of a word, as “oriole" 離黃 (also known as canggeng 倉 庚) (Xu 1998, 4A.142b). The graph was then borrowed, apparently, for the homophonous verb li 'to divide, separate'. This verb was appropriate not just for personal but also for political contexts, as in Confucius's Analects (論語) 16/1: "In his own territory there are divisions and downfalls, leavings and separations, and he cannot preserve it” (邦分崩離析而不能守也) (translation modified from Legge 1893, 1:309). Yet also from as early as the Shijing 詩經 (Book of Songs), it possessed the reverse meaning of "encounter, suffer," with negative implications as in 70/1: "The pheasant got caught in the net" (雉離于羅).

In other words, $l i$ from the beginning is an auto-antonym. These words occur in languages around the world, as with "cleave" in English, which means either "separate" or "adhere," not unlike $l i$ itself. Though the origins of the auto-antonym remain murky, the Freudian interpretation is suggestive. In his classic essay on "The Uncanny," Sigmund Freud discusses how heimlich 'homely', "is a word the meaning of which develops in the direction of ambivalence, until it finally coincides with its opposite, unheimlich" (2007, 127). He further shows how this development reflects the return of repressed emotion, a phenomenon that may bear some relation to the topic under discussion. Some kind of ambivalence in regard to the primary sense of a term causes its meaning to develop in the opposite direction, but without ever replacing the original meaning entirely.

Though this linguistic phenomenon may be ubiquitous, in the Chinese case the double meanings of $l i$ and other key words are fundamental to the development of philosophy and literary culture. For instance, the term luan 亂 normally means "disorder" but can also mean order, an ambiguity suggesting the way that a state of anarchy determines the foundations of the new order, as in the Romance of the Three Kingdoms (三國演義). These

5 One should note also the existence of the bold interpretation of the title as equivalent to the musical title "Laoshang” (勞商), forcefully criticized in Jao 2003. 
auto-antonyms occur even more frequently throughout the Book ofChanges (易經). In fact, Qian Zhongshu 錢鍾書 (1910-1998) has cited the polysemy of the Book of Changes precisely in order to rebut Hegel's disparagement of the Chinese language as being unphilosophical (Qian 2001, 3-4; see also Zhang 1992, 21). This polysemy begins with the very word $y i$ 易 in its title, which can mean "change," "simplicity," or even "non-change." It extends to other vocabulary, such as ge 革, used as the name of hexagram 49 of the Changes, and originally meaning "leather," a tough material resistant to change; symbolically in the Changes, though, it represents total transformation, revolution (Qian 2001, 52).

Thus the philosophical structure of the Changes can help us to appreciate the deeper significance of $l i$ and its polysemy. In particular, li could also mean "to attach," in which sense it was equivalent with yet another homophone, li 麗. ${ }^{6}$ This is its sense as one of the trigrams in the Book of Changes, a broken line intermediating between two whole ones, which is doubled to form hexagram 30, also Li:

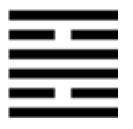

The title of this hexagram is rendered by Richard Wilhelm (in Cary Baynes's retranslation) as "The Clinging." Wilhelm explains, "What is dark clings to what is light and so enhances the brightness of the latter," and quotes one of the earliest interpretations of the hexagrams, the "Commentary on the Judgments" (彖傳): “Thus sun and moon cling to heaven, and grain, grass, and trees cling to the earth" $(1967,119 ;$ Zhou 2011, 182). In other words, the Li hexagram embodies with special vividness the interdependence of things that is a central message of the Book of Changes as a whole.

The text of the full hexagram illustrates the drama that this interdependence entails. On one hand there is the triumphant victory of the righteous leader supported by the forces of light, as in the image text: "That which is bright rises twice: / The image of FIRE. / Thus the great man, by perpetuating this brightness, / Illumines the four quarters of the world" (Wilhelm 1967, 119; Zhou 2011, 182). Yet the middle lines of the hexagram tell of disaster and defeat. The third line reads: "In the light of the setting sun, / Men either beat the pot and sing / Or loudly bewail the approach of old age. / Misfortune"

6 Though $l i$ 離 is a level-tone word, it has a departing-tone variant, identified by Axel Schuessler as an "exopassive derivation" $(2007,348)$. 
(Wilhelm 1967, 120; Zhou 2011, 184). And in the fourth line: "Its coming is sudden; / It flames up, dies down, and is thrown away" (Wilhelm 1967, 121; Zhou 2011, 184).

These two epigrammatic accounts of elegiac songs and abandoned glories could be summaries of the content of the "Li sao" itself, or translations of that long poem into a haiku-like form. For the "Li sao" is on one hand the firstperson narrative of a "madman of Chu” (楚狂人), an exiled courtier singing to himself, primarily of his political woes, but also frequently of transience and the approach of old age. But it is also the heroic epic of a Chinese archetype, the good man whose virtue is only further confirmed by his humiliation and defeat. It is the archetype of $\mathrm{Bi}$ Gan ground up into meat paste for his wise counsel to the wicked tyrant of Shang, or Confucius nearing starvation on the road between Chen and Cai. Yet this epic narrative is relatable entirely in terms of the verb li: our hero encounters suffering, but remains attached to principle, and so manages to depart from his trouble and overcome it, "perpetuating this brightness," the fire that is the Li trigram itself.

Below I will argue that we should indeed understand the character $l i$ in the title "Li sao" in both its senses of "depart" and "encounter" simultaneously. These dual senses can also be recognized in its various usages within the text of the poem itself.

\section{The usage of $l i$ within the "Li sao" poem itself}

Looking at the poem as a whole, li occurs throughout the text in both these senses as well as others, confirming that its narrative is not exclusively one of passive suffering or of determined departure. Instead, the poem enacts a kind of symbolic resolution between the two poles of opposition and escape.

There is one specific usage of $l i$ in the poem which is closely parallel to the sense of "encounter" in the title. This occurs towards the end of the long self-introduction that occupies approximately the first third of the poem, before Qu Yuan begins his journeys and encounters various divine or mythical figures. Summing up his troubles, he exclaims (ll. 111-112):

Advancing, I do not enter but only suffer blame Retreating, I will restore again my initial garb ...
進不入以離尤兮 退將復脩吾初服

It is worth noting that the grammatical structure makes the identification of the meaning of $l i$ somewhat redundant. One might just as easily render the first line, "Advancing, I did not enter, in order to avoid blame." However, 
the interpretation of $l i$ as "suffer" is confirmed by a related usage in another poem in the Chuci.

$L i$ is more commonly used as part of the romantic rhetoric that forms such a fascinating, in some ways inexplicable, component of the "Li sao." This seems to be a direct borrowing from the shamanistic lyrics addressed to various ancient divinities, the "Nine Songs" (九歌), but within the longer narrative of the "Li sao" it becomes stranger and deeper. Close to the beginning of the poem, for instance, Qu Yuan speaks of "separation" - or perhaps better, "breakup" (1l. 45-48):

At the beginning he had made a pledge to me -

But later resented and evaded me, choosing another. $^{8}$

I do not find this separation itself a hardship -

But only grieve for his Divine Consummation's many changes! ${ }^{9}$
初既與余成言兮 後悔遁而有他

余既不難夫離別兮 傷靈脩之數化

Or similarly, while Qu Yuan is seeking out the goddess Fufei 密妃 (perhaps representing an alternative patron in another kingdom?), he complains again (ll. 225-226):

What tumultuous profusion of separations and matches -

Now our dire rift makes it hard to persuade her. ${ }^{10}$ 忽緯繣其難遷

There is wide disagreement among commentators about the referent of the first line here, which is repeated verbatim in another context where it refers to celestial forces (see below). It might best be understood as a kind of formula of Chuci poetics. The implications of the "separations and matches" are determined by the attributes fen 紛 and zongzong 總總, which seem to be synonymous here, describing both their frequency and also chaotic quality, as goddess and suitors are alternately separated and reunited.

7 “Rueful Remonstrance" (惜誦) (see Hong 2002, 4.127).

8 Huang 2011 points out that "other" here refers specifically to believing in slander.

$9 X i u$ 修 is one of the keywords of the "Li sao." It can mean simply "long," but more usually both physical and moral refinement approaching sublimity. Qian Zhongshu distinguishes two senses of “distant worthies” (遠賢) or “refined and pure” (修潔) (2002, 900). I translate it variously below. This proper name (by which Qu Yuan refers to his sovereign) might be rendered more literally "Spirit Sublime" or even "His Sublime Numinosity."

10 Weihua 緯繣 (*waih-wrekh) is an alliterative binome also written 媁㜇, etc. 
Finally, near the conclusion of the journey, Qu Yuan again complains that there is no way to restore a harmonious relationship after divorce (ll. 337-340):

Drive on the flying dragons before me Combine the carnelian and ivory to make my chariot.

What divided hearts can ever be united? I'll travel far off and estrange myself.
為余駕飛龍兮 雜瑤象以為車

何離心之可同兮 吾將遠逝以自疏

In this critical passage, he decides to separate himself entirely from his former home and "estrange himself" (自疏), precisely the same phrasing that occurred in Liu An's appraisal of the poem. Thus Liu An's emphasis on departing, escaping from trouble, is consistent with his overall interpretation of the "Li sao." The primary theme is about moving away from political turmoil towards another, higher place.

Another passage employs li in a similar, though slightly distinct, sense, as in the following speech by Nüxu 女須 (ll. 133-136):11

Why are you so wholly forthright, so fond of perfection -

So magnificently solitary in your comely honor?

Caseweed, carpetgrass, and cocklebur now fill your chamber $-{ }^{12}$

Unlike, alone, and apart, you refuse to submit. 判獨離而不服
汝何博謇而好修兮

紛獨有此姱節

薋蒙葹以盈室兮

In this last line $l i$ is synonymous with the two words in front of it, employing the trope of "triple synonymia" which is quite common in the Chuci. ${ }^{13}$

That the word $l i$ appears quite frequently within the poem is already clear. But it is a long poem, so that a common word would appear five times is not surprising. Still, the following passage where the word appears thrice in rapid succession seems to confirm that the term is indeed a leitmotif in the poem (11. 201-208):

11 Wang Yi makes the implausible claim that she is Qu Yuan's sister, but in fact Nüxu simply means a female shaman (shamanka), as in Ban 1962, 63.276o.

12 Wang Yi claims that these are wicked plants. Perhaps they represent simply common weeds. The enumeration of three in a row may be another example of triple synonymia. Alternatively, $c i$ 薋 could be a loan graph or miswriting of $z i$ 資.

13 Identified in Tang 1984, where it is called liandie 聯迭 (346). 
I command the Phoenix to fly out ahead 吾令鳳鳥飛騰兮

And follow it through day and night.

繼之以日夜

The whirlwind gathers itself up and joins together -

Leads the clouds and coronas and comes to

飄風屯其相離兮

帥雲霓而來御

welcome me. ${ }^{14}$

In tumultuous profusion they split and

紛總總其離合兮

fuse together -

In their multifarious, iridescent splendor they

斑陸離其上下 rise and plummet.

I command the High Lord's watchman to

吾令帝閏開關兮 release the lock -

He leans on Heaven's Gate and stares at me.

倚間闔而望予

Note that line 205, 紛總總其離合兮, is duplicated verbatim in line 225, discussed above. Here, though, since it seems to describe the celestial forces, I translate lihe 離合 as "split and fuse together" rather than as "separations and matches."

All three usages of $l i$ are distinct. First, $l i$ is most likely intended in the same sense as in the Book of Changes, as "clinging"; second, in the compound with he it certainly means "separation"; finally, it appears as one element of the alliterative binome luli 陸離. This same binome occurs early in the poem as well, where it describes the splendor of Qu Yuan's adornments (ll. 117-118):
High stands my crown, poised precipitously -
高余冠之苃苃兮
Broad sweep my pendants in iridescent splendor.
長余佩之陸離

This final usage is not technically a usage of the same word; it may simply be a loan of the graph li to write the second component of another word. Whatever the linguistic relationship, within the composition of a poem the reuse of the same graph seems significant. Likewise, a final usage of $l i$ is in the name of an aromatic plant, 江離 'river lovage'. This plant appears twice in the poem, close to the beginning (l.11) and near the conclusion (1. 324). In this case $l i$ certainly represents a different word, $l i$ 蓠住, but again the graphical echo is significant, particularly as this is one of Qu Yuan's avatar-like aromatics. "Lovage" is a fitting translation not just botanically but also etymologically, since it derives from "love-ache," parallel to the paronomastic usage of $l i$ as the "flower of separation" in Chinese. 
One further piece of evidence is helpful. Though the authorship and dating of all the poems traditionally attributed have rightly been contested, or at least qualified, in modern scholarship, it is reasonably clear that beyond the "Li sao" itself, one of the pieces most likely to date to the earliest stratum of the anthology, and that most closely associated to the historical Qu Yuan, is “Embracing the Sand" (懷沙), whose text is quoted in its entirety in Sima Qian's biography of Qu. That poem employs the word li twice, both times as part of the compound li min 離壂 'meeting with melancholy' (ll. 8 and $55)$. In both cases li can only be understood as "suffer, endure."

This examination of the usage of $l i$ in the "Li sao" is broadly consistent with the complex meanings of the word itself. The two senses of "suffer, meet with" and of "separate from, depart" are both in active use, both inescapable elements of the word's meaning. Beyond those two senses, though, $l i$ is also employed in a range of complementary ways, as an herb emblematic of Qu Yuan's virtue, in its Changes sense of "attaching," and also as part of a binome descriptive of beautiful appearance. In nearly every case within the text of the poem, $l i$ has to be translated differently. Even within the single repeated line $(205 / 225)$ it should be translated in two different ways based on the different subjects.

The varying usages of $l i$ correspond to the countless transformations of the poem's narrative itself, in which the political, religious, and romantic threads all interweave with one another. Qing critic Qu Fu 屈復 already remarked on the "stylistic transformations" (文法變換) of the poem's long narrative: "In the several sections on searching for a bride, the style is transformed. First he seeks her but finds no one, then he meets someone but ultimately is separated from her" $(2014,1.17 \mathrm{a} / \mathrm{b})$. It is a fundamental technique of the poem to present its narrative in multiple stages, with declaration, journey, or dialogue gradually evolving into the next one, which presents a different perspective on Qu Yuan's fate. On a lesser scale, the leitmotif of $l i$ itself transforms throughout the poem, being used to describe both Qu's sufferings and his escape.

\section{Li and aufheben}

I can think of no word in English that could capture each of the senses of $l i$ effectively throughout the poem, as well as in its title. In German, however, there is at least one word that can be used to capture the internal tension of li itself, the self-contradictory significations of "departing" and "encountering" - this is the verb aufheben, or its nominal form Aufhebung, used in the 
philosophical writings of Hegel. As Hegel explains in the Phenomenology of Spirit (Phänomenologie des Geistes), "Aufheben brings out and lays bare its true twofold meaning which we found contained in the negative: to aufheben is at once to negate and to preserve" (translation follows J. B. Baillie in Hegel 1910 [163-164], but replaces his translations of aufheben with the word itself). ${ }^{15}$ It is important to note that aufheben is not originally a technical term, but an ordinary German verb whose meanings can include "to pick up," "to preserve," or "to cancel." Hegel's wordplay has transformed its meaning, though, so that the word has become a major concept of Western thought ever since. Hegel's usage is technical and metaphysical; he speaks, for instance, of the task of "actualizing the universal, and giving it spiritual vitality, by the process of breaking down and superseding (aufheben) fixed and determinate thoughts" (Hegel 1910, 94). He employs aufheben throughout his Science of Logic (Wissenschaft der Logik) as well, and it is a key part of his whole method of dealing with concepts through qualification and negation, using his analysis of a given concept to move forward onto another, contrary one.

This may seem unrelated to the "Li sao," which, though it has its reflective moments, is not a philosophical poem; but the similarity is not so much one of content as a formal one regarding the usage of the word li. Like aufheben, it is a common and not particularly striking word, but Qu Yuan's creative, dual employment of the word achieves an effect parallel to that of aufheben in Hegel's work. Translator Baillie there finds the word challenging enough that he renders it variously, often by paraphrases like "breaking down and superseding." Like $l i$, it seems to reach out in opposite directions that are unlikely to be suggested by a single word.

It would probably not be effective to use the German aufheben itself in an English translation of Chinese poetry today (though it would not have exceeded the creative scope of Ezra Pound). Nor would it be effective to adopt the standard English translation of the term, the awkward and rare English sublate, which is confusing in that its meaning is to "take away" and its etymological sense "to take down," both of which are purely negative. A better choice is sublimate. Sublimation implies a change of state that destroys the original (as in the sublimation of a solid into a gas) and in the process elevates it into a higher state, making it sublime. It is no significant objection to point out that Hegel could have used the German

15 The German text reads: "Das Aufheben stellt seine wahrhafte gedoppelte Bedeutung dar, welche wir an dem Negativen gesehen haben; es ist ein Negieren und ein Aufbewahren zugleich" (Hegel 1968, 72). 
Sublimierung but did not, because it was one of Hegel's avowed goals to write philosophy using Germanic terms, so he preferred the colloquial aufheben over the Latinate sublimieren. In English, by contrast, Latinate terms are common, and sublimate is not overly technical. It has in fact been popularized post-Hegel through its usage in the works of Freud, so much so that it is necessary to keep in mind that its Hegelian sense is different and more abstract than the psychological sense of Freud. With this point in mind, though, it is a more natural and appealing rendering of aufheben than the alternatives in English. ${ }^{16}$

It might seem at first that sublimate is overreading the li of the "Li sao," but if so, it is overreading in a very traditional way. For, as shown above, Liu An's interpretation of the poem, with its aspiration for Daoist purity, suggests already this sense of transcending worldly experience to attain something higher, just as a sublimation in the Hegelian sense is a negation that also attains a loftier goal (in a philosophical sense). This reading is a bit different from the dominant, politicized account of the poem, but it fits rather well with the ending, in which Qu Yuan chooses to "follow Peng Xian" (彭咸). As several modern scholars have shown, this is probably not a single Shang nobleman who drowned himself, as Wang Yi would have it, but rather two ancient shaman-heroes, Peng and Xian. ${ }^{17}$ For instance, the Shanhaijing 山 海經 (Classic of Mountains and Seas) mentions both of these separately as the names of shamans (Yuan 1993, 7.200, 11.263; see also Williams 2018). In this sense, then, "Sublimating Sorrow" is not just a fitting rendering of the two characters li sao, but also a better description of the poem's contents than the alternatives.

Nor is this the first time that a translator has opted to follow Hegel in prioritizing the self-contradictory over the narrowly semantic. Jacques Derrida in his revelatory essay "What Is a 'Relevant' Translation?" argues for translating the verb "seasons," in Portia's famous speech on the "quality of mercy" from The Merchant of Venice, as "relève," precisely by reference to Hegel's Aufhebung (Derrida 2001, 196). For when Portia asserts that "mercy seasons justice," Derrida argues, mercy is both a relief, a relaxation, but also a lifting-up and exaltation, thus employing both senses of relever: "Mercy is a relève, it is in its essence an Aufhebung. It is translation as well. In the horizon of expiation, redemption, reconciliation, and salvation" (Derrida 2001, 197).

16 Garrett Green uses “sublimation” for Aufhebung in his translation of Barth 2006. He has a convincing defense of this choice in his "Translator's Preface" (ix), which I have borrowed here. 17 This was already appreciated before the twentieth century. Yu Yue pointed out that Peng Xian “cannot be identified" 無可考 $(1902,1 b)$. See overview in Chan 1972, 132-136. 
Following both Hegel and Derrida, then, the double meaning here is not an abstract play on words, but a matter of justice and expiation, of death and reconciliation. Hegel's understanding of philosophy is as an activity that ends up fulfilling its own ambitions only by using itself and passing on into another mode of existence: "But the life of the mind is not one that shuns death, and keeps clear of destruction; it endures death and in death maintains its being. It only wins to its truth when it finds itself utterly torn asunder" (Hegel 1910, 93). His grandiose and totalizing rhetoric is not a bad match for Qu Yuan, who says (1. 84): “Though I face nine deaths yet will I never repent!" (雖九死其猶未悔).

\section{Double exposures}

Dealing with complex words is not just a technical problem, but also a matter of dealing with intellectual and spiritual contradictions. The ambiguity of the word li can be represented lexically by recourse to Hegelian Aufhebung, in its anglicization of sublimate. But this is just one step in dealing with the manifold contradictions of the text, such as alternations between the shamanistic and the political, or the literal and allegorical planes. The "Li sao" makes calculated use of lexical ambiguity, as of other poetic tropes, in order to place in productive tension multiple dimensions of reality. These tensions and ambiguities cannot be resolved by translation, only represented by creative translation practices that mimic their complexity using all the intellectual tools at our disposal, from horticulture to dialectics.

The second character in the title "Li sao," for instance, originally has a physical sense of “turbulence." According to Duan Yucai 段玉裁 (1735-1815), it becomes interchangeable with you 憂 because they share a rhyme group, and also "because turbulence brings about worry" (騷動則生憂也) (Xu 1998, 10A.467b). That is to say, sao actually has both physical and psychological referents which are intimately linked. Translating the title as "Sublimating Sorrow" does not do justice to these other implications. On the other hand, taking into account the alternate sense of $l i$ suggested by its usage in 1.136 , discussed above, parallel with 判獨 'unlike, alone', one might render the title as a hendiadys, "Division and Discord." Even though the emphasis of the title is on $l i$, and "Sublimating Sorrow" seems to me to strike the right balance, identifying these intriguing alternatives is an important stage in the process of translation as well. A translation, ideally, goes well beyond selecting among alternative possibilities, and aims to represent multiple levels of signification from the source text; the representation of multiple 
possibilities may not be comprehensive, but that is not so much a problem of translation as of the limits of interpretation itself.

In general, translation can benefit from more explicit and engaged negotiation with linguistic norms, treating the denotations of words more as sociopolitical compromises than as objective facts. The conceptual motion inherent in the word li cannot be captured statically; in responding to the multidimensional quality of classical Chinese, we ought to employ a range of different translation strategies, and reject a foolish consistency. Scholarly translators of classical Chinese texts, whether historical, philosophical, or literary, sometimes propose to translate a single Chinese word in the same way throughout a given work. This approach is fine, maybe even desirable, for legal documents, obviously, and perhaps for some relatively inane philosophical texts, but is pure insanity for poetry - and not the kind appropriate for the "madman of Chu"! Words evolve not just in history but in the very course of a poetic argument; their different hues deepen and pale, or blend together in different ways. Moreover, when rendering challenging words into a foreign language, we should use all the tools available in the target language, including obscure or technical terms as appropriate. ${ }^{18}$ Haun Saussy has recently celebrated the role that Zhuangzi's "extravagant" language has played in translations into Chinese throughout history (2017). In a similar vein, we ought to make use of the extravagant resources of English to translate classical Chinese literature multifariously, and perhaps even to suggest the dialectical oppositions of yin and yang that lie within the semantic range of a single word.

For the "Li sao" from the beginning contains multitudes. Just as the word li occurs within the text in five or so different senses, the poem also presents its narrator in several different guises: as a loyal minister, as a romantic hero, as a magic-wielding shaman with a range of divinities at his beck and call. Even though one reader might emphasize one dimension of the poem, or one particular gloss of the word $l i$, this would not erase the coexistence of all the other possibilities within the text. Thus translation is not, in its first instance, a task of communication between cultures, but rather a matter of interpretation. Any reader of the "Li sao" will struggle with the same multiplicity, and the task of a translation is primarily to convey an interpretation, multifaceted and self-contradictory just like the original text, while achieving its own kind of unity at least at a stylistic level. Yang Lian's

18 I have objected in print to the use of "sashimi" in translating the poetry of $\mathrm{Du} F u$, and I would still be cautious of straining the bounds of historical plausibility (2014). But "sublimation," if it means anything, is an aspect of human experience in any period. 
poem on Qu Yuan offers us the invaluable metaphor of the "double exposure" for the position of the reader/translator/poet looking back at Qu Yuan, but Yang's double exposure is implicit already in the poem's original setting, in "the bright wrinkle of a stretch of water" of the Miluo river. The figure of Qu Yuan is already manifold, already containing both glittering reflections and a dark abyss. A translation continues to reconfigure these images of an irretrievable past, at best a double exposure of an already fragmented vision.

\section{Works cited}

Ban Gu 班固 (32-92), comp. 1962. 《漢書》 [History of the Western Han dynasty]. Beijing: Zhonghua shuju.

Barth, Karl. 2006. On Religion: The Revelation of God as the Sublimation of Religion, translated by Garrett Green. London: T\&T Clark.

Barthes, Roland. 1977. Image, Music, Text, translated by Stephen Heath. New York: Hill and Wang.

Cai, Zong-qi, ed. 2008. How to Read Chinese Poetry: A Guided Anthology. New York: Columbia University Press.

Chan Ping-leung 陳炳良. 1972. “Ch'u tz'ú and Shamanism in Ancient China." PhD dissertation, The Ohio State University.

Derrida, Jacques. 2001. “What Is a 'Relevant' Translation?," translated by Lawrence Venuti. Critical Inquiry 27 (2): 174-200.

Fan Wenlan 范文蘭, comm. 1991. 《文心雕龍注 》 [The literary mind carved in dragon form, annotated]. Taipei:Xuehai chubanshe.

Freud, Sigmund. 2007. “The 'Uncanny," translated by Alix Strachey. In Psychological Writings and Letters, edited by Sander L. Gilman, 120-153. New York: Continuum. Hawkes, David, trans. 1985. The Songs of the South:An Anthology of Ancient Chinese Poems by Qu Yuan and Other Poets. Harmondsworth: Penguin Books.

Hegel, G. W. F. 1910. Phenomenology of Mind, translated by J. B. Baillie. London: George Allen \& Unwin.

—. 1968. Phänomenologie des Geistes. In Gesammelte Werke, Band 9. Hamburg: Felix Meiner Verlag.

Hervey de Saint-Denys, Marquis de, Marie-Jean-Léon Lecoq. 1870. Le Li-sao, Poéme du IIIe siècle avant notre ére, traduit du chinois [The Li-sao, a poem of the third century before our era, translated from the Chinese]. Paris: Maisonneuve.

Hong Xingzu 洪興祖 (1090-1155), ed. 2002. 《楚辭補注》 [Elegies of Chu with supplementary commentaries]. Beijing: Zhonghua shuju, 2002.

Huang Linggeng 黃靈庚. 2011. 〈楚辭簡帛義證〉 [Verification of glosses in the Elegies of Chu based on excavated manuscripts]. 《中國楚辭學》 16: 232-239. 
Jao Tsung-i 饒宗頣. 2003. 《《離騷》勞商辨〉 [Investigating the interpretation of “Li sao” as laoshang]. In 《饒宗頣二十世紀學術文集》 [Collected twentiethcentury scholarship of Jao Tsung-i ], 16: 406-411. Taipei: Xin wen feng chuban.

Jiang Liangfu 姜亮夫. 2002. 〈史記屈原列傳疏證〉 [Detailed collation with commentary of the biography ofQu Yuan in the Historical Records]. In 《姜亮夫全集》 [Complete works of Jiang Liangfu], 8: 1-28. Kunming:Yunnan renmin chubanshe. Legge, James. 1893. The Chinese Classics. Five volumes. Oxford: Clarendon Press. Lessig, Lawrence. 2005. Free Culture: The Nature and Future of Creativity. New York: Penguin.

Mathieu, Rémi. 2004. Elégies de Chu [Elegies of Chu]. Paris: Gallimard.

Owen, Stephen. 1996. An Anthology of Chinese Literature, Beginnings to 1911. New York: Norton.

Qian Zhongshu 錢鍾書. 2001. 《管錐編》 [Limited views]. Beijing: Sanlian shudian. $\mathrm{Qu} \mathrm{Fu}$ 屈復 (Qing), ed. 2014. 《楚辭新注》 [New commentary to Elegies of Chu]. Beijing: Guojia tushuguan chubanshe.

Saussy, Haun. 2017. Translation as Citation: Zhuangzi Inside Out. Oxford: Oxford University Press.

Schuessler, Axel. 2007. ABC Etymological Dictionary of Old Chinese. Honolulu: University of Hawai'i Press.

Sima Qian 司馬遷 (145-86 BCE), ed. 1959. 《史記》 [Historical records]. Beijing: Zhonghua shuju.

Tang Bingzheng 湯丙正. 1984. 《屈賦新探》 [New investigations of Qu Yuan's $f u$ poems]. Jinan: Qi Lu shushe.

Wang Li 王力 et al., eds. 2000. 《王力古漢語字典》 [Wang Li's dictionary of classical Chinese]. Beijing: Zhonghua shuju.

Wilhelm, Richard. 1967. The I Ching, or Book of Changes, translated by Cary F. Baynes, third edition. Princeton: Princeton University Press.

Williams, Nicholas Morrow. 2014. "Sashimi and History: On a New Translation of Du Fu." China Review International 21 (3-4): 201-244.

-.2015. Imitations of the Self:Jiang Yan and Chinese Poetics. Leiden: Brill.

-. 2018. "Roaming the Infinite': Liu Xiang as Chuci Reader and Would-be Transcendent." Tsing Hua Journal of Chinese Literature 20: 49-112.

Wu Fusheng. 2008. "Sao Poetry: The Lyrics of Chu (Chuci)." In How to Read Chinese Poetry: A Guided Anthology, edited by Zong-qi Cai, 36-56. New York: Columbia University Press.

Wu Fuzhu 吳福助, ed. 2007. 《楚辭注繹》 [Elegies of Chu, with commentary and translation], two volumes. Taipei: Liren shuju.

Xu Shen 許慎 (fl. $121 \mathrm{CE}$ ), ed. 1998. 《說文解字注》 [Explication of words and analysis of graphs, with commentary], edited by Duan Yucai 段玉裁 (1735-1815). Hangzhou: Zhejiang guji chubanshe. 
Yang Lian 楊煉. 2017. Narrative Poem 敘事詩, translated by Brian Holton. Hexham, Northumberland: Bloodaxe Books.

Yu Yue 俞樾. 1902. 〈讀楚辭〉 [Reading the Elegies of Chu]. In 《春在堂全書》 [Complete writings from the Hall of Spring's Presence], j. 24. Beijing: Guojia tushuguan chubanshe.

Yuan Ke 袁珂, ed. 1993. 《山海經校注》 [Classic of mountains and seas, with collation and commentary]. Chengdu: Ba Shu shushe.

Zhang Longxi. 1992. The Tao and the Logos: Literary Hermeneutics, East and West. Durham, NC: Duke University Press.

Zhou Zhenfu 周振甫, ed. 2011. 《周易譯注》 [Changes of Zhou, with translation and commentary]. Hong Kong: Zhonghua shuju.

\section{About the author}

Nicholas Morrow WiLliams is associate professor of Chinese literature at the University of Hong Kong and editor of Tang Studies. He is the author of Imitations of the Self: Jiang Yan and Chinese Poetics (Brill, 2015), as well as numerous articles and book chapters. Having earned his PhD at the University of Washington with a dissertation on intertextuality in Six Dynasties poetry, his research interests have since broadened to encompass other aspects of ancient and medieval Chinese literature, the Chuci anthology in particular. 



\title{
9 Mediation Is Our Authenticity
}

\author{
Dagong Poetry and the Shijing in Translation
}

\author{
Lucas Klein
}

\begin{abstract}
This essay starts from the premise that a poem is a translational process: always, not just once it has been translated in the conventional sense. From there, the author complicates and reorients the authenticity claims that have been built into the discourse around both the ancient Shijing and Chinese migrant worker poetry today. He argues that these two poetries' many moments of intralingual, interlingual, and cultural translation constitute and reiterate each other - and that the recognition of this should place proper attention on the work and the art involved in each.
\end{abstract}

Keywords: Chinese poetry, translation, authenticity, Shijing, dagong poetry, cultural translation

Unlike most of the songs nowadays that are being written uptown in Tin Pan Alley - that's where most of the folk songs come from nowadays - this, this is a song ... this wasn't written up there. This was written somewhere down in the

United States. - Bob Dylan (1963)

I start from the premise that a poem is not an authenticity but a translational process - always, not just once it has been translated in the conventional sense. In Chinese poetry, the $c i$ (詞) that were popularized in the Song were first written as lyrics to foreign music, and the regulated verse (律 詩) that made tonal prosody definitive for Chinese poetics was devised in reaction to contact with Indic languages (see Mair and Mei 1991). And the paradigmatic English poem, the sonnet, came from Italian. Poems that reject

Van Crevel, Maghiel and Lucas Klein (eds.), Chinese Poetry and Translation:Rights and Wrongs. Amsterdam: Amsterdam University Press, 2019 DOI: $10.5117 / 9789462989948 \_C H O 9$ 
inspiration from other languages, meanwhile, are bound to draw from the past, translating via their acts of poetic updating. Understood as instances of cultural translation - from abroad or from history - much poetry can be read as taking part in the processes of nativization and foreignization that govern interlingual translation (see Klein 2018). But even aside from the well-known examples of genres, forms, and subject matter crossing geographical and temporal boundaries, a poem is a translational process because it involves the putting of thoughts and emotions into language. Even the most original and heartfelt poetic expression is a translation of feeling into a work of linguistic art.

The best argument for the premise that a poem is not an authenticity but a translational process is, I think, a good interlingual translation - one that brings out the translatedness of the source text. Attention to the approaches that underlie such translations will help explain and ease the epistemological distinction between premodern and modern Chinese poetry that is widely taken for granted, and it will help clarify the relationship between interlingual translation and cultural translation.

This point needs making because we have a habit in the study of Chinese literature to treat the object of our inquiry as authentic, and therefore as essentially untranslatable. As Rey Chow has put it, in sinology, "the practitioners of Chinese writing - or the Chinese practitioners of writing - are, in effect, read as ethnics, or natives, who are endowed with a certain primitive logic" $\left(1998,15^{-16}\right)$. Of course, those taking such an approach do in fact translate the Chinese poetry in question; what I mean is that for them the primary measure of translation lies in the loss of an authentic source. Chinese poetry and Western poetry, in this view, are ontologically separate, and so the truth and essence of Chinese poetry can never quite be captured in the rhetoric of a Western language. (If such translations are simply not very good, for them the lack of quality implies the "untranslatability" of the exalted source texts, as the sacred "originals" they are; for me, however, it implies a lack of appreciation of both the art and the work of the poetry in question).

The assumed untranslatability of Chinese poetry also contributes to the disciplinary divide between Chinese poetry's modern and premodern incarnations - and the notion that modern Chinese poetry is somehow less "Chinese" because less untranslatable (see Klein 2017, 7-9). If a recent Chinese poetic subgenre now offers a way past this disciplinary divide, it does so by providing a way back into authenticity and Chineseness: against the work of writers likely to be noted for their technique and relationship to international literary trends, migrant worker or "battlers" poetry, dagong shige (打工诗歌), tends to get treated as an unmediated expression of the Chinese 
authentic. As Maghiel van Crevel notes, dagong poetry is then understood to exhibit an "authentic poetry's sensitivity and relevance to social realities," which is linked to "literature's relation to national identity" and "a claim to Chineseness" based on "a somewhat unambiguous reading of the Book of Songs 詩經” from China's bronze age (2017a, 275). ${ }^{1}$ Echoing Chow on the "primitive logic," van Crevel elsewhere critiques the way the dagong poet has often been configured as a "noble savage" in the house of poetry (2019).

Such configurations only replay the divide of Chineseness along the axis of translation, with dismissals of how more typically literary poems are said to "translate themselves" (Owen 1990, 31), while dagong poetry's emphasis on "lived experience" (Goodman 2017, 112) raises "the old question of whether the translator is at liberty to 'improve the original'" (van Crevel $2017 \mathrm{~b}$ ). Might attention to the work of translation also close such divides?

Van Crevel has noted that dagong poetry "is often framed in a crude opposition of social significance (high) and aesthetic value (low) that might just not be the whole story" (2017c, par. 101; for further elaboration, see van Crevel 2019). Bringing the work of translation into this story should help alleviate such a crude opposition. Translating contexts here, the case of the workers who write dagong poetry is not unlike that of experimental Asian American poets, whom Dorothy Wang describes in Thinking Its Presence as facing a limited and limiting either-or when it comes to critical appreciation:

Whether critics focus solely on ethnic content in more mainstream Asian American poetry or ... ignore issues of race in avant-garde Asian American poetry and privilege the "purely" literary or formal (against the ethnic), the full complexity of Asian American poetry - and minority American poetry - has not been acknowledged.

$(2014,33)$

Wang shows how ethnicity and avant-garde poetry practice do not need to be at odds. Similarly, my aim here is to show how social significance and aesthetic value do not need to be so crudely opposed - but to make this point, I will focus on translation. I have elsewhere looked into the translingual influences on modern and medieval poetry in Chinese to argue that impressions of poetic Chineseness, from tonal prosody to allusions to the literary past, are a product of translation (2018). Here I will be looking

1 Rather than using either traditional or simplified characters throughout, in citations I follow the publication in question. Since I cite writers who use different translations for dagong poetry and for the Shijing, I will default to romanization in both cases. 
at authenticity claims on both sides of the link van Crevel points to - the Shijing and dagong poetry, in particular Eleanor Goodman's translations in the 2016 anthology Iron Moon - to argue that poetry can never stand outside translation.

Evidence for the necessity of such an argument can be found in Wang's own work, among other places. Writing about Asian American literature, she occasionally touches on Chinese poetry and translation in its many guises. In the back matter, she notes that "what many now consider 'pure' (Han) Chinese classical poetry was influenced by 'barbarian' cultures" - but then she adds a bibliography: "Critics who have written cogently on traditional Chinese poetry and its intersection with Western poetics include [Stephen] Owen, James J. Y. Liu, and Wai-lim Yip" (2014, 346n62). But what have these three said about Chinese poetry's intersection with Western poetics? In Wang's quotation of Liu and Yip to support her reading of Hong Kong-born American poet Marilyn Chin, they both demonstrate the ethnographic treatment of Chinese poetic language, ascribing to it the "primitive logic" which Chow critiques. The "omission of the subject" in classical Chinese poetic grammar, Liu says, gives Chinese poetry "an impersonal and universal quality, compared with which much Western poetry appears egocentric and earth-bound." For Yip, "the classical Chinese language, as it is used in poetry, is free from syntactical rigidities - having no articles, personal pronouns, verb declensions, or connective elements such as prepositions and conjunctions and being indeterminate in parts of speech," which he contrasts with "the predicative activities and habits of mind in Indo-European languages" (quoted in Wang 2014, 156-157). ${ }^{2}$ Not only do the passages cited by Wang recall the "primitive logic" ascribed to Chinese writing, they also undermine the notion of cultural translation for which Wang argues when citing their work.

And interlingual translation? In the book Wang cites, Owen notes that "Translators of Chinese often create their own vision of 'Chinese' literature as a whole, either articulated against English literature or as a possibility within it" (1996, xliii). Elsewhere he has written that translation requires us to

sacrifice Chinese poetics - the openness of relation between words, the parallel structures, the nonfictional poet speaking from a particular moment, moving with experience. But we will choose the best analogues from our own literature: the dramatic monologue, the confessional tradition, the diary. $(1985,125)$

2 Wang "take[s] issue with Liu's praise of the "universal," but her reasoning is race-based (Wang 2014, 156); see her elaboration on pp. 347-348n86. 
At once he ethnographizes Chinese poetics and writes against translation as anything but reiterating difference between "Chinese poetics" and "our literature."

James Liu presents a similar ontological division, played out in a typology of translation: there is the "poet-translator" and the "critic-translator," one translating for readers who "need to know how far a translation resembles the original and not simply how well it reads in English," the other for those who are "in no position to know, and perhaps do not care, how far a translation resembles the original" (1982, 37-38). This is the opposite of Wai-lim Yip's proposition, but Yip also begins with a stark division between Chinese and Indo-European capacities in writing things as they really are: "Until we disarm the tyrannical framing functions of the English language, the natural self in its fullest sentience cannot be released to maximum expressivity." Fortunately, however,

poets and philosophers in the West have already begun to question the framing of language, echoing in part the ancient Taoist critique of the restrictive and distorting activities of names and words and their powerwielding violence ... The[ir] syntactical innovations ... suddenly open up a new perceptual-expressive possibility in English, a new ambience whereby I can stage Chinese poetry according to its original operative dynamics rather than tailoring it to fit the Western procrustean bed.

(1997, xiv)

Modernist and postmodernist American poetry have saved the day, allowing Yip to present the world as it truly is - and as premodern Chinese poetics showed it to be! But while Yip holds out the possibility of comparability, and not just contrast, between Chinese poetry and certain modes of English poetics, such a possibility is established upon an essential difference between the linguistic epistemologies of East and West.

Thus, while Wang argues against ethnographizing Asian American poetry, that is how her sources for thinking on Chinese-English poetry translation treat Chinese poetics. Her work would have benefited from reflection on Zhang Longxi's point that theses such as Owen's, Liu's, and Yip's "put Chinese wen [文] and Western literature in an untenable opposition, a dichotomy between natural manifestation and human creation" $(2005,22)$. Yet it is telling that a scholar of literature should stumble when discussing not only translation, but the relationship between cultural translation and interlingual translation. Too often, when considering the relationship between literature and identity, we fail to think of, and to think through, translation. 
Well, what is the relationship between interlingual translation and cultural translation? Van Crevel distinguishes between cultural translation defined as what Susan Bassnett calls "translation understood figuratively as movements between cultures," on the one hand, and "[c]ulturally inflected interlingual translation," on the other, for which "Eleanor Goodman's textual, paratextual and epitextual translations of battlers poetry come to mind" (he also notes "[t]ranslational aspects of anthropological practice," but this is less relevant to the present discussion). In culturally inflected interlingual translation, the translator "acts on the awareness that interlingual translation is inherently a cultural affair that goes beyond linguistic re-expression, and that the texts in question are inextricable from their contexts in both the source language and the target language." In translational movements between cultures, translation is not necessarily about texts or languages but also or primarily about people, and "is associated with ... hybridity and in-betweenness, and with oppression, resistance and conflict" (2017a, 247-248). Yet how far are these two definitions from each other? Would Goodman's renditions of dagong poetry be possible without a broader awareness of translation understood figuratively as movements between cultures? Could translation be understood figuratively without the work of culturally inflected interlingual translations?

For van Crevel, "we stand to gain from letting [various types of cultural translation] operate alongside one another as the material permits or requires, respecting their distinction and being alert to moments of synergy" (van Crevel 2017a, 248). Here I will extend this awareness to look at assumptions underlying figuration itself and the role these assumptions have played in the construction of notions of Chineseness, authenticity, and the possibilities of translation. Figuration, for instance, is at stake in ideas that modern Chinese poetry is overly Western in its tropes, and that Chinese poetry is supposed to voice an authenticity that functions ethnographically yet inevitably calls translation into question.

Specifically, I look into van Crevel's point about dagong poetry's “authenticity" claims being borrowed from the authority of the Shijing, which grants dagong poetry "an easy edge over the avant-garde's generally cosmopolitan outlook" in current Chinese commentarial discourse (2017a, 275). While he problematizes the binary between "foreign" figuration and the Chinese "authentic," I am not convinced that he has resolved the positional tension between them. I will further the argument that interlingual translation and translation as a trope for movement between cultures require and reiterate each other, then, by drawing on a tradition of scholarship that has critiqued this division. The debates about the reading of the Shijing in this tradition 
of scholarship are important to the antifoundationalist foundation I need to lay out in order to discuss dagong poetry; as such, it is necessary to go through them in some detail. I will then lead this discussion into further consideration of culturally inflected interlingual translations of dagong poetry such as Goodman's. We are faced with a number of interrelated authenticity claims, and my attempt here is to show how they are linked and how translation can help us see their fallaciousness and our way past them.

\section{The Shijing in the midst of mediation}

In his critical commentary on dagong poetry, He Xuan 何轩 writes that his book "borrows the traditional Chinese method of commentary ... modelled on that of the Shijing by Mao Heng 毛亭 and Mao Chang 毛萇 in the Han dynasty of our nation" (2010, iv). Though He describes himself as engaged in a kind of cultural translation, mediating between dagong poets and scholars, clearly he has a sense of what van Crevel calls "the poet's personal experience" and "literature's relation to national identity" as underpinning an authentic Chineseness. He's focus on the poets' "authentic identity 'of the people” (地道“民间”身份) bears this out, as does his citation of Huang Zunxian's 黃遵憲 (1848-1905) famous line in relation to that identity: “They are a distinct collective of those living on the lower echelons of society. They survive by 'battling' it out on the lower echelons, and they try to create poetry according to the principle of 'My hand writes my mouth"” (我手寫我 口). He categorizes the poems in his anthology according to how workers encounter the “mind-body problem" (身心问题) in light of “the quality of 'poetry verbalizing intent"' (詩言志) - taken from the Mao Preface to the Shijing (2010, iv-v). The mind-body problem represents the dualism that the authentic Chineseness of the Shijing and dagong poetry is meant to resolve.

Yet He's simple association of the Shijing with the Mao commentaries demonstrates that as the commentaries were overturned, they were emptied of meaning. As Haun Saussy explains, this took place roughly a century ago: "The campaign to overturn the Mao Prefaces is May Fourth in a nutshell. (It is also a remarkable gesture of devotion to what seemed worth saving in the Confucian canon, despite all that the canon had been made to say)" (1993, 58). The Mao commentaries' mode is allegoresis, reading allegory into the poems. They were overturned because, as Zhang Longxi has written, allegoresis "is a strong interpretation that often ignores, or even does violence to, the letter of the text in order to make it fit within the framework of a religious, moral, political, or philosophical system" $(2005,86)$. By the early twentieth 
century, Saussy explains, "the immorality (in metropolitan eyes) of" much of the Shijing "requires that a new reading be superimposed on the literal meaning ... Reading the poems in their 'original sense' will restore" - so the argument goes - "the original autonomy of the village customs" (1993, 57). Today, according to Zhang,

Scholars and critics tend to see traditional commentaries as unwarranted moral and political overinterpretation imposed on poetry without considerations of its literal meaning or aesthetic values. "The susceptibility to allegorization in the traditional Shih Ching scholarship," as C. H. Wang puts it, "is a manifest distortion of this classic anthology, a distortion both of its generic character and of the original definition of shih in general."

$(2005,98)$

He Xuan says he models his exegesis after the Mao commentaries, but his method is not one of allegoresis. Rather than a metaphorical gloss superimposed on the text, the Mao commentaries have turned into a synecdoche for the text, in all its authenticity as the vox populi ancestor of dagong poetry.

Zhang and Saussy are debating "the metaphor problem" (see Hayot 2011, 97-99), for which the Shijing is the most common reference point. Saussy argues for the possibility of a Chinese poetic allegory, against statements such as C. H. Wang's, above, and claims by Owen and Pauline Yu that the "traditional Chinese reader had faith that poems were authentic presentations of historical experience" (Owen 1985, 57) because "[i]ndigenous Chinese philosophical traditions agree on a fundamentally monistic view of the universe," in contrast to "Western allegory," which "creates a hierarchical literary universe on two levels ... only one of which has ultimate primacy" (Yu 1987, 32, 21). For Saussy, this view denies the artistry of Chinese poetry. Zhang, for his part, believes in the possibility of Chinese allegory, though he argues against the Mao commentaries for a more "literal" understanding of the Shijing: "any figurative or allegorical meaning must be based on the literal sense of the text, and any use of poetry that does violence to that primary context would constitute a breaking of the poem's textual integrity" $(2005,92)$. Their debate has done much to change the discussion about the comparability of cultures and literatures - and, by extension, about translation.

Saussy's first book, The Problem of a Chinese Aesthetic, is usually noted for its first chapter (Chow 1998, 14-15; Hayot 2011, 98), which traces disbelief in Chinese allegory back to the European understanding of China born when Jesuit missionaries debated whether Confucian rites were "religious." Indeed, two earlier scholars in the West with an ethnographic approach to 
translation, Herbert Giles and Marcel Granet, were key links in the Shijing's chain of resignification (see Saussy 1993, 19-20). But the rest of the book lays out a productive argument for how we should understand allegory in the Shijing. The authors of the commentary were disciples of Xunzi 荀 子 - famous for stating that "People are bad by nature; what is good in them is made by effort” (人之性惡, 其善者偽也) (Xunzi 1988, 434) - so the "expressive thesis has to take second place to the prescriptive thesis ... What poetry 'expresses' is human nature, in which case it is evil; or it expresses the second nature of the sages, in which case its cause is not natural but artificial, emanating from a prescriptive sagely decree" (Saussy 1993, 105). The "authors of the Prefaces and commentaries are not afraid to praise their Book of Odes as a made thing, a product of interpretation ... The model for reading," then, "is work, the replacement of a given object by a made one" (118-119). To think otherwise is to fall for a "theory of poetic language that ... has nothing to say about work (which is not work unless it changes something)" (138). ${ }^{3}$ The focus on both art and work are also relevant to any consideration of translating dagong poetry.

Saussy's first monograph is only the first in a series to critique the notion of the authentic - to argue, instead, "that we are always in the midst of mediation, that mediation is our authenticity - whoever 'we' may be" (2001, 3). In his Great Walls of Discourse, he problematizes anew the hypothesis that all Chinese poems are true:

in the study of Chinese poetics, we find a case of incompatibility between the semantics of the quoted language and its place in a quoting syntax. The object-language must at least threaten to break through the metalanguage's syntactic frame, for one mission of such cultural comparison is to call into doubt the assumption that our meta-language (typologically "Western," "modern") enjoys a superordinate, theoretically capable, status and is entitled to determine what "true" means.

$(2001,60-61)$

In The Ethnography of Rhythm, he goes further, looking at the postulation of "oral literature" and its "implication that by 'oral' we must mean 'not written' ... that 'oral literature' is what the work originally (despite the passage of time) and really (despite the words on the page) is" (2016, 1-2).

3 To think otherwise, then, as Saussy explains in his last chapter, is to believe in "Hegel's China ... a realm of indifference that has to be understood in its difference from non-indifference (a difference that history has to consolidate before it can pronounce on it)" (183). 
This, too, is part of a project of undermining the authenticity claims that end up denigrating translation.

Saussy's Ethnography only briefly refers to Chinese literature, to detail how the then new oral theory allowed Marcel Granet "to imagine a social order that would account for both the form and the themes of the poetry" of the Shijing (2016, 28; see 27-33). Edward Shaughnessy has filled in the genealogy of the orality hypothesis as voiced by C. H. Wang and Granet - and by extension, Arthur Waley, whose translation The Book of Songs (1937) was thoroughly indebted to the work of Granet. But when it comes to translation, Shaughnessy as genealogist ends at a remove from Saussy's implications. Examining "the length and breadth of early China's paleographic record," he writes, the premises "concerning the creation and transmission of the Classic of Poetry become ever less persuasive, and the statements concerning the oral nature of the Poetry ... should be subject to re-evaluation" (2016, 146-147). Saussy's critique of the originary seems to have originated another postulation of certain origins.

In another paper Shaughnessy offers an example of the difference it makes to translation whether one believes that the Shijing was transmitted primarily orally or textually. Waley translates the poem Xia wu (下武) from the Daya (大雅) as “Footsteps Here Below." It begins:

Chou it is that continues the footsteps here below. 下武維周
世有哲王
三后在天
王配於京

From generation to generation it has had wise kings.

Three rulers are in Heaven,

He is their counterpart in his capital,

王配於京

The power of generations he has matched; 世德作求

Long has he been mated to Heaven's command 永言配命 And fulfilled what is entrusted to a king. 成王之孚

Has fulfilled what is entrusted to a king,

成王之孚

A model to all on earth below;

下土之式

Forever pious towards the dead, 永言孝思 A very pattern of piety. 孝思維則 
For Shaughnessy, it is "Descending from Wu," and starts:

Descending martially is Zhou, Generations have had wise kings!

The three lords are up in heaven

The king matches in the capital.

The king matches in the capital, Worldly virtue being a mate.

Eternal the matching mandate

The Completing King's trustfulness.

The Completing King's trustfulness

A model for the lands below.

Eternal the filial thoughts,

Filial thoughts are the standard.

$(2015,370-371)$

Certainly the differences between Waley and Shaughnessy as scholars and poets are not reducible to a disagreement over the orality of the Shijing. Nevertheless, "literary qualities" aside, Shaughnessy writes, "I am confident that mine better reflects the original structure and purpose of the poem." Furthermore, his "contribution derives from awareness of a range of bronze inscriptions from the Western Zhou dynasty" (2015, 372) - in other words, the written record. And yet, problematically - at least from the point of view of a critique of the authentic - Shaughnessy offers written transmission as its own authenticity, relying on the history and heritage of writing to produce what he thinks of as a reflection of "the original structure and purpose of the poem." At the theoretical level, he is only disagreeing with Waley, not sublimating or synthesizing his opposition.

Where to from here, then? Orality only needs to posit an authenticity from a Derridean perspective in which it is associated with logos and a metaphysics of presence. But what if this presence might itself be equally absent? What if a written oral can highlight the impermanence of both the oral and the written, just as translation might be able to highlight the translatedness of both source and target texts?

American poet Anthony Madrid does just that in his transcription of a translation mis-inscribed on his memory. Madrid was trying to recite his favorite Shijing poem to his students in Texas, "Thorn Vine on the Wall" (墻有茨), in Burton Watson's translation. It reads: 
Thorn vine on the wall must not be stripped: words in the chamber must not be told. What could be told would be the ugliest tale!

Thorn vine on the wall must not be pulled down: words in the chamber must not be recited. What could be recited would be the longest tale!

Thorn vine on the wall must not be bundled off: words in the chamber must not be rehearsed. What could be rehearsed would be a shameful tale!
墻有茨

不可掃也

中冓之言

不可道也

所可道也

言之醜也

墻有茨

不可襄也

中冓之言

不可詳也

所可詳也

言之長也

墻有茨

不可束也

中冓之言

不可讀也

所可讀也

言之辱也

(Watson 1984, 24)

"So the beauty of the thing," Madrid writes, "is they never tell you what happened in the chamber. But if those walls could speak ...!" His narrative style is irrefutably colloquial, oral - but of course it is written. Watson, meanwhile, only says of the Shijing poems that "Most, if not all, were intended to be sung, though the musical settings were lost long ago" (15), not necessarily embracing, I think, the orality hypothesis. And yet in Madrid's recitation, as transcribed, that is exactly where it goes. His memory was faulty. He writes,

I charged in with complete confidence, but found out right smartually that I was quite unable to retrieve the endings of any of the stanzas. So I just had to make it up as I went along ... But the crazy thing is, the invented stuff that came out of my mouth ... was good. The kids were impressed ... Cheggitout.

Thorn vine on the wall?

must not be stripped.

Words in the chamber ...? 
must not be repeated.

'Cuz what could be repeated ...?

Ugkh. You don't wanna know.

Thorn vine on the wall?

must not be taken down.

Words in the chamber ...?

Shhh. That's - not for you.

'Cuz what happened in that chamber ...?

[wag finger like no-no-no]

Uh-uh. Uh-uh.

Thorn vine on the wall?

must not be fucked with.

Words in the chamber ... uuuhhh.

'Cuz - that ...?

[waving hand in front of your nose in the Mexican manner of waving off a bad smell]

that? ... ooh, ugkh.

Madrid writes, "What came out of my mouth was basically a legitimate translation of what the poem says - it's just not word-for-word. In fact, part of what came out of my mouth wasn't even words ..." Yes, a legitimate translation. But for all that Madrid's words seem spoken, can we, in the end, even be sure that they ever were? He introduces his recitation, "Okay, so now here, carefully reconstructed, using archival footage and oral testimony of eyewitnesses, is what I said, whatever day that was, spring semester, 2017" (2017). Protesting too much, his orality argues against Saussy's contention that the category of "oral literature" asserts "what the work originally (despite the passage of time) and really (despite the words on the page) is." With this written translation of an oral interpretation of a written translation, we have a textual translation - a culturally inflected interlingual translation - that shows translation figuratively as movement between cultures.

\section{Translating the raw materials of dagong poetry}

But can Madrid provide a model for all translations, or even for all translations of the Shijing? Enjoyable as it may be, it does not get us at the culturally agreed-upon "real thing," even with the caveat that the real "real thing" 
cannot exist. In principle, we may agree with Eric Hayot that "literal interpretations are, just like allegorical ones, the products of a set of social interactions that involve language with power," therefore "any claim about the native 'integrity' of a text [cannot] be anything but the first and most oppressive metaphor" (2008, 124-125). But I think we are more likely to be left with Zhang's view, allowing the possibility of allegory but feeling that translation, at least, "must be based on the literal sense of the text."

Can we push further? Monica Zikpi's "response to Zhang” suggests

shifting the basis of cross-cultural understanding and translation from the hermeneutic unveiling of the "original intention" to a deeper, firmer grounding in a philology that accounts for the original's particular historical life, its pre-textual and extra-textual ways of being as well as its mutable material transmission and dynamic interpretive reception.

$(2016,20)$

Today, she writes, "the Shijing yields no 'original' literal sense, but it may translate (etymologically speaking, carry over) some guidelines for its interpretation" (4). So - can this be done with respect to dagong poetry?

As said above, the best argument for a poem's being not an authenticity but a translational process is a good translation. Given the distance between Shijing poetics and the contemporary, not all the philology Zikpi calls for is necessary in translating dagong poetry. Nevertheless, dagong poetry is as embedded as the Shijing in "pre-textual and extra-textual ways of being" (and the concomitant claims), so Zikpi's point still works. I want to argue that Goodman's translations fulfill this with respect to dagong poetry, that they bring out the translatedness of their source by foregoing the "hermeneutic unveiling of the 'original intention" in favor of an account of the poetry's "particular historical life ... its mutable material transmission and dynamic interpretive reception." But first I should note the discursive difficulty in arriving at such a point, because of the weight of the authenticity claim on the poetry in question.

We see this difficulty even in Goodman's own writing on dagong poetry. Explaining the context of her translations, she argues against "focusing on shenfen" 身份 - the authentic "identity" on which He Xuan compiled his anthology - to focus instead "on the notions of experience and material." She is struggling to "shift the emphasis from the poet to the poetry," yet her terms always revert to an authenticity that poetry readers in the West presumably lack: "Someone working in a coalmine or an electronics factory or a printshop has seen, heard, smelled, felt and done things that most of those who fit the 
conventional picture of a poet have not." The presentation of an authenticity behind, but also in, the poetry is ultimately what compelled her to accept the project: "it became clear to me that migrant worker poetry is made by important voices that should be heard, and that it reflects experience of a kind whose expression from an inside perspective is well worth the outsider's while" $(2017,112-113)$. Though she resists the common terminology of shenfen, she shares with critics like He a reliance on experience, voice, and whatever else makes one's identity authentic, rather than crafted - what the poetry, in Saussy's words, "originally (despite the passage of time) and really (despite the words on the page) is." At a deep level, this focus replays what Zhang calls the "dichotomy between natural manifestation and human creation" of "Chinese wen and Western literature," and rhetorically undermines the artistry of dagong poetry.

Too much of such an attitude also argues against the possibility of translation. If what the worker poets write is an authentic expression of their selves and experiences, then communicating that expression over too far a distance - such as in literary translation into English - would alienate those workers from the immediate conditions of their own lives. The translation would become all about serving the "outsider," at the expense (and the economic terminology is not accidental) of the laborers' "inside perspective." In translation, this attitude can be seen behind the stiffness of the versions by the blogger or bloggers called Nào 闹 (2014) of poems by Xu Lizhi 许立 志 (1990-2014), a Foxconn worker who killed himself. Insufficient attention to crafting a poetics in English implies either that $\mathrm{Xu}$ has no worthwhile poetics, or that his poetics must remain forever inaccessible beyond the translational border. From "I Swallowed a Moon Made of Iron" (我咽下一 枚铁做的月亮): “All that I've swallowed is now gushing out of my throat / Unfurling on the land of my ancestors / Into a disgraceful poem" (2014). The text seems to operate according to the idea that its essence has been lost in translation, betraying an idea of dagong poetry as "untranslatable" as defined above, measurable only in terms of loss of the authentic.

Goodman's disagreement about stiff renditions indicates a different attitude about Xu's authenticity. She writes about Nào's word choices:

The closed sound of "un" opening up into the long curl of the "furl" is very appealing ... The first thing I thought when I saw it was, I wish I'd thought of "unfurl"... it's relatively uncommon and has grand resonances, and it demonstrates that the translator has a rich vocabulary. And the original $p u$ 鋪 can legitimately be rendered as "unfurl," although its core meaning is "to pave." 
But she had second thoughts:

The Chinese verb is plain, not grandiose but ordinary ... there is also a problem in what one thinks is being unfurled. Ostensibly, it is a poem. A poem can be unfurled, if it's like a scroll, in some romantic Tang-dynasty image. But this hardly befits Xu Lizhi, who wrote in grungy notebooks. And what is implied in his poem is vomit ("gushing out of my throat"), which definitely can't be unfurled.

$(2017,114-115)$

Goodman's consideration of the word unfurl, from angles of poetics in English to appropriateness to the Chinese vocabulary and overall tone of the poem, demonstrates her sensitivity as both a reader and writer. And her change of mind about the vocabulary on which it hinges demonstrates her ability to make an account of dagong poetry's "pre-textual and extra-textual ways of being."

Goodman weighs contradictory impulses and brings them together into one work of art. It happens again when she writes that the "sensory data" the poets experience in the mine or the factory "may constitute the raw material that goes into a literary work" (112). That there is raw material means that there is work that goes into the literary work. Yet notably, this is not the only time the term appears in her paper: explaining her change of mind about the word unfurl, she quotes translation theorist Antoine Berman about the dangers of "ennoblement," "producing 'elegant' sentences, while utilizing the source text so to speak, as raw material. Thus the ennoblement is only a rewriting, a stylistic exercise based on - and at the expense of - the original" (Goodman 2017, 114). Berman, curiously, seems to want translation not to be work - or not, at any rate, overworked. Goodman, however, states on the one hand that poets can and should treat their sensory data of labor as raw material, but on the other that translators should not poeticize the raw material of their source texts to "ennoble" them. It sounds like a contradiction. But given her artistry, I think it is instead a resolution, bringing together the poem's "mutable material transmission and dynamic interpretive reception."

In her anthology, Goodman's translation, titled "I Swallowed an Iron Moon," reads:

I swallowed an iron moon they called it a screw 
I swallowed industrial wastewater and unemployment forms

bent over machines, our youth died young

I swallowed labor, I swallowed poverty

swallowed pedestrian bridges, swallowed this rusted-out life

I can't swallow any more

everything I've swallowed roils up in my throat

I spread across my country

a poem of shame

(Goodman 2016, 198)

\author{
我咽下一枚铁做的月亮 \\ 他们把它叫做螺丝 \\ 我咽下这工业的废水, 失业的订单 \\ 那些低于机台的青春早早天亡 \\ 我咽下奔波, 咽下流离失所 \\ 咽下人行天桥, 咽下长满水锈的生活 \\ 我再咽不下了 \\ 所有我曾经咽下的现在都从喉咙汹涌而出 \\ 在祖国的领土上铺成一首 \\ 耻辱的诗
}

(Qin 2015, 360)

Perhaps because Goodman brings forth the poem's "dynamic interpretive reception," this translation "raise[s] questions about the translations" for van Crevel. In his review of the anthology, he writes: "For line 4 ("bent over machines. ..'), 低于 in the original should probably be read as meaning 'lower than' rather than 'stooped over.'” And he wonders about "Goodman's use of 'I' in the penultimate line, as the subject of the poem's final sentence": "the absence of another 我 in the penultimate line and 成 in 铺 成 rather suggest something along these lines: 'I can't swallow any more / everything I've swallowed roils up in my throat /(/) and spreads across 
my country / a poem of disgrace'" (2017b). ${ }^{5}$ Are these questions marked by treating dagong poetry as the "authentic expression" that mars Nào's translations?

Van Crevel's criticisms come with a corollary made elsewhere:

For argument's sake, one could even maintain that the degree to which a text is conventionally considered untranslatable and requires rulebreaking is proportional to the potential for poetic translation ... And of course, if we really wanted the same thing as the original, we should discard translation altogether and shed the desire to know what gets said in other languages than the ones we speak.

(2017c, par. 116)

But no matter how good my Chinese may get, could discarding translation altogether ever give me "the same thing as the original"? Am I ever not reading in translation, when reading in a language I learned after childhood? The easy dichotomy between "poetic translation" and "the original," through the cracks of which fall a sense of poetry as translation - as translational in nature and forever engaged in translation - mirrors the discourse around dagong poetry in the literary field with respect to more safely literary poetics, the "crude opposition" between "social significance (high) and aesthetic value (low)" with which van Crevel is so impatient. Can we get to a point where we can see both aesthetics and social significance both in the poetry being translated and in the act of translation?

Though van Crevel's comments about a poem's "untranslatability" requiring rule-breaking demonstrates the complexity in his thinking about translation (and see his discussion of "content bias" in translation, in 2008, 284-288), his stance here is more scholarly than literary. It may even resemble Shaughnessy's attitude toward translation, above, based on the scholar's certainty of his own reading, rather than considering the theoretical inferences to be drawn from counterbalancing that certainty with a consideration of poetics in English. In other words, while van Crevel may be right that Xu's line probably means "lower than machines," is it better than "bent over machines" in conveying the artistry of poets who are menial laborers by trade? Can a translation be right, even if it's wrong?

5 The parenthesis around the virgule marks van Crevel's observation that different publications differ in printing the last four lines as comprising one stanza or two - which, he says, makes a difference to how we might understand the grammar of the clauses. 
While as theorists we might reject belief in the "real thing" of our source texts, as specialists and activists we seem to require it.

Yet this tension with van Crevel's approach to translation reaches resolution, too. It happens in Goodman's republication of the poem in an article on her translations. She takes van Crevel's suggestion to change "bent over machines" to "lower than machines": the linguistic accuracy enables the reader of the translation to sense that the humans may be worth less than the machines they operate. Likewise, she changes the final four lines - though not exactly as van Crevel suggested:

I can't swallow any more

everything I've swallowed roils up in my throat

to spread across my country

a poem of shame

$(2017,113)$

Whereas I said above that Shaughnessy only disagrees with Waley, but does not sublimate his opposition, Goodman's incorporation of van Crevel's alternate readings - his corrections - demonstrates what Zikpi calls the poetry's “mutable material transmission." Van Crevel's more positive comments, such as his praise for Goodman's "reflection on cultural difference" and knowing "when to honor the literal, and when to shun it," come to the fore. The poetry, he writes, "remains true to life in translation" (2017b).

\section{Art and work and the work of art}

The motto of this paper shows Bob Dylan asserting, in his preface to the song "Bob Dylan's Blues," his authenticity over the churned-out production of Tin Pan Alley lyrics. They "may not be pure folk songs," Saussy writes about the poems of the Shijing, "but calling them folk songs has its advantages." His words apply as well to Dylan's songs: "It is an economical move. If a folk song seems to be about poverty or elopement, it must be about poverty or elopement - or at least that is how the scholars view folk song" $(1993,59)$. But there is a cost to that economical move, if it means we overlook the expression as art and work ("which is not work unless it changes something," in Saussy's words). In the case of Dylan, the artistry and change give his words their irony and humor. By the time he recorded "Bob Dylan's Blues" in 1962, he had already established himself in Manhattan, and he was in a Columbia 
Records studio, just a mile and a half from Tin Pan Alley. Meanwhile, the song features not scenes from Dylan's own upbringing in iron-ore country, say, but the manufactured nostalgia of TV shows ("Well, the Lone Ranger and Tonto / They are ridin' down the line / Fixin' everybody's troubles / Everybody's except mine"). United States, indeed!

In premodern China literary writing "was recognizable through its high degree of intertextuality," Saussy points out in his most recent monograph, Translation as Citation. "A text that came into the world without this tissue of connection would give an impression of entire forgetfulness and utter nakedness" (2018, 94). Because the Shijing and dagong poetry seem to stand outside (before, after) that tradition, some have fantasized about their nakedness. But a better way to approach such poetry is as laying bare the kind of artistry and irony with which Dylan betrays his own claims of authenticity. This highlights how the poets of the Shijing and the migrant worker poets of dagong poetry are both working, and working in art. As Saussy writes, "translations are acts, not discoveries" (2001, 31). I have elaborated on how one of Goodman's translations embodies such action, mediating their mediations and translating their cultural translatedness. This means that when she writes of hoping her translations will give migrant workers "some kind of voice, a chance to articulate their own experiences, and to finally be heard - in Chinese, and in other languages" $(2017,126)$, she knows they already have a voice, and she knows it is a voice of both art and work.

\section{Works cited}

Chow, Rey. 1998. "Introduction: On Chineseness as a Theoretical Problem." Boundary $225(3): 1-24$.

Dylan, Bob. 1963. The Freewheelin' Bob Dylan. New York: Columbia Records.

Goodman, Eleanor, trans. 2016. Iron Moon: An Anthology of Chinese Worker Poetry, edited by Qin Xiaoyu. Buffalo: White Pine Press.

-. 2017. "Translating Migrant Worker Poetry: Whose Voices Get Heard and How?" Journal of Modern Literature in Chinese 14 (2)-15 (1): 107-127.

Hayot, Eric. 2008. Review of Allegoresis: Reading Canonical Literature East and West, by Zhang Longxi. Comparative Literature Studies 45 (1): 122-126.

-. 2011. "Vanishing Horizons: Problems in the Comparison of China and the West." In A Companion to Comparative Literature, edited by Ali Behdad and Dominic Thomas, 88-107. West Sussex: Wiley-Blackwell.

He Xuan 何轩. 2010. 《中国 “打工诗歌” 辑录与评点》 [A collection with critical commentary of Chinese "battlers poetry"]. Wuhan: Hubei renmin chubanshe. 
Klein, Lucas. 2017. "Strong and Weak Interpretations in Translating Chinese Poetry." Journal of Modern Literature in Chinese 14 (2)-15 (1): 7-43.

-. 2018. The Organization of Distance: Poetry, Translation, Chineseness. Leiden: Brill.

Liu, James J. Y. 1982. The Interlingual Critic: Interpreting Chinese Poetry. Bloomington: Indiana University Press.

Madrid, Anthony. 2017. “Thorn Vine on the Wall.” The Paris Review (blog), October 11, 2017. bit.ly/2YXY8eX. Accessed March 21, 2018.

Mair, Victor, and Tsu-Lin Mei. 1991. "The Sanskrit Origins of Recent Style Prosody." Harvard Journal of Asiatic Studies 51 (2): 375-470.

Nào 闹. 2014. "The Poetry and Brief Life of a Foxconn Worker: Xu Lizhi (1990-2014)." Libcom.org, October 29, 2014. bit.ly/1oMIgNC. Accessed March 22, 2018.

Owen, Stephen. 1985. Traditional Chinese Poetry and Poetics: Omen of the World. Madison: University of Wisconsin Press.

—. 1990. "What Is World Poetry? The Anxiety of Global Influence." New Republic 203 (21): 28-32.

—, ed. 1996. An Anthology of Chinese Literature: Beginnings to 1911. New York: W. W. Norton.

Qin Xiaoyu 秦晓宇, ed. 2015. 《我的诗篇: 当代工人诗典》 [My poems: the canon of contemporary workers poetry]. Beijing: Zuojia chubanshe.

Saussy, Haun. 1993. The Problem of a Chinese Aesthetic. Stanford: Stanford University Press.

-. 2001. Great Walls of Discourse and Other Adventures in Cultural China. Cambridge, MA: Harvard University Asia Center.

—. 2016. The Ethnography of Rhythm: Orality and Its Technologies. New York: Fordham University Press.

—. 2018. Translation as Citation: Zhuangzi Inside Out. Oxford: Oxford University Press.

Shaughnessy, Edward L. 2015. "Unearthed Documents and the Question of the Oral versus Written Nature of the Classic of Poetry." Harvard Journal of Asiatic Studies 75 (2): 331-375.

- 2016. "The Origin and Development of Western Sinologists' Theories of the Oral-Formulaic Nature of the Classic of Poetry." Bulletin of the Jao Tsung-i Academy of Sinology 3: 133-149.

van Crevel, Maghiel. 2008. Chinese Poetry in Times of Mind, Mayhem and Money. Leiden: Brill.

- 2017a. "The Cultural Translation of Battlers Poetry (Dagong Shige)." Journal of Modern Literature in Chinese 14 (2)-15 (1): 245-286.

-. 2017b. Review of Iron Moon: An Anthology of Chinese Migrant Worker Poetry, translated by Eleanor Goodman, edited by Qin Xiaoyu. MCLC Resource Center. bit.ly/2TejwbC. Accessed January 15, 2018. 
-. 2017c. "Walk on the Wild Side: Snapshots of the Chinese Poetry Scene." MCLC Resource Center. bit.ly/2GaWWhc. Accessed March 14, 2018.

-. 2019. "Misfit: Xu Lizhi and Battlers Poetry (Dagong Shige)." Prism: Theory and Modern Chinese Literature 16 (1): 85-114.

Waley, Arthur, trans. 1937. The Book of Songs. London: Allen \& Unwin.

Waley, Arthur, trans., Joseph R. Allen, ed. and trans. 1996. The Book of Songs: The Ancient Chinese Classic of Poetry. New York: Grove Press.

Wang, Dorothy J. 2014. Thinking Its Presence: Form, Race, and Subjectivity in Contemporary Asian American Poetry. Stanford: Stanford University Press.

Watson, Burton, ed. and trans. 1984. The Columbia Book of Chinese Poetry: From Early Times to the Thirteenth Century. New York: Columbia University Press.

Xunzi 荀子. 1988. 《荀子集解》 [The collected and explicated Xunzi], edited by Wang Xianqian 王先謙. Beijing: Zhonghua shuju.

Yip Wai-lim, ed. and trans. 1997. Chinese Poetry: An Anthology of Major Modes and Genres. Durham, NC: Duke University Press.

Yu, Pauline. 1987. The Reading of Imagery in the Chinese Poetic Tradition. Princeton: Princeton University Press.

Zhang Longxi. 2005. Allegoresis: Reading Canonical Literature East and West. Ithaca: Cornell University Press.

Zikpi, Monica E. M. 2016. “On Translation's ‘Original' and an Emergent Translation of the Shijing." Journal of Oriental Studies 49 (1): 1-25.

\section{About the author}

Lucas KLEIN (PhD Yale) is a father, writer, and translator, as well as associate professor in the School of Chinese at the University of Hong Kong. His translation Notes on the Mosquito: Selected Poems of Xi Chuan (New Directions, 2012) won the 2013 Lucien Stryk Prize, and his scholarship and criticism have appeared in Comparative Literature Studies, LARB, Jacket, CLEAR, $P M L A$, and other venues. Other publications include October Dedications, his translations of the poetry of Mang Ke (Zephyr and Chinese University Press, 2018); and contributions to Li Shangyin (New York Review Books, 2018); and the monograph The Organization of Distance: Poetry, Translation, Chineseness (Brill, 2018). His translations of the poetry of Duo Duo, forthcoming from Yale University Press, won him a PEN/Heim Translation Fund grant. 


\section{Part Three}

Impact 



\title{
10 Ecofeminism avant la Lettre
}

\author{
Chen Jingrong and Baudelaire \\ Liansu Meng
}

\begin{abstract}
This essay reveals how Chen Jingrong realizes the translator's agency in strikingly original ways in her influential mid-twentieth-century renditions of Baudelaire, and how Chen's translations are intertwined with her development of an eco-feminist poetics avant la lettre. Against the backdrop of modern China's tumultuous, politicized encounters with foreign literatures, it highlights Chen's personal trajectory as a female author in a pervasively male-dominated literary field.
\end{abstract}

Keywords: Chinese poetry, translation, Chen Jingrong, Baudelaire, ecofeminism, women translators

Ever since its emergence in the early twentieth century, modern Chinese poetry has been inseparable from the translation of foreign poetry. Many Chinese poets were translators themselves. Arguably, as translators, their primary purpose was to inspire new ways of writing Chinese poetry; and as such, their approach leads to easy association with recent trends of viewing translation as creative writing and recognizing the translator's agency as key to the complex process of translation (Perteghella and Loffredo 2007; Rosario 2012; Babaee 2016).

Among countless poets translated into Chinese, Charles Baudelaire (1821-1867) appears unique for his inexhaustible capacity to inspire successive generations of Chinese poets, from the first translations of his work a hundred years ago to the present day. ${ }^{1}$ Chinese poets and translators have

1 Zhou Zuoren 周作人 (1885-1967) was likely the first Chinese translator of Baudelaire. He first translated Baudelaire's poem “Get Drunk" (Enivrez-vous) in 1918 (Bien 2013, 41) and acknowledged

Van Crevel, Maghiel and Lucas Klein (eds.), Chinese Poetry and Translation: Rights and Wrongs. Amsterdam: Amsterdam University Press, 2019 DOI: 10.5117/9789462989948_CH10 
often followed Western critics and hailed Baudelaire as a representative of Symbolism, as a Satanist, Decadent, and dandy. They have emulated his poetic forms, his use of synesthesia, and his poetic transformation of the dark and ugly. Notably, Baudelaire's zealous Chinese followers have remained mostly a men's club, and they have sometimes interpreted and celebrated his misogynist depictions of women as gestures of rebellion against traditional constrictions on sexuality (Zhang 2009, 77-92; Bien 2013, 55-74). This emphasis on poetic technique and insensitivity to issues of gender equality have been prevalent in the male-dominated field of Chinese poetry at large (see van Crevel 2017, pars. 13-18).

Chen Jingrong 陈敬容 (1917-1989) stands out not only as one of the era's few recognized female poets, but also as the only female among several dozen Chinese translators of Baudelaire. Moreover, her translations count as a legendary inspiration of underground (地下) poetry in the 196os and 1970s, during the Cultural Revolution. Many of the authors in question, especially the ground-breaking Misty Poets (朦胧诗人, sometimes also rendered as "Obscure Poets"), recall their encounters with Baudelaire's poetry through Chen's translations as a defining moment. Yet, despite their acknowledgement of her work, younger generations of Chinese poets have generally regarded Chen as a transparent transmitter of Baudelaire's poetry into Chinese, without registering awareness of her agency as a poet-translator and her unique interpretation of Baudelaire's poetry (Ling 2004, 269; Bei Dao 2005, 86; Liang 2006; Tamburello 2012, 21-46; Bai Hua 2012; Liu 2015).

Tracing back to the 1940s, when Chen first translated and published on Baudelaire's poetry, the present essay examines how she developed a prescient ecofeminist poetics in the male-dominated, culturally and politically repressive literary fields of Shanghai in the 1940s and Beijing in the 1950s, in her translations as in her own poetry - which was clearly influenced by her engagement with Baudelaire. Obviously, Chen's work predates theories of ecofeminism, feminist translation (Palacios 2014; Palmary 2014), feminist critiques of Baudelaire's misogyny (Weinbaum 2003), and discussions of his eco-awareness (Quandt 2015) in recent decades. However, her early immersion in feminist ideals and her personal experience of oppression in a male-dominated society that was rapidly industrializing enabled her to see the interconnectedness of the oppression of women and other marginalized groups such as the poor, the aged, and the sick, on the one hand, and the destruction of nature, on the other. 
Where the analysis draws on English translations of Baudelaire to date, I will refer to Francis Scarfe's (1986) and Keith Waldrop's (2006) renditions. This is because my analysis of Chen's translations focuses on thematics and imagery rather than prosody, and both Scarfe and Waldrop render Baudelaire's poetry as prose and privilege content over form. All English translations from the Chinese, including the English translations of Chen's Chinese renditions of Baudelaire, are mine.

\section{Chen's early representations of Baudelaire}

Chen started reading French poetry extensively when studying French with a tutor in Beijing in fall 1936 (Chen 1984, 2-3; Luo and Chen 2008, 738). She first translated poetry by Baudelaire in 1945, after fleeing her oppressive marriage with Sha Lei 沙蕾 (1912-1986), another Chinese poet, and settling down in Chongqing, the capital of the territory controlled by the Nationalist Party (KMT) during the Second Sino-Japanese War (1937-1945). Supported by her brother and friends, Chen enjoyed a short period of peace and freedom as she was translating French poetry, including a dozen poems by Baudelaire, while also writing her own poetry and essays (Luo and Chen 2008, 729). In 1946 Chen moved to Shanghai, the largest cultural, commercial, and industrial metropolis in China at the time, and started one of the most prolific periods of her literary career (729-731).

To appreciate the significance of Chen's poetics and her interpretation of Baudelaire, it is necessary to understand certain features of the local literary field at the time. The Sino-Japanese war had ended in August 1945, but the civil war between the Chinese Communist Party (CCP) and the KMT had resumed. Ever since 1942, when Mao Zedong 毛泽东 gave his well-known “Talks at the Yan'an Forum on Art and Literature” (在延安文 艺座谈会上的讲话), the CCP had taken the position that literature should be subordinate to politics and use the language of "the masses" to promote the goals of revolution and national survival (Denton 2016).

In KMT-controlled areas, including Shanghai, the CCP's influence permeated many institutions through its underground organization. Consequently, the poetic field in Shanghai was dominated by "People's Poetry" (人民诗歌), a sloganistic political poetry advocating “revolutionary realism" (革命现实 主义) and supposedly catering to the taste of "the masses" (You 1997, 41-42; Jiang 2002, 78-87). It was under these circumstances that Chen published her essay “Baudelaire and the Cat” (波德莱尔与猫) on December 19, 1946 - and that she suffered harsh criticism of her Baudelaire translations and her 
own poetry from an all-male group of leftist critics (You 1997, 42-52). Their criticism was not targeted at Chen's poetry or the quality of her translations per se, but at what they considered Chen's ill-timed decision to translate, emulate, and praise Baudelaire. His style and themes did not fit the needs and standards of "People's Poetry."

Lin Huanping 林焕平, the first to attack Chen, argued that Baudelaire's poetry did not serve the taste of the masses (1946). Li Baifeng 李白凤 criticized Chen's own recent poetry as "Baudelairean," expressing the "fragile sentiments of the petite bourgeoisie or intellectuals in decline." Li condemned "Mr. Chen's" poetry for being "divorced from reality," thus doomed to be "discarded by the masses" $(1947,7)$. Tie Ma 铁马 suggested that "he," meaning Chen, operated "at a distance from our surging times and complex reality" (1946). Li, Tie Ma, and other critics' references to Chen in masculine terms can signal an unexamined assumption that Chen was a man, or else a gesture of deference to an accomplished female author. Either way, it demonstrates how the category of gender had been eclipsed by male-dominated discourses of nation, revolution, and class, in the literary field as in society at large.

On February 7, 1947, in response to her critics, Chen published another essay, “On My Poetry and Poetry Translation” (谈我的诗和译诗) (1947, 7). Different from Chen's erstwhile critics, I hold that her two essays show that her decision to "praise" Baudelaire was not an ill-advised blunder that proved she was out of touch with reality. On the contrary, the essays critique the then prevalent People's Poetry's obliviousness to the pain and suffering of underprivileged groups; and through Chen's reading of Baudelaire from an original, feminist perspective, they articulate a prescient and sophisticated ecofeminist poetics avant la lettre.

"Baudelaire and the Cat" opens with a laconic, one-line paragraph, foregrounding a distinctly personal perspective rather than assuming the tone of "objective" literary analysis: "Baudelaire often makes me think of a cat." Baudelaire wrote a number of cat poems, but the cat was not among his major themes, and has not been identified as such to my knowledge. In the historical setting of Chen's essays, where a highly politicized solemnity and grandiosity held sway, using this image constituted a bold move. The essay's second paragraph is also a single sentence in the source text, now an observation on Baudelaire's self-portrait: "two bright eyes, mixing a scorching heat and an icy coldness; his facial lines blending hardness and softness, all this resembles a cat" (1946b). In both Baudelaire's portrayal and that of the cat, Chen highlights a sharp vision and a sense of the compatibility of opposites. 
Further elaborating the image of the cat, Chen caustically contrasts her ideas with a Darwinian vision of monkeys and humans:

Except for monkeys (according to Darwin's theory, the more advanced among them have long evolved into humans, and some have today evolved to the point of knowing how to slaughter their own kind for pleasure), the smartest of all animals may be the cat. A full body of soft fur, four nimble feet, a pair of sharp eyes, its meowing sounds sometimes warm, sometimes bleak, sometimes so fierce it gives mice the shivers.

(1946b)

Social-Darwinian notions of evolution and progress had been widely embraced by Chinese intellectuals since their introduction into China at the turn of the twentieth century (Song 2015, 34-36, 96-97). Contrary to her predecessors and contemporaries, Chen points out the irony and invalidity of these notions in the brutal reality of war: humans, supposedly the most advanced species, have not evolved into better versions of themselves, but are un-empathetic, savage, and cruel to their own kind, to say nothing of what they do to other creatures. On the other hand, Chen's characterization of the cat - as a complex creature that combines the qualities of gentleness and sharp-eyed vision with the capacity to experience wide-ranging emotions such as warmth, sadness, and fierceness - underscores her ecofeminist emphasis on empathy, a vision that resonates with today's ecofeminism (Gaard 2016, 169). ${ }^{2}$

Chen subsequently turns to European Romanticism, of which she offers a rather conventional picture - but a closer look shows that this serves as a springboard to her highly original interpretation of Baudelaire's poetics. She attributes the decline of Romanticism to the "exaggeration" and "emptiness" of "Romantic passion" and applauds Baudelaire as harbinger of the (Symbolist) new generation by being the first to "hurl the miracle of deep emotions and prescient wisdom into French poetry" (1946b). Significantly, Chen's disparagement of Romanticism can be read as a critique of the People's Poetry that dominated the local literary environment.

Chen then reiterates commonly held views on Baudelaire's poetry, commending its rich colors and musicality, but swiftly shifts to an interpretation from her own perspective. She characterizes Baudelaire as a poet who feels equal empathy for all things, especially "minor and small things," which "he

2 Obviously, what matters here is not most people's general ideas about cats and empathy, but how Chen Jingrong chose to portray the cat. 
paints ... with a layer of miraculous radiance." She highlights the "genuineness and profundity" of Baudelaire's emotions and thoughts as reflected in his poetry, opposing these to the "superficiality and exaggeration" she observes in European Romanticism. She attributes the reason for the quality of his poetry to its origin in "the depth of his emotions and intellect," which in turn "originate from real life" (1946b). The weight of the paragraph falls on the emphasis on "real life," meaning lived experience.

Chen further clarifies the connection between "real life" and a poetics of empathy by juxtaposing Baudelaire's dismal life experience with his empathy for the unfortunate and underprivileged, the powerless and vulnerable:

Baudelaire was a true lover of life. He lived a bleak life and had an odd temperament. He loved many things that others never loved, and he wrote about them with a kind touch. He voiced grievances for all the unfortunate in the crowd: the poor, the handicapped, ugly women, widows, orphans, even lost birds and homeless dogs. He loved clouds, storms, the sea, the scorching sun and the icy moon; he also loved a tiny flower and a minuscule pipe. He also loved cats.

(1946b)

The spectrum of Baudelaire's empathy, as Chen sees it, spans across class, physical ability, physical appearance, marriage and family relations, and age; it extends to animals, the natural environment, and inanimate objects, a view with clear interfaces with today's ecofeminism. As Sam Mickey notes, the point of ecofeminism is to focus on "interconnections and networks of coexistence, which include the entangled categories of race, class, age, ability, religion, nationality, ethnicity, and many others, along with species, gender and sexuality" (2018, xvii). To my knowledge, no other poets or scholars have interpreted Baudelaire's poetics this way. Chen's characterization of Baudelaire is different from, and indeed almost the opposite of, that of most of the male Chinese poets who were inspired by Baudelaire's poetry - and who often celebrated him as a rebel against tradition because of his reputation as a Satanist, Decadent, and dandy (Zhang 2009, 77-92; Bien 2013, 66-69). In fact, Chen's encapsulation of Baudelaire in this passage is a disguised pronouncement of her own ecofeminist poetics, which views the world from the perspective of, and shows equal empathy to, all vulnerable beings in the world.

Conscious of her unusual approach to Baudelaire's poetics, Chen emphasizes the reader/interpreter's active use of their agency. She advocates "looking for" the positive side and "discovering" the ingenuity in Baudelaire's works. She defies commonly held views of Baudelaire as "decadent" and 
identical to other Symbolist poets such as Mallarmé, by highlighting Baudelaire's different class background and poetics. To end her essay, she quotes her fellow female poet Zheng Min 郑敏 (b. 1920): "One can only let more pain heal / those hurting wounds," and emphasizes the paradoxical, soothing power of literary works that treat of pain and sadness (1946b). Baudelaire and Zheng Min, different poets from different worlds, become unlikely allies, both marshaled in the support of Chen's ecofeminist poetics.

In "Baudelaire and the Cat," Chen does not explain her motives for advocating for such empathy with the suffering of the vulnerable, but her second essay, "On My Poetry and Poetry Translation," published less than two months later, offers a clue. The essay rebukes her critics' accusations that she was emulating and imitating Baudelaire, and thus out of touch with reality. Strikingly, in what was a bold move in her day, she foregrounds her identity as a woman, associating her individual suffering with the universal oppression of women:

I have written a lot in the past two years [1945-1946] mainly because I have finally walked out of an oppressive domestic life (it is not hard to imagine how torturing the narrow domestic life is for Chinese women). Besides, the experience of leaving the depression-ridden Lanzhou behind and beginning to face the wide expanse of society has further strengthened my yearning for a bright future and boosted my passion for writing. ...

Chinese women have suffered all kinds of oppression in the millennialong feudal tradition. Until today, no fully reasonable solutions have been reached for social, financial, or many other issues, even though the equality of men and women has been recognized in principle. Women still suffer from stifling oppression. Therefore, we have an all the more urgent yearning for a just life in the future, for truth, justice, and light, and an all the deeper resentment for the feudal tradition and all kinds of unjust conditions.

(1947)

This is the only time that Chen publicly and explicitly links the impediment of her literary pursuits by the literary men closest to her - something to which she repeatedly alludes in her poetry - to a critical social issue that was seen to have no place in public discourse. While the dominant narrative claimed that women's liberation had been achieved and/or was included in society's modern negotiation of nation, revolution, and class, Chen draws on her own experience to show that the oppression of women persisted 
not only in traditional families but also in new-style families that claimed marriage should be a function of romantic love and in society at large. What is more, her insight into the complexity of the issue of gender equality enabled her to perceive "all kinds of unjust conditions," a phrase which recalls her emphasis on "all the unfortunate" in her encapsulation of Baudelaire's poetics; and contrary to her male contemporaries and predecessors' frequent descriptions of Chinese women as helpless victims of oppression, Chen makes the case for women's agency and their empathy for one another and for others, an empathy that is born of suffering. She argues that the endless oppression of Chinese women enables them to urgently and sensitively critique this and other injustices in the world - a view which echoes her reading of Baudelaire's poetics as a poetics of empathy and her association of Baudelaire with Zheng Min.

\section{Chen's translations and her own poetry}

In 1946-1947, Chen translated and published a number of poems by Baudelaire in newspapers in Shanghai and Beiping (now Beijing). These included "Spleen" (Spleen), "Man and the Sea" (L'homme et la mer), "The Living Torch" (Le Flambeau vivant)," "Evening Harmony” (Harmonie du soir), "Music" ("La Musique), and "The Blind" (Les Aveugles) (Zhang 2009, 82). Selected by Chen, all these poems share a thematic of pain, suffering, sadness, and perplexity, as the leftist critics noticed. What they failed to notice was the speaker's persistent search and struggle for a way out of the gloomy condition that Chen accentuated in her translations.

"Music" perfectly demonstrates Chen's active use of her agency as a poet-translator and shows how she molds her poetics into her translations - through modifications and witting or unwitting mistranslations, among other things. The French source text reads,

La musique souvent me prend comme une mer!

Vers ma pâle étoile,

Sous un plafond de brume ou dans un vaste éther,

Je mets à la voile;

La poitrine en avant et les poumons gonflés

Comme de la toile

J'escalade le dos des flots amoncelés

Que la nuit me voile; 
Je sens vibrer en moi toutes les passions

D'un vaisseau qui souffre;

Le bon vent, la tempête et ses convulsions

Sur l'immense gouffre

Me bercent. D'autres fois, calme plat, grand miroir

De mon désespoir!

(Scarfe 1986, 149)

Waldrop's translation reads,

Music often takes me as does a sea! I set sail toward my pale star, under a ceiling of fog or through the vast ether.

Chest out, lungs filled like sails, I scale the backs of banked waves which the night hides from me.

I feel in me the throb of all the passions ships can suffer. Good wind, storm, convulsions

above the yawning gulf - they lull me. At other times: flat calm, great mirror of my despair!

(2006: 91)

Chen's Chinese translation reads,

\author{
音乐有时飘我去, 像大海! \\ 向着我的苍白的星星， \\ 在雾䨠中或是朗空下 \\ 我开始航行。 \\ 胸挺着, 肺张开着 \\ 如像船帆 \\ 我攀上堆叠的水波, \\ 黑夜遮着我。 \\ 我感到热情在体中颤动 \\ 如水之起伏; \\ 大风, 暴雨, 带着骚动
}




\section{在无边的深渊 \\ 摇着我。一有时又水面波静如一面大镜, \\ 照着我失望的悲哀!}

$(1946 a)$

Chen keeps Baudelaire's original sonnet form in terms of the number of lines and their division in stanzas, and follows his indentations, punctuations, and line breaks. Unlike the other poems Chen published at the same time, the translation also stays close to the source text's rhyme scheme. Interestingly, several mistranslations end up enhancing the speaker's agency and illuminating the ecofeminist poetics Chen lays out in "Baudelaire and the Cat."

The most obvious moment occurs in ll. 3-4 of the second stanza. The stanza depicts the speaker imagining riding the sea at night, like a vessel sailing. Both Scarfe's and Waldrop's translations show that the night's darkness prevents the speaker from seeing the huge waves they are riding, thus indicating that the speaker is at risk of falling to their death from this great height (Scarfe 1986, 149; Waldrop 2006, 91). The darkness is depicted as a negative power preventing the speaker from achieving the freedom they seek. Chen, however, turns this negative, hindering power into a positive, empowering ally. In her version, the darkness shields the speaker from being seen, enabling them to enjoy the pursuit of freedom: "I climb the piling waves, / The dark night shielding me."

The third stanza continues the metaphor of the speaker as a ship on the wild sea at night. In ll. 1-2, the speaker's passions are likened to the motion of the ship being rocked by the waves, which must be contained in order for the ship to stay afloat. Scarfe's and Waldrop's translations convey the pain of this struggle. Scarfe writes, "I feel all the passions of a groaning ship vibrate within me" (149). Waldrop writes, "I feel in me the throb of all the passions ships can suffer" (91). Chen's translation eliminates this pain and the conflict. The passions, rather than being contained as a source of suffering, are celebrated as an expression of excitement over the thrilling if dangerous pursuit of freedom. The ocean's waves become an embodiment of the speaker's vibrating passions: "I feel my passions vibrating within my body / Like the undulations of water."

In the penultimate and final stanzas, Chen writes:

$\cdots$

Strong wind, torrential rain, with restlessness

In the infinite abyss

Rock me. - Sometimes the waves are still like a big mirror

Reflecting the sorrow of my disappointment. 
By adding a dash in 1.2 of the final stanza, Chen creates a visual break in the poem. The rest of the stanza depicts a moment of calm on the sea and the speaker's corresponding emotion. Both Scarfe and Waldrop choose the obvious English equivalent to translate the source text's last word, "désespoir," thus portraying the placid sea as a reflection of the speaker's "despair." Chinese also has a direct equivalent, 绝望, which many of Baudelaire's translators use (Dai 1983, 134; Bian 2000, 209; Wen 2007, 177). Chen, however, makes a radical change vis-à-vis the source text and translates “désespoir” as 失望的悲哀 'the sorrow of disappointment', thus erasing the sense of hopelessness while preserving the sense of sadness. The addition of "disappointment" seems to come out of the blue. However, considering Chen's erasure of the emotional conflicts in Baudelaire's speaker and her celebration of their pursuit of freedom in the preceding lines, "disappointment" can be read to echo the break embodied in the dash and to function as a counterpoint to the hopeful excitement experienced by the speaker up to this point. In all, this hints at the preservation of hope and the possibility of future attempts at pursuing freedom.

Chen's sensitivity to the agency of the speaker and her ecofeminist worldview are also evident in her own poetry of the time. In "On My Poetry and Poetry Translation," she cites several of her own poems to refute the charge that her poetry was divorced from reality. One of these poems, "The Inferno Tango" (地狱的探戈舞), exemplifies Chen's ecofeminist critique of injustice, including nuclear warfare. The poem presents a dramatic monologue with the speaker addressing a silent "you," delivering a scathing, ironic critique of the callous nature of "your" beliefs:

\author{
假若我相信月亮会跳跃 \\ 石头会唱歌 \\ 你会流泪 \\ 假若我相信原子弹 \\ 只是另一世界的谷粒 \\ 暴戻是爱的果子 \\ 假若盐失掉了盐味 \\ 会变得比糖更甜蜜 \\ 假若感情是条一鞭子 \\ 生活是一阵雷 \\ 假若整个世界只是 \\ 可以任你信足一踢的足球
}




\section{那末当鸱系狞笑的午夜 \\ 跳起地狱的探戈舞吧 \\ 它将会带给你 \\ 一个比夜更黑的白昼}

3.1.

(Luo and Chen 2008, 136)

Here is "Inferno Tango" in my translation:

Let's say I believe the moon can leap

Stones can sing

You can weep

Let's say I believe atomic bombs

Are just grain kernels from another world

And tyranny the fruit of love

Let's say salt is sweeter than sugar

After losing its saltiness

Let's say feelings are a whip

And life a peal of thunder

Let's say the whole world is just

A rubber ball you can casually kick

Then when the owls laugh hideously at midnight

Dance the inferno tango!

It will bring you

A day darker than night

- March 1

In the first stanza, by first offering two impossible suppositions (that the moon can leap and stones can sing), the speaker implies that their third supposition (that "you" can weep) is equally impossible. But why should "you" be incapable of crying? It helps to read this in the context of the People's Poetry that was prevalent at the time: its advocates believed that poetry should convey the utmost optimism and upbeat passion for revolution and national survival - so shedding tears, taken as a sign of weakness and pessimism, was out of the question. The speaker, however, sees "your" inability to shed tears as an absurdity rather than a sign of strength and power. The following stanzas show that the speaker aligns "your" inability 
to cry with self-centered callousness, cruelty, and a lack of concern and compassion for others and for the world at large.

In the second stanza, the speaker, continuing to juxtapose common-sense statements with the harsh reality of the time, opens with an ominous, apparently nonsensical supposition about nuclear warfare. Written six months after the US military dropped two atomic bombs on Hiroshima and Nagasaki, ending World War II and the eight-year Japanese invasion of China, the poem offers an unusual perspective. While most people were celebrating the defeat of the Japanese military, the speaker calls attention to the self-centered callousness inherent in viewing the bombs as mere otherworldly "grain kernels" - an image normally associated with an ordinary source of basic nutrition and growth but easily associable with the bombs on account of their conical shape - and normalizing and minimizing their terrible impact on countless innocent people's lives.

The speaker offers a second impossible supposition in this stanza, when they reject the bizarre idea that despotic violence is produced by love. In the context of the war, the violence committed against Japanese lives through the atomic bombs was widely justified and celebrated as an act of love for the peace and safety of the rest of the world. For the speaker, however, a compartmentalized vision that pits the strong and victorious against the vulnerable and defeated is as nonsensical as believing that salt can lose its saltiness.

The third stanza continues the juxtaposition of violence and love but offers a chilling depiction of "your" self-obsessed, callous view of the world as just an expendable toy, as though "you" were not part of the world and would not be impacted if it were to perish. In the fourth stanza, the speaker dares "you" to dance the "inferno tango," a passionate dance of love and fighting, and warns the addressee of "a day darker than night," once again evoking the horrifying aftermath of the bombing of Hiroshima and Nagasaki, a catastrophic consequence the self-obsessed addressee would never have imagined. The speaker's empathy for the vulnerable, their astute insight into the complexities of reality, and their piercing critique of the dominant discourse of the day epitomize the ecofeminist poetics Chen outlined in her essays on and translations of Baudelaire.

\section{Chen's later translations}

In the three decades after the CCP took power in China, from the late $1940 \mathrm{~s}$ to the late 1970s - generally known as the socialist period - Mao Zedong's 
vision of literature and art as subordinate to politics became government policy, with mainstream literary style following on from the sloganistic style of People's Poetry in the 1940s. Chen, like many other intellectuals who held different views of literature, felt compelled to give up her own poetry and concentrate on literary translation. She mainly translated "revolutionary" works from other socialist countries - that is, works that would count as ideologically correct in Mao-era China. However, in July 1957, Chen somehow managed to publish her translations of nine poems by Baudelaire in the prestigious journal Translations (译文). Even though she no longer published her own poetry, her translations enabled Chen to continue her ecofeminist counterbid to "revolutionary literature."

Chen selected, translated, and sequenced the poems (which do not appear successively or in this order in Baudelaire's signature collection The Flowers of Evil [Les fleurs du mal]). In the order in which they were published in Translations, they are "Morning Twilight" (Le Crépuscule du matin), "Evening Twilight" (Le Crépuscule du soir), "The Swan" (Le Cygne), "Death of the Poor" (La Mort des pauvres), "Autumn Sonnet" (Sonnet d'automne), "The Enemy" (L'Ennemi), and the aforesaid "Living Torch," "Spleen IV" and "Evening Harmony." Notably, all these poems - picked by Chen, just like her earlier translations - speak from the perspective of the oppressed and the vulnerable.

Here I focus on the poem that opens the series, Chen's translation of "Morning Twilight," in which her ecofeminist poetics is especially apparent, and which reflects most clearly her use of her agency to speak through the translations. A close reading shows that Chen's modifications and several witting or unwitting mistranslations reflect the ecofeminist poetics she had laid out in "Baudelaire and the Cat" and "My Poetry and Poetry Translation" in the late 1940s.

The French version reads,

La diane chantait dans les cours des casernes,

Et le vent du matin soufflait sur les lanternes.

C'était l'heure où l'essaim des rêves malfaisants

Tord sur leurs oreillers les bruns adolescents;

Où, comme un oeil sanglant qui palpite et qui bouge,

La lampe sur le jour fait une tache rouge;

Où l'âme, sous le poids du corps revêche et lourd,

Imite les combats de la lampe et du jour.

Comme un visage en pleurs que les brises essuient, 
L'air est plein du frisson des choses qui s'enfuient, Et l'homme est las d'écrire et la femme d'aimer.

Les maisons çà et là commençaient à fumer.

Les femmes de plaisir, la paupière livide,

Bouche ouverte, dormaient de leur sommeil stupide;

Les pauvresses, traînant leurs seins maigres et froids,

Soufflaient sur leurs tisons et soufflaient sur leurs doigts.

C'était l'heure où parmi le froid et la lésine

S'aggravent les douleurs des femmes en gésine;

Comme un sanglot coupé par un sang écumeux

Le chant du coq au loin déchirait l'air brumeux;

Une mer de brouillards baignait les édifices,

Et les agonisants dans le fond des hospices

Poussaient leur dernier râle en hoquets inégaux.

Les débauchés rentraient, brisés par leurs travaux.

L'aurore grelottante en robe rose et verte

S'avançait lentement sur la Seine déserte,

Et le sombre Paris, en se frottant les yeux,

Empoignait ses outils, vieillard laborieux.

(Scarfe 1986, 202-203)

Waldrop's translation reads,

Reveille sounded in caserns and a morning wind puffed at the streetlamps.

Hour when swarms of evil dreams set dark adolescents writhing on their pillows; when lamps, like a bloody eye pulsing and beating, make red spots on the day; when the soul, under the harsh and heavy weight of the body, imitates the battle between lamp and daylight. Like a face wet with tears dried by the wind, the air quivers with things in flight, the man weary of writing and the woman of loving.

Smoke began to rise from houses here and there. Women of pleasure, livid eyelids, mouths agape, slept their stupid sleep; beggar-women, dragging meager chilly breasts, blew on half-burned logs and blew on their fingers. Hour when cold and close-fistedness combine to aggravate the pains of women in childbirth; like a sob cut short by turbid blood, a distant cock-crow tore the foggy air; a sea of haze bathed buildings and 
in the back of the poorhouse the dying gave their death rattle in uneven gasps. The debauched went home, broken by their exertions.

Shivering Aurora, in a gown of pink and green, rose slowly over the deserted Seine as gloomy Paris, rubbing eyes, took up its tools, old workingman.

$(2006,135)$

This is Chen's translation:

兵营的院落里响起号角, 街头灯火在晨风中摇曳。

这正是那种时辰: 邪恶的梦好象群蜂

把熟睡在枕上的黑发少年刺痛;

夜灯犹如发红的眼睛, 飘忽、震颤,

给白昼缀上一块红色的斑点,

灵魂载着倔强而沉重的身躯,

模仿着灯光与日光的斗争。

犹如微风吹拂流泪的脸面,

空中充满着飞逝的事物的战栗,

男人倦于写作, 女人倦于爱恋。

远近的房舍开始衰出炊烟,

卖笑的女人, 眼皮青紫,

张着嘴睡得又蠢又死;

那些穷妇人, 垂着消瘦冰冷的乳房,

吹着剩火残灰, 朝手指上呵气。

这正是那种时辰: 在寒冷与穷困当中

劳动妇女的苦难更加深重;

犹如一声鸣咽被翻涌的血流打断,

远处鸡鸣划破了朦胧的空间;

一片雾海淹没了所有的建筑,

那些苦人在收容所的深处

打着呃，喘着最后的一口气。

游荡得筋疲力尽的浪子走回家去,

晨羲抖索地披上红绿的衣裳，

沿着寂寞的塞纳河徐徐漫步;

暗淡的巴黎, 睡眼朦胧,

一手抓起工具, 象个辛勤劳动的老人。 
The first adjustment Chen makes is in the title. By rendering this as "Hazy Dawn” (朦胧的黎明) rather than “Morning Twilight," as other translators do, Chen narrows the focus from the twilight to the brief moment before dawn, a moment of liminality, just before night yields to daylight. This shift is reinforced by another change Chen makes in the second stanza. Rather than following the syntactic structure and translate l. 1 as "it was the hour when" as Scarfe does (202) or "hour when" as Waldrop does (135), Chen separates "it was the hour" from the rest of the line, emphasizing this with a colon and by adding "precisely" (正). She makes the same change in the next stanza when the sentence is repeated. Moreover, she makes a rare formal change, by removing the break between the third and fourth stanzas. The poem's concluding lines thus lose the prominence they have in the source text, and the poem's center of gravity shifts to the critical moment before dawn, foregrounded by the adjusted title and the repeated emphases on "the hour" in stanzas 2 and 3 .

What is the significance of this particular moment? With the restructuring of the stanzas, the brief first stanza, a single couplet depicting the pre-dawn moment, gains in prominence. As in some of his other poems, such as "Music," Baudelaire uses the opposition of night and day to symbolize the struggle between body and soul. For Baudelaire, the daylight, heralded by the call of the military bugle in the caserns, signifies hope and enlightenment of the soul. On the other hand, the light from the streetlamp, representing the vanishing night, symbolizes the soon-to-be defeated hindering body. Chen, however, whose earlier translation of "Music" replaces the image of a conflict of body and soul with one of the pursuit of freedom, changes the dynamic between body and soul again in "Morning twilight" and infuses her translation with another new meaning. Unlike Waldrop, who adheres to Baudelaire's original syntax and highlights the agency of the morning wind, Chen emphasizes the persistence of the streetlight. In English translation, her version reads, "In the barracks courtyard bugles start to sound, / Streetlights sway in the morning wind." For that moment, the quiet, quavering pre-dawn lamplight on the street, continues its delicate existence despite the nudging of the morning wind.

This shift of the dynamic between body and soul is most visible in Chen's translation of $11.5^{-6}$ in the second stanza. Scarfe's and Waldrop's translations convey the conflict between the speaker's body and soul through the struggle of night and day, presenting the body as a negative, oppressive force that prevents the soul from achieving transcendence. Chen, on the other hand, presents the body in a positive light as a tired but persistent partner of the soul in their struggle against the daylight: "The soul, carrying the adamant 
and heavy body, / imitates the battle between lamplight and daylight." The word rendered here as "adamant" (倔强) often describes positive qualities such as perseverance in the face of hardship; "heavy" (沉重), appearing together with "adamant," takes on a more positive meaning too, by signifying the physical exhaustion that results from persistent endeavor.

The third stanza highlights the suffering of the poor, especially poor women. In ll. 2-7, we see merciless, heart-wrenching images of suffering women at the bottom of society, recalling Chen's statement about Baudelaire's empathetic love of the vulnerable in "Baudelaire and the Cat." Chen's translation reads,

The woman who sells her laughs, with eyelids black and blue, Mouth open, sleeps like an idiot and as if dead;

Those poor women, with emaciated and ice-cold breasts hanging low, Blow at what remains of the fire and the ashes, breathe on their fingers. It is precisely that kind of hour: in the cold and in poverty The suffering of the laboring women grows ever graver;

Chen substantially diverges from the source text in two places. She mitigates Baudelaire's misogynist depiction of the prostitute sleeping "stupidly" by adding that she is asleep "as if dead" (死) - a standard Chinese expression for sleeping deeply - thus hinting at her exhaustion from a tough life. Secondly, she translates "des femmes en gésine" (of the women in labor) as "of the laboring women” (劳动妇女). This appears to be a (remarkable) error; as Chen also read English, it is possible that it reveals a misreading of the phrase "women in labor." Be that as it may, Chen's word choice replaces a specific kind of suffering by women - the excruciating pain of giving birth - with what she may have seen as a more universal kind of suffering rooted in history, culture, and politics, i.e. the oppression of women at large. Further, the Chinese expression “laboring women" (劳动妇女), a Marxist term for proletarian women widely used during the socialist era, is in accordance with the political environment of the time when the translations were published, and potentially enabled Chen to avoid political persecution. At any rate, "in the cold and in poverty / The suffering of the laboring women grows ever graver" echoes Chen's reference to the exacting circumstances of her own marriage with Sha Lei from 1940 to 1945, and her subsequent observation of the continued oppression of women in modern times (Chen 1947, 7). The resonance of this poem with Chen's experience of suffering and struggle in a male-dominated society and literary field may have been among the reasons why Chen chose "Morning Twilight" as the lead poem in the series published in Translations. 
Chen's own experience of suffering and oppression as a woman, though often compartmentalized as personal misfortune and dismissed as trivial in comparison to her male colleagues' grand discourses of nation, revolution, and class (Tang 2003, 113, 118; Jiang 2006, 31), enabled her to have a profound sensitivity and empathy for the ugly underbelly of society - to which her male counterparts were often blind, both during the civil war and in later years. Baudelaire-à-la-Chen's images of suffering women display a sharp contrast with the idealistic portrayal of empowered rural women in the statesponsored writing of the socialist period. Chen's translation of Baudelaire stubbornly points to a dark side of reality ignored by this propagandistic literature, as the oppression of women, the poor, and other vulnerable groups continued under the new regime, despite its grand discourse of equality for all.

\title{
Conclusion
}

Until her death in 1989, Chen Jingrong never had the opportunity to meet with or learn about the advocates of ecofeminism, feminist translation, and translator agency who were making waves in the West. Throughout her life she searched alone for ways to communicate her prescient observations and her critique of the male-dominated political, cultural, and literary environment in China. As Greta Gaard writes, “Ecofeminists use 'resilience' as a word that means taking survival - and the eco-ethics and community this survival requires - into our own hands" (2018, xv). Chen did exactly what Gaard envisions an ecofeminist doing, in her creative interpretation and translation of Baudelaire, and in her own poetry. She underscored the agency of the reader/translator, amplified the resilient strength of the speaker in Baudelaire's poetry, and made a case for the power of empathy.

In 1978, after a thirty-year silence due to the CCP's restrictive policy on literature, Chen started writing poetry again in a small ground-floor apartment on a busy street in Beijing. "Sour Fruit" (酸果), the first of a series of four poems titled "My Seventy" (我的七十) written around Chen's seventieth birthday, is a perfect summary of her signature perspective:

\author{
没有嫩绿鲜红 \\ 流水哗哗 \\ 漫过堤岸而去 \\ 日月的光华 \\ 照耀众多树木 \\ 偶尔也酒上荆从
}


酒上默默的酸果

酸涩与苦咸

浸透了果肉果壳

果核却无比坚硬

如石

如钢铁

原本是由铁水浇铸而成

在钢铁基座上

它被赋予了

多汁的甘美果肉

那吐着青色光焰的

依旧是粗粮的果壳

(Luo and Chen 2008, 532-533)

there is no tender green nor fresh red

the flowing water gurgles

brims over the bank and is gone

the splendors of the sun and the moon

shine on numberless trees

and occasionally glint on the thorny bushes

and on the silent sour fruit

acrid sour and bitter saltiness

have permeated its flesh and shell

yet the pit of the fruit is harder than ever

like stone

like iron

it was molded from liquid iron

on the top of the iron base

it was bestowed with

juicy sweet flesh

what is emitting an electric blue radiance

is still its coarse shell

(Meng 2015, 17)

Contemplating her life at the age of seventy, Chen compares herself to the sour fruit, an inconspicuous but hardy plant that can survive without much water, 
light, or care. The metaphor sets Chen apart from the male-dominated field of Chinese poetry in the 1980s, where women are overwhelmingly portrayed as young, beautiful, gentle, and in need of protection. Chen further stresses her uncommon position in the poem's opening line. With a firm negation, she makes it clear that a woman like herself does not have the qualities deemed desirable in the stereotype - no eye-catching youthful beauty, no fresh and delicate tenderness. The rest of the first stanza depicts the neglect the sour fruit suffers in the harsh wilderness. It is near the river, but the water "brims over the bank" and flows away, instead of lingering and nourishing it. The sun and moon generously shine on "numberless" taller trees, but only "occasionally glint on the thorny bushes" where the sour fruit grows in silence.

In the second stanza, the poet first draws attention to the impact of life's sufferings on the sour fruit but proceeds to emphasize the plant's toughness and perseverance. The comparisons of the sour fruit to rock and iron in the second and third stanzas might be reminiscent of the "Iron Girl" image of socialist-era propaganda literature; rather than conveying blind optimism and youthful strength, however, Chen's sour fruit underscores persistence and resilience in the face of adversity.

The sour fruit, a plant with no tender green leaves or fresh red flowers, is soaked with the sourness and saltiness of life's sufferings. Its core, though, is as hard as stone and iron. Its shell is coarse but radiant with fire. Tenacity is what enabled the poet to sustain her life-long search for what retrospectively manifests itself as a distinctly ecofeminist poetics that reflects profound empathy for the vulnerable and prescient insight into the catastrophic consequences when this is replaced by the reckless pursuit of power.

\section{Works cited}

Babaee, Ruzbeh. 2016. "Translation and Creative Writing: An Interview with Professor Margaret Rogers." International Journal of Comparative Literature and Translation Studies 4 (1): 1-3.

Bai Hua 柏桦. 2009. 〈始于1979- 比冰和铁更刺人心肠的欢乐〉 [Starting in 1979: A pleasure more piercing to the heart than ice and iron]. In 《七十年 代》 [The seventies], edited by Bei Dao 北岛 and Li Tuo 李陀, 539-540. Beijing: Shenghuo dushu xinzhi sanlian shudian.

Bei Dao 北岛. 2005. 《时间的玫瑰: 北岛随笔》 [The rose of time: essays by Bei Dao]. Beijing: Zhongguo wenshi chubanshe.

Bian Zhilin 市之琳. 2000. 《六之琳译文集 (中卷)》[Translations by Bian Zhilin, vol. 2]. Hefei: Anhui jiaoyu chubanshe. 
Bien, Gloria. 2013. Baudelaire in China: A Study in Literary Reception. Newark: University of Delaware Press.

Chen Jingrong 陈敬容, trans. 1946a. Charles Baudelaire. 〈音乐〉(La Musique) [Music]. 《文汇报.笔会》96, November 15 .

一, trans. 1946b. 〈波德莱尔与猫〉 [Baudelaire and the cat]. 《文汇报.笔会》, December 19 .

一. 1947. 〈谈我的诗和译诗〉 [On my poetry and poetry translation]. 《文汇报. 笔会》, February 7: 7.

一, trans. 1984. Charles Baudelaire and Rainer Maria Rilke. 《图像与花朵》

[Images and flowers]. Changsha: Hunan renmin chubanshe.

Dai Wangshu 戴望舒. 1983. 《戴望舒译诗集》 [Dai Wangshu's poetry translations]. Changsha: Hunan renmin chubanshe.

Denton, Kirk A. 2016. “Literature and Politics: Mao Zedong's 'Yan'an Talks' and Party Rectification." In The Columbia Companion to Modern Chinese Literature, edited by Kirk A. Denton, 224-230. New York: Columbia University Press.

Gaard, Greta. 2016. "From 'cli-fi' to critical ecofeminism: narratives of climate change and climate justice." In Contemporary Perspectives on Ecofeminism, edited by Mary Philips and Nick Rumens, 169-192. London and New York: Routledge.

—. 2018. "Foreword." In Literature and Ecofeminism: Intersectional and International Voices, edited by Douglas A. Vakoch and Sam Mickey, xiv-xvi. London and New York: Routledge.

Jiang Dengke 蒋登科. 2002. 《九叶诗派的合璧艺术》 [The Nine Leaves poetry school's art of fusion]. Chongqing: Xinan shifan daxue chubanshe.

-.2006. 《九叶诗人论稿》 [Essays on the Nine Leaves poets]. Chongqing: Xinan shifan daxue chubanshe.

Li Baifeng 李白凤. 1947. 〈从波德莱尔的诗谈起〉 [A few words on Baudelaire's poetry]. 《文汇报》, January 30: 7 .

Liang Xiaoming 梁晓明. 2006. 〈多多访谈〉 [An interview with Duo Duo]. 《中国 诗刊》1. bit.ly/2U3ZMbk. Accessed August 21, 2018.

Lin Huanping 林焕平. 1946. 〈波德莱尔不宜赞美〉 [It is inadvisable to praise Baudelaire]. 《文汇报》, December 28.

Ling Yue 凌越. 2004. 〈我的大学就是田野 - 多多访谈录〉 [The great outdoors is my university: an interview with Duo Duo]. In Duo Duo 多多, 《多多诗选》 [Selected poems by Duo Duo], 266-293. Guangzhou: Huacheng chubanshe.

Liu Zhirong 刘志荣. 2015. 〈“文革” 中读波德莱尔 - 红色年代里的隐秘阅读 史〉 [Reading Baudelaire during the Cultural Revolution: the secret history of reading during the Red Years]. 《财经》, May 24.

Luo Jiaming 罗佳明 and Chen Li 陈俐, eds. 2008. 《陈敬容诗文集》 [Poetry and prose of Chen Jingrong]. Shanghai: Fudan daxue chubanshe. 
Meng, Liansu, trans. 2015. Chen Jingrong 陈敬容. “My Seventy (No. 1: Sour Fruit)” (〈我的七十 (一: 酸果) 〉). In Chinese Literature Today 5 (1): 17 .

Mickey, Sam. 2018. "Editor's Preface." In Literature and Ecofeminism: Intersectional and International Voices, edited by Douglas A. Vakoch and Sam Mickey, xvii-xiv. London and New York: Routledge.

Palacios, Manuela. 2014. "Translation in the Feminine: Theory, Commitment and (Good) Praxis." Women's Studies International Forum 42: 87-93.

Palmary, Ingrid. 2014. "A Politics of Feminist Translation: Using Translation to Understand Gendered Meaning-Making in Research.” Signs 39 (3): 576-580.

Perteghella, Manuela and Eugenia Loffredo, eds. 2007. Translation and Creativity: Perspectives on Creative Writing and Translation Studies. London: Continuum. Quandt, Karen F. 2015. "Baudelaire and the Poetics of Pollution." Dix-Neuf 19 (3): 244-259.

Rosario, Nelly. 2012. "Seeing Double: Creative Writing as Translation." Callaloo 35 (4):1001-1005.

Scarfe, Francis, edit and trans. 1986. Charles Baudelaire. Baudelaire: The Complete Verse. London: Anvil Press.

Song Mingwei. 2015. Young China: National Rejuvenation and the Bildungsroman, 1900-1959. Cambridge, MA: Harvard University Asia Center.

Tamburello, Giusi. 2012. "Baudelaire's Influence on Duo Duo's Poetry through Chen Jingrong, a Chinese Woman Poet Translating from French.” Asian and African Studies 16 (2): 21-46.

Tang Shi 唐湜. 2003. 《九叶诗人: 中国新诗的中兴》 [The Nine Leaves poets: the resurgence of Chinese New Poetry]. Shanghai: Shanghai jiaoyu chubanshe.

Tie Ma 铁马. 1946. 〈略论陈敬容的诗 - 读了他致一个陌生读者的信以后的感 想〉 [A brief note on Chen Jingrong's poetry - thoughts after reading his letter to an unfamiliar reader]. 《文汇报》, December 30.

van Crevel, Maghiel. 2017. "Walk on the Wild Side: Snapshots of the Chinese Poetry Scene.” MCLC Resource Center. bit.ly/2GaWWhc. Accessed August 6, 2019.

Waldrop, Keith, trans. 2006. Baudelaire. The Flowers of Evil. Middletown: Wesleyan University Press.

Wang Shengsi 王圣思, ed. 1995. 《“九叶诗人”评论资料选》 [Selected critical materials on the "Nine Leaves Poets"]. Shanghai: Huadong shifan daxue chubanshe.

Weinbaum, Alys Eve. 2003. "Ways of Not Seeing: (En)gendered Optics in Benjamin, Baudelaire, and Freud." In Loss: The Politics of Mourning, edited by David L. Eng and David Kazanjian, 396-426. Oakland: University of California Press.

Wen Aiyi 文爱艺, trans. 2007. Baudelaire. 《恶之花》 [The flowers of evil]. Chengdu: Sichuan renmin chubanshe. 
You Youji 游友基. 1997. 《九叶诗派研究》 [Studies on the Nine Leaves poetry school]. Fuzhou: Fujian jiaoyu chubanshe.

Zhang Songjian 张松建. 2009. 《现代诗的再出发: 中国四十年代现代主义诗 潮新探》 [The re-emergence of modern poetry: a new inquiry into modernist poetry in 1940s China]. Beijing: Beijing daxue chubanshe.

Zhou Xuliang 周煦良, ed. 1979. 《外国文学作品选》 [Selections of foreign literature]. Shanghai: Shanghai yiwen chubanshe.

Zou Zhenhuan 邹振环. 1996. 《影响中国近代社会的一百种译作》 [One hundred translated works that influenced modern Chinese society]. Beijing: Zhongguo duiwai fanyi chuban gongsi.

\section{About the author}

Liansu MENG is associate professor of Chinese at the University of Connecticut. Her research interests include modern and contemporary Chinese poetry, unofficial literary magazines, translated literature, Chinese feminism, gender and technology, ecofeminism, ecopoetics, transnational poetics, and comparative poetics. She has published articles on ecopoetics and transnational poetics in modern Chinese poetry. Her monograph Man/Woman, Machine/Nature: Modern Chinese Poetry at the Intersection of Industrialism and Feminism (1915-1980) is forthcoming at the University of Michigan Press. 


\title{
11 Ronald Mar and the Trope of Life
}

\author{
The Translation of Western Modernist Poetry in Hong Kong
}

Chris Song

\begin{abstract}
This essay examines the Chinese-language debut of Western surrealist poetry in Hong Kong and its effect on the local poetry scene through the work of Ronald Mar 馬朗, from the early years of the Cold War era onward. It traces the trope of poetry being "true to life" - as resistance to the surrealist influence - through evolving notions and experiences of Hong Kong identity over time, up to the present day in the post-handover era.
\end{abstract}

Keywords: Chinese poetry, translation, Ronald Mar, Hong Kong, modernism, surrealism

Twenty years since the handover of sovereignty from the British Crown to the People's Republic of China, Hong Kong society has known increasingly severe conflicts with China, fueled by animosity toward the mainland among the local population. Growing up in such a politically intense environment, Hong Kong youths feel that political and economic systems have conspired to leave them a hopeless future. As their demand for universal suffrage in the election of the Chief Executive of the Hong Kong Special Administrative Region government was denied in September 2014, their anxiety finally broke into realization as the Umbrella Movement. Apart from responding through poetry to this large democratic movement, some young local poets perceived a need to redefine the "localness" of Hong Kong poetry. Though without much theoretical depth, their quest is quite clear: they believe that the localness of their poetic language lies, paradoxically, in the distance from external reality - a symbolic denial of the Umbrella Movement's failed demands for universal suffrage, or any further realistic democratization, in

Van Crevel, Maghiel and Lucas Klein (eds.), Chinese Poetry and Translation: Rights and Wrongs. Amsterdam: Amsterdam University Press, 2019 DOI: $10.5117 / 9789462989948$ CH11 
fact - and that their poetry must express such distance through abstract surrealistic imagery.

In 2015, this emerging trend met with a sharp attack by senior poet Chung Kwok-keung 鍾國強. Chung criticizes that their poetry

appears to mean something, but as we read it we find it empty and superficial, elusive and eventually unsolvable ... Instead of enriching the poem and making it more readable, the many ambiguities produced in the process of reading become so many layers of obstacles. Meaning is lost in the labyrinth of language. Emotion in the poem, if any, is abstruse. $(2015,10)^{1}$

Following this critique is Chung's summary introduction to the poetry from Selected Poems of Ten Poets (十人詩選) (Qian 1998). Curated by the prominent Hong Kong poet Leung Ping-kwan 梁秉鈞 (1949-2013), this anthology has achieved canonical status in the history of Hong Kong literature; it collects ten Hong Kong Chinese-language poets whose works have been labeled as "true to life" (生活化). As one of the current leaders of the true-to-life school, Chung wrote this critique out of his dissatisfaction with what he sees as the young surrealist poets' weakness, namely, their dissociating poetry from life. Chung's article was in turn savaged by the young surrealists, who justify their poetic practice on the models of postmodern Taiwanese poets Hsia Yü 夏宇, Hung Hung 鴻鴻, and Luo Chi-cheng 羅智成. They further propose to incorporate their surrealist poetry into the true-to-life tradition for its greater enrichment (Mu 2015; Huang 2015), treating "life" (生活) almost as a purely theoretical concept. In other words, life is theorized away.

This recent dispute over the trope of life in the Hong Kong poetry scene continues a long-lasting resistance against the influence of surrealism since its introduction in the 1950s through translations by Ronald Mar 馬 朗 (1933?), who was born in the United States, came to China at the end of the Second World War, and moved on to Hong Kong after the Communist takeover of the mainland. In this paper, I will explicate the dispute over the trope of life in the ideological environment of Hong Kong in the 1950s and analyze Mar's translation of Western modernist poetry, especially surrealist poetry. By pointing out the inherent contradiction between the real and the surreal in his translations and other writings, I argue that the translation of Western surrealist poetry failed to exert far-reaching influence on the writing of Hong Kong poetry. The reason is that, while inheriting 
poetics borrowed from Western modernism through Mar's translations, the generation of poets who rose to Hong Kong's literary scene in the $1970 \mathrm{~s}$ recanted surrealism out of a need to pursue a cultural identity through the writing of local life. Tracing the transformation of the trope of life since the $195 \mathrm{os}$, this paper offers a reinterpretation of the present trend of surrealism in Hong Kong poetry today.

\section{The trope of life and Romantic poetry}

After the founding of the People's Republic of China in 1949, Hong Kong's Chinese literary landscape was caught in an ideological tug-of-war between two political forces, resulting from a two-way migration of Chinese intellectuals with opposing political beliefs. Many leftist writers who had taken refuge in Hong Kong during the Chinese civil war moved back to mainland China, where they wanted to participate in constructing the culture of New China. They continued to create works that shared the general characteristics of mainland-leftist poetry, usually slogan-laden odes that evoked a nationalistic mood on the theme of founding a new China, everyday people's hard work in everyday life, injustice under capitalism and the forthcoming proletarian revolution in Third World countries, and so on. These works were still published in magazines and newspapers in Hong Kong, especially those controlled by mainland political forces; but without immediate life experiences in the British colony, most "northbound" (北 返) leftist poets produced works that demonstrated detachment from local life, that is, disengagement from the struggle for survival in postwar Hong Kong. At the same time, this struggle for survival became the major concern of "southbound" (南來) right-wing intellectuals, who had recently begun settling in the British colony as a temporary refuge. They did not believe in the Communist vision for China, and took Hong Kong as a springboard to move farther away - toward Taiwan or Southeast Asia, or even farther, to the United States or the United Kingdom.

As the leftists went north, the southbound writers dominated the literary scene of 1950s Hong Kong. They had a few observable similarities: they were considered right-wing, in opposition to the communist left; they considered themselves temporary sojourners in Hong Kong; most of their literary activity was funded by the Asia Foundation (亞洲基金會), established by the United States Information Agency; and their cultural production was usually labeled "greenback culture" (綠背文化). Their journals, Everyman's Literature (人人文學) and Highland (海瀾), were exemplary of their literary 
production. One of the main editors of both of these journals, Li Kuang 力 匡, gained popularity early in the decade with a series of love poems in rhymed quatrains, written for a "short-haired and round-faced" girl back in Guangzhou. A typical poem, highlighting the formal elements of poetry, would be his “A Swallow's Words” (燕語). Its first stanza reads:

Now on your eaves, I must rest here,

Because the flight was long and weary.

"You are a stranger. Not from here!"

Ah, yes, I'm from a far-off country.

我此刻歇息在你底樑上，

爲了疲倦於長途的飛翔;

你說我像是個外地的客人,

是的我正來自遙遠的異鄉。

(Cheng 2013, 52)

The poetic form these right-wing poets chose was very close to the Crescent Society's (新月社) imitation of English Romantic poetry in 1920s Shanghai. Because of this influence, they have been labeled "Romantics" in studies of Hong Kong literature (Leung 1992, 224-227).

A dispute arose among the right-wing poets over emotion in Romantic poetry, and intriguingly ended with a split in their understanding of life. Among the writers associated with Everyman's Literature, Stephen Soong 宋淇 stood out as perhaps the most irascible, leaving him isolated as a translator. Although he wrote articles for Everyman's Literature introducing English poetry, Soong sharply indicted the poetics of English Romanticism as appropriated by Hong Kong's Romantics:

The function of emotion in poetry is esteemed as so high and important, it's as if without emotion, you can't have poetry, a view that follows the flourishing of Romanticism in the West in the $19^{\text {th }}$ century ... However the poetry of the moderns is a reaction against the poetry of the $19^{\text {th }}$ century ... For most modern poets, emotion is dispensable; emotion revealed in poetry is intolerably tacky.

(Soong 1982, 53)

Soong's critique was fiercely rejected by the Hong Kong Romantics. Chang Ting's 長亭 response links their preferred poetic form with their selfperception as “loyalists” (遺民): “The voice of the adherents of a lost nation 
is sad and thoughtful; poets in deep agony mourn their fate and reminisce about the past. This is our only hope of survival" (亡國之音哀以思，其民 困。困頓之民, 哀其所遇, 而追思往昔, 能有所追思, 則仍有一線希望 心之存在也) (Chang Ting 1982, 92-93). Eventually Soong proposed a truce in the debate, associating his distrust of sentimentalism in Hong Kong's Romantic poetry with a pioneering call for modernist poetics, citing Paul Valéry, Rainer Maria Rilke, and T. S. Eliot's use of understatement in "The Hollow Men" (Soong 1982, 97-99; for more, see Chan 2001, 85-93). Finally, Soong revealed:

Anti-communism is important, of course, but we cannot give up everyday life and the factors that maintain it ... On a spiritual level, we cannot give up literature or similar activities, because they nourish us, give us faith in life, keep us sympathetic to humanity.

(Soong 1982,3)

Reading the work of the writers and translators exiled to colonial Hong Kong in the 1950s (and that of those further excommunicated to Taiwan by the "bamboo curtain policy" [竹幕政策] of the Communist Party of China) calls for a sympathetic engagement with their modernist practice alongside their poor living conditions, harsh social milieu, and unenviable geopolitical environment. Once respectable men of letters in China in the 1940s, they were now doing menial jobs in Hong Kong, with some even writing pornography for newspaper supplements to be able to rent a single bunk for an entire family. Some took shelter in wooden sheds, which were vulnerable to typhoons and fires. It was under such humiliating conditions that the southbound writers continued to work to realize their lofty literary ideals, as though this writing was the last chance they had to continue both their spiritual and practical lives - that is, the last chance to hold on to life.

\section{The trope of life in Literary Currents}

Though their approaches were different, right-wing poets' writings and translations assembled a jigsaw puzzle of life in Hong Kong's literary landscape. But against Chang Ting's political sentiment that writing poetry to mourn and reminisce about the past was their "only hope of survival," and in contrast to Soong's apolitical counter-argument that everyday life is outside the political, Ronald Mar proposed a third poetics of life: modernism 
as constructed through the translation of Western poetry in his magazine Literary Currents (文藝新潮) (1956-1959).

Dissatisfied with the bifurcated literary scene in the 1950s, Mar decided to open up a new literary horizon by introducing Western modernism. Mar's bold manifesto called out to rally writers inspired by modernism, albeit with an image from Stalin: "Engineers of the human soul, rally to the flag!” 人類靈魂的工程師, 到我們的旗下來 (1956). This journal not only exerted influence on Hong Kong writers such as Quanan Shum 岑芘南, Wucius Wong 王無邪, and Wai-lim Yip 葉維廉, but also extended to the community of modernists in Taiwan, where it was circulated in the form of handwritten copies. Literary Currents is still considered one of the most important literary journals in the history of Hong Kong literature today.

In studying the poetry translations in Literary Currents, Yau Wai-ping 邱偉平 points out that the journal's advocacy for modernism “was neither a craze for a literary fad nor the pursuit of a new literary form, but came out of the need to borrow modernism to depict the complexity and conflict of modern life" (2013, 78). The trope of life in Literary Currents reveals a deep-seated link to a core concern of high modernism. According to Art Berman, high modernism, associated with the 1920 s of Eliot's The Waste Land and James Joyce's Ulysses, was "the most notable phase of modernism." High modernism is "not a style, a theme, a form, or a school," but rather an expression of a predominant attitude toward the function of literature in society: "[t]he writer undertakes a mission of utmost seriousness: to increase society's self-conscious realization of the unique dilemmas that had emerged as knowledge in every area had been called into question. Literature does not answer those questions; it provides a way of living among them" (1994, 60).

Of all the poetic techniques and thought that Mar and his followers borrowed from Western modernism, the most central component was to find a way to survive their hardships in Hong Kong at the spiritual level, through writing, translating, and commenting on literature. The emphasis on life and on survival sparks through the tireless expression of their aspiration for modernism. In his comment on American modernist poetry, Mar is full of praise:

After American poets turned to modernism, they unfettered themselves, widely using the living language, with fresh images and free forms ... breaking away from tradition, and enhancing expression in poetry ... They have used modern language and modern techniques to depict the most modern moods of Americans and the rhythms of modern life.

$(1956,2)$ 
In the introductory remarks on his translation of Stephen Spender's $195^{2}$ essay “The Modernist Movement is Dead," Yun Fu 雲夫 writes that for Spender,

art does not provide an escape for the artist or the appreciator, but contains "a true conflict in life." It dissects and dissolves all materials of life, emotions, and feelings, and expresses them.

$(1956,2)$

Elsewhere Li Wai-ling 李維陵 postulates that the “modern task” (現代任 務) of modernism is to

encourage man to search for the meaning of his and others' beings in the complex and rapidly changing modern life. This is to say that modern literary art should not only help modern man look courageously at modern life, but also to improve it with confidence.

$(1956,23)$

After all the modernist poetic techniques introduced through translation, after all the undecipherable image-heavy surrealist poems written in and translated into Chinese, and after all the modernist thought pitched to the polarized ideological environment in Hong Kong, eventually their modernist practice simply came down to the will to survive.

\section{The trope of life in Ronald Mar's translation and writing}

Scholarly attention to Mar's introduction of modernism to the conservative literary environment in 1950s Hong Kong has focused either on the poet's political stance or on his original writings (Leung 1982; Lok Fung 1990; Tang 1990; Leung 1992; Au 2010; Yip 2016). A close reading of Mar's translations against the trope of life, which he and his followers fiercely promoted, will crucially complement research to date and deepen our understanding of the inherent paradox that pervades modernism: that is, how the real finds poetic expression in the surreal.

Mar translated modernist poets from the US and the UK for two special features on Western modernist poetry in Literary Currents, and published translations of French surrealist poetry throughout the journal's lifetime, collaborating with various fellow translators. The feature on US poetry contains twenty-three poems by ten American modernists: Wallace Stevens 
(2), William Carlos Williams (3), Ezra Pound (4), Marianne Moore (1), T. S. Eliot (4), Archibald MacLeish (1), e. e. cummings (3), Hart Crane (1), Muriel Rukeyser (2), and Carl Shapiro (2). The feature on UK poetry contains twentyseven poems by ten British modernists: W. H. Auden (4), W. B. Yeats (3), D. H. Lawrence (3), Edith Sitwell (2), Cecil Day Lewis (2), Louis MacNeice (3), Stephen Spender (3), George Barker (2), David Gascoyne (2), and Dylan Thomas (3). ${ }^{2}$ Among the French poets Mar co-translated are Paul Valéry (1), Paul Fort (4), Guillaume Apollinaire (5), Max Jacob (3), Jules Supervielle (3), Remy de Gourmont (3), Paul Éluard (4), Henri Michaux (3), Jacques Prévert (1), René Char (1), André Breton (2), and Robert Desnos (2) - that is, thirty-two poems by twelve poets, mostly surrealists. Each of the three sets - US poetry, UK poetry, and French poetry - is considerably smaller in size than an average anthology in book form, but the selections unmistakably exhibit Mar's modernist aspirations. They constitute the first appearance of many of these poets in Chinese; certainly most of the individual poems had never been rendered into Chinese before. Mar exclusively chose those poets that come under high modernism.

The sense "that life must have an ultimate meaning, but one that can never be made fully explicit," Pericles Lewis explains, "pervades modernism." As a result, the modernists' "literary forms, rather than attempting to arrive at formal perfection, reflected the partial and fragmentary nature of their understanding of their culture" $(2007,120)$. This cultural crisis was perceived not only by high modernists, but also by modernists in Hong Kong like Yun Fu, Li Wai-ling, and Mar. Yau points out that Mar "emphasizes experiments with poetic language and opposes word games; accentuates that literature should face social reality and be tied closely to modern life" (2013, 75-84). This is reflected in his translations finding poetic expression in sudden and overwhelming revelations in the depiction of fragmented life. On this, Mar's 1956 translation of H.D.'s “Pear Tree” (梨樹) is exemplary:

Silver dust

lifted from the earth,

higher than my arms reach,

you have mounted.

O silver,

higher than my arms reach

you front us with great mass;
銀塵

從大地攀高,

高不可攀,

你升高了。

銀色啊,

高不可攀

你以大量迎向我們; 


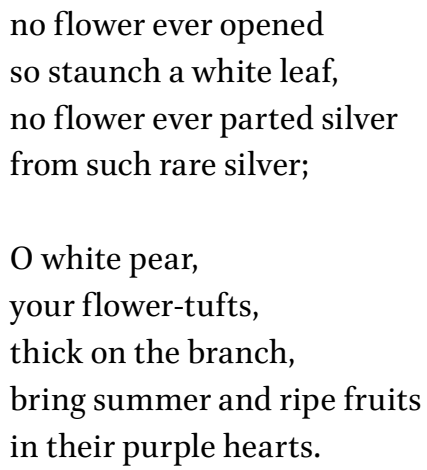

(H.D. 1988, 15-16)
沒有花開過

這樣白無點血的葉子,

沒有花從如此稀少的銀色裏

把銀色分開;

\author{
白梨啊, \\ 你的花簇 \\ 厚結在枝葉上， \\ 帶來夏天和成熟的果實 \\ 在他們紫色的心中。
}

(Mar 2014, 26)

Excusing the glaring mistake of translating the plant name "silver dust" (Jacobaea maritima) as 銀塵 (which literally means "silver dust"), when it should be 銀葉菊 (literally “silver-leaved chrysanthemum"), there is Mar's exceptional treatment of "staunch." As an adjective in H.D.'s line, it means loyal and committed, strong and firm; a straightforward corresponding Chinese translation could be jianzhen 堅貞. But in Mar's line it becomes the adjective baiwu dian xue 白無點血 'white without a stain of blood', which refers to the verb staunch, which means to stop the flow of blood from a wound. Thus, Mar uses a rhetorical device to translate this word: bai wu dian xue is anthimeric to "staunch." His translation rewrites but enriches H.D.'s largely concrete Imagist poem by creating not only the sharp contrast between white and red but also the dichotomy between white's presence and red's absence, between the real and the surreal. In so doing, paradoxically, the absence of the red evermore surrealistically reminds of the red (absence, as Joyce is supposed to have argued, is the highest form of presence). On the one hand, it hints at the speaker's contradictory feelings; on the other, it finds transient and powerful catharsis in this poetic expression, in this sole image from the outside world, in this single fragment of life.

Translations of Western modernist poetry introduced such complex expressions of the trope of life to the writers associated with Literary Currents. They found that the literary techniques employed in Western modernist poetry (which they translated, and rewrote) were embodiments of high modernism's literary aspirations, especially its concern with life at a philosophical level. In translating what they believed to be the most pioneering, often surrealist, poetry of Western modernism, they perceived a possibility of addressing their most real and practical concerns with survival - which was why they were so attracted to modernism in the first place, but this also indicates their poetics was encumbered from the 
beginning by the inherent dichotomy between the real and the surreal. Consequently, in the 1970s, this poetics lost much of its influence on the writing of poetry in Hong Kong, as I shall explain in the next section.

\section{The trope of life and the search for identity}

Literary Currents stopped publishing soon after Ronald Mar moved back to the US in 1958, but its efforts continued in various activities organized by the Association of Modern Literature and Art (現代文學美術協會), in the modernist literary magazines New Currents (新思潮) and Modern Edition (好望角), and in the “Repulse Bay” (淺水灣) supplement of the Hong Kong Times (香港時報), as well as in the Chinese Student Weekly (中國學生周報). All played major roles on the literary scene of Hong Kong in the 196os. The generation of Hong Kong writers who joined the local literary scene in the 1970 s had been nourished primarily on the modernist literature written and translated in the two postwar decades. Unlike the migrant writers in the 1950s, the baby boomers were not so critically concerned with survival in their philosophy of writing and translation, but felt the urge to search for an identity in their literature on the most visible level.

One of the key figures of this generation was Leung Ping-kwan, who revived the Poetry Page (詩之頁) of the Chinese Student Weekly in 1973 and became its last editor, until 1974. Leung described the excitement he had felt when he first encountered the modernist works published in Literary Currents:

Even with Hong Kong's reality as background, people were able to create pioneering works ... works stimulated by Hong Kong's unique time and space ... This taught me, then still searching, that little North Point, where we lived, could become the subject matter of literature.

(Leung 1982, 27)

The modernism promoted in Literary Currents inspired Leung not to adopt avant-garde Western poetics - certainly not the surrealistic poetry of Mar and his fellow author-translators - but simply to treat the place he lived as his subject matter. This inspiration was realized in Poetry Page's advocacy of what he called true-to-life poetry, which could be loosely defined as narrative poetry written in plain language with an emotionally reserved tone, most often set in Hong Kong or about Hong Kong (see Lo 2001 and Wong 2015). His poetry exudes a sense of place and of belonging. 
Thus, the trope of life in poetry was transformed and utilized by Leung and his followers as a means to search for identity in the couleur locale of the poetry they were writing. By advancing the idea of true-to-life, he resolved to distinguish the poetry of Hong Kong from both the poetry of mainland China, which he critiqued as too nationalistic and sentimental, and the poetry of Taiwan, which he believed was too idiosyncratically surrealistic (Leung 2007, 51). Although both were understood reductively in the 1970s, it was enough for Leung to find an opening through which he could define Hong Kong poetry for immediate identification by a local poetry readership and the budding poets associated with the Poetry Page. His efforts in constructing a subjectivity for Hong Kong poetry were further strengthened in the 1980 s by his and other Poetry Page authors' successful defense against the influence of Taiwanese poet Yu Kwang-chung's 余光 中 signature neoclassical style (see Wong 2016). Leung's curation of the above-mentioned monumental anthology Selected Poems of Ten Poets, published a year after the handover, reasserts the stylistic identity of Hong Kong poetry. It is no exaggeration to say that Leung started a true-to-life tradition of Hong Kong poetry in the 1970s and kept it alive for decades. Even after his passing in 2013, his tradition is carried on by middle-aged poets such as Chan Chi-tak 陳滅, Chow Hon-fai 周漢輝 - and, of course, by Chung Kwok-keung, who launched the attack on the surrealist poetry written by some of Hong Kong's youngest poets today.

\section{Conclusion: reading surrealist poetry in Hong Kong}

By reviewing the transformation of the trope of life since the 1950s, this paper offers a new angle on the interpretation of the dispute between the true-to-life school and the young surrealists in Hong Kong today. If the influence exerted by the 1950s translations of Western modernist poetry by Ronald Mar and others gradually decreased over the years, it was because the trope of life, so central to Mar and his followers' modernist practice, lost its historical burden of survival as the writers' core concerns evolved away from this, as a reflection of Hong Kong history. As southbound right-wing sojourners like Mar moved out or settled down more securely in the 1960s, they were followed by 1970 s authors such as Leung Ping-kwan, who had grown up in and with Hong Kong and felt an urgent need to seek a Hong Kong identity and distinguish their writing from that of other sinospheric areas. Leung rejected the surrealist quality of Mar's and his followers' translations and writings, presenting instead an entirely different understanding of life 
in developing a sense of belonging in his treatment of Hong Kong as subject matter per se. Thus, the trope of life transformed into what Leung called true-to-life poetry, by which he tried to protect what he perceived to be a Hong Kong subjectivity. Along these lines, the recent dispute between the true-to-life school and the young surrealists of Hong Kong's poetry scene can be understood as just another round of the former's defense against poetic influence from Taiwan.

The recent trend of surrealism in Hong Kong's poetry scene is, however, also reminiscent of the modernism of Mar and his circle in the 1950s. Despite a gap of half a century, there is an obvious stylistic affinity between the two, in that they both use surreal imagery as a medium to negotiate reality. Representative of Mar's poetry is “A Night in North Point” (北角之夜), a poem widely cited in studies of Hong Kong literature, which bears clear marks of surrealist influence in images such as, "Hence [I] fall into the drunkenness of amethyst” (於是陷入一種紫水晶裡的沉醉) and “creeks of mint wine" (薄荷酒的溪流), ${ }^{3}$ of which Chan Kwok-kuo has remarked that the "surreal allusions help create an effect where everything seems both real and illusory" $(2016,403)$. In theorizing the surreal quality of these young poets' imagery, Mu Yu 沐羽 (2015) and Huang Runyu 黃潤宇 (2015) argue that their imagery deliberately distances them from life to reflect critically upon the relationship between poetry and everyday reality. But compared to Mar and his followers' poetry and translations, the young surrealists' work lacks a genuine concern with life, with living, with survival at a philosophical level; compared to the true-to-life school advanced by Leung Ping-kwan, the young surrealists have yet to express the kind of alternative local subjectivity that could give the (Hong Kong) reader a sense of belonging. As this is an absence, or an incompleteness, that the true-to-life tradition cannot tolerate, their writings read as if written for the mere purpose of counter-attack, with their inspiration from Taiwanese poetry mentioned as a matter of expediency.

As these young poets continue to practice their surrealism, they may well take their poetry even further away from life. They seem to have chosen to ignore the reverberations of contemporary poetry outside the sinosphere. Only too soon have they suffered from the consequences inherent to surrealism, as J. P. Eburne warns, "abstracting its poetic devices and creative processes from ... political imperatives" $(2012,1377)$, not to mention, especially with an eye to their local situation, abstracting the surreal from the real, imagery from life. In other words, their transformation of the trope of life, 
first introduced by Mar and his followers, then tempered by Leung and fellow true-to-life authors, will only further disengage their poetry.

As for their proposal to incorporate surrealism into the true-to-life tradition, they have insufficiently theorized their poetic aspirations, and they have failed to introduce recent surrealist developments in contemporary world poetry - say, through translations of James Tate or John Ashbery - and an engagement with the postcolonial diasporic surrealism of Latin American poets such as Aldo Pellegrini, Braulio Arenas, and Enrique Molina. They even seem to have overlooked the bilingual volumes of Michael Palmer, Yves Bonnefoy, and Coral Bracho, published as part of the International Poets in Hong Kong series. Yet through translation, they could demonstrate, even renovate, their surrealism, just as Mar and his followers did vis-à-vis modernism in the 1950s, thereby bringing a new perspective to the trope of life in Hong Kong poetry. Perhaps only in this way could their surrealist poetry negotiate the current mainstream true-to-life tradition, and could they find a new definition of localness, a new sense of belonging, and a way back to the love of life in Hong Kong.

\section{Works cited}

Au Chung-to 區仲桃. 2010. 〈試論馬朗的現代主義〉 [On Ronald Mar's modernism]. 《文學評論》10,38-47.

Berman, Art. 1994. Preface to Modernism. Chicago: University of Illinois Press. Chan Chi-tak 陳智德. 2001.〈林以亮詩論與 50 年代香港新詩的轉變〉 [Stephen Soong's poetics and the transformation of Hong Kong poetry in the 1950s]. 《作家》11, 85-93.

Chan Kwok-kou. 2016. "Sense of Place and Urban Images: Reading Hong Kong in Hong Kong Poetry." In The Oxford Handbook of Modern Chinese Literature, edited by Carlos Rojas and Andrea Bachner, 399-416. New York: Oxford University Press. Chang Ting 長亭. 1982 [1953]. 〈詩和對詩的感應〉 [Poetry and sensibility]. In 《詩與情感》 [Poetry and emotion], edited by Stephen Soong, 91-93. Taipei: Dalin chubanshe.

Cheng Ching-hang 鄭政恆. 2013. 《五O香港詩選》 [An anthology of Hong Kong poetry of the 1950s]. Hong Kong: Chunghwa Books.

Chung Kwok-kueng 鍾國強. 2015. 〈本土詩的一種面向〉 [A facet of local poetry]. 《明月》11, 9-13.

Eburne, J. P. 2012. "Surrealism." In The Princeton Encyclopedia of Poetry and Poetics, 4th edition, edited by Roland Greene, 1377-1380. Princeton: Princeton University Press. 
H.D. 1988. Selected Poems, edited by Louis L. Martz. New York: New Directions. Huang Wanhua 黃萬華. 2013. 〈從《文潮》到《文藝新潮》: 一條不可忽視的文 學史綫索〉 [From Literary Wave to Literary Currents: an unignorable trace in literary history]. 《山東社會科學》9, 58-66.

Huang Runyu 黃潤宇. 2015. 〈本土詩及日常語言的畫外音〉 [The voice-over of local poetry and everyday language]. 《獨立媒體》. bit.ly/2I5x4Fn. Accessed April 1, 2018.

Lewis, Pericles. 2007. The Cambridge Introduction to Modernism. Cambridge: Cambridge University Press.

Leung Ping-kwan 梁秉鈞. 1971. 《美國地下文學選》 [An anthology of American underground literature] Taipei: Huanyu chubanshe.

-.1982. 〈從緬懷的聲音裡逐漸響現了現代的聲音〉 [Out of a nostalgic voice gradually emerges a modern voice]. 《素葉文學》5, 26-30.

- 1992. "Modern Hong Kong Poetry: Negotiation of Cultures and the Search for Identity." Modern Chinese Literature 9 (2), 221-245.

-.2007. 《僭越的夜行》 [Traversing the night], edited by Chan So-yee 陳素怡. Hong Kong: Wenhua gongfang, 2012.

Li Wai-ling 李維陵. 1956. 〈現代人·現代生活·現代文㙯〉 [Modern man, modern life, modern literature and art]. Literary Currents 《文藝新潮》 7, 21-27.

Lo Kwai-cheung 羅貴祥. 2001. 〈經驗與慨念的矛盾〉 [A conflict between experience and concept]. Hong Kong Literature as/and Cultural Studies 《香港文學@ 文化研究》, edited by Esther Mei-kwan Cheung 張美君 and Stephen Yiu-wai Chu 朱耀偉, 241-252. Hong Kong: Hong Kong University Press.

Lo Wai-luen 盧瑋鑾. 1996. 〈「南來作家」淺說〉 [On the southbound writers]. In Lo Wai-luen, 《香港故事》 [Hong Kong Stories], 118-128. Hong Kong: Oxford University Press.

Lok Fung 洛楓. 1990. 〈香港早期現代主義的發端〉 [The beginning of modernism in Hong Kong]. 《詩雙月刊》8, 30-35.

Mar, Ronald 馬朗. 1956. 〈人類靈魂的工程師, 到我們的旗下來!〉 [Engineers of the human soul, rally to the flag!]. Literary Currents 文藝新潮 1, 1-2.

一, ed. 1956. 〈英美現代詩專輯·美國部分〉 [Special features on British and American modern poetries, American section]. Literary Currents 文藝新潮 7, 47-63.

- 2003. 〈為什麼是現代主義? : 杜家祁、馬朗對談〉 [Why modernism?: a conversation between Du Jiaqi and Ronald Mar]. 《香港文學》224, 21-31.

—. 2014. 《變調: 馬博良譯詩集》 [Variations: collected poetry translations of Ronald Mar]. Macao: Association of Stories in Macao.

$\mathrm{MuYu}$ 沐羽. 2015. 〈本土詩歌風景〉 [A landscape of local poetry]. 《LA PETITE MORT》. bit.ly/2UCgNh7. Accessed September 1, 2018.

Qian Yating 錢雅婷, ed. 1998. 《十人詩選》 [Selected poems of ten poets]. Hong Kong: Qingwen shuwu. 
Soong, Stephen 宋淇. 1982. 《詩與情感》 [Poetry and emotion]. Taipei: Dalin chubanshe.

Song, Chris. 2017. "The Transculturation of American Poetry in China, 1917-1937." Journal of Modern Literature in Chinese 14 (2)-15 (1), 187-211.

Tang Zhenzhao 湯禎兆. 1990. 〈馬朗和《文藝新潮》的現代詩〉 [The modern poetry of Ronald Mar and Literary Currents]. 《詩雙月刊》6, 33-41.

Wong Ka-ki 王家琪. 2015. 〈抒情與寫實: 重釋也斯的「生活化」詩歌主張〉

[Lyricism and realism: re-interpreting Leung Ping-kwan's advocacy of true-to-life poetry]. 《中國現代文學》50, 129-148.

-.2016. 〈本土詩觀的角力史〉 [A history of the opposition of local poetics]. Fleurs des lettres 字花 59, 104-108.

Yau Wai-ping 邱偉平. 2013. 〈《文藝新潮》譯介現代主義詩作的選擇與取向〉

[A study of the translation of modernist poetry in Literary Currents]. Journal of Modern Chinese Literature 11 (1), 75-84.

Yip Wai-lim 葉維廉. 2016. 〈現代主義與香港現代詩的興發〉 [Modernism and the rise of modern poetry in Hong Kong]. 《晶石般的火焰》, vol. 1, 481-484. Taipei: National Taiwan University Press, 2016.

Yun Fu 雲夫, trans. 1956. Stephen Spender, 〈現代主義運動之消沉〉 [The modernist movement is dead] 《文㙯新潮》2, 2-5.

Zhang Songjian 張松建. 2009. 《現代詩的再出發》 [The re-emergence of modern poetry]. Beijing: Beijing daxue chubanshe.

\section{About the author}

Chris Song obtained his PhD in Translation Studies at Lingnan University. Since the early 2010 s he has been managing editor of the Journal of Modern Literature in Chinese and, from 2019, its successor Prism: Theory and Chinese Literature. His research interests include literary translation in the Chinese context, museum translation, and Hong Kong literature. A poet and translator of poetry, he has published five books of his own poetry and many volumes of poetry translation. He is editor-in-chief of the Hong Kong-based Chinese-English bilingual Voice \& Verse Poetry Magazine, and executive director of the International Poetry Nights in Hong Kong. 



\title{
12 Ya Xian's Lyrical Montage
}

\author{
Modernist Poetry in Taiwan through the Lens of Translation
}

\author{
Tara Coleman
}

\begin{abstract}
This essay shows that the postwar Taiwanese poetry scene is a particularly rich example of the fact that translation and its impact come in "vertical" (or indigenous) varieties as well as "horizontal" (or foreign) ones. In dialogue with film theory, the author employs the notion of "lyrical montage" to consider how juxtaposition in Ya Xian's poetry leads to interactions that are mutually transformative and destabilizing, questioning conventional assumptions about the original and the translation.
\end{abstract}

Keywords: Chinese poetry, translation, Ya Xian, Taiwan modernism, montage, lyricism

In a 1956 issue of his journal Modern Poetry Quarterly (現代詩季刊, MPQ), the poet Ji Xian 級弦 (1913-2013) declared, "Modern Chinese poetry is a product of geographical transplantation, not historical heritage. It is a transplanted flower, not a native plant" (quoted in H. Chang 1985, 307-308). Having brought a reputation for avant-garde poetry from mainland China to Taiwan in 1948, Ji Xian was himself a "transplanted flower," and his journal helped to initiate a new modernist movement in Taiwan. In the subsequent “new poetry debate" (現代詩論戰) in the early 1970s and the “native literature movement” (鄉土文學運動) of 1977-1979 (see S. Chang 1993), modernist poets were targeted for their excessive devotion to foreign forms and insufficient concern with local realities.

As Michelle Yeh notes, the organic nature of Ji Xian's metaphor was ignored in favor of a critique of the "unrootedness" of the modernists (2001, 34). Of course, this was an exaggeration of both the theory and the practice of modernist poetry at the time. In Yeh's discussion of the headwinds faced by

Van Crevel, Maghiel and Lucas Klein (eds.), Chinese Poetry and Translation: Rights and Wrongs. Amsterdam: Amsterdam University Press, 2019 DOI: $10.5117 / 9789462989948$ CH12 
$M P Q$ and the poetry it promoted, she notes that vernacular poetry struggled for recognition among students, critics, and the public, who continued to favor old-style poetry $(2007,115-119)$. In addition, anti-communist poetry, with its political themes and sentimental lyricism, was promoted and supported by the Nationalist government and associated cultural institutions, and Ji Xian wished to distance his journal from the project of national restoration without creating political trouble (119-127).

Nevertheless, this sense that modernist poetry favored the "foreign" over the "native" - and that we can clearly distinguish between them - has stuck. Although much important work has been done in the intervening decades to complicate the view of both Taiwanese and Western modernism that emerged in the nativist debates, and to highlight in particular the aesthetic and topical innovations achieved by the modernists within the restrictive aesthetic and political atmosphere of the postwar period in Taiwan, the reputation of modernist poetry has never fully recovered.

Once a dichotomy is set up, it is hard to escape. A common tactic is to create a spectrum in which we suggest that there is more overlap between the two sides of the binary than at first appears, but this leaves the two opposing terms in place. In search of a new method, in what follows I look to the poems of Ya Xian 痘弦 (b. 1932), a founding member of the Epoch Poetry Society (創世紀詩社), to propose re-examining modernist postwar poetry from Taiwan through the lens of translation. Given Taiwan's lack of political status as a nation-state, history of Japanese colonialism, and subsequent period of what Chen Fangming calls "neocolonialism" under Nationalist Party rule $(2007,44)$, the intense focus on the politics of influence and representation in this poetry has left us with an impression that we can only judge these poems as "rooted" or "rootless," or at best as a productive blending of the native and the foreign. In fact, they are the product of multiple layers of translation - interlingual, intralingual, and cultural. In particular, we should recognize how these poets engage with the premodern Chinese poetic tradition in the context of a modern vernacular, free verse form (which itself began in mainland China and migrated to a new cultural and political context in Taiwan), in addition to a wide range of poetic forms and theories which were arriving in Taiwan via translation as well as personal connections these poets had abroad. The voice which emerges in these poems, rather than being a happy amalgamation of these various influences, reveals the fault lines created by their interaction. My project here looks at the effect of this translational context on the formal features of the work of a particular poet, but in so doing, I draw on theories of translation and cross-cultural comparison, as well as the concept of montage in film theory, 
to demonstrate that any such translational encounter reveals as many complexities or ambiguities within languages and cultural traditions as it does gaps between them, creating meaning as much as transmitting it. Ya Xian's later poems provide an especially important insight into these issues because of their affective orientation: their interest in the limitation of our language for bridging the experiential gaps of time and space, but also their belief in the necessity of the attempt.

Like several other of the Epoch poets, Ya Xian was raised in mainland China and arrived in Taiwan around 1949 as part of the Nationalist army, and his work continually returns to the effects of that disruptive experience. Focusing on the juxtaposition of imagery in Ya Xian's poems, I put his work in conversation with Wai-lim Yip's 葉維廉 (b. 1937) poetry and his theory of a convergence between classical Chinese and modernist Anglo-American poetics. Yip's work emphasizes the spatialization of the image in favor of its self-sufficiency and immediacy as a meaning-producing unit, as opposed to narrative interference on the part of the poet. Ya Xian's poems, meanwhile, are interested in the possibility of history, the kind which allows us to transmit understanding across the boundaries of time and space, but they also leave much of the interpretive work up to the reader, because they recognize this project as always in progress. His poems convey the emotional and psychological aspects of an experience in fits and starts, using each juxtaposed piece to open up spaces for new insights on the part of the reader. In the process, they create a special form of lyricism that, instead of being in opposition to narrative or realism, borrows elements of these in order to convey aspects of an embodied experience without imposing a predetermined intellectual or contextual framework. Of course, this approach will always evade the urge to achieve totality, but thinking through translation reminds us that the provisional is not necessarily the incomplete. Recognizing the limitations of our formal structures can be a means of breaking them out of their isolation and placing them into a larger conversation, an ongoing analytical process.

\section{Juxtaposition of forms, juxtaposition as form}

One of the most notable techniques of Taiwanese modernist poetry is the juxtaposition of images - but also independent narrative components - with little in the way of explanation or mediation between them. Although densely packed or fragmented imagery is a feature of much modernism from mainland China, Europe, and North America, it reaches new heights 
in postwar Taiwan. At the same time, juxtaposition has also been cited as a characteristic of premodern Chinese poetry, and thereby as evidence for some of modernist poetry's connection to tradition in addition to the influence of foreign forms.

Wai-lim Yip takes such an approach, in both his theory and his poetry. A prime example is his 1959 poetic sequence "Fugue" (賦格), which features a rapid succession of images and little in the way of mediation by a poetic voice. The first third of that poem is as follows:

North wind, can I bear this one more year?

On the cold street, on the wall, worry rocks the windows and comes in

Carrying border town stories; exhaling a changing earth

The patience of plants and trees, the silence of mountaintops, cast down.

Neighs of Hu horses, beacon fires disturbing

Things that transcend knowledge, the clean white of snow

The majesty of churches and palaces, the disgraceful affairs of deities ${ }^{1}$

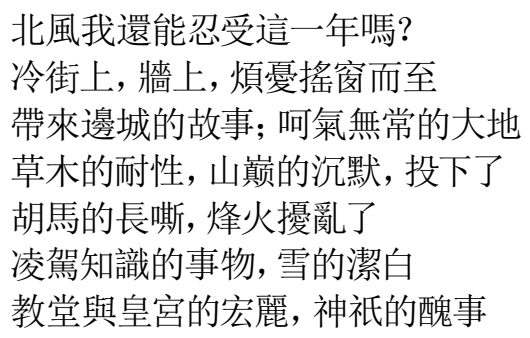

(Yip 2012, 104)

After the question that sets the stage, the stanza moves to a series of descriptive images that work together to create a mood, despite not being syntactically linked. We can connect the images based on a general sense of a scene, with references to the "plants and trees" and "mountaintops." Several of these images contain familiar echoes of classical poetry, such as the “Hu horses" which recalls the line 胡馬依北風 / 越鳥巢南枝, from the Nineteen Old Poems (古詩十九首), translated in Yip's anthology of Chinese poetry as "Tartar horses follow north winds / Birds of Yueh nest on south branches" (1997, 69). Toward the end of the poem, the theme of displacement and the search for meaning in an unfamiliar world, hinted at in this opening,

1 Unless otherwise indicated, translations are mine. Notably, Yip's own translation in Frontier Taiwan of "Fugue" is a creative rewriting into English, as images migrate to different lines and word associations shift, emphasizing the freedom of the images from any overriding sequential logic. 
comes to the surface, but only after a lot of interpretive work on the part of the reader. The images are abstract, or else they displace any reference to the present onto symbols of the past.

Although Yip, who was born in mainland China and spent his adolescence in Hong Kong, was only in Taiwan as a bachelor's and master's student before he left for the US in 1963, he played an important role in the Epoch Poetry Society, among other groups. In particular, his translations into Chinese helped introduce Surrealism and other strains of modernism to Taiwan, and he began writing poetic theory and criticism during this period. "Fugue" is an example of his montage method, which juxtaposes images without intervening explanation. He describes his process as "symphonic ... inspired by the fact that music, as a medium, is not built up by meaning-discharging units but instead by the modulations of time and timbre, both spatially and temporally ... to emulate the morphology of meaning" (2017, 600-601). Ya Xian's seminal poem “Abyss" (深滟) written in the same year, exhibits many of the same tendencies. Although less disjunctive than "Fugue," it is characterized by striking images in a thematic ebb and flow: "this is the face of the day: all the gaping wounds moan, skirts conceal multiplying bacteria" (這是日子的顏面: 所有的瘡口呻吟, 裙子下藏滿病菌) (2010, 230). In lines such as "metropolis, scale, paper moon, the speech of telephone poles" (都 會, 天秤, 紙的月亮, 電桿木的言語) any conceptual unity must be supplied by the reader, based on the overall resonances felt across the poem (230).

For Yip, this approach to imagery pointed to an emerging "ideal convergence" between classical Chinese and modern Western poetics, which began with the Vorticists' emphasis on the "superimposition" of one image on the other, or on the "synchronous relations" between them, an idea which was crystallized through Ezra Pound's view (via Ernest Fenollosa) of the Chinese character as a juxtaposition of objects to form an idea, itself understood as a representation of the condition of nature. In Yip's view, both traditions share an interest in

the acting-out of visual objects and events, letting them explain themselves by their coexisting, coextensive emergence from nature, letting the spatial tensions reflect conditions and situations rather than coercing these objects and events into some preconceived artificial orders by sheer human interpretive elaboration.

$(1997,15)$

By contrast, Michelle Yeh emphasizes "disjunctive juxtaposition" as one of the two key features which distinguish modern Chinese poetry from 
traditional poetry (the other being the "exaltation of metaphor") $\left(1991,5^{8}\right)$. Yeh argues that this approach to imagery did not appear in classical poetry "with the frequency that Yip would have us believe," and additionally, "it is neither prominent among nor independent of other coexisting literary or linguistic factors" (1991, 78). In fact, juxtaposition in classical Chinese poetics was often employed in service of parallelism, where two lines mirror each other in structure, creating an interplay of similarity and difference in order to present a sense of totality, of "complementary aspects within a self-contained whole" (Plaks 1988, 49). This aspect of classical poetics is not often a focus of modern poets seeking to integrate premodern approaches into their work, though it does occur in some lines of the above stanza in "Fugue," such as in the third line.

Overall, Yip's use of juxtaposition in "Fugue" and his comparative analysis suggest that juxtaposition is primarily about cognitive leaps and dissociation - but it can, in fact, have other functions. As Haun Saussy has pointed out, all acts of comparison are indeed "acts," requiring a choice of a broader ontological, theoretical, or rhetorical structure within which the comparison takes place $(1993,35)$. Once these terms are set, we can use them to interrogate either side of the comparison, but we cannot assume that the terms themselves are inherently neutral or stable. We see this in Yip's focus on the independence of images in juxtaposition. Take for example the phrase "beacon fires," which refers to the couplet 烽火連三 月 / 家書抵萬金 from the poem “Spring Scene" (春望) by the Tang poet $\mathrm{Du} F \mathrm{Fu}$ 杜甫 (712-770). Yip translates these lines, "Beacon fires continued for three months on end / A letter from home is worth thousands of gold pieces" $(1997,191)$. In Du Fu the image serves as part of a parallel couplet, but Yip turns it into a free-floating signifier. Throughout the translations in his anthology, originally published in 1976 and for which this theory of convergences serves as an introduction, Yip privileges parataxis at the expense of parallelism or even the practical syntactical requirements of English. This "act" of comparing and translating changes the poetry, both Yip's own and that which he translates, much like a speech act.

Recognizing that fact does not mean we cannot learn anything from comparative analysis, only that we need to acknowledge how our terms enable certain insights and prevent others (see Gu 2005a and 2005b; Hayot 2016; and Klein, in the present volume). From this perspective, the problem with both Yip's position and Yeh's critique is that they define classical Chinese poetics from a comparative standpoint (both historically and geographically), yet without fully acknowledging how that comparative perspective influences the object being defined. This leaves our understanding 
of juxtaposition in a rather awkward position: it is either a matter of breaking apart or leaving unsaid what is meant to be linked, leaving the reader with a sense of disjuncture, or the opposite, transposing a pre-existing series of correspondences from reality into the poem, so that the reader can naturally intuit the links between images based on a shared understanding of the world (a method which, Saussy points out, implies little artistic merit). It does not help us account for juxtaposition which fragments in order to reorient - not permanently but still provocatively.

Unlike the disorienting effect of juxtaposing evocative images in poems like "Fugue" and "Abyss," in his later poems Ya Xian uses juxtaposition without such dramatic spatial and temporal leaps. The poems remain fixed in one moment in time and space, but notable gaps in our comprehension of these scenes remain; they evoke emotional resonances out of ordinary experiences without describing them fully. We see this in his poem "The Nun" (修女), about a Catholic nun in an unnamed location, seemingly near the sea and a military site. The first stanza repeats the phrase that she "always feels that there is something" (總覺有些甚麼) calling to her from far away - yet the poem never tells us what $(1981,147)$. A series of sounds she hears or has heard from afar, such as “bugles” (喇叭), “wind” (風), and a "mandolin" (曼陀鈴), remind her of something she has read in a book, but here the poem not only resists explanation, it resists completing the lines themselves (147-148). After a long dash separating the first part of the poem from the ending, we read:

Wasn't a book once written about this

what happened to that protagonist afterwards

She vaguely ponders. It distracts her ...

eyes closed she leans for a moment on the night while also moving aside the carnations on the piano because they make her heart ache

一本書上會曾經這樣寫過的吧 那主角後來怎樣了呢

暗忖着。逐因此分心了.......

閉上眼依靠一分鐘的夜

順手將鋼琴上的康乃馨挪開

因它使她心痛 
As the nun reflects on the memory of a previous narrative recalled to her by the current sights and sounds, the only full stop of the poem interrupts the line, and then it dissolves into ellipsis. When we emerge from this momentary dream, we are unsure if the nun is asleep as she pushes the carnations away, but we know that her heart aches, despite the fact that neither she nor we seem able to pinpoint whatever trauma may be buried there in her memory. Rather than fill in the gaps to provide an overall sense of who this nun is or what she is remembering, the poem uses the blank spaces created by these interruptions to evoke something more powerful than the images themselves could suggest, while refusing to articulate it for the reader.

To recognize the value of this method and what it represents for this key moment in Chinese poetry, we need a theory which recognizes both the destabilizing effects and the potential for transformative, if provisional, insights generated by any act of translation, including those which involve negotiating between multiple interconnected poetic influences to best convey the affective layer of experience in a period of cultural and historical flux. Against the hierarchical view of translation, which views translations as subordinate to an original, Walter Benjamin famously posits translation as a bi-directional process in which each instance of translation enriches the languages on both sides. For him, neither the source text nor the translation holds the key to the "true" meaning of the word; it exists in a third space beyond (but not above) the two languages, inherent as a possibility in both. Hence his assertion that "to some degree, all great texts contain their potential translation between the lines" (1996, 263).

This extends to a way of thinking about how ideas or forms circulate and develop across space and time. Moving away from the impressionistic, even theological nature of this early Benjamin, which Nick Admussen associates with the "modernist icosis" elsewhere in this volume, Peter Osborne borrows from Benjamin's work on translation and his later writings on history to re-engage cultural studies with historically and politically engaged inquiry. For Benjamin, Osborne notes, objects of historical experience are "constituted through use" while "their truth is nonetheless tied up with the standpoint of the end of time" $(2000,14)$. Osborne points out that translation is often used in cultural theory as a metaphor for the process of comparing concepts cross-culturally, but in such a way as to shut down comparative analysis by suggesting that the historical specificity of the instance makes comparison impossible or at best, treats chronologically later forms as derivative of the original. Instead, he proposes a non-hegemonic view, in which modernism is translatable precisely because it is an abstraction with "distinctive and contradictory features" which yet ties into a "multiplicity" 
of concrete "empirical forms" $(2000,58)$. As it becomes translated into "nonWestern" contexts, it becomes associated with a "radically extended range of forms" through which the (mostly temporally oriented) experiences of modernity are conveyed (61). Following Benjamin's notion of translation as resulting not in loss of meaning but enrichment of sense, Osborne argues that the concept of modernism is similarly transformed by these "new forms of production of 'the modern"' which "fracture its identification with its Euro-American 'original" (61). Rather than think of Taiwanese modernism as having imported and then perhaps synthesized "foreign" forms with "native" ones, as defenders of modernist poetry such as Yip have done, Osborne's model highlights the fact that the very concept of modernism is only conceivable as such speculatively.

Relevant to the current discussion of poetry, the image is essential to both Osborne's and Benjamin's understandings of historicization. Benjamin's concept of the dialectical image appears in a well-known fragment from The Arcades Project:

image is that wherein what has been comes together in a flash with the now to form a constellation. In other words, image is dialectics at a standstill. For while the relation of the present to the past is a purely temporal, continuous one, the relation of what-has-been to the now is dialectical: is not progression but image, suddenly emergent. - Only dialectical images are genuine images (that is, not archaic); and the place where one encounters them is language.

$(1999,462)$

Rather than containing a sedimented version of the past, the dialectical image provides a temporary "flash" of insight into the back-and-forth mediation between "what has been" and the "now." By reading poetic images in this context, we see that while history is only gestured to in its incompleteness, the work of speculation which seeks it out, even through images alone, is the only way we can find new insights into complex, globally significant experiences. For Osborne, as with Saussy, the process of translating concepts across geographical and historical borders involves both describing objects in their relation to one another and creating equivalences that were not there before. The juxtaposition of imagery is a particularly useful technique through which to explore this non-hierarchical model of translation in which translation both transmits and creates, destabilizes and provides flashes of new connective insight, and so I turn now to a more detailed examination of the role of juxtaposition in Ya Xian's later poems. 


\section{The flash of the now (and then) in Ya Xian's poems}

When two images are juxtaposed, there is no inherent relationship between them. The reader must figure out the meaning or context which draws them together, and that relationship need not result in one term being subordinated to the other (as it does in the vehicle/tenor model of metaphor and the source/ target model of translation). How does this take place in Ya Xian's poems?

Ya Xian's poems may display the emotional after-effects of being caught up in a war during his youth, as Zhang Yaxin so poignantly describes (2004, 109), but whereas poems like "Abyss" are more focused on the existential crises of modernity and of cultural dislocation, and therefore range beyond a single space or time, his later poems are more about the way in which memory surfaces in ordinary moments and yet seems to resist our grasp. Near the end of his eleven-year writing career (from 1954 to 1965), instead of presenting visions of a highly sensitive creative consciousness (for which modernist poetry is generally known), his work maps the subtle echoes of this moment of cultural translation and historical transition onto intimate portraits of the lives of ordinary people.

One example is the series of poems written in 1960 which, like "The Nun," provide brief but intimate portraits of people referred to by their role. As we encounter these individuals, past experiences are juxtaposed with their mundane present activities, popping in and out of consciousness for both the reader and the protagonists themselves. “The Colonel” (上校), for instance, focuses on the dissociative effects of war. The opening stanza, containing a series of images about the protagonist's war experience, and the closing one, reflecting on the present, are linked by a one-line stanza: "He has heard history and laughter" (他會聽到過歷史和笑) $(2010,140) .{ }^{2}$ The juxtaposition of past to present is emphasized by a shift from distanced observation in the beginning to a more intimate glimpse into the psychology of the subject at the end, and yet the present remains colored by the past. The closing stanza opens with a question: “What is immortal then?" (甚麼是不朽呢) (140). The question is followed first by the sudden intrusion of the domestic, "Cough syrup, razor blades, last month's rent, and so on” (咳嗽藥刮臉刀上月房租如此等等), before the past blends in with the present: "And under the scattered fire of his wife's sewing machine / He feels that the only thing which can take him captive / Is the sun" (而在妻的縫糿機的零星戰鬥下 / 他覺得唯一能俘虜他的 / 便是 太陽) (140-141). In the tapping of the sewing machine, the colonel hears not

2 In his own translation of this poem, Ya Xian interestingly writes "history and the laughter of history" $(2010,327)$. 
a metal needle but the sounds of battle, like a traumatic memory triggered by a sound resembling the event. What is "immortal" are these traumatically recurring memories $(2010,327)$. The opening and closing stanzas therefore contrast history and memory in terms of the difference between the significant and the ordinary, the impersonal and the personal. In the process, the poem suggests that rather than being paralyzed by history, the colonel maintains the slightest agency in his feeling that only the sun can take him captive now.

In a similar way, words begin to fail at the end of “Wartime” (戰時), written in 1962. It focuses on the death of the speaker's mother, one among many unavoidable deaths brought on by war. As Steven Riep describes, Ya Xian's war poetry frequently "eschews the image of the courageous soldier in favor of the suffering civilian" $(2008,51)$. The first three stanzas emphasize the intensity of the experience of being surrounded by war, in lines such as “incendiary bombs lifted up the boulevard like a fan” (燒夷彈把大街 舉起猶如一把扇子) and “soldiers / marched to the telephone poles under the windows and spread out their notices” (一些兵士 / 走到窗下電桿木前 展開他們的告示) $(2010,65-66)$. Then the poem moves into a commentary on this experience. Earlier in the poem, 我母親 'my mother' implies the presence of a speaker, and here a distinct voice emerges:

And from beginning to end

They wanted nothing more than to force you to choose a river

To go reluctantly in search of the conclusion

Or write long letters to your petite woman in another county

Or startle a field of buckwheat

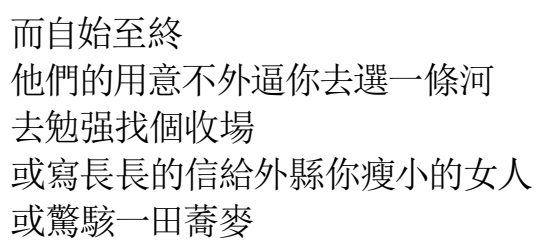

The speaker laments the lack of agency available to the victims of war. The only available options lead to death or unbearable suffering. Once again, however, in the final stanza, the poem becomes more intimate:

But these things are all finished now

The people are tired of keeping watch. And sooner or later you must participate in the 
Construction of grass. Amidst the buzzing of death

Even -

Angels are no longer required

\section{不過這些都已完成了 \\ 人民已倦於守望。而無論早晚你必得參與 \\ 草之建設。在死的管管聲中 \\ 甚至 - \\ 已無需天使}

The anxiety-ridden false choices of the previous stanza are no longer relevant, if only because "sooner or later you must participate in the / Construction of grass" - in other words, we all die eventually and even those left alive are too tired to care.

Despite the fatalistic conclusion, I detect a slight bubbling up of emotion in this final stanza. One signal of this is the punctuation: there is none in the poem until this final stanza, where it suddenly appears in the form of two mid-line full stops, before a dash in the penultimate line. These interruptions give the reader the sense of hesitation or difficulty in reaching the poem's conclusion. The repetition of 已 'already' in the first, second, and final lines of this stanza contributes to the melancholy. This is not really needed in the translation - the present perfect tense gives a similar sense of temporality - but its presence becomes important for the closing three lines, which read more literally as, "In the middle of the buzzing of death / even - / no need for angels anymore." Both the dash and the change in syntax give the impression that this line, among all the descriptions of hardship in this poem, is the one thing that manages to disrupt language itself. Highlighted by its occurrence earlier in the stanza, 已 'already' here reminds us that these changes are not firmly fixed in the past but are recent developments: the events of the poem have only just finished, and the people have grown weary of keeping watch. If the poem conveys the theme of the futility of war amidst all the suffering it causes, this disruptive emotion in the last stanza hangs in the air when the poem is finished, leaving the reader to account for its emergence.

The dominant theories of imagery in the comparison of Chinese and Western poetics do not account for juxtaposition as it works in these poems. Scholars like Yip, Pauline Yu, and Cecile Chu-chin Sun understand the juxtaposition of images to be working within a system of "affective-responsive resonance," where the poet taps into the "mutually affective dynamism 
between man and nature to generate a flow of meaning between 'feeling' and 'scene' that never stagnates" (Sun 2011, 184, 190). Sun attributes this to a Chinese worldview in which all things exist in harmony on the same plane, so rather than bringing together disparate things (as in metaphor), the poem manifests pre-existing correspondences in the world (see Yu 1987 , chapter 1 , for more on this). But as mentioned above, there is a far greater variety of approaches in the premodern Chinese tradition than this theory allows. As Kang-i Sun Chang demonstrates in her analysis of $c i$ poetry (1980), both parataxis and hypotaxis (using connectives to stipulate a temporal or logical sequence) have existed in varying degrees. And Gu Ming Dong argues that Chinese literary scholars developed mimetic theories comparable to Western ones, existing in "symbiosis" with the more prevalent expressionist theories (2005a, 475). His work exemplifies Eric Hayot's observation that, rather than granting counter-examples while insisting on a "fundamental" difference, we cannot allow the pretense of historical rigor to inhibit the flexible thinking required for comparability (2016). Nevertheless, when analyzing Ya Xian's poems, the classical Chinese idea that images can work together to achieve expressive resonance without explanatory elaboration does help us account for their avoidance of a dominant creative consciousness (in the form of a lyric voice, which is often only subtly apparent). At the same time, these poems do not assume that the reader can rely on a shared worldview to intuit meaning beyond the words; in fact, they sometimes seem to question the existence of a coherent world at all.

In contrast to the idea of juxtaposition as creating a mutual interplay of resonant parts, Sergei Eisenstein's theory of montage in film, which has also played an important role in the comparison of Chinese and Western poetics, is often viewed as promoting a form of cognitive dissonance through the juxtaposition of images. However, in Yip's use of Eisenstein's montage theory to elaborate on the workings of classical Chinese poetics, he emphasizes that both approaches preserve "spatial tension between and coexistence among" the images, avoiding the interpretive moves which, as often happens in translation, turn "visual events into statements about these visual events" (1997, 9; see Wen 1979). Indeed, Eisenstein promoted montage as a means of achieving higher-order significance from independent visual units without the use of narrative explanation. For Eisenstein, montage is a "collision" achieved "by the conflict of two pieces in opposition to each other" whether they are narrative units or visual elements in a single frame (1949, 37). Yip's claim for a connection between montage theory and Chinese poetics is buttressed by the fact that Eisenstein explores 
his theory in relationship to his understanding of Chinese characters, though it is worth mentioning that his acquaintance with them is in the context of Japanese culture. Taking a widely shared but oversimplified view of the linguistic function of the characters, Eisenstein discusses their evolution from a resemblance of objects to a combination of images in a single character, aiming to enact a similar shift in cinematography from mere depiction to expressivism. The combination of shots in montage yields not a sum, he says, but a product, a "representation of something that is graphically undepictable" from two things that are, resulting in an "intellectual cinema" (1949, 30).

This is where a key difference emerges between (certain parts of) Eisenstein's theory and the vision of classical Chinese poetics to which Yip compares it. For Eisenstein, the collision of images guides the spectator to adopt the intellectual standpoint of the artist, not the feelings of a scene which, according to Yip, pre-exists both artist and audience. Ya Xian's use of imagery, then, gives a better sense of the tension in Eisenstein's montage theory between the independence of visual units and the broader awareness that should result from their collision. In Ya Xian's case, despite the gaps of juxtaposition, the images do cohere around more abstract themes like war and memory; the reader is guided by a sense of the poet reworking his own experiences. And yet the poems do not trust in language to convey those ideas to the reader. Again, part of the problem with our definition is the comparative framework itself. We could argue that the theory of classical Chinese poetics as largely expressivist and the montage-oriented strain of Euro-American modernism are converging, as Yip does, or we could view Ya Xian's poetry on some sort of spectrum between these two visions. Either way, however, we would be leaving the binary intact.

One way forward is to consider theoretical positions as themselves existing in juxtaposition, rather than oppositional tension. Susan Stanford Friedman argues that collage (inspired by both montage and Dadaism) is a useful model for comparative analysis precisely because it "radically breaks down the hierarchization endemic to both comparison and to Eurocentric formations of global modernisms" (2012, 517). Like Osborne, Friedman stresses that in this model, equivalence does not mean blind equalizing; each text maintains its contextual specificity while being reoriented via juxtaposition with a text from a radically different context. This provides a model for how we can navigate between our different levels of analysis because, "The absolute difference - incommensurability - of texts in the collage remains while the proposed similarity - commensurability - exists 
at the level of theory produced in the act of comparative reading. Such theory ... can in turn change the reading of each text in its other contexts" (517, emphasis added). We hear the echoes of Benjamin, but we also need to remember that the Western modernist technique of collage on which this theory is modeled sought defamiliarization above all else, an "aesthetics of radical rupture" (516). Ya Xian's poems above, though grappling with a similar crisis of modernity and cultural shifts, layer their reflection on these conditions with an attempt to recover something of the past, however incompletely, in its full emotional depth. Defamiliarization is not the goal here.

Placing these various theories of juxtaposition and collage into tension with one another, following the model of Osborne's reading of Benjamin, we are reminded that our comparison can only reveal temporary insights achieved through the positing of equivalences which are always shifting. In that case, we can say that the juxtaposition of images in these poems works in much the same way as the comparison of concepts or the translation between one cultural tradition and the other. Through their juxtaposition, the images function not to radically disorient the reader or to direct their attention through the poem to some intellectual idea beyond it. Nor, in the face of massive historical rupture and cultural change, do they reassert a sense of the world's coherence and natural order. Just as translation between cultures or languages changes the terms on both sides, our juxtaposition of these theories reveals new insights into each, such as Sun's description of the "affective-responsive two-way interplay between external reality and the poet" as one where "the creative process of the poet is now reprocessed and refracted inside the mind of the reader" (211). This sounds rather like Eisenstein, who writes, "The image planned by the author has become flesh of the flesh of the spectator's risen image ... Within me, as a spectator, this image is born and grown" $(1975,34)$. Likewise, we recognize in Eisenstein's discussion of Japanese haiku and tanka poems that he puts emotional transference above the communication of abstract concepts $(1949,32)$. He also uses the language of resonance (characteristic of Sun's analysis) to describe montage as a "conflict between the principal tone of the piece (its dominant) and the overtone" (1949, 79). The use of juxtaposition found in Ya Xian's poems is closer to the Eisenstein who thinks of montage as resonances than the one who emphasizes dialectical unity. Juxtaposition here reveals emotional frequencies by breaking our cohesive sense of the social and psychological world of the subjects, but what we find by tuning in to that frequency is complex or even contradictory. In so doing, it sparks a refashioning of lyricism. 
In one last example, we see how this displacement through juxtaposition results in a lyrical emergence, even though it does not feature a third-person protagonist like the previous examples. In “Ordinary Song” (一般之歌), from 1965:

On that side of the caltrop ${ }^{3}$ is the national primary school, and beyond that is the saw mill

Next door is Auntie Su's garden; growing lettuce, corn

To the left of three maples are a few other things

Down a bit is the post office, a tennis court, then straight to the west is the bus stop

As for the clouds now floating over clothes drying in the sun

As for sorrow probably hiding just up by the railroad somewhere

It always looks like this

May has already come

So quietly accept these things without making a fuss

The 5:45 train speeds past

The river ties a beautiful knot around the bridge pilings then goes off again When grasses set out to occupy the distant graveyard

The dead never look about

And the most important thing is

On that rooftop over there

A boy is eating a peach

May has already come

No matter whose rafters eternity nests in

Quietly accept these things without making a fuss

\author{
鐵跻藜那廂是國民小學，再遠一些是鋸木廠 \\ 隔壁是蘇阿姨的園子; 種着萵苣, 玉蜀乘 \\ 三棵楓樹左邊還有一些别的 \\ 再下去是郵政局, 網球場, 而一直向西則是車站 \\ 至于雲現在是飄在曬着的衣物之上 \\ 至于悲哀或正躲在靠近鐵道的甚麼地方 \\ 總是這個樣子的
}

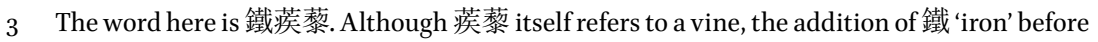
it implies that we should translate it as "caltrop," because that word can refer to both the spiny plant and the spiked metal that is thrown on the ground to puncture tires in a military context. Keeping the implication of the weapon in the line signals that the effects of war are ingrown here. 


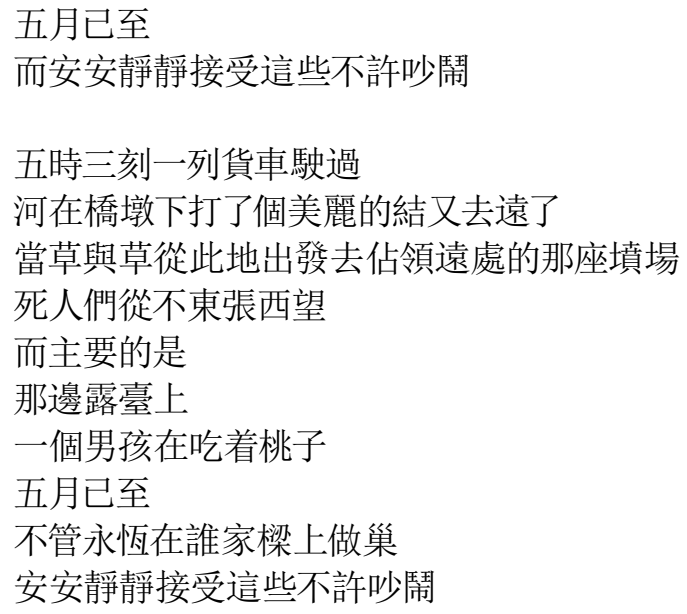

(2010, 206-207)

As the title suggests, this is a portrait of everyday life in a typical village. The images build up much like in a classical poem, but this is a modern scene, intermingling images of a lumberyard and a freight train with those of nature. Despite neither an "I" nor a "you" being mentioned, the poem implies a speaker giving descriptions to someone else. "To the left of three maples are a few other things" implies that these "things" are so ordinary that we do not even need to specify them. There is no explanation of who "Auntie Su" is, as if we already know her and are already part of her world. We have specific spatial descriptions that give us the impression of being able to picture the entire scene, but the information is insufficient to piece these descriptions into a single picture. The opening line posits the reader and speaker on the near side of the caltrop. The following line tells us Auntie Su's garden is "next door," which we could assume means next to the primary school. But where are the next line's maples in relation to the school and the garden? "Down a bit is the post office," raises a similar question: down from what? We might say, therefore, that the juxtaposition of all these descriptors in the poem sets a scene, but in such a way as to require the reader's active imagination to piece it together.

Structurally, too, we have a juxtaposition - between spatial relationships in the first stanza (between the primary school and the lumberyard) and temporal ones in the second stanza (the 5:45 train, the river, a reference to death). Although the poem asserts that "the most important thing is / On that rooftop over there / A boy is eating a peach," these lines cannot banish the quiet expressions of death and sadness from the previous lines. Indeed, just as in the earlier poems, the seeming sense of quiet is encouraged by 
the refrain of the poem, "May has already come / Quietly accept these things without making a fuss," only to be set off balance at the end, with the insertion of "No matter whose rafters eternity nests in" into the refrain. We might interpret this to say that even if the timelessness of the scene is not so timeless for us, if eternity only nestles in someone else's house and not ours (though who can stake a claim to eternity at all?) we should carry on as if we did not already know this. The first line of the refrain, "May has already come," suggests not just that winter has passed, but that May has come more quickly than expected, and we as readers are drawn into that sense of time by the use of 已 'already'. Then again, the fact that the line bears repeating, and that it needs to be interrupted by the insistence that "no matter" what, we should "quietly accept these things," indicates that it is not really that easy to calm the disquiet that may linger under the surface, the awareness of the hidden sorrow and the dead in "that distant graveyard" - which is far, yes, but close enough that we almost feel that we can see it when the speaker says 那座 'that one'.

\section{Conclusion: lyrical montage}

Through these poems we can start to identify the contours of what we might call Ya Xian's lyrical montage. Their straightforward language and familiar imagery create a fluid reading experience, making one hesitate to use the word "juxtaposition" to describe the structure. There is no sense of collision or defamiliarization between the lines here. At the same time, the logical and thematic connections between the lines remain loose. Especially in "Ordinary Song," we see how the flexibility of perspective as the reader shifts from one image to another yields a sense of sequence, but without providing a space that is coherent enough to support a distinct temporality. More significantly, while the surface of these poems appears to convey a message to the reader, the underlying impression is less intellectual than emotional, and more open-ended than Eisenstein's "dialectical unity." The Taiwanese modernist poets in general were more interested than Eisenstein was in freeing poetic imagery from didacticism (in a historical or moral sense). In their exploration of not just the limits of poetic language but also the limits of historicism itself, Ya Xian's poems spark a non-developmental dynamism in which there is no hierarchy between the concrete images and the significance that comes from juxtaposing them; they evade this mimetic function at precisely those moments when we might most expect it. 
What we learn by juxtaposing these theories of translation and crosscultural comparison is that whether we are talking about metaphor, modernism, or translation itself, all are concepts which can be more or less expansive in their definition, depending on what kinds of examples one uses to create the category. This shows both their translatability and untranslatability at the same time. In the act of comparison, cultural translation, or historical analysis, we can choose either the hierarchical view in which the original or authentic event / language / cultural object is primary, or we can choose the view that sees the two sides as mutually interactive. By reading Ya Xian's poems as the second type, I do not mean to suggest that they are simply a blend of two traditions in a way that contributes to both. Instead, I wish to emphasize the provisional, if transformative, nature of that interaction, to which we all need to be more attuned. The theories of translation and cross-cultural comparison I have discussed here - including those by Benjamin, Saussy, Eisenstein, and Friedman - all highlight the episodic manner in which that kind of change in thinking necessarily occurs, and that is the framework which helps us grasp the most lasting insight of Ya Xian's poetry. In other words, as we choose the more dialectical view of translation, we lose the certainty of meaning and reference to a stable reality (or cultural "root"), but we gain in an appreciation of the position which the poet himself occupied both linguistically and culturally. We also come to recognize a form of lyricism that, besides images, also uses pieces of a story to tap into emotional tones and overtones of the past, without pretending that we can access our social world or memory in anything other than flashes of recognition.

\section{Works cited}

Benjamin, Walter. 1996. "The Task of the Translator," translated by Harry Zohn. In Selected Writings: Volume I 1913-1926, edited by Marcus Bullock and Michael W. Jennings, 253-263. Cambridge, MA: The Belknap Press of Harvard University Press.

—. 1999. The Arcades Project, translated by Howard Eiland and Kevin McLaughlin. Cambridge, MA: The Belknap Press of Harvard University Press.

Chang Han-liang. 1985. "The Surrealist Episode in Contemporary Chinese Poetry in Taiwan, 1956-1965." In Proceedings of the Xth Congress of the International Comparative Literature Association, edited by Anna Balakian, 307-315. New York: Garland Publishing.

Chang, Kang-i Sun. 1980. The Evolution of Chinese Tz'u Poetry: From Late T'ang to Northern Sung. Princeton: Princeton University Press. 
Chang, Sung-sheng Yvonne. 1993. Modernism and the Nativist Resistance: Contemporary Chinese Fiction from Taiwan. Durham, NC: Duke University Press.

Chen Fangming. 2007. "Postmodern or Postcolonial? An Inquiry into Postwar Taiwan Literary History." In Writing Taiwan: A New Literary History, edited by Carlos Rojas and David Der-wei Wang, 26-50. Durham, NC: Duke University Press. Eisenstein, Sergei. 1949. Film Form: Essays in Film Theory, translated and edited by Jay Leyda. New York: Harcourt, Brace and World, Inc.

—. 1975. The Film Sense, translated and edited by Jay Leyda, 3-65. New York: Harcourt Brace Jovanovich.

Friedman, Susan Stanford. 2012. "World Modernisms, World Literature and Comparativity." In The Oxford Handbook of Global Modernisms, edited by Mark Wollaeger and Matt Eatough, 499-524. Oxford: Oxford University Press.

Gu, Ming Dong. 2005a. "Is Mimetic Theory in Literature and Art Universal?" Poetics Today 26 (3): 459-498.

-. 2005b. "Mimetic Theory in Chinese Literary Thought." New Literary History $36(3): 403-424$.

Hayot, Eric. 2016. “Against Historicist Fundamentalism." PMLA 131 (5): 1414-1422.

Osborne, Peter. 2000. Philosophy in Cultural Theory. New York: Routledge.

Plaks, Andrew. 1988. "Where the Lines Meet: Parallelism in Chinese and Western Literatures.” Chinese Literature: Essays, Articles, Reviews (CLEAR) 10 (1/2): 43-6o.

Riep, Steven L. 2008. "The View from the Buckwheat Field: Capturing War in the Poetry of Ya Xian.” In New Perspectives on Contemporary Chinese Poetry, edited by Christopher Lupke, 47-64. New York: Palgrave Macmillan.

Saussy, Haun. 1993. The Problem of a Chinese Aesthetic. Stanford: Stanford University Press.

Sun, Cecile Chu-chin. 2011. The Poetics of Repetition in English and Chinese Lyric Poetry. Chicago: The University of Chicago Press.

Wen Renping 溫任平. 1979. 〈電影技巧在中國現代詩裡的運用〉 [The use of film technique in modern Chinese poetry]. In《現代詩導讀》 [A reader's guide to modern poetry], edited by Zhang Hanliang 張漢良 [Chang Han-liang] and Xiao Xiao 蕭蕭, 315-356. Taipei: Guxiang chubanshe youxian gongsi.

Ya Xian 瘂弦. 1981. 《瘂弦詩集》 [The collected poems of Ya Xian]. Taipei:Hongfan shudian.

一. 瘂弦. 2010. 《瘂弦詩集》 [The collected poems of Ya Xian]. Taipei: Hongfan shudian.

Yeh, Michelle. 1991. Modern Chinese Poetry: Theory and Practice Since 1917. New Haven: Yale University Press.

- 2001. "Frontier Taiwan: An Introduction." In Frontier Taiwan: An Anthology of Modern Chinese Poetry, edited by Michelle Yeh and N. G. D. Malqvist, 1-53. New York: Columbia University Press, 2001. 
—. 2007. "On Our Destitute Dinner Table: Modern Poetry Quarterly in the 1950s." In Writing Taiwan: A New Literary History, edited by Carlos Rojas and David Der-wei Wang, 113-139. Durham, NC: Duke University Press.

Yip Wai-lim 葉維廉, ed. and trans. 1997. Chinese Poetry: An Anthology of Major Modes and Genres, second edition. Durham, NC: Duke University Press.

一. 2012. 《葉維廉五十年詩選(上 )》 [Wai-lim Yip, fifty years of poetry: selections. Part one.] Taipei: Guoli Taiwan daxue chuban zhongxin.

—. 2013. "Quest for the Right Poem: My Modernist Beginnings." Chinese Literature Today 3 (1/2): 126-133.

—. 2017. "Hong Kong Modernism and I." A New Literary History of Modern China. Cambridge, MA: Harvard University Press.

Yu, Pauline. 1987. The Reading of Imagery in the Chinese Poetic Tradition. Princeton: Princeton University Press.

Zhang Yaxin 章亞昕. 2004. 〈詩與真:亞弦的體驗〉 [Poetry and truth: Ya Xian's personal experience]. In Zhang Yaxin, 《情繫伊甸園:創世紀詩人論》 [Longing for Eden: analysis of the Epoch poets]. Taipei: Wenshizhe chubanshe.

\section{About the author}

Tara Coleman is assistant professor of English at LaGuardia Community College in the City University of New York. Her doctoral dissertation, which brings together modern Chinese-language poetry and film to explore the role of lyricism in mediating historical experience, was completed at Rutgers University in 2016. Her current projects examine the ethical, formal, and affective consequences of the interaction between poetry and visual media. She also studies critical pedagogies, particularly the role of critical reading in the college classroom. 



\title{
13 Celan's "Deathfugue" in Chinese
}

\author{
A Polemic about Translation and Everything Else \\ Joanna Krenz
}

\begin{abstract}
This essay reads three embattled Chinese renditions of Celan - by Wang Jiaxin, Bei Dao, and Yi Sha - for what they reveal about discourse on poetry and poetics, and on translation, in mainland China today. Drawing on historical context as well as images of poethood and poetry, it asks why Celan is so important for contemporary Chinese poets, and contextualizes this question in debates and polemics that go back to the 1980 s and continue today.
\end{abstract}

Keywords: Chinese poetry, translation, Paul Celan, Bei Dao, Wang Jiaxin, Yi Sha

In the mid-200os, the mainland-Chinese literary scene saw an emotional polemic on poetry translation, triggered by Bei Dao's 北岛 criticism of Chinese translations of Paul Celan, especially those authored by Wang Jiaxin 王家新. The polemic, which engaged poets from different camps, deepening divisions that go back to the 1980s and 1990s, soon evolved into what might be called a discussion about everything. In November 2017, during a poetry translation workshop in Beijing organized by Wang, I experienced firsthand how sensitive the topic of poetry translation continues to be for Chinese poets today, with Celan as a particularly striking example. Their official and unofficial conversations, in which Celan's name occurred nearly as frequently as "poetry" and "translation" - sometimes seemingly as a synecdoche for one or the other - prompted the questions that inform this essay.

Why is Celan so important for contemporary Chinese poets? Is it because he fits Chinese models, or myths, of poetry? Or, conversely, because his

Van Crevel, Maghiel and Lucas Klein (eds.), Chinese Poetry and Translation:Rights and Wrongs. Amsterdam: Amsterdam University Press, 2019 DOI: 10.5117/9789462989948_CH13 
work is expected to fill a local gap? Is it possible that Celan-in-Chinese somehow connects with local authors' experience of Chineseness in its contemporary mainland variety? Is he the Other, or the Our? If the latter, then whose, exactly?

\section{Meridian as parallel: coordinates of Celan's poetry}

In his early twenties, Paul Celan, a German-speaking Jewish poet born in 1920 in the Kingdom of Romania, experienced the cruelties of World War II, including the death of his parents in a Nazi camp. The second half of his life passed in emigration, in Austria and later in France. In 1970, bereft of friends, anguished over unfair accusations of plagiarism by Claire Goll, the widow of Yvan Goll, a German-French poet whose work Celan had once translated (cf. Meltzer 1994, 64-66; Eskin 2008, 11-14), he ended his life by throwing himself into the Seine.

Celan's poetry, written in German, his mother tongue but also the language of his mother's murderers, reflects the complexity of his personal story. Yet for all its legendary obscurity and idiomaticity, it is arguably anything but hermetic. In a famous 1960 speech on art and poetry, "The Meridian," Celan explains:

[I]t is very common today to complain of the 'obscurity' of poetry. Allow me to quote ... a phrase of Pascal's which I read in Leo Shestov: Ne nous reprochez pas notre manque de clarité, car nous en faisons profession [Do not reproach us for our lack of clarity, for we make this our business]. This obscurity, if it is not congenital, has been bestowed on poetry by strangeness and distance (perhaps of its own making) and for the sake of an encounter.

$(2003,46)$

He asserts that his poetry "has always hoped ... to speak also ... on behalf of the other ... perhaps an altogether other," while simultaneously "holding its ground ... in order to endure, call[ing] and pull[ing] itself back from an 'already-no-more' into a 'still there'" (48). This apparent contradiction is resolved in the figure of the meridian, of which Celan says:

[I] find something which consoles me a bit for having walked this impossible road in your presence, the road of the impossible. I find the connective which, like the poem, leads to encounters. 
I find something as immaterial as language, yet earthly, terrestrial, in the shape of a circle which, via both poles, rejoins itself and on the way serenely crosses even the tropics: I find... a meridian.

(54-55)

From this image can be drawn an entangled spatiospiritual geography of Celan's poetry. Here, a poetic meridian is a vertical line between opposite metaphysical poles, which provides longitudinal, horizontal coordinates that position individuals on parallels of our worldly existence, in our involvement with our environment and our interactions with others. Or, if we read the metaphor from an (inter)cultural perspective instead of an (inter)subjective one: on a line that extends horizontally from East to West, Celan's place on the earthly map is described by the vertical coordinates of his spiritual lineage and a nebulous, painful sense of history as descending from heaven to earth through human bodies. The vertical and the horizontal come together and mutually co-define in the finely woven lattice of Celan's poetic language. Once they fall apart, poetry becomes unorientable.

This meticulous entanglement is not an effect of the poet's supernatural skills, and its reconstruction does not require special talents or profound erudition on the part of the reader. It is a matter of attention, assures Celan, and adds: "Attention, if you allow me a quote from Malebranche via Walter Benjamin's essay on Kafka, 'attention is the natural prayer of the soul'" (50). Yet, in the throes of postwar polemics on literature and art which culminated in Theodor Adorno's dictum that to write (lyrical) poetry after Auschwitz is barbaric, there was little room for attentive reading. "The Meridian" was Celan's attempt to defend himself against those who accused him of taking artistic advantage of the traumatic experience of his nation; and against those, German critics among them, who tried to present him as a master of metaphor whose poetry carries a contextless, universal message for humanity. Now that politics no longer overshadows art to the extent that it did in the 1940 and 1950s, these discrepancies have become less visible. Still, scholarship to date can leave one with the impression that there are two irreconcilable Celans who give mutually exclusive answers to the same questions. One is vertical: conscious of his Jewish roots, well versed in the Bible and the Kabbalah, shaped by the unspeakable experience of the Holocaust, fighting Job-like battles with his ruthless God. The other is horizontal: torn asunder by the experience of exile, wandering between countries and languages, yearning for true dialogue based on mutual understanding. 


\section{Celan in the crossfire}

The fate of Chinese authors who suffer political oppression has been compared to that of Jewish authors during and after the Holocaust, especially in Chinese-language commentary (but also in commentary in Western languages; see, for instance, Law 2003). The case of Liao Yiwu 廖亦武, discussed by Rui Kunze in her contribution to this book, is an example of such attempts at establishing linkage between the darkest pages of Jewish and Chinese history. Among other things, it presents us with a cultural translation of trauma. First, the translation of Jewish trauma into post-1989 Chinese sociohistorical discourse by Liao and his audiences (for example, Liao often mentions Elie Wiesel and is frequently compared to him); and then, once Liao found himself in Germany - where he fled in 2011 - the retranslation of Chinese trauma into German cultural production, for instance through performances such as the theater project The Bullet and the Opium: Forbidden Biographies (Die Kugel und das Opium - Verbotene Biographien) in Berlin (Marx 2016).

I feel little enthusiasm for such comparisons, since they do no justice to the unique historical experience of either nation. Still, far be it from me to criticize the parties involved for what may well be an attempt to satisfy a basic human, psychological need. While trauma is itself unreachable through language, its terrible meaninglessness is the very factor that stimulates the production of meaning in the surrounding symbolic space, through language among other things.

The history of the contemporary Chinese poetry scene starts from the trauma of the Cultural Revolution (1966-1976), and later includes the trauma of the 1989 Tiananmen massacre. Just like the Holocaust in the West, the Cultural Revolution in China reset local literary discourse. Forced to consider everything anew, Chinese authors and critics sought inspiration in postwar literature from the West, by Jewish authors among others. Perhaps this is the main reason that today, forty years on, the force lines of the Chinese literary field are structured in ways that recall mid-twentieth-century European culture. This is indirectly confirmed by similarities in the reception of Celan's poetry in post-1976 China and post-1945 Europe. Read along the force lines of the Chinese literary field, Celan's poetry splits into patterns that are virtually identical to those identified in Western scholarship above. This is illustrated by essays on Celan by two poets who represent opposite camps on the poetry scene, Yu Jian 于坚 and Song Lin 宋琳.

Yu presents Celan as a dispirited King David singing psalms in the ruins of the temple that only his fellow sufferers of misfortune can understand. 
In this vision, Celan's poetry travels vertically between heaven, earth, and she'ol, where the dead wait for the Messiah - and it is locked in this single dimension.

I hold that what was said about translations of Celan is just a lie. He is untranslatable, in every respect. Celan is a local knowledge ...

Celan's poetry is a thing that cannot be experienced.

Perhaps some things on the surface can be translated, for example, meaning. Especially those common "politically correct" issues. Or his condemnation of violence.

But it is not where Celan's “sense” [意思] lies. This is a less important aspect of his poetry. Its core is Judaism. And Judaism is a local knowledge, even if it has great ambitions.

Auschwitz in the depths of language.

Tormented words.

His aspiration was perhaps to become the King David of words. Let readers and translators make his dream of universality come true, through radical distortion.

$(2014,4-5)$

Song's Celan, in turn, is an apostle of the universal whose metaphors traverse boundaries between East and West and between different epochs:

The poet Celan, a survivor, a Jew ... an exile in the German language, a great master of metaphor. He wrote in difficult times. Chasing away evil spirits, searching for a proper form of resistance ... he recorded an indelible testimony. At a spiritual level, his work is like a "stretto" dialogue with Hölderlin, Kafka, Tsvetaeva, and Mandelstam ... Thanks to his ingenious magic, which transforms words, after his death he still continues as a modern man.

$(2008,31)$

I should add that in discourse on poetry in China today this polarized picture of Celan emerges from multiple, more nuanced confrontations of different languages and visions over the past four decades. The field was shaped by tensions between Obscure Poetry (朦胧诗) and the Third Generation (第三代) in the 1980s, and by a high-profile polemic within the latter group in the late 1990s, between so-called Popular (民间) and Intellectual (知识分子) writing - and the force lines were drawn through 
debates on themes also central to Celan. Exile and suicide were prominent among these, because of their topicality on the Chinese poetry scene and their mythogenic potential. Both themes have long traditions in Chinese poetry and discourse on Chinese poetry. ${ }^{1}$ They combine in the ancient poet Qu Yuan 屈原, an exiled official of the state of Chu said to have taken his own life. In the late twentieth century, an entanglement of the exile and suicide myths is found in Gu Cheng 顾城, a key representative of Obscure Poetry. Gu killed himself in 1993 while living in exile in New Zealand, after having murdered his wife Xie Ye 谢烨.

After 1989, exile became something of a generational experience of authors associated with Obscure Poetry. Among the most prominent, Bei Dao, Yang Lian 杨炼, and Duo Duo 多多 settled abroad due to the credible threat of persecution and limitation of their artistic freedom. Also, several Third Generation poets, most of whom would later be associated with the Intellectual camp, lived abroad for extended periods. Among them were Wang Jiaxin and Song Lin. Others chose what was called "inner emigration" in wartime Germany, meaning mental dissociation from the social-political environment in which one is physically based. These various forms of emigration provoked aggressive reactions by members of what would later be known as the Popular camp, whose tacitly recognized leaders were Yu Jian and Han Dong 韩东. In the 1990s, their attacks centered on Wang Jiaxin. Wang's emigrant episode in London - where he lived in 1992-1993 - and his professed brotherhood with Western and Russian emigrant poets were ridiculed as pseudo-exile by Yi Sha 伊沙 among others.

The suicide theme received a powerful impulse after Haizi 海子 killed himself in March 1989, at age twenty-five. He was called a martyr of poetry, and his death was attributed to solitude and spiritual banishment, as inherent parts of the poet's fate. Widely associated with the end of the high-culture fever (文化热) of the 1980s, Haizi's decision was seen as transcending individual tragedy. And along with exile, suicide soon became a foundational myth of what would in the late 199os be called Intellectual writing. In the emerging Popular camp, voices argued in defense of a personal, intimate death, as opposed to a faceless, shareable death. Many other discussions derived from, or recombined, the threads of exile and death-and-suicide.

In light of the above, in the case of Celan's poetry, the task of the Chinese translator appears particularly daunting. First, because of this poetry's sheer difficulty. Second, because of a perennial issue in literary translation that is

1 See van Crevel 2008, chapters 1 and 12 (poetical debates on the contemporary Chinese poetry scene), 4 (exile), and 3 (suicide). 
made especially acute by the intensity of poetical debate in China: to what extent should - and can - the translator disentangle themselves from local literary discourse and speak from the source instead? Third, and related: to what extent is the translator willing, or do they desire, to sacrifice the discursive benefits of working along the force lines of the Chinese literary field? The latter two issues appear particularly complex for translators who identify as poets and are involved in local polemics, as is true for those whose renditions we will consider here: Wang Jiaxin, Bei Dao, and Yi Sha - and it is, of course, precisely for this reason that they offer direct insight into current Chinese discourse on poetry.

\section{The debate}

Scattered Chinese translations of poetry by Celan - from the German source texts and via intermediary English versions - appeared in Taiwan, Hong Kong, and China in the 1970 s and the 1980 s, the earliest authored by Wai-lim Yip 葉維廉 (1976) and Qian Chunqi 钱春绮 (Qian and Gu 1988). Their circulation was limited, but they ignited sinophone readers' interest in the author of "The Meridian." In the early 1990s, Wang Jiaxin translated a few dozen poems via English. Around the same time, Zhang Zao 张柊 was translating Celan from the German. Trained in German literature and then based in Germany, Zhang was another poet who was later associated with the Intellectual camp. Some of his translations were published in Today (今天) in $1991 .^{2}$ The first collection of Celan's poetry in Chinese, translated by Wang in collaboration with Rui Hu 茌虎, a scholar of German literature, came out in 2002. For a time it went unchallenged on the domestic poetry scene, perhaps because the Popular camp was keeping its distance from foreign authors, and most Popular authors couldn't comment on the translations inasmuch as they did not read German or English. But in 2004, in “Celan: It's Time for the Stone to Blossom” (策兰: 是石头要开花的时 候), Bei Dao, then living in the US, criticized the work of Wang, Qian, and Zhang, focusing especially on Wang's and Qian's renditions of "Deathfugue" (Todesfuge), and offering his own.

Bei Dao's essay elicited an emotional reply from Wang in the same year, in “Something Hidden or Kept Secret: Answering Bei Dao" (隐藏或保密了

2 Eight poems translated by Zhang were first published in the second issue of Today in 1991. In 2015, they were reprinted in a collection of Zhang's translations (3-15). 
什么: 对北岛的回答). ${ }^{3}$ This set the tone for a "total" debate that was soon joined by several voices from the Popular camp. The aforesaid existential threads of the literary discourse reemerged - most of all those on exile and death-and-suicide - and the original rhetoric of the two camps was recycled for addressing the issue of translation. The most conservative among the Popular authors, like Yu Jian, stuck to their guns. To them, more translations merely meant more evidence of the untranslatability of Celan, if not of poetry per se. But others tried to incorporate translation as an integral part of their literary strategies. Working with his wife Lao $\mathrm{G}$ 老 $\mathrm{G}$ (who reads English), Yi Sha proposed another relay translation of "Deathfugue" in the 2013 anthology When You Are Old: New Translations of 100 World-Famous Poems (当你老了: 世界名诗10o首新译). Together, Wang Jiaxin's, Bei Dao's, and Yi Sha's renderings of "Deathfugue" constitute a fascinating record of the debate. On the textual surface, between the wounds and scars of Celan, we find traces of the translators' struggles with themselves and, sometimes, with each other. ${ }^{4}$

Not just on the Chinese literary scene, "Deathfugue" is itself a poem that encourages, and actually embeds, discussion on translation. Celan wrote it in German in 1944 as "Todestango" (Deathtango), but it was first published in 1947, in a Romanian translation called "Tangoul Morții” by Celan's friend Petre Solomon. The German source text appeared in 1948. The poem's three-year voiceless existence, between its writing and its first publication, and its one-year banishment into another language, after which it was modified and renamed by its author, are an integral part of the text. Almost every phrase in the poem reminds one of the shocking non-obviousness of Celan's choice to write in German.

Below I cite the German source text and John Felstiner's translation, which I find the best of the various English renditions I have seen, and the most non-obvious. Wang Jiaxin's and Bei Dao's essays on translating Celan show that they were familiar with Felstiner's translation and his commentary on Celan's work. They also consulted Michael Hamburger's translation (Celan 1972, 33-34 or later editions). Yi Sha does not list his sources. His phrasing often appears to reflect Hamburger's word choice and

3 Bei Dao's essay was first published in Harvest (收获) 2004 (4), and Wang's response appeared in Red Rock (红岩) 2004 (6). Here, I cite Bei Dao's essay as reprinted in Bei Dao 2011, and Wang's response according to Wang 2008, where it was republished with some changes as "Something Hidden or Kept Secret: Taking Issue with Bei Dao” (隐藏或保密了什么: 与北岛商榷).

4 Translations of Celan published in Taiwan and Hong Kong will not be considered here, because the issues under scrutiny are part of mainland-Chinese discourse on poetry; because Qian Chunqi did not enter the debate, I will not dwell on his translations. 
syntax. However, he translates "Germany" as the slightly archaic Deyizhi 德意志, which is phonetically closer to the German Deutschland than the currently more common Deguo 德国; this suggests he may also have read Felstiner's translation or Jerome Rothenberg's (Celan 2005, 46-47), both of which retain Deutschland and a few other expressions in German.

\section{Todesfuge}

Schwarze Milch der Frühe wir trinken sie abends

wir trinken sie mittags und morgens wir trinken sie nachts

wir trinken und trinken

wir schaufeln ein Grab in den Lüften da liegt man nicht eng

5 Ein Mann wohnt im Haus der spielt mit den Schlangen der schreibt der schreibt wenn es dunkelt nach Deutschland dein goldenes Haar

Margarete

er schreibt es und tritt vor das Haus und es blitzen die Sterne er pfeift seine Rüden herbei

er pfeift seine Juden hervor läßt schaufeln ein Grab in der Erde er befiehlt uns spielt auf nun zum Tanz

${ }^{10}$ Schwarze Milch der Frühe wir trinken dich nachts wir trinken dich morgens und mittags wir trinken dich abends wir trinken und trinken

Ein Mann wohnt im Haus der spielt mit den Schlangen der schreibt der schreibt wenn es dunkelt nach Deutschland dein goldenes Haar Margarete

15 Dein aschenes Haar Sulamith wir schaufeln ein Grab in den Lüften da liegt man nicht eng

Er ruft stecht tiefer ins Erdreich ihr einen ihr andern singet und spielt er greift nach dem Eisen im Gurt er schwingts seine Augen sind blau stecht tiefer die Spaten ihr einen ihr anderen spielt weiter zum Tanz auf

Schwarze Milch der Frühe wir trinken dich nachts

${ }^{20}$ wir trinken dich mittags und morgens wir trinken dich abends wir trinken und trinken ein Mann wohnt im Haus dein goldenes Haar Margarete dein aschenes Haar Sulamith er spielt mit den Schlangen Er ruft spielt süßer den Tod der Tod ist ein Meister aus Deutschland ${ }^{25}$ er ruft streicht dunkler die Geigen dann steigt ihr als Rauch in die Luft dann habt ihr ein Grab in den Wolken da liegt man nicht eng 
Schwarze Milch der Frühe wir trinken dich nachts wir trinken dich mittags der Tod ist ein Meister aus Deutschland wir trinken dich abends und morgens wir trinken und trinken der Tod ist ein Meister aus Deutschland sein Auge ist blau er trifft dich mit bleierner Kugel er trifft dich genau ein Mann wohnt im Haus dein goldenes Haar Margarete er hetzt seine Rüden auf uns er schenkt uns ein Grab in der Luft er spielt mit den Schlangen und träumet der Tod ist ein Meister aus Deutschland

35 dein goldenes Haar Margarete dein aschenes Haar Sulamith

(Celan 2013, 36-38)

\section{Deathfugue}

Black milk of daybreak we drink it at evening we drink it at midday and morning we drink it at night we drink and we drink we shovel a grave in the air there you won't lie too cramped

5 A man lives in the house he plays with his vipers he writes he writes when it grows dark to Deutschland your golden hair Margareta he writes it and steps out of doors and the stars are all sparkling he whistles

his hounds to come close he whistles his Jews into rows has them shovel a grave in the ground he commands us play up for the dance

10 Black milk of daybreak we drink you at night we drink you at morning and midday we drink you at evening we drink and we drink A man lives in the house he plays with his vipers he writes he writes when it grows dark to Deutschland your golden hair Margareta

15 your ashen hair Shulamith we shovel a grave in the air there you won't lie too cramped

He shouts jab this earth deeper you lot there you others sing up and play he grabs for the rod in his belt he swings it his eyes are so blue jab your spades deeper you lot there you others play on for the dancing

Black milk of daybreak we drink you at night

${ }^{20}$ we drink you at midday and morning we drink you at evening 
we drink and we drink

a man lives in the house your goldenes Haar Margareta your aschenes Haar Shulamith he plays with his vipers He shouts play death more sweetly this Death is a master from Deutschland

${ }^{25}$ he shouts scrape your strings darker you'll rise then as smoke to the sky you'll have a grave then in the clouds there you won't lie too cramped

Black milk of daybreak we drink you at night we drink you at midday Death is a master aus Deutschland we drink you at evening and morning we drink and we drink

$3^{0}$ this Death is ein Meister aus Deutschland his eye it is blue he shoots you with shot made of lead shoots you level and true a man lives in the house your goldenes Haar Margarete he looses his hounds on us grants us a grave in the air he plays with his vipers and daydreams der Tod ist ein Meister aus Deutschland

35 dein goldenes Haar Margarete dein aschenes Haar Sulamith

(Felstiner 1995, 31-32)

\section{How (not) to translate Celan: what poets say about translation}

Bei Dao writes of Wang Jiaxin's ${ }^{5}$ translation: “[D]egrading ['Deathfugue'] to such an extent that it proves inferior even to sanwen [散文] - what a pity for Chinese readers who may thus see in Celan anyone but the great master of language" $(2011,353)$. Sanwen can be translated as "prose" or as "essay," with "essay" best reflecting specific features of Wang's work: poetically almost unprocessed, semantically underdetermined language that the reader needs to fill with inter- and extratextual knowledge. In his rejoinder, Wang does not deny Bei Dao's observation. Instead, he turns it to his own advantage in his critique of what he sees as Bei Dao's lack of empathy, solidarity, and emotional imagination:

Bei Dao is blind to all of this. Maybe for him poetry is just lyricism, metaphor, and image. Maybe it is precisely this disbelief in the capacity of

5 Bei Dao speaks of Wang and Rui's translation, but Wang claims the translation as his own and says Rui "checked my translations meticulously against the German source text, but in 'Deathfugue' he did not make any essential changes" $(2008,36)$. 
poetry that makes him criticize others' translations for being sanwen-ized, or "even less than sanwen."

$(2008,41)$

To Bei Dao, poetry is almost absolutely translatable, without taking recourse to non-poetic techniques. Perhaps this is a consequence of his poetics at large, which was influenced by Russian Formalism's emphasis on the power of form and the poetic function of language, as Jacob Edmond shows elsewhere in this volume. And notably, to some extent, Bei Dao's view is in line with Celan's argument in "The Meridian," where it is poetic language that synchronizes the poet's physical and spiritual geographies. But, Celan reminds us, this can happen only if this language satisfies two conditions: attention - or, rephrased in terms of attitude, attentiveness - as opposite to what the author calls automaton, and openness to the Other. In these respects, Bei Dao's approach raises questions. He holds, for example, that the Chinese language itself is inherently "suitable for translation," especially the translation of poetry, and that the grammatical and lexical material it offers is "flexible and varied, and draws on everything that is around; except for neologisms and puns, which are always difficult to render, it is almost omnipotent" (2011, 353).

Bei Dao's confident and, as one might say in the present context, almost automatic conclusion is based on his observation that Mandarin easily handles one of the most perplexing problems faced by German-English translators, i.e. what Felstiner describes as "the irreconcilable paradox embedded in the two halves of Celan's genitive, Fugue of Death," which in English "loses the German genitive's compactness - Todesfuge - the compact, so to speak, between order and rupture, the word's two sides" (1986, 253-257). Bei Dao writes that in Chinese this compactness is "very natural (很自然).” The nouns for death (死亡) and fugue (赋格) can be directly paired without any unsightly "grammatical glue" (语法胶) like the English of $(2011,353)$ - fortuitously removed by Felstiner, but present in other English renditions.

It is doubtful whether Bei Dao, who notes that he understands but a single word (Deutschland 'Germany') of the German source text, would have realized this point if it were not for Felstiner's essay, but it features prominently and assumes the status of a stylistic principle in his poetics of translation. This is evenly pointed out by Wang Jiaxin in "Something Hidden," and later put more forcefully by Huang Canran 黄灿然, a poet originally from Fujian then living in Hong Kong, who has translated Celan himself (but not "Deathfugue"; for his translations of other poems, see Celan 2010). 
Huang observes that Bei Dao, while "perfecting" extant translations of poems by Rilke and Lorca, deletes all instances of 的, an (optional) subordinating marker of attribution or possession in Chinese, and other function words; and that this is presumably in order to make his idiom approximate the conciseness of classical Chinese (2006).

Also, while modern Chinese offers interesting solutions for some lexical issues in the translation of "Deathfugue," Bei Dao does not discuss them. For example, in the source text, 1l. 7-8 contain the macabrely meaningful internal rhyme Rüden (hounds) + Juden (Jews). Felstiner finds it impossible to transfer this, so he substitutes it with another rhyme: close + rows. In Chinese the source rhyme is translatable into a graphic or visual rhyme, no less macabre than its acoustic counterpart. The first character of the word for Jew (犹太人) consists of a (loosely) phonetic element 尤 plus a (loosely) semantic component $X$, and the latter is a variant of the character 犬 ‘dog, hound'. Additionally, the phonetic element 尤 bears a striking visual resemblance to 犬.

Another challenge for the English translator is the recurrent, ominous alliteration of Schlangen 'snakes' and schreiben 'write'. For Schlangen Felstiner uses the semantically narrower term vipers, in assonance and near-alliteration with "writes." Here, too, Chinese offers a solution, which is used by Wang Jiaxin: she 蛇 'snake' and shuxie 书写 'write'. Bei Dao opines that this should be adjusted to xie xin 写信 'write a letter'. As Wang notes, this is needlessly narrow and indefensibly disambiguating.

Bei Dao's belief in the near-absolute translatability of poetry (into Chinese) appears to be based on a belief in the limitless potential of the Chinese language, and of his own poetic idiom - which leads to a notable, sinicizing convergence of the idiolects of Celan, Rilke, and Lorca, particularly in their rhythmical patterns. This is unacceptable to Wang Jiaxin and Yi Sha. In "Something Hidden," starkly different from Bei Dao's self-confidence, Wang writes:

I realize that to gain insight into Celan's work will take my entire life. It requires faithfulness and patience, that "secret love hidden from people's eyes." It requires constantly returning to Celan's untranslatable vocabulary and his darkness, until it is finally lit up or we arrive at a more profound understanding.

$\left(2008,5^{0-51)}\right.$

Yi Sha takes translatability for granted, like Bei Dao, but that is their only commonality (Yi Sha and Lao G 2013, 1-3). In Yi Sha's opinion, present-day 
translations into Chinese are hampered by the presence of the translator's idiolect across all of their various translations, and by basic linguistic misunderstandings. But while he points out countless "self-evident mistakes" in translations by others (2), he himself makes such mistakes as well. In “Deathfugue," for example, he renders ll. 6-7 as 他写道: 黑暗正在降临 德意志, 你的金发的玛格丽特 / 他写信, 然后走出门去, 满天繁星闪炼 'He writes: darkness descends on Germany, your golden-haired Margarete / He writes a letter, and then goes out, the sky is full of sparkling stars'. Lexico-semantic problems aside, Yi Sha's use of punctuation suggests a vision of translation in which shortening the distance between the author and his contemporary (Chinese) audience requires stripping the poem of ambiguity and limiting its discursive versatility. Instead, in line with his own Popular-poetic style, he refocuses the poem around simple, straightforward language, presumably because he considers this comprehensible to any reader.

\section{Sense, sound, and strain: what translation says about poets}

One salient feature of Wang Jiaxin's translations is a consistent effect of estrangement. Through the long lines of Wang's "Deathfugue," the reader wanders as if through spacious arcades, open-ended like those in the eponymous project of Walter Benjamin, whose translation theory Wang often cites: the poem's windows are open for various contexts to enter, so the wanderer can pick and choose. However, one must tread carefully because the ground is uneven, irregularly paved with what Bei Dao might consider "prosaically" or "essayistically" scattered words.

There are several areas where Wang seems especially cautious, perhaps because he feels the turbulence caused by the draught of the extratextual "sense" in the poem's arcades. There, he appears to slow down, in order for his readers to consciously consider the consequences of their intervention in the text, just like the translator has done. The pace decreases most dramatically where Wang introduces the poem's protagonists. There, the language is belabored and borders on being awkward, especially when juxtaposed with Bei Dao's polished phrases. Consider, for example, Wang's rendition of $A /$ a man [who] lives in a house (1l. 5, 13, 22, 32). Bei Dao translates concisely, omitting the verb: 那屋子里的人 'a person in the/that house'. Wang translates more literally and meticulously: 住在那屋子里的男人 'a man who lives in the/that house', as if the translator paused to observe. Whereas Bei Dao starts the sentence with 那屋子里 'in the/that house', Wang 
begins with the verb 住 'live' (in the sense of reside), shifting focus from the surroundings to the protagonist. This shift is even more pronounced in $\mathrm{Yi}$ Sha's version, which opens with 一个男人 'a man': 一个男人呆在屋子里 'a man stays in a/the house'.

In Bei Dao's rendition, Der Tod ist ein Meister aus Deutschland, the poem's signature phrase, becomes 死亡是来自德国的大师 'Death is a/the master who comes from Germany / whose origins lies in Germany', suggesting the master is of German descent. Yi Sha follows the same sentence pattern, but renders the German der Tod 'death' as 死神, a common expression for death in a general sense but literally "god of death," and Deutschland 'Germany' as 德意志, as noted above. Wang has 死亡是一位从德国来的大师 ‘Death is a master who comes / has come from Germany', which may or may not mean that Death is German. Death might be a demon without a homeland, who sojourns wherever he - with the masculine pronoun reflecting Der Tod in the original - is invited. Again, Wang seems to carefully examine this passerby, giving the reader time to consider various interpretations and implications.

And this matters a great deal, as is clear from Wang's analysis of the lines where Margarete and Sulamith appear: "dein goldenes Haar Margarete / dein aschenes Haar Sulamith." Bei Dao and Yi Sha have 你 [ 的] 金发的玛 格丽特 / 你 [ 的] 灰发的素拉米斯 'your golden-haired Margarete / your ashen-haired Sulamith' (Yi Sha with the subordinating marker 的, Bei Dao without it), bringing out the physical presence of the women as well as their belonging to, or being owned by, another person, probably the man who writes. Wang translates: 你的金色头发玛格丽特 / 你的灰色头发 素拉米斯 ‘your golden hair Margarete / your ashen hair Sulamith', where the women's hair is the grammatical subject, not the women-as-persons. According to Wang, Margarete and Sulamith are "carriers of different hair, different ethnicity, different stories" $(2008,41)$. He presents an insightful analysis of relationships between the writing man and the two women, showing how the women's (de)subjectivization and (de)individualization operate in the poem.

Sensitive to the slightest flow of "substance" from the textual to the lived and from the lived to the textual, Wang scrutinizes the poem in order to determine whether its words and phrases matter in and of themselves as elements of physical or spiritual reality, or rather function as figures of speech or tropes. Unlike Bei Dao and Yi Sha, he detects the metaphorical implications of "golden hair" and "ashen hair," and realizes the literalness of another forceful image: the smoke from the cremation furnaces, the final element of the genocidal machinery of the concentration camps. Bei Dao 
and Yi Sha interpret as in "he shouts scrape your strings darker you'll rise then as smoke to the sky" as signaling a comparison. They use the word 像 '(just) like' to narrate what is going to happen to the Jews. Rising like smoke to the sky has much less dramatic connotations than rising in the form of smoke - indeed, it could even be taken as an allegory for a soul released and ascending to heaven. Wang's translation leaves no room for doubt: 尔后你 们就会化为烟雾升向空中 'then you will turn into smoke and rise to the sky'. Preceded by this image, the image of the dead "lying not too cramped" (不拥挤) reveals its dark irony.

Conversely, Wang also strays from the original, sometimes more so than Bei Dao and Yi Sha. In l. 24 his translation of the English play (for the German spielen), which can mean "play music / a musical instrument," "play a game," "perform a role," or "have fun, amuse oneself," stays close to the latter meaning. Rather than, for instance, something like 更甜蜜演奏死 亡 'play Death more sweetly', as if Death were a piece of music, he renders the line as 更甜蜜和死亡玩 'play more sweetly with Death', just like the playing with the snakes elsewhere in the poem. Bei Dao and Yi Sha steer clear of this pitfall. Another image that is distorted in Wang's translation is that of the Jews playing musical instruments to accompany the dancing. In Wang's version, this changes into a scene where the Jews themselves play and dance (表演跳舞 'play and dance' and 给我们跳舞 'dance for us'). In a third example, for the bullet that "shoots you level and true," unlike Bei Dao and Yi Sha, Wang does not provide the technical detail that the bullet is made of lead, but focuses on the person shooting, repeating the pronoun: 他 用子弹射你他射得很准 'he shoots you with a bullet he shoots accurately'.

Aside from the question of whether these omissions are intentional, they appear to mirror the translator's rhythm of thought. Notably, this resembles the rhythm of Celan's own vocal interpretation, ${ }^{6}$ though Wang says he has never listened to or viewed any audio or video recording of the poet's recital. Bei Dao mentions one such recording, calling Celan's diction as "now plain, now shrill" $(2011,354)$. It would seem to me that Wang more adequately reproduces the musical effect of the poem in German as recited by Celan, even if this effect is not generated by the musical properties of the translator's language. Where Celan modulates his tone, as if imitating the orders of the camp guards, Wang speeds up, or rather: his thought appears to accelerate. Line length does not decrease significantly - on average Wang's lines are longer than those in the source text by two to four syllables - but

6 Paul Celan's reading of "Todesfuge" is available online, e.g. at bit.ly/2GmJreg (accessed March $25,2018)$. 
the translator becomes limited in his semantic scope, less equivocal and more concrete. Where Celan's recital becomes mesmerizingly monotonous, Wang's translation generates ambiguity, allowing all kinds of context to enter the poem.

Yi Sha's lines are long too, in some cases as many as ten syllables longer than the source text, as we see in l. 4: 我们用铲子在空中挖出墓穴在那里 你躺下不会觉得太窄 'with shovels we dig a grave in the air [when] you lie down there you will not find it too narrow'. The (co)verb 用 'use' or 'with', the verb 觉得 'think, reckon, find, feel', and the directional complement 下 'down' have no lexical anchorage in the source text. Theoretically, these modifications should dynamize the scene. But the dynamic of Yi Sha's translation does not make the action more vivid. Rather, it functions as a microdynamic that works within individual actions and makes these more strained and more physical. Sometimes, this leads to near-tautology (e.g. dig a grave using shovels), and sometimes to complication: the dead are said to lie down and perceive their grave in a particular way, which grants them an agency that is not there in the original.

YiSha's translation hinges on its description of concrete actions. Occasionally, these break down the visual and acoustic structures of the source text, reconfiguring lines and adding line breaks and pauses between more or less obvious recitation units: reading the long 1.4 naturally in one breath, as Celan does in the recording, would be difficult in Yi Sha's translation. His earthly, straightforward phrases are also less likely to become contextually active in the way they do in Wang's translation. If any abstract or metaphysical meaning manages to flow into the poem between one move of the shovel and the next, it is turned back to its universal physical, prelingual source, and presented as an extension of palpable, lived reality.

Yi Sha's rendition is not unlike that of Qian Chunqi, which both Wang Jiaxin and Bei Dao consider stylistically awkward: lacking the right rhythm (Wang 2008, 39; Bei Dao 2011, 351), "imperfect" (Wang 2008, 39), and "sluggish" (Bei Dao 2011, 352). Qian also tends to produce more concrete, fixed images than those in the source text, through his word choice and by using multiple spacing within lines, which has an effect that is similar to that of punctuation. Wang defends him, noting that his imperfection is that of a pioneer and the inelegance of his rendition should be forgiven $(2008,39)$. Yi Sha's heavy style is not so much that of a pioneer as that of an engineer who tries to make the gravity of the language work for their own project.

Remarkably, the lines in Bei Dao's translation are usually two to four syllables shorter than Celan's, even though translations often avail themselves of extra descriptive elements lest too much content be lost. But Bei 
Dao occasionally sacrifices sense for sound, presumably to make the text run more smoothly and rhythmically - in musical not semantic terms. However, this is not necessarily in sync with Celan's voice. Unlike Wang, Bei Dao encourages the reader to surrender to the translator's rhythm, rather than co-shape it by adding their own semantic "beats." The most evident manifestation of Bei Dao's emphatic presence as a translator appears in the final passage of his interpretation of "Deathfugue." Here he appropriates its aforesaid, dramatic signature phrase almost as background music to his essay, interspersing his final sentences with the refrain: "Death is a master from Germany" (2011, 354). Wang Jiaxin objects:

I think, were Celan still alive, hearing his poetry repeated again and again, he would be upset. Because he wasn't one to play on people's heartstrings ... He never wished to expose his suffering to earn people's compassion, and never presented the Holocaust to assert the moral superiority of the Jewish nation. Instead, by arriving at the core of the language, by digging deeply in search of an individual voice, he began his heavenly journey. Why not see this? Why not respect it?

$(2008,46)$

\section{So?}

In the context of contemporary Chinese poetry polemics, from the three Chinese renditions of "Deathfugue" emerge two Celans - an "Intellectual," horizontal Celan who begs for better understanding, and a "Popular," vertical Celan whose secrets the reader is asked to dig for in a grave, deeply and tautologically: "using shovels." Two Celans, and one Bei Dao, who positions himself outside the Chinese poetry scene and tries to reconnect the two Celans through polished phrases without grammatical glue. Bei Dao produced his translation before Yi Sha. But he knew Qian Chunqi's and borrowed from its down-to-earth yet linguistically precise awkwardness as much as he borrowed from the "prosaic" or "essayistic" nature of Wang Jiaxin's rendition, aiming to balance and re-entangle the two dimensions of Celan's writing.

Bei Dao's approach has its merits. Minimally, it was not unrelated to Celan's own (impossible) ideal of poetry as laid out in "The Meridian." Would Bei Dao's translation have been more successful if it had displayed more attention, in Celan's terms? Perhaps, but not necessarily. Later, Meng Ming 孟明, translating from the German, adopted a similar approach, in 
his bilingual Selected Poems of Paul Celan (保罗.策兰诗选), published in Taiwan in 2009 and republished in China in 2010. Instead of privileging his own idiolect, Meng relied on idiomatic classical Chinese. But he, too, failed to integrate the coordinates of Celan's oeuvre for good. Something stronger than language split them again, as is in evidence in Yu Jian's and Song Lin's diametrically opposed essays - both of which refer to Meng's translations.

Or might this be a matter not of strength, but of method? In one of Celan's last works, "Place-Change" (Ortswechsel), dedicated to the Israeli writer Ilana Shmueli, whom Celan loved platonically, he gives yet another, now almost "other-shorely" interpretive hint, and leaves the reader with the shortest, most essential question. In Susan Gillespie's translation:

PLACE-CHANGE among the substances:

you, go to you, join in

with missing

earthlight,

I hear, we were

a heavenly bloom,

this is yet to be proven, from

somewhere on high, along

our roots,

two suns, do you hear, there are

two,

not one -

so?

(Celan 2011)

Rereading the polemic through this poem may prove instructive for understanding the misunderstanding of Celan in China. It is a coincidence, but a telling one, that "Place-Change" offers a picture that visually and conceptually constitutes a reversal of, and perhaps a remedy for, the clichéd myth of Tang-dynasty poet Li Bai. Believed to have drowned when attempting to embrace the moon's reflection on the surface of a river, he is supposed to have died the most poetic death in history, in which his spirit reached its apogee. The myth still haunts the Chinese poetry scene, but it does no justice to Li Bai and it does not benefit today's poets. Celan's proposition is radically different. Instead of imitating Li Bai, cultivating poethood, and 
quarreling about whose garden pond has the prettier or more moon-like reflection of the moon, it might be refreshing to engage in a "place-change," if only for a moment, for the duration of a poem; and, instead of writing/ reading/translating along the force lines of the earthly literary field, to try to do so "along [the] roots" that are above our heads. This way, one might be able to collect the "missing earthlight" from the moon's surface to arrive at a more complete and more transparent image of (Celan's) poetry, and - looking through poetry's eyes - a more complete and more transparent picture of the world.

Controversy surrounding the translation and reception of Celan is not a specifically Chinese problem. I believe it occurs in the literatures of many languages (e.g. German, English, Polish, and Russian, to mention only the other languages I read). At the same time, it lays bare issues that are specific to particular, local discourses. There is an apparent paradox in Celan's poetry. It manages to embrace the universal, and it is exceptionally prone to "local diseases." His poems are powerful, in that they shake our structures of feeling and thinking, and they are vulnerable, in that tiny cuts on their skin that have not yet turned to scars are easily contaminated by scattered pieces of the structures they shake loose - uncontrolled threads of discourse and emotions - and they fester and grow, and tear the text apart.

For the translator, Celan's work is a touchstone of artistic craftsmanship and attentiveness, but even more one of intellectual and spiritual freedom. The same may hold for the entire literature of the target language in question. Poems like "Deathfugue" work as tiny, hypersensitive litmus papers, revealing to what extent the host literature has the ability to take a leap of transcendental imagination to reach for the "heavenly bloom," without tripping over its own polemics, biases, and expectations at large.

\section{Works cited}

Bei Dao 北岛. 2011. 〈策兰: 是石头要开花的时候了〉 [Celan: it is time for the stone to blossom]. In: 《北岛作品精选》 [Selected poems by Bei Dao]. Wuhan: Changjiang wenyi chubanshe, 347-375.

Celan, Paul. 1972. Paul Celan: Selected Poems, translated by Michael Hamburger and Christopher Middleton. Harmondsworth: Penguin Books.

- 2003. Collected Prose, translated by Rosemary Waldrop. New York: Routledge.

- 2005. Paul Celan: Selections, edited by Pierre Joris, various translators. Berkeley and Los Angeles: University of California Press. 
—. 2009. 《保罗策兰诗选》[Selected poems by Paul Celan], translated by Meng Ming 孟明. Shanghai: Huadong shifan daxue chubanshe.

—.2010. 〈保羅·策蘭詩七首〉 [Seven poems by Paul Celan], translated by Huang Canran 黄灿然. 《字花》 26, 123-125.

-. 2011. "Change-Place" (Ortswechsel). In: "From The Correspondence of Paul Celan and Ilana Shmueli," translated by Susan H. Gillespie, American Poetry Review 1, 25-33.

—. 2013. Psalm und andere Gedichte / Psalm i inne wiersze [Psalm and other poems], bilingual, selected and translated by Ryszard Krynicki. Kraków: a5.

Eskin, Michael. 2008. Poetic Affairs: Celan, Grünbein, Brodsky. Stanford: Stanford University Press.

Felstiner, John. 1986. "Paul Celan's Todesfuge." Holocaust and Genocide Studies 2-1: 249-264.

-. 1995. Paul Celan: Poet, Survivor, Jew. New Haven: Yale University Press.

Huang Canran 黄灿然. 2006. 〈粗率与精湛 (上、下)〉 [The coarse and the exquisite (part 1 \& 2)]. 《读书》7, 148-159 \&《读书》8, 133-136.

Law, Kam-yee, ed. 2003. The Chinese Cultural Revolution Reconsidered: Beyond Purge and Holocaust. Basingstoke: Palgrave Macmillan.

Marx, Johanna, Bettina Hoppe and Mario Röllig. 2016. Die Kugel und das Opium: Verbotene Biographien. Ein Theaterprojekt mit Texten von Liao Yiwu (The Bullet and the Opium: Forbidden Biographies. A Theater Project with Liao Yiwu's Texts). Berlin: Stephan-Knies-Produktion.

Meltzer, Françoise. 1994. Hot Property: The Stakes and Claims of Literary Originality. Chicago: The University of Chicago Press.

Qian Chunqi 钱春绮 and Gu Zhengxiang 顾正祥, ed. and trans. 1988. Selected German Lyric Poetry (德国抒情诗选). Xi'an: Shaanxi renmin chubanshe.

Song Lin 宋琳. 2008. 〈幸存之眼 - 读策兰的诗〉 [The survivor's eye: reading Celan's poetry]. 《外国文学》6, 25-31.

van Crevel, Maghiel. 2008. Chinese Poetry in Times of Mind, Mayhem and Money. Leiden: Brill.

Wang Jiaxin 王家新. 2008. 〈隐藏或保密了什么: 与北岛商榷〉 [Something hidden or kept secret: taking issue with Bei Dao]. In: 《为凤凰找寻栖所》[Find a perch for the phoenix]. Beijing: Beijing daxue chubanshe, 34-53.

- 2009. 〈为了保罗. 策兰 - 在台北德国文化中心的讲演〉 [For Paul Celan: a lecture at the Taipei Center for German Culture]. Poemlife. bit.ly/2Zo8St1. Accessed June 16, 2018.

Yi Sha 伊沙 and Lao G 老 G, eds. and trans. 2013. 《当你老了: 世界名诗10o首新 译》 [When you're old: new translations of 100 world-famous poems]. Xining: Qinghai renmin chubanshe. 
Yip Wai-lim 葉維廉, ed. and trans. 1976.《眾樹歌唱: 歐洲、拉丁美洲現代詩選》

[Singing trees: selected modern poetry from Europe and Latin America]. Taipei: Liming wenhua shiye gongsi.

Yu Jian 于坚. 2014. 〈读书笔记 2013〉 [Reading Notes 2013]. 《北京读书报》, February 19, 3-5.

Zhang Zao 张柊. 2015. 《张柊译诗》 [Zhang Zao's poetry translations]. Beijing: Renmin daxue chubanshe.

\section{About the author}

Joanna Krenz is assistant professor at Adam Mickiewicz University. Her research focuses on literature and its interactions with other disciplines, especially the sciences: her PhD dissertation (Leiden University, 2018) proposes a physics of literature to explore the linkage of essayism and emigration in contemporary Chinese literature. Her book-length ChinesePolish poetry translations include Come In, World, a collection of Yu Jian's poetry of which she is also the compiler (Świecie wejdź [Wydawnictwo Akademickie DIALOG, 2017]), and Homecoming, a collection of Li Hao's poetry (Powrót do domu [Kwiaty Orientu, 2018]). 


\title{
14 Trauma in Translation
}

\author{
Liao Yiwu's "Massacre" in English and German
}

Rui Kunze

\begin{abstract}
This essay traces various cultural translations of Liao Yiwu's poetry into English and German. It foregrounds a tight entanglement of literature and politics that starts with the suppression of the 1989 Protest Movement in China and extends to a dynamic engendered by publishers, prize-giving bodies, and prestigious cultural figures abroad. It reveals the complexities of communicating trauma between East and West and the gripping textual traces that are left in the process.
\end{abstract}

Keywords: Chinese poetry, translation, Liao Yiwu, cultural translation, trauma, poetry performance

Fuling, a river town in Sichuan province, June 4, 1989. Poet Liao Yiwu 廖 亦武 (b. 1958), a rising star on the late 1980 s poetry scene, recites sections three and four of his long poem "Slaughter" (屠杀). He does this at home, for an audio tape recorder, in the presence of two close friends, Canadian student of sinology Michael Day and fellow poet Li Yawei 李亚伟.

Liao and Day had seen soldiers patrolling in Fuling on June 1, when Day arrived from Beijing to stay at Liao's house. In the evening of June 3 , at home, Liao completed sections three and four of "Slaughter" under unbearable inner pressure. Then Day, who had been outside, came back to his house, and Li Yawei joined them later. At six a.m. the next morning, after a night filled with scattered news about the killings that are remembered as June Fourth (六四), when the army broke up the student-led pro-democracy and anti-corruption protests in Beijing and other cities in China, Liao finished recording his performance of the poem. He made three copies of the original tape and labeled them “The Era of Protest” (抗议的时代). He gave the copies

Van Crevel, Maghiel and Lucas Klein (eds.), Chinese Poetry and Translation: Rights and Wrongs. Amsterdam: Amsterdam University Press, 2019

DOI: $10.5117 / 9789462989948 \_C H 14$ 
to Day, who would be traveling to other parts of China, for him to share the poem with others.

This is Liao's recollection of these fateful days, as recorded in his memoirs $(2003,2004 a, 2011)$. (Detailed letters Day wrote to a friend at the time indicate that Liao was still working on the poem on June 6 and finished it around June 10, and that the recording did not take place until June $18 ;{ }^{1}$ while this discrepancy highlights the complexity of the phenomenon of memory in theory and practice, it does not essentially affect the argument made in these pages. We will revisit it later.) In March 199o, Liao was arrested and sentenced to four years in prison for counter-revolutionary propaganda and agitation, one of several Sichuan poets who were jailed after June Fourth (Day 2005, 348-349). Day was expelled from China in November 1990.

There was a recent collective memory of using poetry recitation for protest and mourning. On April 5, 1976, during the annual Tomb-Sweeping Festival for honoring the dead, thousands had recited poetry on Tiananmen Square when mourning premier Zhou Enlai, to voice their discontent with the government. Zhou had passed away in January and was widely seen as a counterweight to egregious political trends during the Cultural Revolution (1966-1976). Those who were then arrested as "counter-revolutionaries" were rehabilitated in 1978, and an anthology of the poetry associated with what became known as the Tiananmen Incident was published by the People's Literature Press (Tong 1978).

Just like the 1976 demonstrations, the 1989 protests began with the mourning of a popular political figure on the square - this time Hu Yaobang 胡耀 邦, who had died in mid-April - but they lasted for seven weeks and were incomparably larger in scope, triggering student and civilian protests in various cities all over the country. The crackdown started in the early hours of June 4 in Beijing, with estimates of the death toll ranging from several hundreds to several thousands. It expanded into a nationwide purge in subsequent years, with targets including public intellectuals and those in cultural circles. While Chinese and foreign citizens and institutions have advocated for public debate on June Fourth ever since, references to the event and its victims continue to be censored in China. Along with a general sentiment of depoliticization that has accompanied the country's radical economic liberalization since 1992, this has made June Fourth, often coded as "1989," a contested site of memory politics. All the more so because it was televized real-time by media around the world, just like the various more successful protest movements in that fateful year elsewhere 
in the world, which led to the disintegration of the Eastern bloc and shook the communist narrative worldwide.

Liao Yiwu's life was permanently changed by June Fourth. When he left prison in 1994, he was doubly disenfranchised, from the poetry scene and from society. He turned to non-fiction writing, in which he recorded the life stories of subalterns in Chinese society, but suffered constant surveillance and harassment by the police, who regularly confiscated his manuscripts. In July 2011 he fled to Germany, where he has lived in exile since, and received various literary prizes, including the 2011 Geschwister-Scholl Prize, named after two anti-Nazi activists, and the 2012 Peace Prize of the German Book Trade. The jury of the latter called him a "people's writer" who stands for "human dignity, freedom, and democracy."

Despite Liao's shift from poetry to non-fiction, "Slaughter," later known as “Massacre” (大屠杀), which is how I will refer to it from here on, has remained at the center of his literary biography, as a turning point in his life and the subtext of his later non-fiction writing. The poem has four sections. Liao appears to have completed sections one and two in May 1989 and originally conceived the poem, together with two other long texts from 1988 , as part of a trilogy in which he meant to criticize "the simultaneous physical and spiritual 'slaughter' of Chinese civilization" (Day 2005, 349350). In Liao's typically verbose style, the speaker in sections one and two of "Massacre" expresses shock, confusion, and resentment in the face of rampant commercialism in late 1980 os China, a theme many other authors were addressing as well. Leaving the exact date aside, it is clear that sections three and four were completed in June 1989, writing of and responding to "an all too real slaughter" (Day 1992c, 50). Section three is a polyphonic text portraying a panicky, chaotic scene, where an army follows order to kill defenseless civilians. Section four features the speaker reflecting on the need to retain the historical memory of violence, its perpetrators, and its victims. Often presented as a single text, sections three and four have come to be known as the text of "Massacre" in the course of time.

In this essay, I attempt to demonstrate that trauma plays a key role in the cultural translation of "Massacre." I argue that both "Massacre" and Liao's memoirs - which address his creation and performance of the poem - are texts produced in response to his personal trauma of June Fourth; and that their translations across media and cultures in English and German contexts show Liao interacting with other agents in the translational process to construct various narratives of this personal trauma, which in their turn feed into the construction of June Fourth as a cultural trauma in the larger post-1989 world. 


\section{Trauma and cultural translation}

Drawing on Freudian psychoanalysis, Cathy Caruth's work on narrative and history characterizes trauma as a compulsively recurring experience of the survivor, whose narrative of "a belated experience" of suffering bears the impact of the event's "incomprehensibility" (1996, 2, 6, 7). The connection between a traumatic narrative and the historical event that underlies it therefore lies in indirect referentiality: "For history to be a history of trauma means that it is referential precisely to the extent that it is not fully perceived as it occurs, or ... that a history can be grasped only in the very inaccessibility of its occurrence" (18). Thus narrating (personal) trauma reveals, according to Michael Berry, "a crisis of representation" (2008, 17, citing Joshua Hirsch).

Recent studies link personal trauma to more general sociopolitical conditions and gesture towards a cross-cultural perspective for understanding history through the prism of personal trauma. Michael Rothberg has proposed to study anachronistic and anatopic (dis)placements of trauma in literary works so as to bring together different traumas "as singular yet relational histories" with a multidimensional memory. This method, Rothberg says, can develop "differentiated maps of subject position and experience" and theorize "the differentiated ... landscapes of violence" (2008, 225, 231, 232), which may help "reconceive the link between cultures" through trauma (227). Following Slavoj Žižek's application of Lacanian trauma, Sebastian Liao (2014) argues that the debates on translating European literary modernism into Chinese poetry in the twentieth century are symptomatic of China's traumatic encounter with various colonial powers.

Against the backdrop of these various theorizations of trauma, the present essay adopts Jeffrey Alexander's distinction of personal trauma and "cultural trauma." Alexander presents cultural trauma as the result of a social process of constructing narratives of sufferings (2004). It occurs "when members of a collectivity feel they have been subjected to a horrendous event that leaves indelible marks upon their group consciousness, marking their memories forever and changing their future identity in fundamental and irrevocable ways" (1). Cultural trauma is therefore a "master narrative of social suffering" (15). By way of an example, Alexander outlines a transformation in the (American) construction of the mass killings of Jews in World War II, from a specific, situated war crime to a universalized symbol of human suffering and moral evil. He identifies two narrative modes in different phases of the process: a "progressive" narrative that sees Nazi anti-Semitism as a locally situated war crime that was overcome by the allies, and a "tragic" narrative developed later that sees barbarism lodged in modernity, with 
everyone as potential victim and perpetrator (227-229). As protagonists the progressive narrative features the liberating hero (e.g. the American GI), while the tragic narrative involves those who are "in the grip of forces larger than themselves, impersonal, even inhuman forces that often are not only beyond control but, during the tragic action itself, beyond comprehension" (226). Alexander argues that the universalization of the Jewish genocide into "a traumatic event for all of humankind" (197) requires, among other things, its dramatization across media to create a sense of identification on the part of the audience, by appealing to the affective and the experiential.

Alexander's example implicitly involves cultural translation. Two of three categories of cultural translation as summarized by Maghiel van Crevel are particularly useful here: "culturally inflected interlingual translation" and "the general activity of communication between cultural groups" (2017, 247-248). The notion of cultural translation can thus be used to examine power relations and legitimacy in translational practices at multiple levels. We can study not just the "movement of meaning" (Bhabha 1994, 228) in the individual translator's choices at the textual level; but also, at the metatextual level, the role of discourses and institutions in cultural communications. This resonates with Doris Bachmann-Medick's suggestion of considering the "translational collective," namely not just the mediating practices of the translator but also "the whole chain of translations via institutions, instruments, and technical conditions," which have an equally active mediating function $(2014,129)$.

Below, I first sketch the production and circulation of "Massacre" in relation to various versions of Liao Yiwu's memoirs (Chinese, English, and German), arguing that it is an unstable source text whose changes, coupled with its different contexts, create different narratives of Liao's personal trauma as well as different interpretations of the poem itself. I then try to demonstrate that both Liao's personal trauma and the phenomenon of cultural trauma are at work in the interlingual translators' renditions of "Massacre." Next, I analyze five examples of the transmedial performance of "Massacre" in different linguistic and cultural contexts, showing concretely how the poem-in-performance travels from expressing personal trauma to constructing cultural trauma.

\section{The source text on the move: from "Slaughter" to "Massacre"}

Liao Yiwu has published, reworked, and republished his memoirs over the years, in Chinese and in translations into English and German among other 
languages. In Testimonies: Speaking for China's Subalterns (證詞: 為中國底 層賤民代言, 2004a) published by the US-based Mirror Books, he changes the poem's name from 屠杀 'slaughter' to 大屠杀 'massacre', a term that conjures large numbers of deaths and great historical significance. While in the main text, the third and fourth sections of the poem are presented under the title "Slaughter," in paratexts such as photograph captions (248), Liao's curriculum vitae $(487,489,490)$, and the book's inside back cover, the poem is referred to as "Massacre." I agree with Day $(2005,349 n 624)$ that this was likely the first time the title was changed in print. Keeping "Slaughter" for the main text may have been in order to retain the factuality of the ur-story, but at the same time the switch to "Massacre" in the paratexts signals Liao's intention to posit June Fourth as a cultural trauma that far transcends his personal story - also by implying its comparability to the Holocaust, often rendered in Chinese as the "Massacre" (大屠杀) as well. Later, the change would lead to the English and German translations of the title as "Massacre" and "Massaker," respectively.

On the 2010 anniversary of June Fourth, Liao Yiwu published the poem's full text in Chinese as "Massacre" on the website Free Writing (自由写作), an online platform of the Independent Chinese PEN center, founded by Chinese-language writers in exile in 2001. This is, to my knowledge, the single publication of the Chinese source text that comprises all four sections of the poem. The first two sections were partly translated by Day in his 2005 dissertation. As mentioned above, it appears they were written in May 1989, after Liao visited Beijing in March and April together with Li Yawei (Day 2005, 350; Liao 2011, 49). The beginning of section one addresses an elevated and (self-)tormented misfit. In Day's translation:

\section{Cry! Cry! Cry! Cry! Cry!}

The only person this century to squander his tears

The only person this century to soar beyond mankind

The only person this century with the courage to obstruct the tide of history Crycrycrycrycrycrycrycrycry!

$(2005,350)$

As the text runs on, the misfit addressed as "you" turns out to be a poet, and an alter ego of the speaker (to whom I will refer with male pronouns, in light of the linkage of the text to Liao Yiwu's personal experience, as explicitly identified by himself). "You" is compared to tragic poet-hero figures from Chinese antiquity such as the exiled official Qu Yuan 屈原 
and the rebellious general Xiang Yu 项羽 - both expressed in verse their bitterness over not being acknowledged by their contemporaries (and both committed suicide). The speaker laments that "you" suffers similarly:

Too bad nobody knows you. The fasting, petitioning students don't know you. The capital under martial law and the soldiers don't know you.

(Day 2005, 351)

These sentences echo Liao's own experience in Beijing in March and April 1989, when he did not feel welcome. As he describes in his memoir, with a touch of irony: "Since poetry and recitation could not conquer the capital, we ... returned to Fuling indignant and bitter" $(2011,49)$.

In Fuling, Liao wrote sections three and four. In Chinese, they appear in full in all three published versions of his memoirs: Catastrophe: An Individualistic Testimony around the Year 1989 (天劫 - 八九前后的个人 主义证词, 2003, 14-16), the aforesaid Testimonies (2004a, 41-45), and the latest - and perhaps the fullest - version, June Fourth: My Testimony (六 四: 我的證詞, 2011, 61-65). ${ }^{2}$ Section three starts, in verse, with the speaker describing the order given to soldiers to kill. The text then switches to what is best described as stream-of-consciousness prose, with the voices of soldiers delirious from the act of killing mixing with those of helpless victims, living and dead, who are begging for mercy. Section four returns to verse, where the speaker urges his alter ego "you" to cast off fear, stop crying, and mourn the dead and testify for history. In all three versions of his memoirs, Liao claims that he completed these two sections in the evening of June 3, or roughly eight hours before the killings of June Fourth took place $(2003,16$; 2004 a, 45; 2011, 65); this evokes a romanticist vision of poethood as marked by enigmatic prescience or hypersensitivity - and, of course, by predestined suffering. He added the following dedication to sections three and four: "To the $2 \mathbf{2 0}^{\text {th }}$ anniversary of the French Revolution, the $7 \mathrm{o}^{\text {th }}$ anniversary of the May Fourth Movement, and those who have died in the politically motivated massacre of 3 June" (Day 2005, 352n633). ${ }^{3}$

Consistent as the story is in all three versions, it is not necessarily precise in the sense of historical accuracy, especially regarding Liao's first recitation

2 When citing passages that occur in all three versions (sometimes with slight variations), I quote from Liao 2011.

3 The May Fourth Movement was an iconic moment in Chinese history, closely associated with liberation from the weight of tradition, modernization, and the emancipation of China in the modern world. It was named after student demonstrations on May 4, 1919, in Beijing. 
of the poem in the presence of others. His description of the night from June 3 to June 4 comes across as something between reality and a nightmare:

I lay in bed, but another I walked through the wall and straight into the TV screen. I pushed down [the news anchors of the China Central Television Station] Du Xian and Xue Fei to take their places ... My lips protruded into the form of a gun, shooting everyone in the audience, while military boots were trampling over my skull. I grabbed the microphone, trying to resist the invisible power that was crushing me. Then I heard [my wife] A Xia scream - she was prizing my fist open, because I had squeezed her hard on the arm and left a large bruise there.

$(2011,67-68)$

Liao also makes two retrospective comments before discussing the actual recitation. The first portrays the recitation as an instinctive act, in which his artistic drive towards self-destruction converges with a historical incident; and the second contrasts the lack of emotional expression in the historical record with the need for emotional investment in recitation $(2011,68)$. Several pages on, Liao concedes that he may have forgotten things and confused the sequence of events; and he writes that in prison, when he was interrogated, he denied Li Yawei's presence when he recorded the poem at home, and that this came close to erasing his own, actual memories (2011, 72-73). These ambiguities and ambivalences allow Liao to offer, in Alexander's terms, a tragic narrative of his trauma in relation to June Fourth, in which Liao-as-protagonist is characterized by his inability to comprehend the event and control his own fate.

Liao Yiwu describes how he saw Day pack the tapes after the recitation: "I stared at Day, who opened his big vagabond's backpack and put in these seeds of fire [火種]. This was a slow process of burning myself to death" $(2011,69)$. These sentences depict the narrator's attempt to grapple - belatedly - with his traumatic experience by trying to track down its cause. The expression "seeds of fire" is intriguing, for it creates almost an anticlimax. It evokes the familiar metaphor for ideas that start a revolution, also used in Mao Zedong's adage that “a single spark can start a prairie fire" (星星之火, 可以燎原), and thus highlights the agitational potential of the tapes and - again - their transcendence of Liao's personal situation. But the next sentence neutralizes this by pulling it closer to its original meaning to locate a tangible starting point for the destruction of the individual person called Liao Yiwu.

The same moment, however, is rewritten in the English edition of Liao's memoir, translated by Huang Wenguang, For a Song and a Hundred Songs: A Poet's Journey through a Chinese Prison: "Day, my fellow artist-protestor, 
stuffed them in his huge vagabond's backpack. We jokingly decided that these were 'sparks of fire'” (Huang 2013, 31). Not only does the sentence about self-destruction in the Chinese version disappear here, but Day, a sinologistfriend in the Chinese version, becomes a "fellow artist-protestor." Even if Liao and Day were joking, the "sparks of fire" imply that the tapes carried a message of political agitation, reinforcing Liao's image as a poet-dissident and a voice of protest. Thus, the English edition creates a progressive narrative - again, à la Alexander - of Liao's traumatic experience of June Fourth. Liao's protest against political authority then anticipates his later suffering in prison and his ultimate escape into freedom. Reviewing For a Song and a Hundred Songs, Nick Holdstock detects this logic when he points out that the narrative struggles with its own attempts "to shape Liao's life into a conventional tale of triumph over adversity" (2013). In his "Translator's Note," Huang writes that he consulted Liao extensively on the translation to make adjustments and rearrangements in late 2011 (2013, 402-403). As such, the English translation may well reflect Liao's own (re)interpretation of his autobiographical narrative and the relevant source text(s). In this sense, Liao almost assumes the role of translator himself.

A similar, progressive reading of Liao Yiwu's memoirs is offered by Romanian-German literary author and Nobel Laureate Herta Müller, in a speech delivered in Berlin for the launch of the German edition of Liao's memoir, which she describes as a "prison book" $(2012,36)$. Locating Liao's trauma in his prison experience, she downplays the first part of the book, close to a hundred pages, which displays the narrator's precarious grasp and representation of the events that led to his imprisonment. Müller compares the publication of Liao's memoir to that of Boris Pasternak's Doctor Zhivago (До́ктор Жива́го) in the Soviet era - also first published outside the author's native land - and praises Liao's powerful writing on human nature and suffering in the prisons of a state she describes as "a Maoist relic disguised as an economic miracle" (33). This implicitly contrasts the "antiquated" Maoist state with the "modern" economic miracle, suggesting the assumption of a progressive history of modernity. Müller thus celebrates Liao's success of publishing his memoir in the modern, free world (Germany) as a triumph over premodern unfreedom.

\section{Interlingual translations of "Massacre"}

To my knowledge, the first translation of "Massacre" was into English. In March 1992, Michael Day's translation of sections three and four appeared 
under the title “The Howl” (1992a) in Geremie Barmé and Linda Jaivin's New Ghosts, Old Dreams: Chinese Rebel Voices, which "explore[s] the social and cultural roots of the 1989 Protest Movement" (1992, xv); the editors came up with the title and made some other textual adjustments without contacting Day - perhaps they were unable to contact him, since his contribution had first reached them anonymously through a third party. ${ }^{4}$ Later in the same year, Day published sections three and four in Pen International: Bulletin of Selected Books (1992b) and the Sonoma Mandala Literary Review (1992c), with the latter including a brief introduction to the poet and the poem. Unbeknownst to Day, his translation of section four also appeared in Index on Censorship as "Slaughter: Part IV" (1992d). ${ }^{5}$ Over twenty years later, in 2013, Day's translation of sections three and four was attached to For a Song and a Hundred Songs, as a single, long poem, and named "Massacre" (Day 2013). In June 2019, at a book launch held in London for Love Songs from the Gulags, a collection of Liao's prison poetry in Day's translation (Day 2019), Day claimed that he had originally translated the title as "Slaughter," attributing the change to "Massacre" in For a Song and a Hundred Songs to the editors, "for reasons that have nothing to do with poetry" (a recording of the event can be viewed on YouTube [the87 press 2019]).

German translations appeared after Liao had fled from China to Germany and cover only sections three and four. Entitled "Massaker," these were included in Hans Peter Hoffmann's translation of Liao's memoir, whose publication was timed to coincide with Liao's arrival in Germany as a writer in exile in July 2011 (Liao 2012, 156). Hoffmann's translation was reprinted in 2012, with some changes, in a slim, stylish collection called Massacre: Early Poems (Massaker: Frühe Gedichte), edited by Hoffmann, in uniquely numbered copies.

As mentioned above, section three portrays a scene of violence by mixing the voices of the speaker, the perpetrators, and the victims, and section four reflects on violence and history through the eyes of the speaker, who urges his alter ego "you" to testify. Here, drawing on examples in Day's and Hoffmann's texts, especially in passages that foreground perpetrators and victims, violence and history, I will argue that trauma is at work both in the source text and in the lexical, syntactic, and prosodic choices of translators and editors to make the poem intelligible in the target language.

At the beginning of section three, “unarmed thugs" (手无寸铁的暴 徒) encounter “professional killers” (职业杀手), and this is exactly how 
Day translates these two terms. Hoffmann's translation of the latter as "Berufskiller" is also straightforward, and neither translator revises their word choice across their various publications. “Thugs” (暴徒) is a pejorative term that was used in the Chinese state media for the protesters once the crackdown had begun. Day's "unarmed thugs" effectively conveys the sense of absurdity in the oxymoronic phrase in the source text (1992c, 52; 2013, 395). Hoffmann's choice of "Unruhestifter" 'agitator', literally "creator of unrest," brings out the political awareness of the protesters $(2011,42 ; 2012,9)$.

As for other words in the source text that refer to the perpetrators, we find 㓣子手 'executioner' and 屠夫 'butcher'. Day translates both as “butcher.” Turning an executioner into a butcher draws the image away from one of authority-sanctioned killing (quite aside from its justness or the lack thereof). It also suggests dehumanization of the victims and - by invoking a colloquial use of the image - a violent cruelty on the part of the perpetrator. This shift can be read as reflecting the translator's outrage at June Fourth; while any translator could feel this, Day probably experienced June Fourth more immediately than most. That said, his translation flattens the differences between executioners and butchers.

Hoffmann uses Mörder 'murderer' for both terms in his 2011 translation, distinguishing them from his Berufskiller by removing Berufs- 'professional' and using the Germanic equivalent of the English "killer." On balance, this flattens the differences between the three source-text terms for the perpetrators even more than does Day's translation. In his 2012 version, more accurately, for the executioners and the butchers, Hoffmann opts for Henker 'executioner' and Schlächter 'butcher', now fully mirroring the source text.

Both the source text and translations evoke the global cultural trauma of the Holocaust to condemn the violence and immorality of slaughter. “Cremator” in the source text - 焚尸炉, literally “corpse-burning oven” - for example, offers an image that facilitates historical association with the Holocaust. Both Day's “cremator" (1992c, 53) and Hoffmann's “Krematoriumsöfen" (2011, 44; 2012, 11) stay close to the source text. Later Day revised his translation into the more graphic "corpse incinerator" $(2013,397)$, but for conveying the darkness of state-organized systematic killing, this is perhaps less powerful than "crematorium," which is how Barmé and Jaivin adjusted Day's translation (1992a, 102).

As with my tentative invocation of Day's personal experience of June Fourth, one might wonder if Hoffmann's background may have played a role in his strategies of translating "Massacre" at large, as a citizen of a nation and native speaker of a language that have thoroughly addressed the collective memory of dictatorship and state violence - even if, just as 
in Day's case, this remains a speculative question. In this light, Hoffmann's use of liquidieren 'liquidate' to translate the soldiers' shouts of “干掉” 'get rid of, throw out' is an interesting lexical choice. Day translates this colloquial expression straightforwardly as "do away with": "Do away with all beauty! Do away with flowers! Forests. Campuses. Love. Guitars and pure, clean air!" (1992c, 52). Hoffmann's rendition conveys the idea of killing in a technical, dehumanizing way. While there is no way of knowing the translator's intention, for the reader this word will likely recall the cultural trauma of the Holocaust.

Another interesting moment in the relation of source and target texts to the historical memory of violence and suffering appears in the translators' interpretations of 作为一次次杀翏的见证, a syntactically ambiguous phrase in section four of the poem. Day's 1992 and 2013 translations read, respectively: "[Let your sobs] ... give repeated testimony of the slaughter" (1992c, 54) and "[Let your sobs] ... give repeated testimony of the Massacre" $(2013,399)$. He interprets 杀翏 'slaughter, massacre' as specifically referring to June Fourth. Hoffmann's translation, on the other hand, links 次次 'once and again' in the source text not to the testimony but to the repeated occurrence of massacres in human history, rendering 一次次杀 翏的见证 as “Zeuge aller Massaker” 'witness of all massacres'. For the last sentence: 在这史无前例的屠杀中只有狗崽子能够幸存 'in this historically unprecedented slaughter, only dog whelps can survive', Day stays close to the source text: "In this historically unprecedented slaughter ..." (1992c, 55) and "In this historically unprecedented massacre ..." (2013, 400; sic, lowercase " $m$ "), retaining the source text's traumatized focus on the killings of June Fourth through claiming its uniqueness. Hoffmann's translation, on the other hand, omits the adjunct 史无前例的 'historically unprecedented': "Dieses Massaker überleben nur Hunde" 'Only dogs survive this massacre' $(2011,46)$. Hoffmann recalls his choice as an attempt to offer a strong final chord to the poem, ${ }^{6}$ which suggests he found this more significant than the attributive "historically unprecedented." One might ask, of course, whether the collective memory of the Holocaust might make it problematic to call June Fourth historically unprecedented. Barmé and Jaivin, on the other hand, replace Day's "spawn of dogs" (1992c, 55; 2013, 400) for 狗崽子 with the expletive "sons of bitches" (105), a highly colloquial and somewhat clichéd expression of indignation and anger.

The interlingual translations discussed above demonstrate key moments in the "movement of meaning" in cultural translation. Below, we turn to the 
ways in which Liao's recitation of his poetry bring home the performative nature of cultural communication (Bhabha 1994, 228).

\section{Transmedial performances of "Massacre"}

Peter Middleton sees recitation as molded by "the contingent relations of place, people, and history" (1998, 268). John Crespi argues that poetry recitation shows "the contingencies of poetry in living action" that "move in many directions, revealing multilayered, real-world dimensions of poetic creation and reception" $(2009,5)$. Such contingencies in (live) poetry performance are clearly in evidence in Liao Yiwu's recitations of “Massacre." In his essay “Recitation” (朗 诵), Liao says poetry recitation has saved him from mistrusting words and the nihilism he had felt as a poet since 1988 . Recitation, he writes, offers a means of deeper communication beyond written words. As great reciters of poetry he names tragic historical figures such as the aforementioned Xiang Yu and Jing Ke 荆轫, who risked his life to assassinate the powerful emperor of Qin, calling them men whose deeds corresponded to their words $(1997,49-50)$. This idea resonates with what Liao later terms "the Way of the body" (身体的道) in June Fourth: My Testimony, where he celebrates ancient philosophers ranging from Confucius 孔子 to Mozi 墨子 for their willingness and ability to put their ideas in practice $(2011,36)$. Evidently, Liao perceives poetry performance as a process of transforming the page-based text into an action undertaken by the performer, towards communication that is driven by a visceral power.

That Liao's recitation is powerful is attested by a short letter from literary critic and political dissident Liu Xiaobo 刘晓波, the 2010 Nobel Peace Prize laureate who died in custody in China in 2017, and one of the most famous survivors of June Fourth. Liu, who had returned from abroad to join the students in Tiananmen Square, was instrumental in persuading the students to leave the square and thus avoiding even greater bloodshed. Used as the preface for the Chinese (2011) and German versions of Liao's memoir, Liu's 1999 letter articulates his mortification as a traumatized survivor when he heard Liao's performance of "Massacre." He writes: "Your voice makes me wonder whether I have sufficient reason to live on ... All human beings have died, only dog whelps can survive! Am I a dog whelp?" (Liao 2011, 4).

Below, in five examples, I examine the transformation of meaning-making from the page-based text to the multimedia performance of the poem, calling attention to transmedial interactions that create a new experience of the poem, which affects the text's various manifestations when it communicates trauma across media, languages, and cultures. 
(Mis)quoting Theodor Adorno as having said that "There are no poets after Auschwitz," Liao's memoirs invoke the Holocaust in order to refer to June Fourth as a cultural trauma, foregrounding the poet as the traumatized subject (2011, 236). ${ }^{7}$ Liao was present at all the performances of "Massacre" reviewed here - as the central performer and/or as its poet-creator - and his status as a survivor of (suffering related to) June Fourth, including his exile from China, would have instilled the performances with a sense of authenticity.

As noted above, Liao Yiwu's memoir claims that the first performance of "Massacre" took place on the early morning of June 4, 1989, with Michael Day and Li Yawei present. The audio recording, which is part of the Liao Yiwu Documents contributed by Day to the Digital Archive for Chinese Studies (DACHS) and can be accessed online, lasts around twenty-eight minutes. ${ }^{8}$ The performance is structured consciously to create a sense of drama, mostly through intense, highly charged repetition. With Jean-Michel Jarre's Equinox (on a tape supplied by Day) as background music, Liao starts by imitating the orders of a military march, resonating with the start of section three, where the army is given the order to kill. Next emerges the Chinese pop song “Let the World Be Full of Love" (让世界充满爱), a charity single dedicated to 1986, the International Year of Peace, by one hundred Chinese singers, while the voices of Liao, Day, and Li become audible one after another, increasingly louder and higher in pitch, in both Chinese and, less recognizably, English : “I protest! I protest!... Protest! PROTEST!” (抗 议). Liao then solemnly reads the dedications. Throughout the poem, he performs various voices, inserting animal-like howls between the sections. The recording ends like it started, with the orders to the soldiers, the repeated "I protest! Protest!" and the dedications. Equinox sounds again and then recedes into the background, to the sound of breaking glass.

Liao freely repeats phrases and sentences for dramatic effect. The most prominent repetition - in the written text as well as in the recitation - is that of the expression "blast away" (扫射) in section three, as an order to, and an exclamation by, the soldiers. On the page it regularly repeats three times, but in his recitation Liao repeats it up to six to seven times, sometimes leading into a repetition of only the second syllable, 射 'shoot', which also connotes ejaculation. When followed by the phrase "it feels good! So good" (好过瘾啊 'truly addicting'), this creates an auditory imagination of not

7 Adorno writes: "to write a poem after Auschwitz is barbaric" (nach Auschwitz ein Gedicht zu schreiben, ist barbarisch) (1986 [1977], 30).

8 Liao 2004b. 
just rapid fire but also indulgence in (violent) pleasure. Towards the end of section three, "Let the World Be Full of Love" becomes audible again, with these lyrics: "Year after year we welcome tomorrow / And year after year we have a tomorrow." The bitter irony in the performance, of extreme expressions of violence encountering a mellifluous celebration of hope and love, appears neither in the written text nor in other recitations.

In section four, the speaker scolds his alter ego "you" for uselessly crying:

People with no understanding of the times, people in the midst of calamity, people who plot to shoot down the sun.

You can only cry, you're still crying, crycrycrycrycrycrycrycry! CRY! CRY! CRY!

(Day 1992c, 54)

But suddenly Liao inserts into the recitation: "You're crying! You're crying! You're crying! I will kill you. You're crying! You're crying! I won't allow you to cry!" Notably, in all of the written text, not a single "I" appears. So who is this "I"? The perpetrator? Or the poet entering the diegesis, indicting himself for his powerlessness by threatening to kill an alienated alter ego called "you?" Here, the poet's (reciting) voice disrupts the speaker's (written) voice.

In his memoirs, Liao describes the feeling of listening to his recording together with his friends among the sound of police-car sirens outside shortly after June Fourth as one of pride but also estrangement from his reciting self: "Although I had enjoyed [the tape] many times, the Liao Yiwu in it still made me gasp for air" $(2011,82)$. He says he walked around in Fuling with the tape, playing it for his friends whenever possible and observing their reactions. "When I saw their face turn pale, I would be flooded with emotion. I didn't want to become a hero, but when the whole world went insane, how could I control myself?" (86). At one point, his friend Zeng Lei 曾磊, who worked at a military academy in Chongqing - and would be arrested in 1990, as one of six people who were making a video version of Liao's poem “Requiem" (安魂) (Day 2005, 349n625) - encouraged him to recite naked under the spotlights of the academy's recording studio, to which Zeng had access. Liao recalls having misgivings: "The space was too big and I tried my best to fill it up ... Once I punched myself in the face so hard that it swelled up. This is how this self-important style of performance took shape, and it lasted for many years" $(2011,86)$. The tragic narrative he constructs is characterized by equivocation and alienation in his description of the period following June Fourth, especially in regard to his penchant for (spectacular) performance. 
In the English edition, however, his performances are rewritten into a purposeful use of art for protest:

I would play the 'Massacre' tape and gauge the reaction to my reading. I never intended to be a hero, but in a country where insanity ruled, I had to take a stand. 'Massacre' was my art and my art was my protest.

(Huang 2013, 41)

Here, Liao's retrospective certainty and purposefulness turn his first recitation into part of the poet's teleological journey from protesting to prevailing over state power, and make his memoirs into a performance of identity, as a dissident writer. This is also exemplified in his performances of "Massacre" for international audiences in Stockholm and at the New York Public Library (NYPL), where text and poet are recontextualized and presented as testimony literature and dissident writer in exile, respectively. In these situations, Liao's recitation wants to be what it can never be, namely the re-enactment of the un-re-enactable experience of trauma.

On the night of March 19, 2013, Liao recited "Massacre" on the Sergels public square in the Stockholm city center, together with Swedish singer Maria Rosén and Germany-based Chinese artist Meng Huang 孟煌. This recitation, available on YouTube (ddzhggchd 2013), starts with Rosén and Meng chanting in low voices, respectively, a Swedish folk song and Meng's “Letter to Liu Xiaobo in Prison” (给狱中刘晓波的信). Suddenly Liao breaks in with a repeated roar of "I protest," fiercely shaking an abacus for rhythm. This is followed directly by his sensational verbal "shooting" ("Blast away! blast away!") and the description of a bloodbath (the underlined text is only in the recitation, not in the written text):

You aren't able to pass over wall after wall of fire. Aren't able to swim across pool after pool of blood. Blood, blood, so much blood. Power will be triumphant forever.

(Day 1992c, 53)

By excerpting and rearranging the text and by reiterating images of violence (blast away, fire, blood), Liao opens his performance with a portrayal of arbitrary state violence against its helpless victims. His own physical presence on the spot - as the poet, the survivor, and the exile, the performer - reinforces the authenticity of the poem as a piece of experiential testimony to the audience passing through the public square (most of whom could not have been expected to know Chinese). 
In section four, the speaking voice reflects on the situation of "we," a pronoun that may be read as identifying all those present - the performer/ poet and the audience - in the context of oral performance. Again, Liao changes the order of the written text, and he adds new phrases (underlined below) to criticize "our" muteness:

We stand on a great road but no one is able to walk.

We stand in the midst of brilliance but all people are damned [他妈的] blind.

We stand on a great road but no one is able to walk.

We all have mouths but we are mute

Everyone is mute, everyone is mute, everyone is mute, everyone is mute...

(Day 1992c, 54)

Why is "muteness" repeated in this recitation? Given the time (early 2013) and place (Stockholm) as well as the evocation of Liu Xiaobo in the performance, it is safe to say that this performance is related to the Nobel Prize. Liu's absence from the 2010 Nobel award ceremony, symbolized by the famous empty chair, was widely cited in European mass media as an illustration of the Chinese government's dictatorial nature. (As a work of performance art, Meng sent a chair to Liu at his prison address in March 2011 - which he could not track any more once it entered China.) By drawing on Liu's reputation in relation to June Fourth, Liao and Meng call attention to their own persecution as artists by the same merciless state. By chastising "everyone" for being "mute," Liao reiterates his accusation of the Nobel committee of failing to uphold the moral responsibility of boycotting the Chinese state, an accusation that also recalls Liao and Meng's protest at the award ceremony of the Nobel Prize for Literature to Mo Yan 莫言 in December 2012 (Tao 2012).

Also in 2013, Liao recited "Massacre" at the NYPL to celebrate the launch of his memoir in the US, roughly along the lines of the Stockholm performance. His recitation, together with NYPL director Paul Holdengräber's introduction of the poem and their conversation (interpreted by Huang Wenguang), was posted on the NYPL website as video and audio files. Both Holdengräber and the title slide of the on-screen projection of the English translation claim that Liao composed "Massacre" on the morning of June 4, 1989. Moreover, in the slide the poem's dedication is changed. The victims of June Fourth are named first, and the seventieth anniversary of the May Fourth Movement is not mentioned (NYPL 2013). Presumably May Fourth would have meant little to the local audience, but its erasure is ironic, as the Movement's official historiography as a patriotic student movement 
served as a major inspiration for the 1989 student protests that ended with June Fourth. The changes therefore radically recontextualize the poem. The NYPL audience would likely have assumed that Liao wrote the poem solely in response to the June Fourth killings, confirming his identity as a dissident writer resisting a dictatorial government and hence forced into exile; they would have viewed June Fourth in light of the general image of the French Revolution as a movement in pursuit of democracy and freedom. Judging by the event's representation online, and in light of these various observations, the performance could have presented a stereotypical story of disaster-and-diaspora victimhood.

Six years later, in 2019, on the thirtieth anniversary of June Fourth, Liao performed "Massacre" together with Michael Day once again, at the London book launch mentioned above. Day read the full text in English translation while Liao interjected passages from the poem in Chinese and played various musical instruments (the 87 press 2019). If their shouts of "I protest" in Chinese and English bring to mind their previous joint performance, then here Day's role as an essential collaborator - or as Liao likes to say, as his "accomplice" - is foregrounded. In all, Day has actively and substantially participated in Liao's creative work and contributed considerably to the poem's transmedial and global circulation.

A final example reaffirms that Liao's performances of "Massacre" in transnational contexts take June Fourth beyond China's borders - this time to a country with recent memories of socialism. Actress Johanna Marx performed "Massacre" (Massaker) in German in the theater project The Bullet and the Opium: Forbidden Biographies (Die Kugel und Das Opium: Verbotene Biografien), staged in the Berlin-Hohenschönhausen Memorial in September 2016, and recorded on DVD through crowdfunding. The poem was recontextualized yet again, this time by some of Liao's non-fiction in German translation, about Chinese individuals suffering under various political campaigns in China, and by Mario Röllig's story about how he was thrown in prison for being gay in the German Democratic Republic (East Germany).

A part of the Memorial was the prison where Röllig was sent at the time and where he now acts as a witness-guide to the totalitarian past. Its grey cement walls powerfully suggest to the performers and the audience what a prison looks and feels like. All the stories are narrated in the first person by German actors and actresses, who appear in short films or on stage. One of them is Liao's own account of writing and hiding manuscripts in prison and smuggling them out, as told by Marx, with Liao Yiwu playing the flute behind her on the stage. Marx's performance of "Massacre" takes place towards the end of the program and lasts nine minutes, during which 
she holds a placard which reads, in German: "Crime: Wrote a poem." It is preceded by an excerpt of Liao's 1989 audiotape, played off-stage, where Liao's dramatic weeping voice can be heard, while Liao himself sits in the first row of the audience.

The artistic method of presenting two Liaos at the same time, one mediated in various ways and one physically present, brings to mind the Memorial's - and the (German) audience's - own history before and after 1989. Different from the estranged selves that Liao portrays in his memoirs, these two represent a consistent progression of time and history. The "I-narrative" in this theater project not only presents the interlingual translation of Liao's poem and stories, but also foregrounds the possibility of translating suffering across cultures. Röllig claims that once someone is imprisoned they will never be the same. Therefore, even though the East German regime collapsed in 1989, personal traumas of political oppression have lingered on. Thus the project suggests the possibility that individual stories and memories from two countries of the former communist bloc may communicate and merge into a shared past - which, in its turn, may produce a transnational cultural trauma in the course of time.

\section{Conclusion}

This case study of "Massacre" in English and German contexts demonstrates, through the prism of trauma, the significant role of cultural translation in building, mediating, and communicating memory and history. A traumatized subject, Liao Yiwu is both the translated and the translator, in his renaming, excerpting, rearranging, and recontextualizing of the source texts. As a translator he has interacted with other agents of the translational collective (interlingual translators, editors, award jurors, readers, co-performers, etc.) to bring on the impact of his personal trauma in relation to June Fourth, and thus to contribute to constructing June Fourth as a cultural trauma that does not stop at China's borders.

\section{Works cited}

Adorno, T. W. 1986 [1977]. "Kulturkritik und Gesellschaft" [Cultural criticism and society]. In Kulturkritik und Gesellschaft I/II: Gesammelte Schriften Band 10 [Cultural criticism and society I/II: collected writings, vol. 10], edited by Rolf Tiedemann, 11-30. Frankfurt: Suhrkamp. 
Alexander, Jeffrey C. 2004. "Toward a Theory of Cultural Trauma." In Cultural Trauma and Collective Identity, edited by J. C. Alexander, R. Eyerman, B. Giesen, N. J. Smelser, and P. Sztompka, 1-30. Berkeley: University of California Press.

-. 2004. "On the Social Construction of Moral Universals: The 'Holocaust' from War Crime to Trauma Drama." In Cultural Trauma and Collective Identity, edited by Alexander et al., 196-263.

Bachmann-Medick, Doris. 2014. "From Hybridity to Translation: Reflections on Travelling Concepts." In The Trans/National Study of Culture: A Translational Perspective, edited by D. Bachmann-Medick, 119-136. Berlin: De Gruyter.

Barmé, Geremie and Linda Jaivin, eds. 1992. "Introduction.” In New Ghosts, Old Dreams: Chinese Rebel Voices, xv-xxvi. New York \& Toronto: Random House.

Berry, Michael. 2008. A History of Pain: Trauma in Modern Chinese Literature and Film. New York: Columbia University Press.

Bhabha, Homi K. 1994. The Location of Culture. London and New York: Routledge. Caruth, Cathy. 1996. Unclaimed Experience: Trauma, Narrative, and History. Baltimore: Johns Hopkins University.

Crespi, John A. 2009. Voices in Revolution: Poetry and the Auditory Imagination in Modern China. Honolulu: University of Hawai'i Press.

Day, Michael Martin (as Anonymous), trans. 1992a. "The Howl." In New Ghosts, Old Dreams, edited by Geremie Barmé and Linda Jaivin, 100-105. New York: Random House.

一, trans. 1992b. “Slaughter 屠杀 (poem by Liao Yiwu 廖亦武).” PEN International: Bulletin of Selected Books Vol. XLII, No. 2: 92-94.

—, trans. 1992c. "Liao Yiwu and 'Slaughter' 屠杀 (essay about and translation of this 1989 poem by Liao 廖亦武)." SONOMA MANDALA Literary Review (Fall): 48-55.

—, trans. 1992d (unnamed). "Slaughter. Part IV." Index on Censorship 21 (8): 34.

—. 2005. "China's Second World of Poetry: The Sichuan Avant-Garde, 1982-1992." PhD dissertation, Leiden University. bit.ly/2GbJGst. Accessed February 20, 2018. —, trans. 2013. "Massacre." In Huang, For a Song and a Hundred Songs: A Poet's Journey through a Chinese Prison, 395-400.

-, trans. 2019. Yasuo (Liao Yiwu), Love Songs from the Gulags. London: Barque Press.

ddzhggchd. 2013. “廖亦武《大屠杀》.”Youtube, March 29. bit.ly/2YYQ6CA. Accessed March 21, 2018.

Hoffmann, Hans Peter, trans. 2011. Für ein Lied und hundert Lieder. Ein Zeugenbericht aus chinesischen Gefängnissen [For a song and a hundred songs: a testimony from Chinese prisons]. Frankfurt: S. Fisher.

—, ed. and trans. 2012. Massaker:Frühe Gedichte [Massacre: early poems]. Berlin: hochroth. 
Holdstock, Nick. 2013. "For a Song: Liao Yiwu's Prison Memoir." Los Angeles Review of Books, June 4. bit.ly/2Z7ShDY. Accessed June 10, 2018.

Huang Wenguang, trans. 2013. For a Song and a Hundred Songs: A Poet's Journey through a Chinese Prison. Boston: Houghton Mifflin Harcourt.

Liao, Sebastian Hsien-hao. 2014. "From Poetic Revolution to Nation-(Re)building: Vicissitudes of Modernity in Modern Chinese Poetry." In Modern China and the West: Translation and Cultural Mediation, edited by Peng Hsiao-yen and Isabelle Rabut, 303-326. Leiden: Brill.

Liao Yiwu 廖亦武. 1997. 〈朗诵〉 [Recitation].《山花》6: 47-53.

- 2003. 《天劫 - 八九前后的个人主义证词》 [Catastrophe: an individualistic testimony around the year 1989] (online publication in MS Word file). bit.ly/ 2Vz1XVU. Accessed March 12, 2018.

一. 2004a. 《證詞: 為中國底層賤民代言》 [Testimonies: speaking for China's subalterns] (also rendered in English in colophon as Living Testimonies: stories of people behind the bars in China [sic]). Carle Place: Mirror Books.

—. 2004b. "Liao Yiwu Audio Files." Digital Archives for Chinese Studies, Leiden Division. bit.ly/2GmOXoc. Accessed March 20, 2018.

一. 2010. 〈大屠杀(长诗)〉 [Massacre (long poem)]. 《自由写作网刊》, July 4. bit.ly/2D6GSe3. Accessed March 20, 2018.

- 2011. 《六四: 我的證詞。從先鋒派詩人到底層政治犯》[June Fourth: my testimony. From avant-garde poet to political prisoner]. Taipei:Yunchen wenhua.

—. 2012. Erinnerung, bleib ... Memory, remains ... 回忆, 仍留下... Berlin: Lieblingsbuch.

Marx, Johanna, Bettina Hoppe, and Mario Röllig. 2016. Die Kugel und das Opium: Verbotene Biographien. Ein Theaterprojekt mit Texten von Liao Yiwu (The bullet and the opium: forbidden biographies. A theater project with Liao Yiwu's texts). Berlin: Stephan-Knies-Produktion.

Middleton, Peter. 1998. "The Contemporary Poetry Reading." In Close Listening: Poetry and the Performed Word, edited by Charles Bernstein, 262-299. New York: Oxford University Press.

Müller, Herta. 2012. "Mit diesseitiger Wut und Jenseitigen Zärtlichkeiten" [With this-worldly rage and otherworldly tenderness]. In Liao Yiwu, Erinnerung, bleib ... Memory, remains ... 回忆, 仍留下..., 32-37. Berlin: Lieblingsbuch.

NYPL. 2013. "Liao Yiwu in Conversation with Paul Holdengräber." New York Public Library, June 13. on.nypl.org/2YYExez. Accessed April 5, 2018.

Rothberg, Michael. 2008. "Decolonizing Trauma Studies: A Response." Studies in the Novel 40 (1-2): 224-234.

Stiftungsrat des Friedenspreises Deutschen Buchhandels. 2012. "Der Preisträger 2012: Liao Yiwu. Begründung der Jury"[The 2012 laureate: Liao Yiwu. The jury's motivation]. bit.ly/2ULlaGs. Accessed May 21, 2018. 
Tao, Anthony. 2012. "That Streaker at the Nobel Banquet Was Artist Meng Huang, Accompanied by German Peace Prize Recipient and Chinese Exile Liao Yiwu." Beijing Cream, December 14. bit.ly/2UJbFrm. Accessed September 4, 2018.

the87 press. 2019. "Liao Yiwu and Michael Day Barque Press Launch 2019." Youtube, June 13. bit.ly/2yFKkcX. Accessed August 5, 2019.

Tong Huaizhou 童怀周. 1978. 《天安门诗抄》 [Poetry from Tiananmen]. Beijing: Renmin wenxue chubanshe.

van Crevel, Maghiel. 2017. "The Cultural Translation of Battlers Poetry (Dagong shige)." Journal of Modern Literature in Chinese 14 (2)-15(1): 245-286.

\section{About the author}

Rui KUNZE is currently a DFG-funded research fellow at the University of Erlangen-Nuremberg. Her research interests lie in Chinese literature and culture from the late nineteenth century onward. She is the author of Struggle and Symbiosis: The Canonization of the Poet Haizi and Cultural Discourses in Contemporary China (projektverlag, 2012). Her work on science fiction, the history of science, and cultural entrepreneurialism in modern and contemporary China has appeared in East Asian History, Twenty-First Century (二十一世紀), Concentric: Literary and Cultural Studies, and China Perspectives. 


\title{
15 A Noble Art, and a Tricky Business
}

\author{
Translation Anthologies of Chinese Poetry
}

Maghiel van Crevel

\begin{abstract}
This essay suggests that in the early twenty-first century, Chinese-toEnglish presents a fascinating case study for the genre of the multipleauthor translation anthology - because of infighting on the Chinese poetry scene, foreign readers' unfamiliarity with this poetry, and profound changes in where the anthologists come from and what language they speak, with both questions taken in the broadest sense.
\end{abstract}

Keywords: Chinese poetry, translation, poetry anthologies, translation anthologies, non-native translators

Translation anthologists make very different books and say very different things about them. Let's consider some examples.

Yang Lian 杨炼, one of the editors of Jade Ladder: Contemporary Chinese Poetry, calls the anthology "a gathering of the best of Chinese poetry in the last thirty years" (Herbert et al. 2012, 41). In comparison, Liang Yujing's 梁 余晶 preface to his Zero Distance: New Poetry from China is low-key. Liang feels translation should prioritize "the young, the new and the unknown" $(2017,7)$, and paints his work as a translator as shaped by serendipity. And, he notes, "considering China's population and the number of poets, I will never say the poems in this book are the best I can find in China" (9). Brian Holton, co-editor and primary translator of Jade Ladder, cautions against solo translation by native Chinese speakers out of their mother tongue (Herbert et al. 2012, 351). Liang Yujing is a native Chinese speaker who solo-translates out of his mother tongue.

In In Your Face: Contemporary Chinese Poetry in English Translation, Ouyang Yu 欧阳昱 likens his work as editor and translator to "smuggling [the

Van Crevel, Maghiel and Lucas Klein (eds.), Chinese Poetry and Translation:Rights and Wrongs. Amsterdam: Amsterdam University Press, 2019

DOI: $10.5117 / 9789462989948 \_C H 15$ 
poems] into Australia as if they were illegal immigrants that this country never likes." But, he says, they will come in all the same, like "boatloads of people" have done, "whether you like it or not" $(2002,1)$. A decade later, in Breaking New Sky: Contemporary Poetry from China, rather than xenophobic chauvinists, Ouyang sees an audience of "Australian poetry lovers," to whom he promises "an eclectic selection of what are the most interesting, the most enticing, the most loveable poems, and the most controversial." They come from an ancient "poetry nation," and the anthology is "purely a labour of love" (2013, 9). In Your Face was privately funded. Breaking New Sky was funded by the Australian Council for the Arts.

In 1987 the Beijing-based Chinese Literature Press presented Julia Lin 林 明晖 with a collection of Chinese women's poetry and invited her to serve as its translator and English editor. Lin had moved from China to the US in 1949 to attend college and was professor of English at Ohio University. Her preface shows the work was completed in 1988, but Women of the Red Plain: An Anthology of Contemporary Chinese Women's Poetry was not published until 1992. Foreign distribution was by Penguin. Since the Chinese Literature Press must play by the rules of PRC cultural policy and propaganda, there is nary a word about June Fourth, the violent suppression of the 1989 Protest Movement that figures so prominently in early 1990 s foreign-produced anthologies of Chinese literature. That several authors are introduced by the Press as having "worked on the agricultural farms" squeezes another elephant into the room: the havoc of the Cultural Revolution (1966-1976), when countless urban youths were sent to the countryside. Lin's preface is brief, the author bios are written in Press officialese, and poets are listed alphabetically. One gets the sense that, beyond a gender-stereotyped Publisher's Note whose key assertion is that women write about feelings, the last thing the Press wanted to do, or wanted Lin to do, was to tell an actual story of modern Chinese women's poetry.

Almost twenty years later, Lin's Twentieth-Century Chinese Women's Poetry lists its contributors by birth year: poets from China in part I, overlapping with those featured in Women of the Red Plain but mostly represented by different texts, and poets from Taiwan in part II (2009). Her preface retains some passages from the 1992 anthology, for instance on her translational poetics, but she now speaks out on the significance of matters such as this poetry's feminist consciousness and its probing of the female psyche and sexuality. The contrast is thrown into even sharper relief by a thoughtful introduction by Lin and Nicholas Kaldis that does tell a story, with its origins in a draft by Lin that must go back to the late 1970s. Both anthologies are important books, but their maker finds herself in utterly different places in 1992 and 2009. 
The difference between Lin's two books foregrounds the impact of circumstance, which matters always. For the translation of poetry, circumstance includes everything from mass-media coverage of geopolitics - say, images of China in foreign newspapers - to the energy of small-press publishers that advance literary experiment.

But what anthologists do, and what they say they do, also reflects their individual agency and hence their positionality and their inclination. And notably, these things gain in significance in the case of contemporary mainland-Chinese poetry in translation, for three reasons. First, the foreign reader's unfamiliarity with this poetry. Second, the rapid increase of multilingualism in China and people's growing international mobility, with prominent roles for anthologists who hail from China and operate in English, in various places in the world. And third, the ways in which this poetry's sheer diversity and dynamism and its contestations inside China play out outside China.

What, then, are some of the salient issues that emerge from multipleauthor translation anthologies of contemporary mainland-Chinese poetry? ${ }^{1}$ Based on a lateral reading of about twenty such books published since the 1990s, I examine six monolingual specimens, whose primary intended readership is a general and not typically China-literate audience in the target culture, in loosely chronological order. I focus on paratext, a phenomenon whose importance for translation anthologies is well established. I privilege paratext of the kind that is part of the book in question - introductions, afterwords, author selection and sequence, bios, endorsements, and so on, also known as peritext - and only sporadically draw on the epitextual variety, in occasional references to book reviews.

\section{The genre, and the modern Chinese case}

In a study of Polish poetry in English translation, Bohdan Piasecki proposes a methodology for studying multiple-author translation anthologies (2010). He notes that as a relatively safe investment for the publisher, such anthologies constitute the vehicle of choice for foreign poetry. Indeed, for peripheral cultures and languages, he writes, they are often the only way for foreign poetry to reach its readers (9-10). (It is safe to say that modern Chinese

1 Bruno 2012 has an inventory for the years 1982-2009, also listing multiple-author books of greater scope in time and place, and single-author books. Later items are found in the MCLC Resource Center bibliographies. 
poetry remains peripheral vis-à-vis English and other European languages today, just like modern poetries in other non-European languages.) Piasecki further notes that translation anthologies tend to be taken as expressions of expert authority; and, at the same time, that the individual poems in them are subjected to triple decontextualization, from the individual author's oeuvre, their cultural milieu, and the source language (9). One might make that quadruple for anthologies with contributions by multiple translators, as distinct from the relative consistency one may expect in a single translator (or a single pair of translators working together), aside from the pros and cons of either situation. Piasecki concludes that translation anthologies afford maximum "opportunity for manipulation" (18) - in the translation studies sense of the word, not as a value judgment (e.g. Hermans 1985).

The anthologies discussed here show that in the case of contemporary Chinese poetry in English, opportunity for manipulation as an inherent condition of the genre is further expanded by the special significance of the anthologists' agency, positionality, and inclination. This makes for a variegated picture that defies easy categorization, also because individual anthologists engage in different ways with the demons that have haunted modern Chinese poetry from the start. These are classical Chinese poetry, (modern) foreign poetry, and something I abbreviate as "China," meaning a composite set of social and political realities that this poetry is often expected to reflect. Vis-à-vis the indigenous classics, modern Chinese poetry is widely considered to fall short. Vis-à-vis the foreign, it is regularly dismissed as imitative, no matter how often everyone reminds everyone else that, for instance, ur-Western-modernist Ezra Pound was inspired by premodern Chinese and Japanese poetry. And "China" rears its head, especially abroad, when poetry from the mainland is compulsively framed as being about its authors' native country and constituting political dissent.

\section{The changing of the guard}

The present essay follows on from a study by Cosima Bruno in which she shows that the paratextual message of three translation anthologies in the early 1990 s is marked by a politico-contextual focus of foreign discourse on contemporary Chinese poetry (2012, 264-268). The books in question are Edward Morin's The Red Azalea: Chinese Poetry since the Cultural Revolution (1990), Donald Finkel's A Splintered Mirror: Chinese Poetry from the Democracy Movement (1991), and Tony Barnstone's Out of the Howling Storm: The New Chinese Poetry (1993). Politicization of Chinese poetry - meaning 
overdetermination of this poetry as embodying dissent and resistance - is manifest in their titles, and has been ongoing ever since the emergence of Obscure Poetry (朦胧诗, sometimes also called Misty Poetry) in the journal Today (今天) in the late 1970s.

A change occurs when younger generations take center stage in translation anthologies. Wang Ping's 王屏 New Generation: Poems from China Today (1999) presents a transitional moment between Obscure poetry's nearmonopoly on foreign exposure and a more diverse, less politicized presence of Chinese poets in translation. As such, while her anthology contains much poetry written in the 199os, Wang's preface still dwells mostly on poetic trends and developments in the 1980s, the decade of high-culture fever (文 化热). At the same time, she clearly refers to the 1990s when she notes the "cynicism and materialism that have begun to emerge as part of Chinese life" and younger poets' "distaste for the relentless advance of capitalist mass culture" (24). More generally, the China demon rides again when she mostly contextualizes poetry in terms of social development. While Wang doesn't mention June Fourth, which was a powerful catalyst of change in Chinese poetry from one decade to the next, American poet John Yau's introduction to the volume uses June Fourth as its opening frame, and almost obsessively dwells on political repression, in a mismatch with the poetry it claims to introduce and with Wang's preface.

As regards Wang's positionality as editor and translator, key points include her personal trajectory and her method of translation. Her preface, author bio, and translator bio tell us she grew up in China and graduated from Peking University before moving to the US in 1985 and turning herself into a literary author publishing in English; New Generation originated in a Master's thesis in comparative literature at New York University, and the anthology's publication by the Hanging Loose Press was funded by the New York State Council on the Arts and the Fund for Poetry; and Wang produced the translations jointly with an impressive lineup of American poets, in what appears to have been an engaged, dialogic project with a native speaker of the source language at the center. Similar approaches would be followed by other anthologists in later years, sometimes also involving native-Anglophone scholars in addition to poets. Interestingly, Wang writes that the Chinese poets "speak to us as representatives of a country and culture very different from our own," thus identifying as American (29).

A prevalent typology of anthologies includes the general or survey type, which is the default type for anthologies of national literatures, with more or less explicit claims to representativeness; the special interest type - women's poetry, workers poetry, war poetry, and so on; and the programmatic type, 
which aspires to innovative intervention, for instance by launching a movement or supporting one among several competing poetics in a given literary field, and disrupting canonization rather than reaffirming it (Seruya 2013). Successful programmatic anthologies can become survey anthologies over time, and their distinction is complicated in interesting ways in translation anthologies, as we will see below, but it is safe to say that New Generation is of the survey type. It features twenty-four authors, sixteen men and eight women.

Assessing the representativeness of any multiple-author anthology is difficult. Doing so for contemporary Chinese poetry at any point since the mid-1980s is extra difficult in light of the flood waves of publications and the diversity and dynamism of the Chinese poetry scene. Still, New Generation definitely foregrounds important names and trends, although their interrelatedness is obscured by the alphabetical order in which the authors are presented. Sequencing poets by name disregards the cumulative, intertextual, constellational nature of literary production, and diminishes the potential of anthologies to create a whole greater than the sum of its parts and to let the decontextualized poems speak to one another in novel ways - an effect that can be enhanced in translation anthologies by the encounter with the target culture and its poetry. Sequencing poets by name suits reference works and readers who know what they are looking for, but for most anthologies it is arbitrary and arguably constitutes a forfeiture of editorial vision.

\section{Pushing your welcome abroad and fighting the canon back home}

Ouyang Yu trained in English and American literature in China in the late 1970 and early 1980 . This rendered the Chinese poetry of those years "totally unreadable and unlikeable" in his eyes $(2013,5)$. He moved to Australia in 1991 and has since become a prolific author and translator who publishes in English and Chinese and cultivates his status as enfant terrible of AustralianChinese literary encounters. His two translation anthologies, mentioned above, are remarkable in that they attack the reader in the target culture and the canon in the source culture, In Your Face mostly the former and Breaking New Sky mostly the latter.

In Your Face is a special issue of Otherland, a journal founded by Ouyang in 1994, and its physical qualities (paper, typography, layout) are clearly DIY. The introduction, named after Ouyang's image of poems as illegal immigrants, helps to establish a provocative discourse featuring a "thankless" Australian 
audience (Ouyang 2002, 1). They hardly "give a damn about poetry, still less about Chinese poetry," a claim Ouyang backs up by citing, as a badge of pride, his anthology's "saga of failure" (3) - meaning its rejection by multiple publishers. A quote by Ouyang Jianghe 欧阳江河 on the back cover adds a racial twist: "why have so many chinese migrated into english, / making an effort to become yellow-raced white people ...?” The introduction warns that those "who want to see the Western version of democracy and freedom here will be disappointed" (3), and that "there is something in me that refuses to be colonized by the West, epitomized by the very English language. Hence this anthology, to give back what has been rejected, in your face" (4).

After his provocation of the Australian and more broadly the Anglophone reader, Ouyang Yu explains his selection of source texts by pointing to the diversity and vitality of contemporary Chinese poetry. He advertises especially what I have called the earthly camp in this poetry - in opposition to the elevated camp, which we will encounter below - and its transgressive sides (van Crevel 2008, ch. 1; 2017, pars. 122-125). Among other things, he notes that the poems in In Your Face "are mildly and sensitively anti-Western" and "sexy" (Ouyang 2002, 2), which turns out to mean their subject matter includes sex work, as perceived by the consumer. As such, while the anthology features seventy-two authors of varying persuasion - all except two from mainland China, sixty-three male and nine female - it displays a partisan, programmatic orientation that explicitly directs foreign perspectives on Chinese poetry to particular factions on the domestic poetry scene. (This makes it all the more surprising that In Your Face, too, lists its authors in alphabetical order.) Ouyang takes a critical view of the canon, saying that "big shots" such as Bei Dao 北岛 "have been too well published and anthologized for me to bother" (2), his diction subverting a conventional discourse of the responsibility held by the anthologist. And indeed, there are some glaring absences that reaffirm Ouyang's pro-earthly and anti-elevated orientation: Zhai Yongming 翟永明 and Xi Chuan 西川, for example.

All anthologies have inherent (re)canonizing intentions and effects, whether the texts they contain count as canonical already or as "unknown, forgotten, marginalized" (Seruya 2013, 2). Translation anthologies may feature texts that have prior canonical status in the target culture - say, the so-manieth translation of Baudelaire into Dutch - as well as texts that are little known outside the source culture. Anthologization of the latter tends to rely heavily on source-culture canons, especially if the anthologists are native speakers of the target language and source and target language and culture are far apart. Most of the anthologies discussed here were compiled by native speakers of the source language instead, but it remains rare for 
a translation anthology to contest the source-culture canon as fiercely as Ouyang does.

Similar to In Your Face, Ouyang's 2013 anthology Breaking New Sky features a large number of poets in alphabetic order - forty-four contributors in all, thirty-three male and eleven female - but there is greater variation in the space allotted to individual poets, with woman poet Lu Ye 路也 out-paging everyone else. In his introduction, Ouyang looks back at a decade of teaching poetry translation in Melbourne. He senses that there is a change in the air because his students, who are not poetry experts, display a "sensitive, versatile and down-to-earth" taste and "avoid anything big-sounding or lyrically obscure" (5). What they get to see is, of course, what their teacher wants them to see, and Ouyang explains that he starts by showing them a selection of poems he likes.

Ouyang links his students' stylistic preferences to ongoing contestations of the canon in the source culture. Expressing frustration with the mainstream habit of enumerating accolades in author bios, he says the Chinese poetry scene is now home to "a democracy of poetic voices that are outside official fame and status" (6). And true enough, Breaking New Sky contains work by many young authors who are not among the regular fare presented in high-profile Chinese-language anthologies. However, they appear alongside several older, über-canonized poets from the mainland and Taiwan. Also, while some of the author bios are of the impish kind - Zhang Zixuan's 张子 选 simply reads "Zhang Zixuan is a stranger to me" (121) - many are filled with the accolades Ouyang so despises, introducing authors rather tiredly as "widely published" and the recipients of various poetry prizes, a commodity that has proliferated in China in the last two decades.

In all, to this reader - who is not its primary intended, non-China-literate reader - the introduction is an unconstrained piece that cuts itself loose from what is by now a richly documented history of the Chinese poetry scene since the Cultural Revolution. Ouyang's story begins, for instance, with his disdain for the official poetry of the Maoist years but then fast-forwards to the early twenty-first century, blotting out the explosion of poetic development in the 1980s and 1990s. This may explain why, in an endorsement on the back cover, Australian poet Brian Castro claims that the anthology "marks a sea-change in the form" and "exhibits a liberating, existential dimension previously constricted by propaganda and self-censorship." Castro's statement is misguided, and it sustains the foreign politicization of Chinese poetry.

Of course, Ouyang has never claimed, and has in fact consistently disclaimed, representativeness and responsibility. More generally, assessing 
a translation's "fidelity" is as problematic for a book-length anthology as it is for a single word. On that note, Castro praises Ouyang's method of "direct translation," which Ouyang says is "a way of translating the words or expressions as they are, in the original" rather than matching them with "something roughly equivalent in the target language." This, he says, "results in poetry that fills the lacuna of a target language" with something "so quotidian in the source language, that one's sense is numbed, adding strangeness to the beauty of the translated poem." As an example, he cites “windscape” for 风景, usually rendered as “landscape" (9-10). In all, his method appears to revolve around literalness, and to aim at defamiliarization and foreignization. It has met with critical responses (e.g. Ferney 2014) and sympathetic ones (e.g. Harvey 2015).

\section{Imperfection}

This takes me to what I will call the legitimacy of non-native linguistic "imperfection." I am not a native speaker of English myself, so I may be out of my depth here (which might make the argument recursive in interesting ways). The issue is linked to the ever-growing problem of the hegemony of English in world literary discourse, but it is worth asking if it also occurs in other languages. In the present context, it arises from the observation that while Ouyang Yu's command of English is phenomenal, his translations and their paratexts regularly contain turns of phrase that a native speaker would not use.

I am, needless to say, not implying that in a given discursive situation, all native speakers will use the exact same words; or that linguistic nativeness and foreignness are self-evident, stable, or unproblematic categories, a myth dispelled in different if related contexts by Jing Tsu and Rey Chow in their discussions of the Chinese diaspora (Tsu 2010) and postcoloniality (Chow 2014). Nor am I referring to imperfection, and related notions such as failure, as instances of willed foreignization à la Venuti (2018), where the translator intentionally makes themself and the translation visible in areas such as the lexicon, syntax, rhetoric broadly defined (including imagery), and more generally the linguistic reflection of social norms and values. Willed foreignization, or the refusal to nativize, sets out to challenge mainstream tropes for successful translation such as fluency, transparency, seamlessness, and so on - tropes that are quite literally utopian, in their denial of the source text as a place of its own - in order to resist the tyranny of the target language and its (translation) culture. See, for instance, Jenn Marie Nunes's 
engagement with Yu Xiuhua's 余秀华 poetry in this book; and Madhu Kaza's advocacy of immigrant and diasporic approaches summed up in the image of "kitchen table translation" (2017); and the discourse surrounding "ethnic" Englishes - or Frenches, or Chineses, and so on.

Rather, I mean ever so slightly "off" usage that looks like it is unintentional, often surrounding little things whose elusiveness is well known to foreign language learners who do in fact aspire to some kind of standard proficiency or mastery. Think articles, particles, prepositions, punctuation, verb tense and mode, singular and plural forms; and, more generally, the unspectacular idiomaticity and the subtle navigation of linguistic register and collocation that glue such native usage together. There are several instances of such deviation from the native norm in Ouyang's words as cited in the preceding pages. In the final paragraph of the previous section, for instance: "fill the lacuna of a target language" and the comma after "so quotidian in the source language."

Why am I making this point? Not, obviously, to reinstate the simplistic notions of "right" and "wrong" that this book critiques, in regard to translation or to linguistic usage at large. I am making this point because it forces us to revisit the dogma, or the rule, or the expectation, or the memory, that says literary writing does not allow for imperfection of this kind - or to reaffirm this as a misconception. Of course, the publishing business is marked by anarchy in comparison with just a few decades ago; and copy-editing is not what it used to be; and there are multiple Englishes; and the downside of hegemony is that everyone has access to what was once your language and can mess with it. But who says you cannot say "fill the lacuna of a target language" instead of, for instance, "fill lacunae in the target language," even if this deviation from a more or less consensual native norm is unintentional? And who is "you" in this statement? The native speaker, for sure, but what about the foreign speaker who solo-translates out of their mother tongue, in Holton's words, or solo-writes in a foreign tongue?

In any event, what Ouyang has called his refusal to be colonized by the West as epitomized by the English language makes it likely that he would reject the "correction" of his "errors" - even if he might resolve not to make the error in question again. Scare quotes, not because I believe either notion has lost its purchase in literary writing but because it appears reasonable to assume that even as Ouyang continues to work toward the perfection of his English, he is well aware of its imperfection - and not worried about it.

But this is not merely, or even primarily, about Ouyang Yu. Who else might be not worried, in which constellations of languages and cultures? Does imperfection work the same for Baudelaire in Dutch as for contemporary 
Chinese poetry in English? I suspect there would be little tolerance for imperfection in the former case. Aside from the question of whether this should elicit boos or cheers, what might it tell us about the issue more broadly? Acceptance can signal a willingness to decenter normativity, as in Dimitra Harvey's review of Breaking New Sky (2015), although she focuses on imagery rather than native-usage glue; and this willingness may stem, in part or in whole, from the sense that when a language becomes a world language, it also becomes common property. But acceptance can also signal indifference - and might this be more likely when the source language is peripheral in the literary system? Lucas Klein has asked whether anthologies of Chinese poetry in translation "expand the field of American poetry, or exist at a sequestered, even ghettoized remove" (2011). The question is at once activist and rhetorical.

\section{Not just the poetry but also the polemics}

If Ouyang's anthologies are partial to the earthly camp on the domestic Chinese poetry scene, three big anthologies published in the US between 2007 and 2013 are similarly programmatic in their preference for the elevated camp. This shows in their selection of authors and in the discourse of their introductions. In other words, partisan positionings on the Chinese-domestic poetry scene are transplanted to translation anthologies. From a theoretical perspective, this is noteworthy in that it undercuts the genre's conventional association with the survey type rather than the programmatic type, discussed above.

The books in question are Zhang Er 张耳 and Chen Dongdong's 陈东东 Another Kind of Nation: An Anthology of Contemporary Chinese Poetry (2007), Wang Qingping's 王清平 Push Open the Window: Contemporary Poetry from China (2011), and Ming Di's 明迪 New Cathay: Contemporary Chinese Poetry (2013). These three books clock in with male and female authors at sixteen to eight, forty-two to seven, and nineteen to six, respectively (but an actual page count reduces female-authored poetry in New Cathay to one seventh of the book). All three were edited by native speakers of Chinese and translated by multiple scholars and poets, with native speakers of English in the majority, Push Open the Window mostly in single-translator projects and the other two books in collaborative ones.

Here I will focus on the monolingual New Cathay (the other two books include the Chinese source texts), which was published by Tupelo Press with support from the Harriet Monroe Poetry Institute of the US-based 
Poetry Foundation. Editor Ming Di's trajectory is similar to that of Wang Ping and Ouyang Yu. She was born and grew up in China, did graduate studies in linguistics at Boston University, and is resident in the US, while continuing to visit China regularly for collaborative projects. A two-way literary translator of Chinese and English, she is an internationally active contributor to academic and cultural exchange, and is affiliated with poetry festivals in Rotterdam and Berlin.

The transplantation of domestic issues to translation anthologies can wear the guise of best-of representativeness - which holds for Another Kind of Nation and Push Open the Window, even though the specialist will spot the markers of their partisanship - or it can happen in full view, as in Ouyang's anthologies, and in New Cathay. In the rift between earthly and elevated aesthetics in Chinese poetry that culminated in the 1998-20oo polemic of so-called Popular (民间) and Intellectual (知识分子) writing, Ming Di explicitly sides with the elevated and the Intellectual. As such, it makes sense that she presents this poetry's encounter with Western modernism in highly positive terms; by contrast, Popular voices have accused it of selling out to the West. Remarkably, Ming Di also says the Intellectuals "have been underrepresented in studies of Chinese poetry" (2013, xvi). This is untrue - it was at the time and remains so today - and many would hold that the opposite is true.

I have noted that modern Chinese poetry continues to be haunted by its classical forebears. But in Chinese-domestic discourse in the new century, this poetry's relation to the classics has also been portrayed as an asset - and it appears as such in translation anthologies as well. In Another Kind of Nation, Zhang Er links contemporary poetry to aesthetic, metaphysical, and linguistic-philosophical notions rooted in ancient Chinese culture, in somewhat exoticizing fashion (2007, 3, 6-8; like Wang Ping, Zhang Er identifies as American: "By looking at them, we look at our own world and ourselves" [5]). And in New Cathay, contemporary poetry's relation to the classical tradition is the opening shot. Ming Di writes that in the 1990s and 2000s, after many years of influence from the West, the poets "have been trying ... to 'return' to ancient literary traditions." What does this actually mean? Rather than writing poetry the way it was written in the past, she says, they "adopt a classical 'spirit' in perspectives and emotional appeals" (2013, xiii).

She later returns to the issue, but without textual evidence beyond the assertion that Duo Duo's 多多 “repetition of adverbials is a re-creation of repeated patterns in ancient poetry" (xvi). Citing a Chineseness that "traces back to ancient tradition," she declines to define this and instead invites the reader to discover it for themself (xxi-xxii). In all, New Cathay takes domestic 
debate on contemporary poetry's relation to classical poetry straight to the foreign audience, but it does so in a claim that comes across as wishful, and less substantiated than might be required in Chinese-language discourse.

\section{Climbing between earth and heaven}

Contemporary poetry's relation to classical poetry is also addressed in Jade Ladder: Contemporary Chinese Poetry, cited at the beginning of this essay. Edited by Scottish poet W. N. Herbert and Chinese poet Yang Lian with Chinese-English and Chinese-Scots translator Brian Holton and Chinese poet and critic Qin Xiaoyu 秦晓宇, this anthology was published by Bloodaxe in the UK with support from the Arts Council England (2012). It has an abundance of explicit paratext by all four editors, and its implicit paratext includes the selection of fifty male and three female poets. This latest in a series of head counts I have included for each anthology is an extreme example of how translation anthologies mirror a deeply disturbing male dominance on the Chinese poetry scene (van Crevel 2017, pars. 13-20 and 95-97). Of the four reviews of Jade Ladder I have seen, the only one to note this - and the only female-authored - is that by Liansu Meng (Burnhope n.d., Radford 2013, Taylor 2013, Meng 2015).

Yang's introduction positions all of Chinese poetry in a lineage going back over two millennia and says contemporary poets are "watched," as in monitored by authority figures, by classical greats Qu Yuan 屈原 and Du $\mathrm{Fu}$ 杜甫 (Herbert et al. 2012, 42). Qin discusses classical presences in the contemporary in more detail, in his introductions to sections in the book that are dedicated to lyric poems, narrative poems, neo-classical poems, sequences, experimental poems, and long poems. The category of the lyric is taken broadly and Qin barely broaches the question of its applicability to poetry written in antiquity and poetry written in the twenty-first century, or the question of how Chinese and English notions of the lyric relate. While he offers more textual evidence for contemporary engagement with indigenous traditions than do Zhang Er and Ming Di, the discussion remains limited to a very small number of poets (mainly Zhang Zao 张冭) and is conducted at a high level of abstraction. Qin's discussion of narrativity (215-216) is not immediately convincing when he suggests kinship between classical forms such as Music Bureau poetry (乐府) and the narrative poetry (叙事诗) of the 1990s (see van Crevel 2008, ch. 8).

Jade Ladder exudes a solemn ambition. As Yang explains, its title refers to a vision of the mythical Mount Kunlun as a ladder that "the holy could climb 
between earth and heaven" (Herbert et al. 2012, 32). Herbert calls the ladder a symbol for "the transit of the Chinese poem between the imagination and the world" (17). He says that on contemporary Chinese poetry, "for the [Anglophone] general reader, for the student or even the teacher, there are few authoritative resources available" (19), and this is the gap Jade Ladder wants to fill. Critical of anthologies to date, he finds "the point of finish" of most Chinese poetry in translation "premature" (22), and wonders what Chinese poets "think about their representation in translation in the West" (20). Accordingly, he sets great store by a critical, multiple-actor translation method involving "poet-to-poet" translation (21).

Herbert, who has made multiple visits to China since the mid-20oos, is aware of the diversity and dynamism of the Chinese poetry scene. He speaks of "one of the world's most thorough and exciting experiments in contemporary poetry" (17). At the same time, just like Brian Castro, he falls prey to familiar patterns of foreign politicization of this poetry when he praises what it has "achieved in the face of much oppression and official constraint" (22). Censorship remains forcefully operational in China, but oppression and constraint are certainly not the first things that the bustling poetry scene of the past forty years brings to mind.

Another misrepresentation occurs when Yang writes that Jade Ladder attempts to present "a complete picture of the complex and exciting events which have been unfolding in contemporary China," and "locate this in the depths of its poetry" (41). In Paul Barnaby's words, this would make it the type of anthology that wants to offer "a state-of-the-nation survey or potted social history of the source culture" $(2002,86)$. But this goal remains out of reach, for two reasons. First, it clashes with the anthology's professed aim to present the poetry with full respect for the autonomy of the artwork, or indeed with this autonomy as its point of departure. Witness, among other things, the pointed absence of biographical information on the poets, a standard feature of the other anthologies sampled for this essay.

Second, Jade Ladder overwhelmingly features poets who rose to prominence in the 1980 s and the 1990s, and hardly any poets who emerged in the 200os - when new poetic trends continued to proliferate and the internet and social media added an entirely new dimension to the poetry scene that is aesthetic as well as social in nature (Inwood 2014). Yang's general introduction is memoir-like and dwells at length on the 1980s and on exile poetry after June Fourth, and its attention to older generations drowns out Qin's notes on more recent developments.

In a related point,Jade Ladder's overbearing allegiance is with the elevated pole on the wide aesthetic range of contemporary Chinese poetics. This is 
not counterbalanced by the inclusion of two unignorable representatives of the earthly camp, Yu Jian 于坚 and Yi Sha 伊沙 (Han Dong 韩东 should have been equally unignorable, but is ignored nonetheless). In all, precisely because Jade Ladder aspires to be comprehensive and authoritative, its bias in the interrelated areas of gender, generation, and aesthetics is all the more conspicuous.

In regard to translation method, the emphasis in Jade Ladder on bilingual collaboration and the involvement of poets in addition to those who primarily identify as translators recall Wang Ping's, Zhang Er and Chen Dongdong's, and Ming Di's anthologies, but there is a difference - which constitutes, at the same time, a similarity with the early 1990 anthologies edited by Morin, Finkel, and Barnstone reviewed by Bruno. W. N. Herbert, the ultimate arbiter of the poetry collected in Jade Ladder, is a native speaker and poet of the English language; and the primacy of poetic, native-normative English is reaffirmed by the central translator, Brian Holton.

Jade Ladder ends with Holton's "Phrases That Shall Be Musical in the Mouth," an essay that shows him as deeply committed to, and highly demanding of, the translation of (Chinese) poetry, and as opinionated and polemical. I quote at length to zoom in on an issue that recurs throughout the present essay:

And here I must address native Chinese translators: substituting English dictionary definitions for Chinese words does not make a poem ... The idea is still current in China that, since non-native speakers cannot read Chinese with the necessary sensitivity to nuance, then all translations of China's astonishingly diverse and accomplished literature should be done by Chinese people only ... The first part of that statement is perfectly true ... To state, however, that only Chinese people should translate out of their mother tongue ... is, quite simply, nonsense. Of all the millions of Chinese speakers of English, only a vanishingly small proportion have mastered the language to the point where they can produce literary texts of any quality. The vast majority of Chinese-English literary translation simply does not work, because fluency is not at all the same as mastery ... If you're Chinese and want to translate Chinese poetry ... then you only need one thing, and that is a collaborator with a high level of competence as a writer who is a native speaker of your target language ... non-native versions rarely work as poetry: the non-native can never see the text in the same way as the native speaker - in effect, they are reading different poems, as each brings a different set of values and expectations to the text, and the text can't not be read through the lens of these values and 
expectations. This, in our case, is an unavoidable result of the gap between the cultures of China and the cultures of the English-speaking world.

(Herbert et al. 2012, 351-352)

There is some rhetorical flourish here. Also, I dispute that, in the places where it matters, the idea is current that translation from the Chinese must only be undertaken by native speakers of Chinese. More interesting is that Holton touches only fleetingly on what I have called linguistic imperfection, in his reference to mastery (which, if you think about it, is a concept whose routine conjunction with a "native" language is strange, and indeed disturbing in its conjunction with foreign languages, in the context of colonialism and otherwise). And, conversely, that he invokes cultural difference to explain his assertion that non-native versions rarely work as poetry. Venuti posits the need to recognize cultural difference as always unapologetically operational in translation, and as anything but the disqualifying force Holton makes it out to be. This has helped to establish a vision of (poetry) translation that sheds hierarchical thinking about the source text as originary and the translation as derivative. Especially because Holton subscribes to this vision (353-354), his depiction of cultural difference as a "gap" that produces "unavoidable results" is surprising.

\section{No one cares}

I began this essay by contrasting Jade Ladder with Zero Distance: New Poetry from China, and will end by showing that the differences between these two books extend to every dimension. Liang Yujing, the editor and solo translator of Zero Distance, is a native speaker of Chinese, born in China and trained there in English literature. He began writing poetry in English in 2008. Like several of the other anthologists whose work I have considered above, he is a two-way literary translator of Chinese and English. He moved to New Zealand in 2014 and, at this writing, is doing $\mathrm{PhD}$ research on contemporary Chinese poetry there. That there is "imperfection" in his English usage has not kept him from publishing authored and translated poetry in various journals in the Anglophone world.

Zero Distance was published in 2017 with support from the Hawai'i Community Foundation by Tinfish Press, a not-for-profit publisher dedicated to experimental poetry from the Pacific region with other Chinese poetry projects to its name. It contains the work of twenty-nine authors. Most were born in the 1980 s or 1970s, are little known beyond the in-crowd, and 
are very much part of trends and developments in the 2000s and 2010s. The anthology's orientation is on the earthly and transgressive side of things, and Yi Sha and Ouyang Yu are included as patron saints from older generations. "Zero Distance" is the name of a poem by Ouyang, and Liang cites Ouyang's notion of direct translation and Yi Sha's Poetry Canon for the New Century project (新世纪诗典) (7; see van Crevel 2017, pars. 127-136). At twenty male to nine female authors, the anthology does better than most for gender balance, but Liang is not satisfied with the numbers and identifies male dominance as a problem on the Chinese poetry scene, recalling how a woman poet withdrew her work for fear it might "bring her trouble" (Liang 2017, 8). He ends a nutshell history of contemporary Chinese poetry by saying that, "to some extent, poetry has become the freest form of literature in China," and that this is because "no one cares" (6). Rather than a lament, this comes across as a celebration of the space and the style Liang appropriates, as an anthologist who sits squarely in the twenty-first century.

\section{What's new?}

Some things never change. Modern Chinese poetry's three demons have haunted translation anthologies starting with Harold Acton and Ch'en Shih-hsiang's 陈世骧 (1936) and Robert Payne's (1947) books. So has the male dominance that has marred the modern poetry scene from the beginning: a fourth demon, albeit one who operates throughout the world. Acton and Ch'en's and Payne's anthologies are all-male, and Payne calls the “sentimentality" of some of the New Poetry (新诗) “excusable” in Bing Xin 冰心, “who was after all only a woman" (13).

But other things do change, and on balance, anthologies of contemporary Chinese poetry in English translation have changed a great deal in recent decades. Against the background of transformations in Chinese society and Chinese-foreign relations at every level from geopolitics to individual identity, there has been a notable diversification in where the anthologists come from, literally and otherwise, as well as in the body of texts on which they draw, born of a poetry scene in relentless tumult. This is an intersectional process that mobilizes multiple axes of positionality: Chinese and English nativeness and foreign literacy, age, gender, individual and collective experiences of the presence of politics in literature, local and international networks, allegiance to particular camps in source-culture poetics, translation methods, institutional affiliations and resources. And: various perspectives on modern Chinese poetry's demons. 
Speaking of which... in a rich, critical essay on the translation and introduction of this poetry in the US, written in Chinese and published in China, Ming Di says that Chinese poets ought to be thinking about what is "poetically special about contemporary Chinese poetry that could truly raise Western poets' interest." But then she catches herself and adds in the same breath that of course, "Chinese poetry has its own development, and need not deliberately change for the outside world" (2015, 72-73).

Contemporary Chinese-English translation anthologies embody the encounter of outside narratives and inside stories, and the complexity of that encounter.

\section{Works cited}

Acton, Harold and Ch'en Shih-hsiang, trans. 1936. Modern Chinese Poetry. London: Duckworth.

Barnaby, Paul. 2002. "Scotland Anthologised: Images of Contemporary Scottish Identity in Translation Anthologies of Scottish Poetry." The Scottish Review 3 (1): 86-99.

Barnstone, Tony, ed. 1993. Out of the Howling Storm: The New Chinese Poetry. Hanover: Wesleyan University Press.

Bruno, Cosima. 2012. "The Public Life of Contemporary Chinese Poetry in English Translation." Target 24 (2): 253-285.

Burnhope, Mark. N.d. Review of Herbert et al. 2012. Magma Poetry, no date. bit.ly/ ${ }_{2} \mathrm{G}_{2} \mathrm{lYxf}$. Accessed April 1, 2018.

Chow, Rey. 2014. Not Like a Native Speaker: On Languaging as a Postcolonial Experience. New York: Columbia University Press.

Ferney, Liam. 2014. Review of Ouyang 2013. Rabbit 12: 118-124.

Finkel, Donald, trans. 1991. A Splintered Mirror: Chinese Poetry from the Democracy Movement. San Francisco: Northpoint Press.

Harvey, Dimitra. 2015. Review of Ouyang 2013. Mascara, May 25. bit.ly/2OX6jDD. Accessed April 1, 2018.

Herbert, W. N. and Yang Lian with Brian Holton and Qin Xiaoyu, eds. 2012.Jade Ladder: Contemporary Chinese Poetry. Tarset: Bloodaxe.

Hermans, Theo, ed. 1985. The Manipulation of Literature: Studies in Literary Translation. London: Croom Helm.

Inwood, Heather. 2014. Verse Going Viral: China's New Media Scenes. Seattle: University of Washington Press.

Kaza, Madhu, ed. 2017. Kitchen Table Translation. Special Issue of Aster(ix) Journal, July 2017. 
Klein, Lucas. 2011. "Anthologies and Anthologies." Blog post, Notes on the Mosquito: A Blog on Xi Chuan and Chinese Poetry in English Translation, December 10. bit.ly/2KgtiL8. Accessed April 1, 2018.

Liang Yujing, ed. and trans. 2017. Zero Distance: New Poetry from China. Kāne'ohe: Tinfish.

Lin, Julia C., ed. and trans. 1992. Women of the Red Plain: An Anthology of Contemporary Chinese Women's Poetry. Beijing: Chinese Literature Press, and London: Penguin Books.

-, ed. and trans. 2009. Twentieth-Century Chinese Women's Poetry: An Anthology. Armonk: M. E. Sharpe.

Meng Liansu. 2015. Review of Herbert et al. 2012. MCLC Resource Center. bit.ly/ 2U6FLRp. Accessed April 1, 2018.

Ming Di, ed. 2013. New Cathay: Contemporary Chinese Poetry. North Adams: Tupelo Press.

一明迪. 2015.〈影响与焦虑: 中国当代诗在美国的译介状况〉 [Influence and anxiety: the introduction and translation of contemporary Chinese poetry in America]. In《他者眼光与海外视角: 世界视野中的中国当代文学》 [The gaze of the Other and foreign perspectives: contemporary Chinese literature in the eyes of the world], edited by Zhang Qinghua 张清华. Beijing: Beijing daxue chubanshe.

Morin, Edward, ed. 1990. The Red Azalea:Chinese Poetry since the Cultural Revolution. Honolulu: University of Hawai'i Press.

Ouyang Yu, ed. and trans. 2002. In Your Face: Contemporary Chinese Poetry in English Translation. Otherland 8.

—, ed. and trans. 2013. Breaking New Sky: Contemporary Poetry from China. Parkville: Five Islands Press.

Payne, Robert, ed. 1947. Contemporary Chinese Poetry. London: Routledge.

Piasecki, Bodham Andrzej. 2010. "Anthologies of Contemporary Polish Poetry in English Translation: Paratexts, Narratives, and the Manipulation of National Literatures." PhD dissertation, University of Warwick.

Radford, Andrew. 2013. Review of Herbert et al. 2012. Translation and Literature 22: 142-148.

Seruya, Teresa. 2013. "Anthologies and Translation." In Handbook of Translation Studies: Volume 4, edited by Luc van Doorslaer and Yves Gambier, 1-6. Amsterdam: John Benjamins.

Taylor, John. 2013. Review of Herbert et al. 2012 among other books. The Antioch Review, March 1: 382-389.

Tsu, Jing. 2010. Sound and Script in Chinese Diaspora. Cambridge, MA: Harvard University Press. 
van Crevel, Maghiel. 2008. Chinese Poetry in Times of Mind, Mayhem and Money. Leiden: Brill.

- 2017. "Walk on the Wild Side: Snapshots of the Chinese Poetry Scene." MCLC Resource Center. bit.ly/2GaWWhc. Accessed April 1, 2018.

Venuti, Lawrence. 2018. The Translator's Invisibility: A History of Translation, third edition. New York: Routledge.

Wang Qingping, ed. 2011. Push Open the Window: Contemporary Poetry from China. Port Townsend: Copper Canyon Press.

Wang Ping, ed. 1999. New Generation: Poems from China Today. New York: Hanging Loose Press.

Zhang Er and Chen Dongdong, eds. 2007. Another Kind of Nation: An Anthology of Contemporary Chinese Poetry. Jersey City: Talisman House.

\section{About the author}

Maghiel van CREVEL is professor of Chinese language and literature at Leiden University. A specialist of contemporary poetry, he has published a dozen books in English, Dutch, and Chinese, including scholarly monographs and edited volumes, literary translations, and language textbooks. His research draws on extensive fieldwork undertaken since the early 1990s. See, for instance, the long essay "Walk on the Wild Side: Snapshots of the Chinese Poetry Scene" (2017), downloadable at the MCLC Resource Center. 


\section{Index}

The main entries for most Chinese names are given in Hanyu pinyin, but some are rendered in alternative romanizations to respect convention or the preference of the person whose name is transcribed. Alternative orthographies are provided to redirect the reader where this seems useful. For example: “Xia Yu, see Hsia Yü.” Latinized names of canonical philosophers and English translations of the titles of classical texts (sometimes eponymous with their author) redirect to a main entry in Hanyu pinyin. For example: "Mencius, see Mengzi" and "Book of Songs, see Shijing."

Acton, Harold 347

Adorno, Theodor 289,322

Alexander, Jeffrey $\quad 312,313,316,317$

Allen, Clement 70

Allen, Joseph $\quad 7^{0}$

Analects see Lunyu

Anzaldúa, Gloria 29n3

Apollinaire, Guillaume $\quad 256$

Arenas, Braulio $\quad 261$

Ashbery, John $\quad 261$

Auden, W. H. $\quad 256$

Bachmann-Medick, Doris $\quad 14,313$

Bai Juyi 94, 95, 106

Baillie, J. B. 193

Ban Gu 185, 186

Barker, George $\quad 256$

Barmé, Geremie $\quad 318-320$

Barnaby, Paul 344

Barnstone, Tony 334,345

Bassnett, Susan 206

Baudelaire, Charles $\quad 9,12,131 n 12,139,225^{-245}$, 337,340

Baxter, Glen 160, 166

Baynes, Cary 187

Beatrijs 96

Bei Dao 12, 13, 135-154, 287-306, 337

Benjamin, Walter $14,114,115,118,272,273$, 279, 283, 289

Berman, Antoine $\quad 216$

Berman, Art 254

Berry, Michael 3on 4, 312

Bethge, Hans 93

Bhabha, Homi 14

Bing Ma 62

Bing Xin 117n3, 347

Bishop, Elizabeth 55

Blasing, Mutlu $175^{\mathrm{n} 12}$

Bonnefoy, Yves 261

Book of Changes

see Yijing
Book of Documents

see Shujing

Book of Odes

see Shijing

Book of Songs see Shijing

Bracho, Coral $\quad 261$

Bradbury, Steven 115

Brâncuși, Constantin 15

Breton, André $\quad 256$

Brown, Bill 74

Brown, Marshall $\quad$ 175n13

Bruno, Cosima $\quad 334,345$

Cao Xueqin $102 \mathrm{n} 12$

Caruth, Cathy 312

Castro, Brian 338, 339, 344

Celan, Paul $\quad 9,13,287-306$

Chamberlain, Lori $\quad 25,38$

Chan Chi-tak 259

Chang, Kang-i Sun 277

Chang Ting 252, 253

Chan Kwok-kuo 260

Char, René $\quad 256$

Chen Dongdong 341,345

Chen Fangming $\quad 266$

Cheng Junying $71,76,81,82,84$

Chen Huan $71,72,76,84$

Chen Jingrong $12,13,131 \mathrm{n} 12,225-245$

Ch'en Shih-hsiang 347

Chen Yanbing $\quad \mathbf{1 5 3}_{7} \mathrm{n}_{7}$

Chesterman, Andrew 48

Chi Hsien see Ji Xian

Chin, Marilyn 204

Chow Hon-fai 259

Chow, Rey 202-204, 339

Chuci 181-197

Chung Kwok-keung 250, 259

Chung, Ling 159,165

Classic of Mountains and Seas see Shanhaijing 


\section{Classic of Poetry see Shijing \\ Confucian see Kongzi \\ Confucius see Kongzi}

Crane, Hart $\quad 256$

Creeley, Robert 137

Crespi, John 321

cummings, e. e. $\quad 256$

\section{Daode Jing} see Laozi

Day Lewis, Cecil $\quad 256$

Day, Michael 309, 310, 314, 316-320, 322, 326

de Gourmont, Remy $\quad 256$

Derrida, Jacques 194, 195, 211

Desnos, André $\quad 256$

Dickinson, Emily 27, 34

Dooling, Amy 56

Doolittle, Hilda see H.D.

Du Fu 98, 99, 196n18, 270, 343

Duan Yucai 195

Duo Duo 292, 342

Dylan, Bob $\quad 201,219,220$

Eburne, J. P. 260

Eisenstein, Sergei $\quad$ 277-279, 282, 283

Eliot, T. S. $31,136,137 \mathrm{n} 3,253,254,256$

Éluard, Paul $\quad 256$

Eshleman, Clayton $\quad 151$

Even-Zohar, Itamar 138

Falcón, Sylvanna M. $\quad 29 n 3$

Fan Jian 3on 4

Fan, Travis see Fan Jian

Feeley, Jennifer 12, 119-121

Fei Ye 142, 148, 149

Felstiner, John $\quad$ 294, 295, 298, 299

Feng Menglong 90

Fenollosa, Ernest $\quad 16,269$

Finkel, Donald 334, 345

Fludernik, Monika 161-165, 171-173

Fort, Paul $\quad 256$

Frankel, Hans 103,104

Freud, Sigmund $\quad$ 186, 194

Friedman, Susan Stanford $\quad 278,283$

Frodsham, J. D. 95, 101

Frost, Robert $\quad 10,96,150,175$

Fuller, Michael 71

Fusek, Lois $\quad 160,167$

Gaard, Greta 243

García Lorca, Federico

Gascoyne, David $\quad 256$

Gautier, Judith 93

Ghosh, Ranjan 136n2
Giles, Herbert 209

Gillespie, Susan 305

Godard, Barbara 37,120

Gogol, Nikolai 138

Goll, Claire 288

Goll, Yvan 288

Goodman, Eleanor 204, 206, 207, 214-217, 219,220

Göransson, Johannes 36,38

Graham, A. C. $\quad 95,101,104$

Granet, Marcel $\quad$ 209, 210

Green, Garrett $\quad$ 194n16

Gu Cheng 292

$\mathrm{Gu}$, Ming Dong 277

Gu Yunpu 142

H.D. 256,257

Haizi 292

Halberstam, Jack 35

Hall, Donald $46,51,5^{2}, 60$

Hamburger, Michael 294

Han Dong 292,345

Han Han 64

Han Shan 11, 90-93, 100, 104, 105

Harvey, Dimitra 341

Hawkes, David $\quad 98,101 n 12,182,183$

Hayden, Robert 45

Hayot, Eric $\quad 117 n_{3}, 214,277$

Heaney, Seamus $57-60$

Hegel, G. W. F. $\quad 183,187,193-195,209 n 3$

Heidegger, Martin 148, 149

Hejinian, Lyn 137

Henricks, Robert C. 92, 105, 106

Henschke, Alfred see Klabund

Herbert, W. N. 14, 343-345

Herrera, Juan Felipe 62

Hervey de Saint-Denys, Marquis de, MarieJean-Léon Lecoq $185^{\mathrm{n}} 4$

He Xuan 207, 208, 214, 215

Hinton, David $153 \mathrm{n}_{7}$

Historical Records see Shiji

Hoffmann, Hans Peter $\quad 318-320$

Holdengräber, Paul 325

Hölderlin, Friedrich $\quad 291$

Holdstock, Nick 317

Holton, Brian $\quad 182,183,331,340,343,345,346$

Hong Hong see Hung Hung

Hsia Yü 115,250

Hu Shi 139

Huainanzi 185

Huang Canran 298, 299

Huang Rui 147

Huang Runyu 260

Huang Wenguang $316,317,325$

Huang Zunxian 207

Huerta, Elise $30 n_{4}$ 
Hughes, Langston $\quad 49,5^{\circ}$

Hulme, T. E. $37 \mathrm{n} 3$

Hung Hung 250

Inwood, Heather 64

Jacob, Max $\quad 256$

Jaivin, Linda $\quad 318-320$

Jakobson, Roman 137, 139, 141-144, 147, 150-152

Jarre, Jean-Michel 322

Jennings, William 70

Ji Xian 265, 266

Jiang Jianyuan $71,76,81,82,84$

Jiang Liangfu $\quad 182$

Jonker, Dirk 90

Joyce, James $128,254,257$

Kafka, Franz $\quad 289,291$

Kaldis, Nicholas 332

Kant, Immanuel 139

Karlgren, Bernhard $70,74,77,78,84,97$

Kaza, Madhu 340

Klabund 93

Klein, Lucas $\quad 114,115,125,151,341$

Kong Yingda $70,73,84,85$

Kongzi 99, 182, 185, 186, 188, 207, 208, 321

Korteweg, Anton 90

Kroll, Paul $\quad 74,76$

Kronovet, Jennifer see Stern, Jennifer

Lao G 294

Laozi 14

Lawrence, D. H. $\quad 256$

Legge, James $70,73,77,78,84,96,97$

Leung Ping-kwan $\quad 250,258-261$

Levine, Philip $\quad 5^{0}, 5^{1}$

Lewis, Pericles $\quad 256$

Liang Yujing 331, 346, 347

Liao, Sebastian 312

Liao Yiwu 13, 130, 290, 309-327

Li Bai 94, 305

Li Baifeng 228

Li Fuyan 100

Li He 95, 101, 102

Li Kuang 252

Li Qingzhao $159,165,168$

Li Shangyin 97, 101

Li Shaojun 65

Li Wai-ling $\quad 255,256$

Li Yawei $309,314,316,322$

Li Yongpu 63

Lin Huanping 228

Lin, Julia $\quad 332,333$

Lingenfelter, Andrea 121

Liu An 184, 185, 186, 190, 194

Liu, James 101, 204, 205

Liu, Lydia $\quad 113,114,124$

Liu Xia $\quad 12,124-129$
Liu Xiaobo 124, 321, 324, 325

Lorca

see García Lorca, Federico

Lu Xun 138, 139

Lu Ye 338

Lugones, Maria $\quad 38,39,40$

Lunyu 186

Luo Chi-cheng $25^{\circ}$

Luo Zhicheng

see Luo Chi-cheng

Ma Ruichen 71

MacLeish, Archibald $\quad 256$

MacNeice, Louis $\quad 256$

Madrid, Anthony $\quad$ 211-213

Maier, Carol 25

Malebranche, Nicolas $\quad 289$

Mallarmé, Stéphane $\quad 231$

Mandelstam, Osip 291

Mang Ke 147

Mao Chang see Mao Heng and Mao Chang

Mao commentary see Mao Heng and Mao Chang

Mao glosses see Mao Heng and Mao Chang

Mao Heng and Mao Chang $70,71,73-76,79$, $82,84,85,207,208$

Mao Prefaces

see Mao Heng and Mao Chang

Mao Xinren 142

Mao Zedong $147,227,237,238,316,317,338$

Maoshiyinde see Mao Heng and Mao Chang

Mar, Ronald $\quad$ 13, 249-261

Marx, Johanna $\quad 326$

Marx, Karl 147

McSweeney, Joyelle 36

Mencius see Mengzi

Meng Huang 324,325

Meng, Liansu 343

Meng Ming 304, 305

Mengzi $\quad 71,72$

Meschonnic, Henri $\quad 118,119,121,125,126,129$, 130

Miao Yüeh $173 n 10$

Michaux, Henri 256

Mickey, Sam 230

Middleton, Peter 321

Ming Di $\quad 12,124,126,127,341-343,345,348$

Mirikitani, Janice 63

Mo Yan 325

Mohabir, Rajiv $\quad 115,116$

Molina, Enrique $\quad 261$

Moore, Marianne $\quad 256$

Moraga, Cherríe $\quad 29 n 3$

Moretti, Franco $\quad$ 135, 136, 140

Morgan, Monique 162 
Morin, Edward $\quad 334,345$

Mozi 321

$\mathrm{Mu} \mathrm{Yu} 260$

Müller, Herta 317

Nabokov, Vladimir 137

Nào 215,218

Nash, Jennifer 29n3

Nelson, Sierra $\quad 1^{2} 3 n_{5}$

Noguchi Yonejirō 137

Nowak, Mark 64

Olson, Charles $\quad 136,137$

Osborne, Peter $\quad 272,273,278,279$

Ouyang Jianghe $12,115,121-125,130,337$

Ouyang Xiu 16o, 166

Ouyang Yu $331,332,336-342,347$

Owen, Stephen $\quad 96,98,99,185 \mathrm{n} 4,204,205,208$

Palmer, Michael $\quad 261$

Pascal, Blaise $\quad 288$

Pasternak, Boris $12,135^{-15}, 317$

Payne, Robert $\quad 347$

Pellegrini, Aldo $\quad 261$

Perloff, Marjorie $\quad 175 \mathrm{n} 12$

Piasecki, Bohdan 333, 334

Porter, Bill see Red Pine

Pound, Ezra $\quad 16,31,70,74,77,97,136,137,193$, $256,269,334$

Prévert, Jacques $\quad 256$

Prince, Gerald $\quad 162$

Qian Chunqi 293, 294n4, 303, 304

Qian Zhongshu 187,189 n9

Qin Xiaoyu 129, 343, 344

Qiu, Jack Linchuan 64

Qu Fu 192

Qu Yuan 12, 181-197, 292, 314, 343

Quanan Shum 254

Ramazani, Jahan $\quad 135,140$

Records of the Historian see Shiji

Red Pine 104-106

Rexroth, Kenneth $\quad 159,165$

Rich, Adrienne $\quad 5^{2-5} 6$

Riep, Steven 3on4, 275

Rilke, Rainer Maria $\quad$ 253, 299

Robinson, Douglas 116,118

Röllig, Mario 326, 327

Romance of the Three Kingdoms see Sanguo yanyi

Rosén, Maria 324

Rothberg, Michael 312

Rothenberg, Jerome 295

Rouzer, Paul 71, 104-106
Rowe, Aimee Carillo $\quad 38,39$

Rui Hu 293, 297

Rukeyser, Muriel $\quad 256$

Sang, Tze-lan 30 n $_{4}$

Sanguo yanyi 186

Saussy, Haun $70,75,196,207-210,213,215,219$, $220,270,271,273,283$

Scarfe, Francis $\quad 227,234,235,241$

Schafer, Edward $101 n 10$

Schuessler, Axel $\quad 187 \mathrm{n} 6$

Seaton, Jerome $\quad 160,166,167 \mathrm{n}_{5}$

Sha Lei 227,242

Shakespeare, William $\quad 78,82,83,164 \mathrm{n} 3$

Shanhaijing 194

Shapiro, Carl 256

Shaughnessy, Edward 210, 211, 218, 219

Sheehan, Julie 62

Shen Rui 3on 4, 34

Shestov, Lev (Leo) 288

Shi Zhi 34n6

Shici 72

Shih, Shu-mei $\quad 5^{6}$

Shiji $71,72,184,185$

Shijing 11, 12, 69-86, 96, 97, 186, 201-220

Shklovsky, Victor $137-139,141,142,144,146$, $147,150,151$

Shmueli, Ilana 305

Shujing 72

Shuowen jiezi 70

Sidney, Philip 164n3

Silliman, Ron $\quad 137$

Sima Qian 71, 184-186, 192

Simon, Sherry 57

Sitwell, Edith $\quad 256$

Slauerhoff, J. $\quad$ 94, 95

Snyder, Gary 91

Solomon, Petre 294

Song Lin $\quad 290-292,305$

Soong, Stephen $\quad 252,253$

Spender, Stephen $\quad 255,256$

Spivak, Gayatri Chakravorty 24

Steiner, George $\quad 65$

Stern, Jennifer $\quad 12,124,126,127$

Stevens, Wallace 255

Sun, Cecile Chu-chin $\quad 276,277,279$

Sun, Veronica 74

Supervielle, Jules $\quad 256$

Tagore, Rabindranath $\quad 117 \mathrm{n}_{3}$

Tate, James $\quad 261$

Tawada Yoko 38

Thomas, Dylan $\quad 256$

Tie Ma $\quad 228$

Tsu, Jing 339

Tsvetaeva, Marina 291

Turner, Matt $\quad 115,116,121$ 
Valéry, Paul 253, 256

van Crevel, Maghiel $\quad 34,56,116,129,203,204$, 206, 207, 217-219, 313

Van Zoeren, Steven $\quad 70$

Venuti, Lawrence $\quad 28,30,32,339,346$

Vermeer, Hans 48

Waldrop, Keith $\quad 227,233-235,239,241$

Waley, Arthur $\quad 70,73,74,77-79,82,84,94,95$, 97, 101, 210, 211, 219

Walton, Kendall 174

Wang, C. H. 208, 210

Wang, David 56

Wang, Dorothy 203-205

Wang Jiaosheng 168

Wang Jiaxin $13,149,287-306$

Wang Ping $335,342,345$

Wang Qingping 341

Wang Xianqian 84

Wang Xiaoni 11, 45-65

Wang Yi $185,190,194$

Watson, Burton 211, 212

Watten, Barrett 137

Weinberger, Eliot $\quad 10,114$

Wen Tingyun $\quad 160,166,167$

Whitman, Walt 61

Wiesel, Elie 290

Wilbur, Richard 65

Wilhelm, Richard $\quad 187$

Williams, William Carlos 256

Woerner, Austin $\quad 12,115,121-124$

Wolf, Werner $\quad 166,173 n 9$

Wolfson, Susan $\quad 175^{\mathrm{n} 13}$

Wong, Wucius 254

Wright, C. D. 126

Wright, Chantal 38

Wu Feiyue 129

Xi Chuan 337

Xi Xi 12, 119-121, 125, 128, 130

Xia Yu

see Hsia Yü

Xiang Xi 74

Xiang Yu 315,321

Xie Ye 292

$\mathrm{Xu}$, Hangping $30 \mathrm{n}_{4}$

Xu Lizhi $47,48,51,55,64,215,216$

Xu Zhen 15
Xu Zhimo 139

Xue Wei 100

Xunzi 209

Ya Hsien

see Ya Xian

Ya Shi 9, 115

Ya Xian 13, 265-283

Yang Lian $14,31,182,183,196,292,331,343$, 344

Yao Jiheng 71

Yau, John 335

Yau Wai-ping 254, 256

Ye Weilian see Yip, Wai-lim

Yeats, W. B. $\quad 256$

Yeh, Michelle $\quad 265,269,270$

Yi Sha 13, 287-306, 345, 347

Yijing 187, 191, 192

Yip, Wai-lim 204, 205, 254, 267, 293

Yu Guangzhong see Yu Kwang-chung

Yu Jian 290, 292, 294, 305, 345

Yu Kwang-chung 259

Yu, Pauline $\quad 208,276$

Yu Xiuhua 11, 23-41, 116, 130, 340

Yu Yue 194n17

Yun $\mathrm{Fu} \quad 255,256$

Yurcic, Jason L. 61

Zang Di $11,45^{-6} 6$

Zeng Lei $\quad 323$

Zhai Yongming 337

Zhang Er 341-343, 345

Zhang Longxi 147, 205, 207, 208, 214, 215

Zhang Yaxin 274

Zhang Zao $\quad 293,343$

Zhang Zixuan 338

Zheng Min 231, 232

Zheng Xiaoqiong 11, 45-65

Zheng Xuan $70,73,74,76,81,84,85$

Zhou Zan 56

Zhou Zuoren $\quad 225 \mathrm{n} 1$

Zhu Xi $70,73,78,79,84,85$

Zhuangzi 139, 196

Zikpi, Monica $\quad 214,219$

Žižek, Slavoj 312 
